PROTEST AND SOCIAL MOVEMENTS

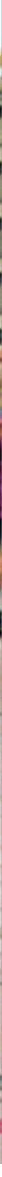

Edited by Aidan McGarry, Itir Erhart, Hande Eslen-Ziya, Olu Jenzen, and Umut Korkut

The Aesthetics

of Global Protest

\title{
Visual Culture and Communication
}


The Aesthetics of Global Protest 


\section{Protest and Social Movements}

Recent years have seen an explosion of protest movements around the world, and academic theories are racing to catch up with them. This series aims to further our understanding of the origins, dealings, decisions, and outcomes of social movements by fostering dialogue among many traditions of thought, across European nations and across continents. All theoretical perspectives are welcome. Books in the series typically combine theory with empirical research, dealing with various types of mobilization, from neighborhood groups to revolutions. We especially welcome work that synthesizes or compares different approaches to social movements, such as cultural and structural traditions, micro- and macro-social, economic and ideal, or qualitative and quantitative. Books in the series will be published in English. One goal is to encourage nonnative speakers to introduce their work to Anglophone audiences. Another is to maximize accessibility: all books will be available in open access within a year after printed publication.

Series Editors

Jan Willem Duyvendak is professor of Sociology at the University of Amsterdam. James M. Jasper teaches at the Graduate Center of the City University of New York. 


\title{
The Aesthetics of Global Protest
}

\author{
Visual Culture and Communication
}

\author{
Edited by \\ Aidan McGarry, Itir Erhart, Hande Eslen-Ziya, Olu Jenzen, \\ and Umut Korkut
}


Cover illustration: With permission of Seamus Travers, Travers Photography, Dublin, Ireland.

Cover design: Coördesign, Leiden

Lay-out: Crius Group, Hulshout

$\begin{array}{ll}\text { ISBN } & 978 \text { 94 } 63724913 \\ \text { e-ISBN } & 978 \text { 90 } 48544509 \\ \text { DOI } & 10.5117 / 9789463724913 \\ \text { NUR } & 697\end{array}$

\section{()) (1) $\Theta \Theta$}

Creative Commons License CC BY NC ND (http://creativecommons.org/licenses/by-nc-nd/3.o) (.) All authors / Amsterdam University Press B.V., Amsterdam 2020

Some rights reserved. Without limiting the rights under copyright reserved above, any part of this book may be reproduced, stored in or introduced into a retrieval system, or transmitted, in any form or by any means (electronic, mechanical, photocopying, recording or otherwise).

Every effort has been made to obtain permission to use all copyrighted illustrations reproduced in this book. Nonetheless, whosoever believes to have rights to this material is advised to contact the publisher. 


\section{Table of Contents}

List of Figures and Tables

Acknowledgements

Preface: Devisualize

Nicholas Mirzoeff

Introduction: The Aesthetics of Global Protest: Visual Culture and Communication

Aidan McGarry, Itir Erhart, Hande Eslen-Ziya, OluJenzen, and Umut Korkut

\section{Part I: Performance, Art and Politics}

1 Queer Visual Activism in South Africa

Tessa Lewin

2 The Use of Visibility in Contentious Events in Northern Ireland Katy Hayward and Milena Komarova

3 Maybe, We Will Benefit from Our Neighbour's Good Fortune: An Exhibition on Collectivity, Community, and Dialogue in Turkey Işıl Ĕgrikavuk

4 Political Street Art in Social Mobilization: A Tale of Two Protests in Argentina Holly Eva Ryan

5 Archiving Dissent: (Im)material Trajectories of Political Street Art in Istanbul and Athens

Julia Tulke

6 The Introvert's Protest: Handwriting the Constitution and the Performance of Politics

Interview with Morgan O'Hara by Aidan McGarry 


\section{Part II: Visual Activism and Digital Culture}

7 Photography and Protest in Israel/Palestine: The Activestills Online Archive

Simon Faulkner

8 Drones, Cinema, and Protest in Thailand

Noah Viernes

9 Bearing Witness to Authoritarianism and Commoning through Video Activism and Political Film-making after the Gezi Protests 191 Özge Özdüzen

10 Music Videos as Protest Communication: The Gezi Park Protest on YouTube

Olu Jenzen, Itir Erhart, Hande Eslen-Ziya, Derya Güçdemir, Umut

Korkut, and Aidan McGarry

11 The Activist Chroniclers of Occupy Gezi: Counterposing Visibility to Injustice

Dan Mercea and Helton Levy

12 When Twitter Got \#woke: Black Lives Matter, DeRay McKesson, Twitter, and the Appropriation of the Aesthetics of Protest

Farida Vis, Simon Faulkner, Safiya Umoja Noble, and Hannah Guy

\section{Part III: Conclusion}

13 Conclusion: Reflections on Protest and Political

Transformation since 1789

269

Jim Aulich

Index 


\section{List of Figures and Tables}

\section{Figures}

Figure 0.1. Whirling Dervish with gas mask, Taksim Square, 2013. Photo by Seamus Travers.

Figure 1.1. Sulaiga. From The Sistaaz Hood Gallery, 2016.

Photo credit: Robert Hamblin.

46

Figure 1.2. Stills from the video piece InterseXion, 2016. Photo credit: Robert Hamblin.

Figure 1.3. FAKA, 2016. Photo credit: Nick Widmer.

Figure 2.1. Map of Ardoyne from Google Maps. Map data (C)2019 Google.

Figure 2.2. The Orange parade through Ardoyne on 12 July 2012. Image (c) Katy Hayward.

Figure 3.1. HAH, Without Encountering, site-specific installation. Dadans, Playing House, performance.

Figure 4.1. First Siluetazo, 20-21 September 1983. Two silhouettes on an urban wall. Photograph courtesy of Edward Shaw.

Figure 4.2. First Siluetazo, 20-21 September 1983. Silhouette of a baby/toddler on an urban wall. Photograph courtesy of Edward Shaw.

Figure 5.1. Memorial for Alexandros Grigoropoulos and Berkin Elvan in Athens-Exarcheia, 2015. Photography by the author.

Figure 5.2. Graffiti slogans on the floor of Taksim Square during the Gezi protests, 11 June 2013. Photograph by Eser Karadağ via https://flic.kr/p/eJQdsv.

Figure 6.1. 'We the People'.

Figure 7.1. Oren Ziv, 'Protest calling for the release of Israeli soldier Elor Azaria, Tel Aviv, Israel, 19.4.16', 2016.

Reproduced with permission of Oren Ziv/Activestills. 164

Figure 8.1. Drone Space. Self-sketch of a drone capture.

Figure 8.2. Throwing stones scene from The Asylum (dir. Prapat Jiwarangsan, 2015). 184

Figure 8.3. The continuity of work during a military coup, from Night Watch (dir. Danaya Chulphuthipong, 2015). $\quad 185$

Figure 9.1. Özatalay's drawing of Semih Özakça. 
Figure 10.1. A çArşı supporters' banner in Gezi Park with the slogan 'Taksim is ours. çArşı is ours. The street is ours'. Licensed under the Creative Commons Attribution-Share Alike 2.o Generic license.

Figure 11.1. The time distribution of Occupy Gezi tweets for May-June 2013. $\quad 238$

Figure 12.1. The arrest of the African-American celebrityactivist DeRay McKesson during a Black Lives Matter event. Source: AP Photo/Max Becherer.

Figure 13.1. Darko Vojinovic, Opposition Rally, Belgrade Yugoslavia, 14 April 200o. Source: Darko Vojinovic/ AP/Shutterstock.

\section{Tables}

Table 10.1. Data Set of Tweets and Content from the 'Aesthetics of Protest' Project. 


\section{Acknowledgements}

This book is an attempt to better understand how protest movements around the world express themselves, raise awareness, and communicate with diverse publics. The book began through research conducted on the 'Aesthetics of Protest: Visual Culture and Communication in Turkey' project, which was generously funded by the Arts and Humanities Research Council (AHRC) in the UK from 2016 to 2018. The project brought together an interdisciplinary group of scholars to explore the Gezi Park protests in Turkey in 2013, specifically how protestors engaged with digital media, visual culture, art, and aesthetics. We are grateful for the constructive input from our advisory board members: Gillian Rose, Guy Julier, Dan Mercea, and Clare Saunders.

As we presented our research in diverse places, including Lebanon, India, Colombia, the UK, Netherlands, Italy, Hungary, Turkey, Norway, Denmark, the USA and Spain, we saw parallels and overlaps with other protest movements around the world. The editors are incredibly grateful to those scholars, artists, and activists in this volume who joined us to examine how protestors perform and communicate their ideas and interests through aesthetics.

The key ideas and outline for the book was presented at a workshop at Cosmos (The Centre on Social Movement Studies) at the Scuola Normale Superiore in Florence, Italy, in December 2017. The introduction for this book was written at Cosmos, where Aidan McGarry was a visiting scholar in November 2017. We are very grateful to Donatella della Porta and Alice Mattoni for hosting us and providing the space for reflection and concentration. The editors presented the research for the book and several chapters at the Swedish Research Institute in Istanbul (SRII) in December 2017 and received generous feedback from scholars and activists. Our thanks to them. Finally, sincere thanks to the wonderful staff and fellows at the Netherlands Institute for Advanced Study (NIAS) in Amsterdam where Aidan McGarry was a EURIAS/Marie Skłodowska-Curie Fellow in 2018/2019.

We are grateful for the brilliant ideas and help of Catherine Moriarty, Derya Güçdemir, and Emel Akçali. And thanks to the photographer Seamus Travers for allowing us to use his beautiful work as the book cover.

The book would not be possible without the input of our research participants who engaged with us, sometimes at their own personal risk. The book is inspired by and dedicated to those scholars, activists, journalists, 
and artists who live and work under repressive and authoritarian regimes but who courageously shed light on injustices and struggle to ensure that their voices are heard.

Aidan McGarry, Itir Erhart, Hande Eslen-Ziya, Olu Jenzen, and Umut Korkut Amsterdam, May 2019 


\title{
Preface: Devisualize
}

\author{
Nicholas Mirzoeff
}

At the moment of neoliberalism's beginning, Stuart Hall (2017) declared: 'When a conjuncture unrolls, there is no "going back." History shifts gears. The terrain changes. You are in a new moment.' And here we are, once again in such a moment. For Hall, the method was 'Marx plus Fanon', which I will invert for this moment to read 'Fanon plus Marx.' Fanon here stands for the politics of decolonization, from the territorial acknowledgement of Indigenous claims to Palestine and South Africa's Fall-ism: all must fall. Patriarchy must fall, white supremacy must fall, all forms of hierarchical relation must fall (Bofelo 2017). Marx stands for the circulation of socially mediated capital in the era of biopolitical production, which Michael Hardt (2012) calls ' $[t]$ he production of ideas, images, languages, code, affects, and social relationship'. Unlike Hall's 'conjuncture' in which all aspects of the social were connected via the economic, the present is a moment of disjuncture in which it seems that things fall apart. The rupture with neoliberalism's 'common sense' was felt first in the megacities of the global South and their regions but can be felt everywhere now. For the real conditions of existence have changed. Since 2008, more people live in cities than in the countryside for the first time in history. Since 2011, the global majority is aged under 30. In 2014, half the world's population gained access to the Internet. And in May 2014, carbon dioxide crossed 400 part per million for the first time in millions of years. Add to this the post-2008 disaster capitalism that has foisted precarity on the $99 \%$ to make spectacular inequality structural.

There is, then, a rupture with and within the society of control. It has spread from beginnings in the global South to Europe, North America and East Asia. The rupture remains active. Rupture is a break in space and time, a break, actual or imaginary, with previous ways of being, seeing and relating change. Once in the rupture, we find, in the manner of Jacques Rancière, that 'the rupture is not defeating the enemy. It's ceasing to live in the world the enemy has built for you' (Loret 2011). Neoliberalism created a public-private urban space where only 'passive recreation' was allowed, to

McGarry, A., I. Erhart, H. Eslen-Ziya, O.Jenzen, U. Korkut (eds), The Aesthetics of Global Protest: Visual Culture and Communication. Amsterdam: Amsterdam University Press, 2020 DOI 10.5117/9789463724913_PRE 
quote the rubrics now applied in Zuccotti Park, New York, where Occupy Wall Street once camped. If the paradigm spaces of neoliberalism were non-places, like airports, malls and amusement parks, the space of disjuncture is the concrete park where sitting is not allowed, the side of the road where there is nowhere for people to walk, the subway station with no elevator and all those other notionally public spaces that are no one's land. Neither common or corporate, public or private, these are the zones where the non-person may die. These conditions are in flow from global South to North, just as the new authoritarianism in the global North is the reflux of neocolonial formations to their places of origin.

Rupture is a place of density and proximity, a stepping outside the boundaries proposed by the society of control. In a moment of rupture, even such non-space can take on new meanings and temporalities become uneven. People claim that space to invent the commons of the future. Neoliberalism asserted that, in the words of Margaret Thatcher, 'there is no alternative.' But now there is, whether it is the radical right and revived authoritarian nationalism or social movements like South Africa's successful student movement Fees Must Fall, which placed education as a common good above government finances. And in this rupture we are looking to see what's happening - in 2017, 1.2 trillion photographs were taken. Four hundred hours of YouTube are uploaded every minute; 3.5 billion Snaps are posted to Snapchat every day. This is not global narcissism but a symptomatic response to the experience of rupture and the crisis of the representation principle, from politics, to mental health and the possibilities of appearance. What people are trying to create are not just images but a just image of their own situation.

I want to appropriate Hannah Arendt's (1998: 199) evocative phrase 'the space of appearance' to describe both the segregated space delineated by white supremacy as 'public' and counterclaims to appearance. But I use it in a very different way. Arendt described this space as that which occurs 'wherever men are together in the manner of speech and action', in the democracy of the ancient Greek city state, or polis, founded (as she herself attests) on the exclusion of women, children, non-Greeks and enslaved human beings (ibid.). By the time everyone is left out, only $3 \%$ or $4 \%$ of the population were part of this so-called democracy. It was more exactly a space of representation because all those admitted represented the title of free, male citizens. Understood this way, Arendt's space of appearance was as the infrastructure of white supremacy (see Bernasconi 2000; Allen 2004; Gines 2014). There is another appearance that is not representation, either in the political or cultural sense. It is the very possibility of appearing directly. In the non-enclosed encounter, prefiguring an outside to coloniality, I see 
you and you see me and the look that passes between us is not singular and cannot be owned, it is common. It is an apprehension of the claim of the other to the right to look. That look that is exchanged in friendship, solidarity and love. I do not speak in that moment; I wait, I listen, even and especially if you do not talk. We do not and cannot enter the space equally because history and ancestry cannot be abolished. To appear here is not optical. It is the combination of the embodied mediation of appearance; an awareness of time that respects the ancestors and remembers the future; an engagement with the land on which the appearance takes place; and a commitment to the reciprocity and consent of that appearance.

In this space, as Judith Butler (2015:110) put it when speaking of ethical action, 'I am undone as a bounded being.' Just as we are in love - another space of rupture between two or more persons. The space of appearance is, then, unbounded, before and after enclosure. In its oscillation between networked digital spaces and refunctioned urban space, the space of appearance breaks the frame, exceeds and extends representation, even as it is the object of depiction. What appears is a glimpse of the society that is (potentially) to come. It is a space of and in abolition, creating the possibility of abolition democracy. And in so doing the past is also seen differently, both in the ways that it shapes and determines the present, and in pasts that have not been fully recognized or allowed to be. The space of appearance is not universal and it is not unchanging. Unlike the modern (according to Bruno Latour), however, we have often been able to appear to one another. Those in protest have nonetheless failed to make it sustainable.

Aesthetics is exactly why that hasn't happened. As Frantz Fanon (2005:3) identified long ago, coloniality is sustained by the 'aesthetic forms of respect for the established order', from flags and parades to monuments and museums. This process was central to the formation of visuality as a colonial technology. The space of appearance today is the workshop for the production of devisuality, meaning the undoing of visuality by decolonization. Devisualizing means undoing the processes of classification, separation and aestheticization formed under settler colonialism as what I would now call the coloniality complex. It had variants from the plantation complex to that of imperialism and counterinsurgency, even as the fundamental techniques remained constant. Today, the oversight of the plantation has been intensified and technologized into the carceral state, CCTV or the missile-carrying video-enabled drone. Like the two-headed creatures of so many mythologies, devisualizing will require decolonizing past and present formations. From the past comes an understanding of 'the' state and its relation to a supposed 'state of nature' that needs to be undone. If colonial 
reason proposes the Leviathan as its agent, devisualizing Leviathan means becoming ungovernable, then and now. The deep classifications of colonizer and so-called 'savage' (because let's not euphemize what coloniality does) create divides of space and time that cleave the understanding of life. To leave it here, if the history of racial capitalism has been the history of racialized exploitation, another history is (still) possible, despite everything. Or more exactly, herstory, transtory and/or ourstories. And that is the beginning.

\section{References}

Allen, Danielle. 2004. Talking to Strangers: Anxieties of Citizenship since Brown v. Board of Education. Chicago: University of Chicago Press.

Arendt, Hannah. 1998. The Human Condition. Chicago: University of Chicago Press. Bernasconi, Robert. 2000. 'The Invisibility of Racial Minorities in the Public Realm of Appearances', in Phenomenology of the Political, ed. Kevin Thompson and Lester Embree, 169-187. Amsterdam: Amsterdam University Press.

Bofelo, Mphutlane wa. 2017. 'Fallism and the Dialectics of Spontaneity and Organization', Pambazuka News, 11 May. https://www.pambazuka.org. Accessed 15.01.19. Butler, Judith. 2015. Notes toward a Performative Theory of Assembly. Cambridge, MA: Harvard University Press.

Fanon, Frantz. 2005. The Wretched of the Earth, trans. Richard Philcox. New York: Grove. Gines, Kathryn T. 2014. Hannah Arendt and the Negro Question. Bloomington: Indiana University Press.

Hall, Stuart. 2017. 'Gramsci and Us', Verso Books Blog, 10 February. https://www. versobooks.com/blogs/2448-stuart-hall-gramsci-and-us. Accessed 15.01.19.

Hardt, Michael. 2012. 'Falsify the Currency!', South Atlantic Quarterly 111(2): 359-379. Loret, Eric. 2011. "La Rupture, c'est de cesser de vivre dans le monde de l'ennemi”: L'art de Jacques Rancière', Liberation, 17 November. https://next.liberation. $\mathrm{fr} /$ livres/2011/11/17/la-rupture-c-est-de-cesser-de-vivre-dans-le-monde-de-lennemi_775223. Accessed 15.01.19.

\section{About the Author}

Nicholas Mirzoeff is a Professor of Media, Culture, and Communication at New York University. He is visual activist, working at the intersection of politics and global/digital visual culture. His most recent book How to See the World was published by Pelican in the UK (2015) and by Basic Books in the US (2016). 


\title{
Introduction: The Aesthetics of Global Protest: Visual Culture and Communication
}

\author{
Aidan McGarry, Itir Erhart, Hande Eslen-Ziya, Olu Jenzen, \\ and Umut Korkut
}

\begin{abstract}
Protest movements are struggles to be seen and to be heard. In the last 60 years protest movements around the world have mobilized against injustices and inequalities to bring about substantial sociocultural, sociopolitical, and socio-economic changes. Whilst familiar repertoires of action persist, such as strikes, demonstrations, and occupations of public space, the landscape is very different from 60 years ago when the so-called 'new social movements' emerged. We need to take stock of the terrain of protest movements, including dramatic developments in digital technologies and communication, the use of visual culture by protestors, and the expression of democracy. This chapter introduces the volume and explains how aesthetics of protest are performative and communicative, constituting a movement through the performance of politics.
\end{abstract}

Keywords: protest, communication, aesthetics, voice, performance, visual culture

\section{Introduction: The Performance of Protest}

Protest movements are a key function of democracy. They represent an expression of ideas and principles to challenge dominant orthodoxies and have resulted in significant changes to policies and legislation as well as to attitudinal transformations in local, national and international contexts. Protest movements show no signs of abating in the twenty-first century as

McGarry, A., I. Erhart, H. Eslen-Ziya, O.Jenzen, U. Korkut (eds), The Aesthetics of Global Protest: Visual Culture and Communication. Amsterdam: Amsterdam University Press, 2020 DOI 10.5117/9789463724913_INTRO 
people challenge governments, regimes, economic structures, austerity, material inequalities as well as advocate for global issues such as food, water, energy, healthcare, and climate change. And in spite of critiques of identity politics and the mainstreaming of queer theory, identity continues to anchor political struggles around the world (McGarry and Jasper 2015; McGarry 2017).

Protest is an operation of democratic power which can be performative; it is both an act and an enactment. Protest is a collective struggle which calls into question 'the inchoate and powerful dimensions of reigning notions of the political' (Butler 2015: 9). The democratic public performs its existence through resistance: it demands recognition, embodies visibility, articulates a political voice, and communicates ideas/demands. In doing so, protest constitutes 'the people', and through the aesthetics of protest, rupture conventions of doing politics. Protests emerge when people come together to react against exclusion, inequality and injustice, usually propagated by the state or government, though other actors or structures including environmental precarity or economic instability can mobilize people to act. Protest is possible because we have inalienable rights to assemble, to associate, and to speak though this does not necessarily mean that we want to be included in the dominant political order, as many protestors, from Occupy to the Arab Spring, seek to overhaul governments and economic and political regimes. Rather, the enactment of protest signifies democracy in its most essential form, one that is founded on action and enactment: 'Democracy is, properly speaking, the symbolic institution of the political in the form of the power of those who are not entitled to exercise power - a rupture in the order of legitimacy and domination. Democracy is the paradoxical power of those who do not count' (Rancière and Panagia 2000: 124).

Protest is not only concerned with seeking recognition; protest seeks to disrupt the existing political order, transcend or abandon its ideological trappings, and create new possibilities. In the Gezi Park protests in Turkey in 2013, protestors created a new collectivity, one that had not existed before. The 'Gezi spirit' was created by heterogeneous people coming together and crafting something new that fractured the existing order, narratives, and ideologies (Akçalı 2018; McGarry et al. 2019). This became a focal point, which oriented protestors in terms of their ideas, possibilities, and identities. 'Gezi spirit' denotes the enactment of solidarity rather than a collective identity so that performing solidarity is created through different voices being heard. This shows that different voices are possible. The performance of protest in Gezi Park, by women, by Alevi, by football fans, by Kurds, by Kemalists, by LGBTIQ, anti-capitalist Islamists, as well as those whose exclusion by 
the government cannot be easily reduced to identity positions, is based on participation, communication, and interaction. Protest interaction occurs in a demonstration or a march, but the occupation of public space facilitates the creation of new publics and possibilities and allows for the expression of dissenting voices which challenge the political legitimacy of the state or an authority. In this respect, the occupation of a public space such as in Tahrir Square in Cairo or Gezi Park creates and amplifies a political voice, meaning that aesthetics of protest is a form of communication with the potential to inspire and mobilize people to action.

This book maintains that aesthetics are more than Kantian interpretations of what is beautiful or pleasing to the eye but comprise a range of performances. In this respect, we build on the recent work of cultural sociologists who seek to understand the role of aesthetics in social relations and political life, particularly 'the role that aesthetics play vis-à-vis social change' (Olcese and Savage 2015: 723). Whilst aesthetics can be understood as a quality, style, taste or value, we believe this positivist position fails to capture the complex communicative and expressive processes in protest action, and what it means for democratic processes. Research has explored aesthetic choices which protestors use when capturing and communicating ideas, which is bound up with the visual framing or staging of protests (Veneti 2017). In the past, those who capture protest images can help to communicate ideas about the protestors, to raise awareness and visibility, and certainly aesthetics can act as a resource for further mobilization (Doerr et al. 2013). We seek to shift our focus to protestors themselves and help reveal how protestors document and produce protest through aesthetics. This means that value judgements regarding 'pure aesthetics' (sidestepping the issue of whether such judgements are possible) are less interesting for us as the expression or performance of protest and what it means for communication and solidarity. This volume is partly motivated by a desire to show how aesthetics are harnessed by sociopolitical and sociocultural actors through protest and have the power to transform existing structures, ideas, and orthodoxies. Moreover, the various contributors seek to politicize aesthetics, conceiving aesthetics as a practice, a resource, a choice with instrumental and expressive components. Tulke's (2013) research on street art in Athens highlights three overlapping levels of significance: the appropriation and reinterpretation of urban space, the actual message encrypted, and the subsequent generation of alternative discursive communication channels. As we shift our focus from subjective taste and style we are able to capture the aesthetics of protest, its materiality and visual dimensions, its silence, its vocalization, and its rhythm. 


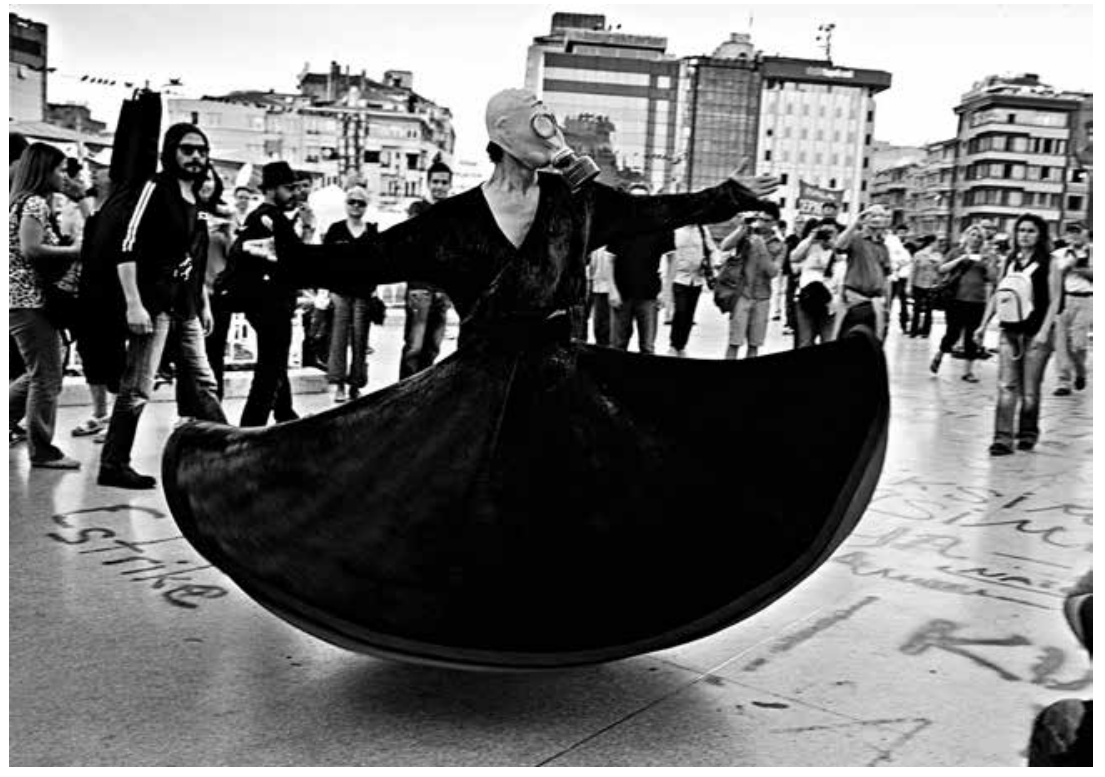

Figure 0.1. Whirling Dervish with gas mask, Taksim Square, 2013. Photo by Seamus Travers.

We understand the aesthetics of protest to be the slogans, art, symbols, slang, humour, graffiti, gestures, bodies, colour, clothes, and objects that comprise a material and performative culture with a high capacity to be replicated digitally and shared across social media networks, ideological terrain, state borders, and linguistic frontiers. A key concern for this book is how the aesthetics of protest are expressed, what they communicate, and its significance for political voice. In the same vein, the dramatic proliferation of digital technologies and images of protest reveals different possibilities for articulating a political voice. Politics is not produced solely by the vocalized claims or demands of protestors but by their action, and sometimes their inaction, thus the aesthetics of protest reveals how democracy is constituted through 'a complex interplay of performance, images, acoustics and all the various technologies engaged in those productions' (Butler 2015: 20). Performance is a form of agency expressing a political voice. The political voice that emanates from the aesthetics of protest cannot be reduced to verbal utterances or background noise; political voice communicates resistance and solidarity. Performativity enacts the power of individuals and groups united in a common message but does not necessarily carry a specific demand as recent protest movements such as Occupy have demonstrated. Not surprisingly, the aesthetics of protest is acutely important for minority 
and marginalized voices that might remain invisible or not heard, such as refugees in Calais or Lesbos, peasant farmers in South America or queer people in Russia. It is surprising how little attention has been given to the role of performance in political activism and social movements.

The solidarity expressed through performance during protests draws attention to those silenced voices laying claim to the democratic sphere, drawing attention to their collective existence, and challenging existing forms of political legitimacy (Butler 2015). As students protested in front of the central government offices in Hong Kong in 2014, police used pepper spray and tear gas to disperse the crowds. Students used the only thing they had, i.e. umbrellas, to protect themselves. Within days, hand-drawn yellow paper umbrellas appeared on the barricades surrounding the protestors and pro-democracy citizens began changing their Facebook profile photos to pictures of yellow umbrellas. Umbrellas disappeared from stores across the territory and reappeared as impromptu public art on city streets. The umbrella was a perfect symbol for the demonstration as it spoke of orderly civic life, of conscientiousness, of ordinary middle-class respectability (Matchar 2014; Ma and Cheng 2019). The innocuous yellow umbrella became a symbol for democracy; a visual and expressive medium to communicate a political voice. Aesthetics of protest carry a potential symbolic resonance bound up with identities, affect, attitudes, and new meanings and knowledge; aesthetics are thus a dynamic process which are attuned to adapt to and support rapid social change engendered by protest movements. Political voice is not concerned with merely being recognized or included in the existing political order; it seeks to rupture dominant political, cultural, and economic structures.

Performance is uniquely placed to fuel political activism as it develops new materiality, the use of bodies, and is often artistically creative, symbolic, and interactive (Serafini 2014: 323-324). The Aesthetics of Global Protest: Visual Culture and Communication highlights the role of art in politics (Reed 2005) and builds on the contribution of artists through 'creative activism' (Rubin 2018) to show how protestors across the world use aesthetics in order to communicate their ideas and ensure their voices are heard. This book looks at protest aesthetics, which we consider to be the visual and performative elements of protest, such as images, symbols, graffiti, art, as well as the choreography of protest actions in public spaces. Through the use of digital technologies and social media, protestors have been able to create an alternative space for people to engage with politics that is, in theory, more inclusive and participatory than traditional electoral politics. This volume focuses on the role of visual culture in a highly mediated 
environment and draws on case studies from Europe, Thailand, South Africa, USA, Argentina, and the Middle East in order to demonstrate how protestors use aesthetics to communicate their demands and ideas. The book focuses on protests which have manifested around the globe rather than protests which span the globe as transnational protests. It examines how digital media is harnessed by protestors and argues that all protest aesthetics are performative and communicative.

\section{Visual Culture and Digital Communication}

The time is right to examine how aesthetics of protest have transformed thanks to developments in visual culture and communication, both of which have been key components of protest movements over the years. Recently, waves of protests have emerged from São Paolo to Hong Kong and Seoul that are original in their cultural and artistic production and expression. They employ artistic forms that have proliferated from those on the margins of society and retain a creative and handmade quality (Caldeira 2013), frequently enlisting popular culture tropes. The appropriation of visual culture by protestors has been explored, notably the Vfor Vendetta mask of Guy Fawkes, which has become emblematic of the Occupy and Anonymous protests (Kaulingfreks and Kaulingfreks 2013), along with the image of Ché Guevara for resistance movements on the left (Memou 2013). Whilst conventional forms of democracy, such as political party membership or voting, have declined around the world, political voice is increasingly expressed and performed through a variety of text, visual, graphic, and communication forms (Loader and Mercea 2012: 5). Protest movements in the last decade were amongst the first to use global social media in combination with aesthetics of protest to try and create 'visual thinking' (Mirzoeff 2015) about representation and social change, to constitute groups and communicate key ideas and demands. What we are witnessing is an opening up of the public, facilitated by social movements, which expands the range of voices that can be heard and diverse expressions of political voice. Many of these voices are articulated visually as our volume illustrates.

This book explores the importance of social media understood not just as a tool to disseminate information (Walgrave et al. 2011), but also as a mechanism allowing people to communicate visually and engage in a nonmaterial space, which impacts on how aesthetics represent and constitute the polity (Rancière 2006). In this respect, digital technologies expand our understanding of how and where politics is done. We understand social 
media as a space that complements the physical or material manifestation of protest in parks, squares and streets. Even protest activities and movements which focus exclusively on digital spaces cannot be entirely disentangled from the material power of mass mobilization in public space. The overall aim of this book is to investigate the aesthetics of protest in protest movements in order to understand the forms of political expression and participation that are intertwined with, but not limited to, digital media. This book will lead to advances in knowledge of protest movements today by developing an understanding of protest aesthetics and their effect in creativeness, consciousness-raising, identity formation and overall in the articulation of opinions and demands.

Protest movements that straddle material and virtual spaces are on the rise across the world with people becoming increasingly able to engage with media technologies in order to be more visible and to ensure their voice is heard (Couldry 2006, 2010; Castells 2012; Barbas and Postill 2017). Research on the Arab Spring and Occupy movements reveals the importance of social media as a key tool for communication between protestors (Bennett and Segerburg 2013) and facilitating mobilization (Gerbaudo 2012), but less is known about how protestors use visual culture to communicate their ideas, identities and interests across diverse social spaces, both material and virtual. It is clear that people are able to harness different media and digital technologies to produce and disseminate ideas, which reflect their realities. Researchers do not yet comprehend the contemporary potentials of visual culture and digital media in affecting social change (Walgrave et al. 2011). That is why this book signifies an attempt to redress this shortcoming and explore how groups challenge authorities using visual culture, performance, and digital media. We explore political mobilization today and seek to understand the role of social media in communicating visual culture and deliberation processes and expression across diverse publics (Brunsting and Postmes 2002), particularly as it relates to marginalized communities and voices. Through aesthetics, protestors' ideas, preferences, and interests are represented and articulated publicly (Werbner et al. 2014). The questions guiding this book are: What are the implications for society of the evolving aesthetics of protest in an age of rapidly changing visual and technological culture? What is the significance of protest aesthetics and their potential in communicating meaning, identity negotiation and in the articulation of opinions and demands? What motivates protestors in their choices of visual communication and mediation? To what extent are aesthetics of protest communicative and performative, and what impact do aesthetics of protest have on the articulation of political voice? 
Visual images help protestors to be visible and to communicate. Digital technologies and social media platforms are developed with specific purposes in mind, which facilitate activities such as our capacity to photograph and upload images onto social media platforms from our smartphones, whilst precluding others, such as our restricted ability to register an emotional response to a status update. Digital technologies retain a materiality, which inform what is possible and encourage us to engage with technology in prescriptive ways due to the design. Such teleological issues are fundamental to how and why we use social media platforms, and, of course, if we choose not to. For protestors, social media is useful to exchange ideas, share information regarding activities, and raise awareness of a protest. Research has noted how social media offers a space for the creation of counterpublics to challenge existing power holders, for new social meaning to emerge, and is based on the assumption that digital technologies such as smartphones and social media platforms afford people an opportunity to participate in politics. This is important for protest movements, which seek to challenge mainstream media, especially in those regimes and contexts which curb and monitor Internet access. Often social media complements a protest, acting as another space to facilitate participate, mobilization and build solidarity but online protest alone is not sufficient to sustain a movement.

Digital technologies themselves are not 'inherently democratic' (Loader and Mercea 2012:3) as there are significant issues of access to and visibility within social media platforms. However, the possibilities for participation and communication have far reaching potential for radical transformative democracy, understood as democratic processes which are more inclusive, deliberative and participatory (Van Reybrouck 2016). There is a significant amount of hyperbole, which in the past has declared 'Twitter revolutions' and arguments that, amongst others, the Egyptian revolution in 2011 was thanks to social media. Such technological determinism simplifies the relationship between media communication and social movements (Morozov 2011). As a corollary, the dismissal of digital activism as 'clicktivism' or 'slactivism', due to the fostering of lightweight relationships and favouring of less commitment than the physical investment in time and risk ignores important mobilization and communication interactions that happen in digital spaces (Earl and Kimport 2011; Bennett and Segerberg 2013). Whilst the power of social media in different protest movements is open to debate, it offers the possibility to explore media ecologies, mediation and communication (Mattoni and Treré 2015). This is why the visual realm is so important. Visual activism means we can 'use visual culture to create self-images, new ways to see and be seen, and new ways to see the world' (Mirzoeff 2015: 297). 
In order to better understand the relationship between protest action, digital technologies and communication, it is necessary to explore how meaning is constructed through the performance of protest, that is, the sociocultural framing and communication of aesthetics. Tacchi et al. (2003) argue that we should pay attention to the role of actors as well as the content of communication. Hence, we look at the role of visual culture produced and disseminated during protests. Performance becomes for us a frame to better understand and articulate our being in social, political and technological spaces and the potentialities of communication and mediation. Performativity is an empowering concept, politically and artistically, because it not only explains how norms are constituted but also shows that change and invention are always possible (Kember and Zylinska 2010: 3). Contestation is a permanent condition of politics, which allows for ruptures. Sometimes we witness the gradual shift of attitudes, ideas, practices and values, such as those engendered by second-wave feminism, the black civil rights movement and peace movements in the 1960 s and 1970s, whilst other times a rupture is a dramatic fissure resulting in the transformation of economic and political structures.

Visual culture is the 'shared practices of a group, community or society through which meanings are made out of the visual, aural and textual world of representations and the way looking practices are engaged in symbolic and communicative activities' (Sturken and Cartwright 2009: 3). Gerbaudo (2014: 266) argues that social media becomes a 'source of coherence as shared symbols - an act of/a sort of centripetal focus of attention - which participants can turn to when looking for other people in the movement', thereafter orienting protests by providing a focal point. That is why political voice is a form of agency that communicates ideas of solidarity - fundamental for protest movements in order for individuals and groups to coalesce and intersect. Though not insignificant, the lines between individual and collective mobilization are increasingly blurred (Kaun et al. 2016). Digital media extends the parameters of who can participate by opening up new paths for communication and mobilization whilst creating 'more decentralized, dispersed, temporary and individualized forms of political action which then subvert the notion of the collective as singular, unified, homogeneous, coherent and mass' (Kavada 2016: 8). Kavada (2016) is critical of entrenched ways of understanding protest movements with success being measured against demands and argues that the constitution of the movement itself as a political actor can, in itself, be a political outcome. This distinction is crucial if we are to understand how protestors expand the scope of how communication is possible, which extends to the creative use 
of visual culture as a way to articulate political voice and express solidarity. The aesthetics of protest is a form of communication which creates a new way to engage and participate and is potentially powerful in consciousness raising, fostering solidarity and mobilization.

Visual culture is highly visible through a series of 'compressed performances' (Pinney 2004), which is now frequently played out on social media. Rose (2014: 13) argues that visual images are 'a trace of social identities, processes, practices, experiences, institutions and relations: this is what they make visible' and it is here where the social and political world is produced and communicated. We can add an additional layer because visual culture such as photographs of protest can 'speak' about things that are not immediately visible. The visual political voice can challenge how discursive interventions are made and communicate ideas and issues, which are latent or invisible. Visual culture works to record things, to represent, to signify, to make visible, to argue, to create affect, and the form can be frivolous or meaningless: 'they are sent as messages to maintain or destroy social relationships; and they achieve this through what they show, how they are seen, and what is done with them' (Rose 2014: 20). If visual culture is rendered meaningful depending on the context of its use, then protest movements challenge where meaning is made; through communication and exchange across digital and material spaces.

\section{Between Digital and Material Space}

Whilst there is a propensity to only consider urban spaces as those where protest is possible and where democracy happens, it is important to note how protest manifests in digital spaces through various technologies and media. Public spaces are a stage on which protestors express solidarity and challenge the legitimacy of political and economic structures, and provide conditions where citizenship can be performed (Clark et al. 2014). Protest movements such as Indignados in Spain, Maidan in Ukraine, and various Occupy mobilizations emerged to 'collect the space itself, gather the pavement, and animate and organize the architecture' (Butler 2015: 71). The appropriation of public space to express power is a long-standing strategy of the state (Taylor 1994). When people assemble in a public space they challenge the idea that the state alone has the authority to determine how it is to be used, whether for ritualistic pageantry or as an expression of state power. During the Red Shirt protests in Bangkok, blood was collected from an estimated 70,00o protestors, pooled together and then poured at 
the gates of Government House as a way to draw attention to the violence and exclusion against sections of Thai society. In this respect, 'the art of urban protest thus confronts the question of who can speak beyond the conventions of the state in non-conventional ways' (Viernes 2015:133). The political meaning and consequence of the act of contesting public space is dependent on visibility; for example, those who prayed publicly in Tahrir Square, Cairo, during the Arab Spring represent a non-violent battle for control of public space (El-Hibri 2014).

Digital spaces also challenge state power by facilitating the horizontal exchange of knowledge and ideas. Such participation and interaction across social media are not reliant on mainstream media, but actively circumvents it in order to allow different voices to be heard. As protestors document and photograph and record protest activities they communicate information and help foster a counterpublic, meaning that protest images have the potential to contribute to a vibrant public sphere (Olesen 2013). In this way, the Indignados in Spain used visual images to capture public performances which develop 'shared and translocal ways of thinking and acting in public rather than a manifestation of the multitude' (Rovisco 2017:347), but there is also identity work at play. In this respect, the public square acts as a theatre where the individual and collective identities of protestors are performed, as it communicates ideas of democracy, including specific demands and grievances. There is a conventional understanding of social media as a new scale where democracy is enacted: protestors harness public space which social media then amplifies to diffuse protest action with the intention of reaching different publics and extending beyond state borders. For some protestors, gaining international attention is a goal whereas for others the diffusion of ideas is less important; the use of English language or symbols is important for protestors to show solidarity with one another. Notably, visual culture has the capacity to cut across linguistic frontiers even if, at times, satire and humour gets lost in (visual) translation.

This raises a question as to how the aesthetics of protest matter across different scales and whether the performance of protest can collapse more rigid distinctions between what is considered to be 'online' (material) and what is considered to be 'offline' (digital) or not. Certainly, sociocultural and sociopolitical opportunities are transformed by digital technologies with user-generated content prominent on sites such as Facebook, Tumblr, Instagram, YouTube and Twitter that host images, movies, videos, and live-stream. Such visibility can be double-edged with surveillance and monitoring of protestors by state authorities, as well as on social media, which can make protestors vulnerable to political adversaries and the state 
(Milan 2015). During protest action, users can navigate digital technologies to dissolve geographies and ascribe meaning to activities. The interface between material and digital space is facilitated by human agency that requires attention to human practices, such as protest aesthetics, which ultimately produce meaning.

A key contribution of this volume will be to demonstrate how aesthetics of protest render distinctions between digital and material spaces negligible, and instead shift our focus to consider the interplay between material and digital spaces as a democratic space that enables political voice to be heard. Meaning becomes dispersed, diverse and driven at the interface between digital and material spaces thanks to 'human reflection, creativity and routine' (Rose 2016: 21). Thereby, the performance of protest not only questions and subverts ideas of where politics is done, but constitutes a rupture to the existing political order by its enactment. The question is not how much the material or digital space accounts for but what the interaction between online and offline spaces means for democratic expression, political voice, visibility and notions of solidarity. As an example, protestors playfully subverted the supposedly rigid distinctions between online and offline during the Indignado occupation by creating an 'analogue Twitter' at the height of the Plaça de Catalunya encampment with protestors writing 'tweets' on Post-it notes and sticking them to a pedestal in the square (Rovisco 2017). The presence of digital space offers opportunities to structure interaction across different actors (such as public, protestors, politicians, media, government) with some social media platforms being 'a mechanism to co-constitute and co-configure the digitally networked protest space' (Bennett and Segerberg 2013: 95). Digital technologies allow a flexible means for protestors to access and navigate protest space, irrespective of their geographic location, but physical presence at a protest can engender different sensory experiences such as smell of tear gas, which is not easily communicated across digital spaces. In this regard, digital technology is not an independent actor but emerges in the context of specific cultural and social settings (Kaun et al. 2016:2). Digital technologies do not merely facilitate communication and participation but actually constitute the demos by allowing different voices to be heard and expressed in creative and often radical ways. Bennett and Segerberg (2013: 42) maintain that 'communication mechanisms establish relationships, activate attentive participants, channel resources and establish narratives and discourses' and thereby approach communication as primarily concerned with organization rather than action. This book focuses on agency and enactment rather than the organization of protest. 


\section{Outline of the Book}

Our book explores how communication and performance constitutes protest movements. This core argument runs through each chapter. One of the advantages of this approach is that it allows us to observe diverse aesthetics of protest at work within complex protest movements and carefully analyse the role of performance and communication. Whilst there are cross-cutting themes which emerge across the chapters such as performance, communication, agency, art, visual culture and digital media, each chapter helps to develop a nuanced understanding of aesthetics of protest. However, there are also contradictions and tensions which emerge across the volume, not least a clear agreement on the definition and interpretation of aesthetics of protest. Rather than find diverse conceptualizations of aesthetics of protest problematic for our central argument, we believe that they enrich our conceptual, empirical, and methodological development, and reflect the multifaceted and contested nature of aesthetics of protest. The Aesthetics of Global Protest: Visual Culture and Communication presents diverse cases from across the globe from multidisciplinary perspectives, including fine art, performance art, photography, sociology, politics, media and communication, and development studies. A common refrain across the book is a call for engagement between aesthetics and protest, using the latter as a lens to understand the former. These chapters render social and political practices a lived experience through protest which remind us that 'aesthetics alerts us to the creativity involved in routine social practices' (Olcese and Savage 2015: 724). The book develops three angles from and through which to better capture the aesthetics of protest.

First, the book argues that we should move beyond strict Kantian interpretations of aesthetics which has been a cornerstone of the arts and humanities for centuries. We do not slay this giant but modestly seek to agitate for change by showing the creative potential of agency through aesthetics of protest. For this reason, we have included two artists in the volume to understand artist practice (see Eğrikavuk; O'Hara) as well as scholars who work on artistic media and expression such as photography (see Faulkner), performance art (see Lewin), street art and graffiti (see Ryan; Tulke), and video (see Viernes). The key claim here is that art is not a value but a practice which yields insights and understandings as well as creating worldviews and meanings. Second, the book argues that visual activism is a mediated space of resistance (see Mirzoeff). The visual realm, which comprises the use of visibility and visual culture by protestors, is not just a monolithic optical entity but demands a response. The visual 
realm is therefore relational in that it requires recognition or a response from others; aesthetics of protests are a form of visual mediation to engage in this dialogue (see Hayward and Komarova; Faulkner). In this respect, mediation can be enacted through embodied performances (see Vis et al.; Lewin) challenging the centrality of a materialist ontology which grounds Kantian interpretation of aesthetics. But we also see this in the deployment of visual media by protestors to contest dominant narratives and to ascribe meaning to real-world events (see Faulkner; Viernes; Özdüzen; Jenzen et al.). Thirdly, the books explores the interplay between material and digital realms for protestors, attempting to show how protest is not confined to specific sites and spaces (or scales). Aesthetics of protests allow us to capture the interplay between material and digital spaces (see Mercea and Levy; Özdüzen; Jenzen et al.; Vis et al.) which become spaces of resistance.

This volume understands the aesthetics of protest as both communicative and performative. Throughout the chapters, certain approaches like slogans, art, music, symbols, slang, humour, graffiti, gestures, bodies, colour, and objects were taken as means to understand how the aesthetics of protest are expressed, what they communicate, and their significance for political voice. The diversity of approaches used in this book reflects the richness in its methodology, its flexible, diverse nature allowing us to understand the dynamic process from different angels and reveals different possibilities for articulating aesthetics of protest. For instance, Chapter 1 explores visual activism and the way in which it complicates/broadens conventional conceptions of activism in South Africa, which operates at the complex intersections of race, class and gender. Chapter 2 is based on ethnographic fieldwork on the Protestant/Unionist Orange Order in Northern Ireland, analysing and interpreting the ongoing events as both territorial struggles and quest for visibility. In Chapter 3 Eğrikavuk looks at the work produced by artist collectives in Turkey four years after the Gezi Park protests. Chapter 4 examines the active resistance taking place in Argentina by the mothers of the 'disappeared' coinciding with another public protest where life-sized paper bodies were deployed during the protest. Chapter 5 develops a case study of spatial politics of street art within the framework of 'right to the city' activism. In an interview with Morgan O'Hara, Chapter 6 discusses her approach to the performance of protest: handwriting the US Constitution as silent collective resistance. Chapter 7 conducts a visual analysis of a small number of photographs of demonstrations selected from the online Israel/ Palestine-based photographic collective while Chapter 8 uses independent Thai cinema as a regime of fictionality where the personalization of protest 
returns. In Chapter 9 Özdüzen analyses censored films and popular activist videos from Turkey whilst Chapter 10 carries out qualitative thematic analysis of music videos during Gezi Park protests. Chapter 11 analyses four Occupy Gezi hashtags through in-depth interviews whilst in Chapter 12 the appropriation of the symbol of protest explores how aesthetics are mediated and performed by activists. In all these chapters both the similarity and the diversity of the methodological approaches provides the richness of this volume. Such differences in the methodology enables us to understand the dynamic process of aesthetics of protest from different angels.

The book is divided into two sections with six contributions in each section, followed by a conclusion, which examines the role of visual culture in protest. The first section focuses on 'Performance, Art, and Politics'. First, in this section, in South Africa visual activism has a different epistemological history and contemporary form thus setting the scene for subsequent chapters. Lewin's chapter uses the work of South African artists FAKA, a queer performance duo, and Robert Hamblin, a fine art photographer, to explore visual activism and the way in which it complicates/broadens conventional conceptions of activism. Hayward and Komarova use one of the most contentious annual protests, an Orangeman parade, in Belfast, Northern Ireland, to explore how participants are engaged in a quest for visibility and show how the ways in which this is managed and performed can be decisive. At this point we introduce an artistic perspective from Eğrikavuk, an artist who uses an exhibition that she curated in Istanbul in 2017 entitled Maybe, We Will Benefit from Our Neighbour's Good Fortune to examine the role of art collectives and the artwork produced as performances of protest in a post Gezi Park political context. The following two chapters address the use of street art by protestors. Ryan situates street art in Latin America, particularly in Buenos Aires, as one example of 'politics by other means', and encourages an appreciation of the 'ambiguity' of such street art, which has both an aesthetic and a political dimension and value. Tulke then asks whether graffitied slogans or large murals, creative interventions into public space have the potential to stage meaningful encounters between city dwellers and the urban landscape they inhabit, inscribing alternative histories and possibilities into the very surface of the city. This chapter stages a dialogue between Athens and Istanbul, exploring how in each case interventions into public space formed part of a larger aesthetics of protest, while also reflecting on how the material shift from physical to digital space may transform the perception and meaning of an artwork. Finally, this section concludes with an interview between New York-based artist, Morgan O'Hara and McGarry, who explore the notion of the 'introvert's 
protest' and the performance of protest through the 'Handwriting the Constitution' project.

The second section is 'Visual Activism and Digital Culture'. In order to understand how photographs function in relation to protest, Faulkner looks at Activestills, an Israel/Palestine-based photography collective that was established in 2005 and currently involves Israeli, Palestinian, and international photographers, who have focused their photographic practice on the depiction of protests and political struggles, primarily in the Occupied Territories, but also within Israel. Viernes explores the cult of visuality in Bangkok protest culture and the role of drones, video and cinema, which intervene in visual protest culture. The next three chapters cover the Gezi Park protests in Turkey and start by developing Viernes's intervention on the role of video and mediation of protests. Özdüzen examines the intersection of Turkish politics and alternative visual and digital media in order to delineate the ways in which activists/artists have coped with the process of polarization in Turkish society. She pays particular attention to text and context of censored films and widely circulated activist videos in an increasingly authoritarian political context. Jenzen, Erhart, Eslen-Ziya, Güçdemir, Korkut, and McGarry explore the use of music videos produced and shared on YouTube during the Gezi Park protests and assesses music was deployed by protestors with the purpose of expressing solidarity and community. Mercea and Levy draw on research with protestors at Occupy Gezi Park, who were selected for their enduring commitment to the protest evidenced by their communication on Twitter. Tweeting enabled the representation as well as the choreography of the collective action and channelled the imagery of police repression as a non-violent counterweight substantiating the violence perpetrated against the activists. The final chapter from Vis et al. in this section looks at the Black Lives Matter (BLM) protest in the USA. It examines a photograph of the arrest of BLM activist DeRay McKesson in Baton Rouge in July 2016, which encapsulates and makes visible a number of tensions namely the profit driven interests that underpin Twitter and the technology sector resulting in a superficial notion of being 'woke', as well as a contradictory engagement with black political culture. Aulich provides a conclusion by elegantly weaving the themes of the book such as mediatization, aesthetics, and protest through significant manifestations of protest across time. He presents an argument which reminds us of the importance of historicizing social movements to better understand evolving aesthetics of protest and how these are linked with democratic expression and consolidation. 


\section{References}

Akçalı, Emel. 2018. 'Do Popular Assemblies Contribute to Genuine Political Change? Lessons from the Park Forums in Istanbul', South European Society and Politics 23(3): 323-340.

Barbas, Angel, and John Postill. 2017. 'Communication Activism as a School of Politics: Lessons from Spain's Indignados Movement',Journal of Communication 67(5): 646-664.

Bennett, Lance, and Alexandra Segerberg. 2013. The Logic of Connective Action: Digital Media and the Personalization of Contentious Politics. Cambridge: Cambridge University Press.

Brunsting, Suzanne, and Tom Postmes. 2002. 'Social Movement Participation in the Digital Age: Predicting Offline and Online Collective Action', Small Group Research 33(5): 525-554.

Butler, Judith. 2015. Notes toward a Performative Theory of Assembly. Cambridge, MA: Harvard University Press.

Caldeira, Teresa. 2013. 'São Paolo: The City and Its Protest', Open Democracy, 11 July. https://www.opendemocracy.net/en/opensecurity/sao-paulo-city-and-itsprotest/. Accessed 28.06.19.

Castells, Manuel. 2012. Networks of Outrage and Hope: Social Movements in the Internet Age. London: Polity.

Clark, John, Kathleen Coll, Evelina Dagnino, and Catherine Neveu. 2014. Disputing Citizenship. Bristol: Polity.

Couldry, Nick. 2006. Listening Beyond the Echoes: Media, Ethics, and Agency in an Uncertain World, Boulder: Paradigm Press.

Couldry, Nick. 2010. Why Voice Matters: Culture and Politics after Neoliberalism. London: Sage.

Doerr, Nicole, Alice Mattoni, and Simon Teune. 2013. 'Towards a Visual Analysis of Social Movements, Conflict, and Political Mobilization', in Advances in the Visual Analysis of Social Movements, ed. Nicole Doerr, Alice Mattoni, and Simon Teune, xi-xxvi. Bingley: Emerald Group.

Earl, Jennifer, and Katrina Kimport. 2011. Digitally Enabled Social Change:Activism in the Internet Age. Cambridge, MA: MIT Press.

El-Hibri, Hatim. 2014. 'The Cultural Logic of Visibility in the Arab Uprisings', International Journal of Communication 8: 835-852.

Gerbaudo, Paolo. 2012. Tweets and the Streets: Social Media and Contemporary Activism. London: Pluto.

Gerbaudo, Paolo. 2014. 'The Persistence of Collectivity in Digital Protest', Information, Communication and Society 17(2): 264-268. 
Jackson, Sarah J., and Brooke F. Welles. 2015. ‘Ferguson Is Everywhere: Initiators in Emerging Counterpublic Networks', Information, Communication and Society 19(3): 397-418.

Kaulingfreks, Ruud, and Femke Kaulingfreks. (2013) 'In Praise of Anti-Capitalist Consumption: How the Vfor Vendetta Mask Blows up Hollywood Marketing', Ephemera 13(2): 453-457.

Kaun, Anne, Maria Kyriakidou, and Julie Uldam. 2016. 'Political Agency at the Digital Crossroads?', Media and Communication 4(4): 1-7.

Kavada, Anastasia. 2016. 'Social Movements and Political Agency in the Digital Age: A Communication Approach', Media and Communication 4(4): 8-12.

Kember, Sarah, and Joanna Zylinska. 2010. 'Creative Media between Invention and Critique, or What's Still at Stake in Performativity?', Culture Machine 11: 1-6.

Loader, Brian D., and Dan Mercea. 2012. 'Networking Democracy? Social Media Innovations in Participatory Politics', in Social Media and Democracy: Innovations in Participatory Politics, ed. Brian D. Loader and Dan Mercea, 1-10. Oxon: Routledge.

Matchar, Emily. 2014. 'The Yellow Umbrella of Democracy', The Medium, 21 October. https://medium.com/re-form/the-yellow-umbrella-of-democracy-d25801d5441d. Accessed 13.05.19.

Ma, Ngok, and Edmund W. Cheng, eds. 2019. The Umbrella Movement: Civil Resistance and Contentious Space in Hong Kong. Amsterdam: Amsterdam University Press.

Mattoni, Alice, and Emiliano Treré. 2015. 'Media Ecologies and Protest Movements: Main Perspectives and Key Lessons', Information, Communication and Society 19(2): 290-306.

McGarry, Aidan. 2017. Romaphobia: The Last Acceptable Form of Racism. London: Zed.

McGarry, Aidan, and James M. Jasper, eds. 2015. The Identity Dilemma: Social Movements and Collective Identity. Philadelphia: Temple University Press.

McGarry, Aidan, Itir Erhart, Hande Eslen-Ziya, Olu Jenzen, and Umut Korkut. 2019. 'Beyond the Iconic Protest Images: The Performance of "Everyday Life" on Social Media During Gezi Park', Social Movement Studies 18(3): 284-304.

Memou, Antigoni. 2013. 'Re-appropriating Ché's Image: From the Revolution to the Market and Back Again', Ephemera 13(2): 449-451.

Milan, Stefania. 2015. 'Mobilizing in Times of Social Media: From a Politics of Identity to a Politics of Visibility', in Critical Perspectives on Social Media and Protest: Between Control and Emancipation, ed. Lina Dencik and Oliver Leister, 53-72. London: Rowman \& Littlefield.

Mirzoeff, Nicholas. 2015. How to See the World. London: Pelican.

Morozov, Evgeny. 2011. The Net Delusion: The Dark Side of Internet Freedom. New York: Public Affairs. 
Olcese, Cristiana, and Mike Savage. 2015. 'Notes towards a "Social Aesthetic": Guest Editors' Introduction to the Special Section, British Journal of Sociology 66 (4): $720-737$.

Olesen, Thomas. 2013. 'Dramatic Diffusion and Meaning Adaptation: The Case of Neda', in Spreading Protest: Social Movements in Times of Crisis, ed. Donatella della Porta and Alice Mattoni, 71-9o. Colchester: ECPR Press.

Pinney, Christopher. 2004. 'Photos of the Gods': The Printed Image and Political Struggle in India. London: Reaktion.

Rancière, Jacques. 2006. The Politics of Aesthetics, London: Continuum.

Rancière, Jacques, and Davide Panagia. 200o. 'Dissenting Words: A Conversation with Jacques Rancière', Diacritics 30(2): 113-126.

Reed, T.V. 2005. The Art of Protest: Culture and Activism from the Civil Rights Movement to the Streets of Seattle. Minneapolis: University of Minnesota Press.

Rose, Gillian. 2014. 'On the Relation between "Visual Research Methods" and Contemporary Visual Culture', Sociological Review 62(1): 24-46.

Rose, Gillian. 2016. Visual Methodologies: An Introduction to Interpreting Visual Material. London: Sage.

Rovisco, Maria. 2017. 'The Indignados Social Movement and the Image of the Occupied Square: The Making of a Global Icon', Visual Communication 16(3): 337-359.

Rubin, Rachel Lee, ed. 2018. Creative Activism: Conversations on Music, Film, Literature and Other Radicals Arts. London: Bloomsbury.

Ryan, Holly Eva. 2015. 'Affect's Effects: Considering Art-Activism and the 2001 Crisis in Argentina', Social Movement Studies 14(1): 42-57.

Serafini, Paula. 2014. 'Subversion through Performance: Performance Activism in London', in The Political Aesthetics of Global Protest: The Arab Spring and Beyond, ed. P. Werbner, K. Spellman-Poots, and M. Webb, 320-340. Edinburgh: Edinburgh University Press.

Sturken, Marita, and Lisa Cartwright. 2009. Practices of Looking: An Introduction to Visual Culture. Oxford: Oxford University Press.

Tacchi, Jo, Don Slater, and Greg Hearn. 2003. Ethnographic Action Research: A User's Handbook. New Delhi: UNESCO.

Taylor, Peter. 1994. 'The State as Container: Territoriality in the Modern World System', Progress in Human Geography 18(2): 151-162.

Tulke, Julia. 2013. Aesthetics of Crisis: Political Street Art in Athens in the Context of the Crisis. MA thesis, Humboldt University of Berlin.

Van Reybrouck, David. 2016. Against Elections: The Case for Democracy. London: Bodley Head.

Veneti, Anastasia. 2017. 'Aesthetics of Protest: An Examination of the Photojournalistic Approach to Protest Imagery', Visual Communication 16(3): 279-298. 
Viernes, Noah. 2015. 'The Aesthetics of Protest: Street Politics and Urban Physiology in Bangkok', New Political Science 37(1): 118-140.

Walgrave, Stefaan, W. Bennett, Jeroen Van Laer, and Christian Breunig. 2011.

'Multiple Engagements and Network Bridging in Contentious Politics: Digital

Media Use of Protest Participants', Mobilization 16(3): 325-349.

Werbner, Pnina, Martin Webb, and Kathryn Spellman-Poots, eds. (2014) The Political Aesthetics of Global Protest: The Arab Spring and Beyond. Edinburgh: Edinburgh University Press.

Yang, Guobin. 2016. 'Narrative Agency in Hashtag Activism: The Case of \#BlackLivesMatter', Media and Communication 4(4): 13-17.

\section{About the Authors}

Aidan McGarry is a Reader in International Politics at the Institute for Diplomacy and International Governance at Loughborough University, London. His research focuses on social movements, protest, political voice, and marginalized communities (www.aidanmcgarry.com). He is the author of four books, including Who Speaks for Roma? (Continuum, 2010) and Romaphobia: The Last Acceptable Racism in Europe (Zed, 2017). He was Principal Investigator of an Arts and Humanities Research Council (AHRC)funded project 'Aesthetics of Protest: Visual Culture and Communication in Turkey' (www.aestheticsofprotest.com) from 2016 to 2018. In 2018-2019 he is a EURIAS/Marie Curie Fellow at the Netherlands Institute for Advanced Study in Amsterdam, where is writing a book on political voice.

Itır Erhart is an Associate Professor in the Department of Media and Communication Systems, Istanbul Bilgi University. She is the author of the book What Am I?' and several articles on gender, sports, human rights, social movements and media, including 'United in Protest: From "Living and Dying with Our Colors" to "Let All the Colors of the World Unite"' and 'Ladies of Besiktas: A Dismantling of Male Hegemony at Inönü Stadium'. She is also a social entrepreneur and an Ashoka fellow.

Hande Eslen-Ziya is an Associate Professor of Sociology at the University of Stavanger, Norway. She has a gender specialization from Central European University, in Budapest, Hungary. Her research has been published in Social Movement Studies, European Journal of Women's Studies, Culture, Health and Sexuality, Leadership, Men and Masculinities, and Social Politics. Eslen-Ziya has also authored a book that investigates how men construct their identities 
throughout their developmental trajectories: The Social Construction and Developmental Trajectories of Masculinities (Istanbul Bilgi Universitesi Yayınları, 2017).

Olu Jenzen is Principal Lecturer at the University of Brighton, UK, and the Director of the Research Centre for Transforming Sexuality and Gender. Her research ranges over different themes in Media Studies and Critical Theory, with a particular interest in the aesthetics of protest, social media and LGBTQ activism and popular culture.

Umut Korkut is Professor in International Politics at Glasgow School for Business and Society at Glasgow Caledonian University. Prof. Korkut has expertise in how political discourse makes audiences and has recently studied visual imagery and audience making. Prof. Korkut is the Lead for the EU AMIF (Asylum and Migrant Integration Fund)-funded project 'VOLPOWER: Enhancing Community Building and Social Integration through Dialogue and Collaboration amongst Young Europeans and Third Country Nationals', which assesses youth volunteering in sports, arts, and culture in view of social integration. He is also the Primary Investigator for the Horizon 2020-funded RESPOND and DEMOS projects on migration governance and populism. 



\section{Part I}

Performance, Art and Politics 



\title{
1 Queer Visual Activism in South Africa
}

\author{
Tessa Lewin
}

\begin{abstract}
While the form of visual activism currently being developed in the United States and Western Europe is more commonly linked to street protests or activist campaigning and is often explicitly anti-capitalist, in South Africa visual activism has a different epistemological history and contemporary form. In the South African context, much visual activism is closely linked to the fine art market and its associated institutions. This is exemplified by the queer black South African photographer Zanele Muholi. Going beyond the body of work available on Muholi, however, this chapter uses the works of other South African artists, namely FAKA and Robert Hamblin, a fine art photographer, to explore visual activism and the way in which it complicates/broadens conventional conceptions of activism.
\end{abstract}

Keywords: Visual activism, queer, South Africa, FAKA, Robert Hamblin

\section{Introduction}

In this chapter I focus on queer visual activism in South Africa, which operates at the complex intersections of race, class and gender. ${ }^{1}$ The term 'visual activism' in South Africa is closely linked not only with the visual material that supports public protests, but with extensive artistic and photographic practices that can themselves be seen as forms of protest. I explore two contemporary examples of queer visual activism: the conceptual photography of Robert Hamblin and the performance work of FAKA and explore what it is in their work that constitutes activism in this

1 This chapter draws on my doctoral research for my thesis on Queer Visual Activism in Contemporary South Africa.

McGarry, A., I. Erhart, H. Eslen-Ziya, O.Jenzen, U. Korkut (eds), The Aesthetics of Global Protest: Visual Culture and Communication. Amsterdam: Amsterdam University Press, 2020 DOI 10.5117/9789463724913_CHO1 
specific sociocultural and sociopolitical context. ${ }^{2}$ The work of both FAKA and Hamblin is embedded in a politics of decolonization that recognizes how important visual aesthetics have been in the historical maintenance of racial capitalism (see Mirzoeff, this volume). Their work is best analysed through a lens of intersectionality that understands race, class, gender and sexuality as mutually co-constituting, interconnected systems of identification. Drawing on the work of black feminists, whose writing critiques the historical erasures of Western feminism, their work explicitly refuses to address sexuality in isolation from other forms of inequality (Crenshaw 1989; Mohanty 1988; Hill Collins and Blige 2016).

Robert Hamblin is a white, middle-class transgender man, whose project interseXion was produced in collaboration with The Sistaaz Hood, a black trans women sex worker support group. interseXion is the culmination of several years of their joint work on self-representation and identity. Very broadly, it can be seen as an advocacy project contributing to the lobbying for the decriminalization of sex work and as a pedagogical project that raises awareness around some of the socio-economic challenges faced by trans women sex workers in South Africa. Hamblin uses his images not just to generate income for himself, but also to mobilize resources for the members of The Sistaaz Hood. At its heart, though, it is also about using portrait photography to build relationships and to support psychosocial well-being.

FAKA is a queer black performance duo based in Johannesburg, made up of Desire Marea and Fela Gucci (the performance personas of Buyani Duma and Thato Ramaisa). FAKA's performance first emerged through a blog platform that the pair set up as an online networking and showcasing space for queer black South Africans. They perform in both clubs and galleries and continue to be involved in online fashion spaces. FAKA has recently been employed as brand ambassadors for Adidas and has worked with Versace, ${ }^{3}$ and the duo embrace this 'commodification of "blackness"' (hooks 2014: 152) as part of their broader project of challenging and remaking normative reality. I read this performative engagement with corporate capital through what Muñoz terms 'a mode of being in the world that is also inventing the world' (Muñoz 2009: 121). They are performing against the popular notion that one cannot be both queer and African (Ekine 2013) or male and

2 Post-apartheid South Africa remains one of the most racially divided and unequal societies in the world (Sulla and Zikhali 2018), with high levels of gender-based violence (Jewkes 2016), and gender and sexuality have emerged as significant sites of contest (Posel 2005).

3 Their track 'Uyang'khumbula' was chosen to launch Versace's 2019 Spring/Summer Fashion Show in Milan. 
feminine. They also view their visual activism as a pathway to the economic freedom denied to black South Africans prior to 1994 (Posel 2010; Southall 2007). The notion of economic freedom has taken on increased importance in South African public discourse in recent years as exemplified by the populist political party the EFF (Economic Freedom Fighters). ${ }^{4}$

\section{Visual Activism}

The term 'visual activism' has been used in a diverse range of contexts to describe a very broad range of activities from protest graffiti (Thomas 2018), political funerals (Thomas 2017), action research using photo elicitation (Wilson and Milne 2015) to fine art photography that allows the photographic subject some control over the framing of their portrait (see Hallas 2012). In the United States the first use of the term in academic literature I have identified was Cvetkovich's (2001: 285) writing on the activist groups Fierce Pussy, whose projects included wheat-pasting posters on the streets of New York (Burk 2015), and Lesbian Avengers, who staged performative protests (Rand 2013). Both groups were formed by members who were at the frontline of AIDS and queer activism throughout the 1980 s and early 1990s (Rand 2013: 122).

Currently, in the United States and Western Europe 'visual activism' is a term used to describe a form of activism based broadly in visual culture that has emerged following the financial and economic crash of 2008. These images are linked to political protest with examples including the burst of graffiti art that appeared in Cairo during the Arab Spring (Khatib 2013) or the now famous image of a ballerina on the bull statue that an Adbusters poster used to call for the occupation of Wall Street (McKee 2016a). These images often exceed or are situated outside of the formal institutions of the art world. This form of visual activism is more commonly linked to street protests or activist campaigning and is often explicitly linked to struggles against global capital and neoliberalism (Demos 2016; McKee 2016a, 2016b; Sholette 2017).

\section{Visual Activism in South Africa}

In post-apartheid South Africa, in contrast, much contemporary visual activism is closely linked to the fine art market and its associated institutions, 
and many visual activists see engagement with the institutions of the art world as a significant opportunity. This is exemplified by the black queer photographer Zanele Muholi, who has consistently described their own practice as 'visual activism' since their first solo exhibition at the Johannesburg Art Gallery in 2004 (Muholi 2009). Muholi's work has been exhibited extensively, both within South Africa and internationally, and their work points to a need to acknowledge the many different public spaces within which visual activism can be sited. Additionally, although Muholi's images are striking, and they themselves make significant epistemological and pedagogical interventions, much of what constitutes their activism is not apparent in these images. Through the activities surrounding the project that Muholi founded (inkanysio.org) and their training and mentoring of many other queer black South Africans, Muholi has used their visual practice to develop a community of black South African queers (Thomas 2013). What is significant is that their work, and that of many other visual activists in South Africa, uses the visual artefact (be it a performance or image) to build literal, metaphoric and relational value. Muholi's work builds on long history of activism both in the South African context and elsewhere that uses art as 'a constitutive force in the building of social movements' (Holmes 2012) 5 and fuses this with an astute awareness of how the art market and art institutions can amplify the message their work seeks to convey.

The term 'visual activism' appears to have emerged in South Africa at a similar time to its emergence elsewhere. South African visual theorist Kylie Thomas notes first hearing the term 'visual activism' in 2001 used by South African documentary photographer Gideon Mendel to describe his own HIV/AIDS activist work (Thomas 2017: 266). Mendel started calling himself not a documentary photographer where he was 'passively' witnessing subjects, but a visual activist since he had started actively trying to engage the participants of his photographs in their own representation. Mendel was working with Medicins sans Frontières (MSF) and the Treatment Action Campaign (TAC) on a series of photographs and films that were designed to support TAC's campaigning for the state provision of anti-retroviral drugs to HIV-positive people in South Africa (Hallas 2012).

South Africa has a rich history of activism at the intersection between art and politics. 'Visual activism' as a term is beginning to be retrospectively applied to this history of activism (Thomas 2017). Beginning with the 1950s many artists and photographers saw themselves as activists first and artists second while

5 Thompson's (2015) notion of art as creating 'structures of resonance' is a similarly useful concept here, as is Muñoz's (1999) discussion of 'queer worldmaking' in Disidenitifications. 
their work ranged from the photography documenting apartheid in the 1950 s to the art centres established in the 1970s that both supported individual artists and anti-apartheid activities. ${ }^{6}$ Through to the mid-1980s, with the heightening of the anti-apartheid movement, there emerged a significant international interest in South African visual production. Patricia Hayes suggests that after 1994 'the locus of the photograph shifted from the media to the gallery' (2011: 264). Certainly, both Hamblin and FAKA see the gallery as an important site for activist work as well as a space that allows them to access an international art market that supports their work (both literally and symbolically).

Following the Bantu Education Act of 1953, artists have worked in a context where black students were only taught subjects that would prepare them for unskilled service-based jobs in the labour market (Williamson 1989: 9). Moreover, these artists were continuously denied access to the galleries and museums, which were then the sole preserve of South Africa's white population (Lilla 2017). Both these factors cast a particular light on the historical importance of both FAKA and Sistaaz Hood's contemporary engagement with art institutions.

While visual activism during apartheid tended to focus on the antiapartheid struggle, after apartheid (1994) HIV/AIDS was seen by many as the 'new struggle' (Hayes 2011). Many of the photographers, who had been active in the anti-apartheid struggle, turned their attention to photographing HIV and AIDS (Wienand 2012: 177). There were numerous visual responses to the epidemic (Roberts 2001; Allen 2009; Thomas 2014) with evident close links between activist networks and artists.

The queer visual activist work of Robert Hamblin and FAKA builds on South Africa's legacy of anti-apartheid and HIV/AIDS activism. Their work exhibits two characteristics that reflect the historical lineage of their practice. The first is that they both exhibit a networked approach to visual practice that is strongly rooted within the social and look for multiple opportunities to build and sustain themselves through their work across activist, academic, media, entertainment, and art world platforms. The second is that both of them are consciously using money earned to further their activist work and hence are mostly pragmatic both in terms of making a living and enabling their activism as well as about the necessary collusion with global capital involved in the art market.

6 The activities of one such art centre (the Community Arts Project in Cape Town) is documented at http://www.sahistory.org.za/article/community-arts-project-cap, accessed 12.02.19, and its poster production in Berndt (2007). Seidman (2007) gives a broad overview of anti-apartheid poster production in South Africa. 
In the post-apartheid context, for FAKA, as black South Africans, engaging with the global market is seen not just a necessity, but as a right as well as an important post-apartheid freedom. This is because of the extent to which the apartheid government controlled what, how and when black South Africans were allowed to both acquire and spend money as their authority extended from the systematic forced removal of black South Africans from arable land to micro-management of what they were allowed to buy (Posel 2010). South Africa is still the most socio-economically unequal country in the world (Sulla and Zikhlai 2018). Although since the end of apartheid South Africa's upper classes are no longer exclusively white, the burden of poverty is still predominantly borne by its black African population (Durrheim et al. 2011: 17). In this context, for black South Africans, 'economic freedom', the right to earn money and control these earnings, is understood to be an expression of post-apartheid democracy (Posel 2010). This is a very different positionality to, for example, the France-based art collective LABOFII (Laboratory of Insurrectionary Imagination) that have pulled out of exhibitions sponsored by corporate capital as an anti-capitalist gesture (Demos 2016: 89). Hamblin and FAKA both employ strategies to engage and manipulate art institutions in a way that helps build and support both their political agendas and their communities.

\section{Relational Visual Activism}

interseXion, a collaboration between Robert Hamblin and The Sistaaz Hood fuses Hamblin's facilitation and advocacy skills from his NGO work with a fine art sensibility that has produced an extraordinarily beautiful and valuable body of art. This multidisciplinary approach that embeds the visual within a much broader social network characterizes the conception of this form of contemporary South African queer visual activism. interseXion grew out of a slow, in-depth, exploratory process during which Hamblin and The Sistaaz Hood jointly developed and negotiated their representation. Hereby, I try to give a detailed sense of this process, as an example of a form of visual activism, where the production of images contains and motivates a process of empowerment and movement building (through the production of the image) and pedagogy (through its display).

Hamblin's long-term collaborative project with The Sistaaz Hood, interseXion was exhibited at the Iziko National Gallery in Cape Town from March to July 2018. interseXion explores the complexities of sex work in South Africa. Hamblin contrasts his own trans identity as a privileged person in 
contrast with that of a homeless black trans women sex workers. interseXion comprises three series: The Sistaaz Hood Gallery (fig. 1.1), Diamond Town Girls and the installation InterseXion (fig. 1.2), which is made up of photography and video work. ${ }^{7}$ l look here at The Sistaaz Hood portraits and the video piece in InterseXion.

Hamblin started his professional career as a commercial photographer, before co-founding Gender DynamiX, a Cape Town-based NGO that supports transgender and gender non-conforming people. In 2012 Hamblin began to pursue a full-time career as a fine art photographer and thanks to his experience as a transgender advocate Hamblin helped to establish a support group for transgender women, SWEAT (Sex Workers Education and Advocacy Task Force), which supports the health and rights of sex workers. The Sistaaz Hood's first advocacy project was a joint photography project with Hamblin (named The Sistaaz Hood Gallery) exploring their representation. The development of the support group, and this body of work, is inseparable.

When The Sistaaz Hood learned that Hamblin was a photographer, they asked to be photographed. Over a period of several years, Hamblin and Sistaaz Hood, together, very consciously negotiated the terms of their engagement. Their photography project began as part commission part mutual exploration. As Hamblin recalls, one of the group instructed him:

You photograph rich women, and you do Photoshop on them, then they can just look amazing. You'll do the same with us. (Hamblin 2016)

Hamblin became interested in exploring in how transgender experiences illuminated social fault lines. Below, he reflects on this:

What happens when a male gives up his power? What happens when a poor person gives up masculine privilege. What happens to a black person within the patriarchy that transitions to being a woman? It's all there at this intersection. [...] A black transgender woman is all the intersections that we can look at where the patriarchy goes wrong. (Hamblin 2016)

Hamblin is articulating the fact that a black transgender sex worker exists at the intersection of numerous structural oppressions of race, class, gender, and sexuality. 


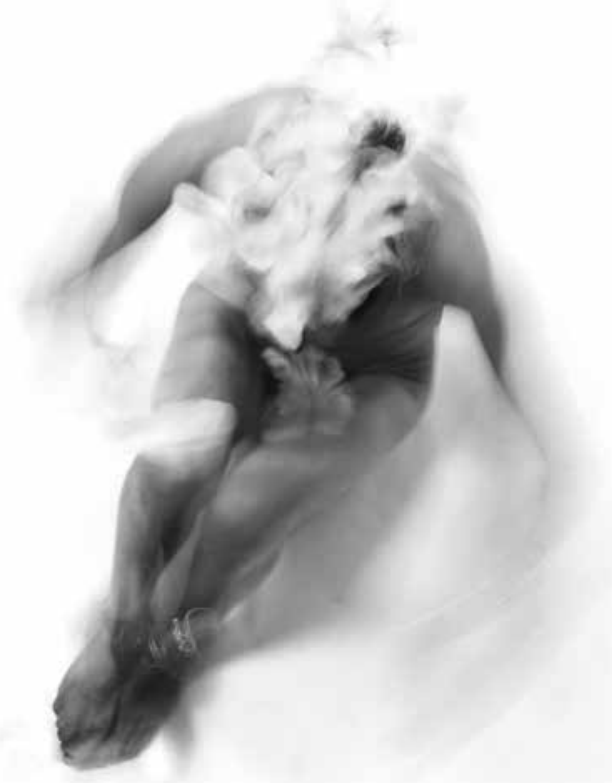

Figure 1.1. Sulaiga. From The Sistaaz Hood Gallery, 2016. Photo credit: Robert Hamblin.

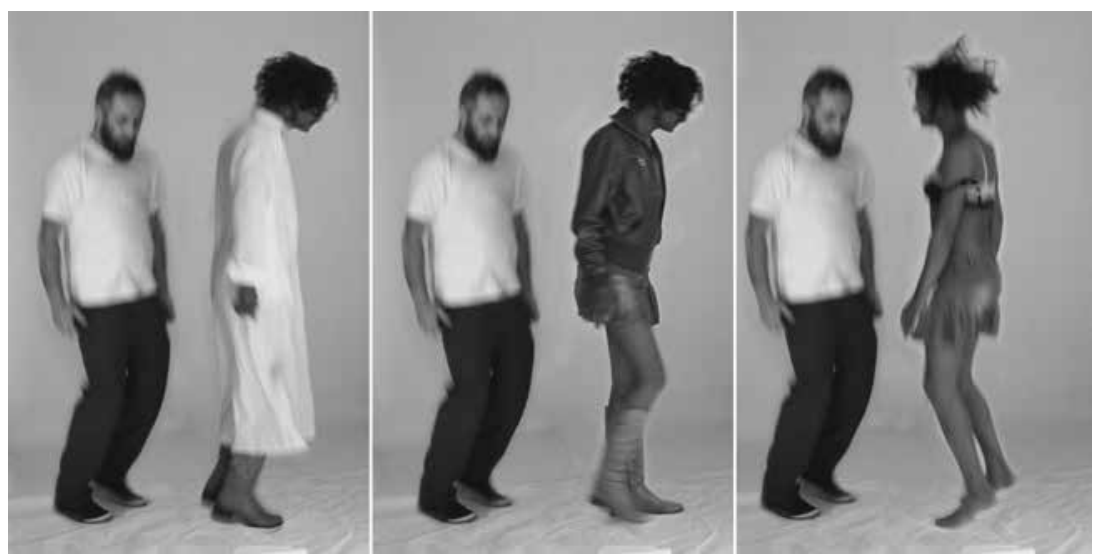

Figure 1.2. Stills from the video piece InterseXion, 2016. Photo credit: Robert Hamblin.

The form of Hamblin's photographs emerged through the mutual exploration of identity and representation that took place in his workshops with The Sistaaz Hood. Hamblin spoke about the process out of which The Sistaaz Hood portraits emerged: 
[A] beautiful thing that came for me from discussions around the project was about representation, you know, how do other artists look at us, how does the media look at us, we looked at all those things, very, it got more formalized and workshoppy. And then, how do you want me to look at you? What do you want me to see? They were all like 'well we're sex workers, so we want to be sexy, um, you have to pay us if you want to take off our clothes, we want to take our clothes off, because we are poor, we are never going to be able to alter our bodies, but people think we're crazy when we tell them that we're women, so we want to show that we don't have breasts, we're not ashamed of being poor, or that we're never going to be able to have breasts, we're not crazy, we know we don't have breasts. So, that was one of the elements, I had to show that, and then we spoke a lot about the performances they do when they are doing sex work. There's a lot of movement involved, so they have to perform, to obscure, to obscure, you know, their male bodies, so that's where the movement came from. (Hamblin 2016)

Hamblin's trademark long exposures which create a blurring of the image are here about obscuring the women's male-presenting bodies and showing the movement symbolic of the multiple performative moves they make. As in his other work, they are also about a refusal of fixed notions of identity. Hamblin describes revisiting the same themes within the group, and over several years, developing both a visual and verbal language with which to communicate. Through the collaborative process of crafting visual representations of themselves, Hamblin and The Sistaaz Hood go through a process of transformation in relation to their understanding both of themselves and of each other. Their visual project, and the work that both parties do in engaging with it, creates a space in which they both become active and learn from each other. Below, Hamblin talks about the importance of the collaboration being not so much about the image creation, but the mutual (self-)learning it facilitated:

So, it was an amazing collaboration that way, not a collaboration like we're making art together. A collaboration like in we're getting to know our identities here, and we are arming ourselves against a communal enemy. Ya, so that was the process of working with them. Very laborious. (Hamblin 2016)

It is the artefact that both arises out of this process, and also facilitates and contains the process. So, the activism is located at multiple points within 
and around the visual image and the interactions it both creates as well as by which it is created. Making this process of mutual (self-)learning through the artwork, which constitutes both a trace and distillation of the process, public is a brave act of pedagogy. It is also a further (public) assertion of both value and solidarity.

Hamblin's video piece InterseXion is about the bodies in which the intersections of class, gender and race collide. It reflects the maturity of the Hamblin/The Sistaaz Hood partnership. The video piece explores many of the themes of The Sistaaz's Hood portraits with much of same visual language but with the entry of Hamblin into the frame. Hamblin and (Leigh) Davids, one of The Sistaaz Hood, are juxtaposed on screen against a white floor and background in what reads as a dark-humoured nod to the hetero-iconography of wedding figurines. Davids (on the right of the screen) moves constantly, shifting between different identities, performatively required to be always on the move. Davids's movement is punctuated by the soundtrack in which she narrates her rejection from her community that led her living on the streets:

[W]ithin town you have poor trans people, living in communities out of the streets, and you have white rich trans people, and they live at home, and they live at home, home. I am here but able to tell them what it really is to be black, to live in poverty, and what it's like to not be accepted within society, due to the colour of your skin.

Although Hamblin and Davids share a trans gender identity, their race and class positions radically alter their experience. Davids's own story in the soundtrack is constantly, somewhat annoyingly, interrupted by her refrain: 'The colour of Robert's skin. Robert as a man, has an advantage, has an advantage.'

This serves the dual function of constantly emphasizing Robert's privilege both as a man and as white, and actively reinserting, or making dominant, Robert's presence even within Davids's own narrative, and thus re-inscribing both the mutual contingency of their positions and Robert's privilege.

Part of the discussions and negotiations around developing interseXion have also been about how best to navigate finances. Hamblin talks about trying to develop 'better ways' for artists to be, not just in terms of the content of his photographs, but also how he manages any income from the work. Here he explains how they have agreed to share any money that interseXion generates:

I paid them [The Sistaaz Hood members] for the shoot. A fee was negotiated [...] and then I gave them commission on sales on the first edition of 
the print. Anyway - so that. And then, except for that, they are my 50 per cent partners. So, after all the costs have been paid, and the commissions have been paid, then the profit on the work, I get half and the group gets half. ${ }^{8}$ (Hamblin 2016)

This financial arrangement reflects Hamblin's acknowledgement of the collaborative nature of the work. The work toured in 2017 and Hamblin travelled with members of The Sistaaz Hood group. It is partly the extent to which Hamblin acknowledges the collaborative debt that makes this work both queer and activist.

Tragically, Leigh Davids died on 27 February 2019, two weeks before her $40^{\text {th }}$ birthday. Her death has transformed her work into an archive of her struggles to be seen and heard, and her desire for solidarity (see McGarry et al., this volume). For Davids, this work had very real political stakes. interseXion was not just part of an advocacy campaign to decriminalize sex work, and it was not just a mutual exploration of trans-identity and representation. It was also about using visual production to create literal and symbolic capital, both for those directly involved in the project, and for future generations.

\section{FAKA's Subversions}

The following section examines the performance practice of the duo FAKA, whose practice moves between gallery spaces, fashion blogs, and festivals. FAKA talk about themselves not just as a duo, but as a 'queer movement' (Duma 2015). They envisage themselves as mothers of the 'House of FAKA', after the New York ball culture documented in Paris Is Burning (Livingston 1990), using their practice to create a safe space for a community of fellow queer black South Africans. In the section that follows, I draw on an interview that I conducted in 2015 in Johannesburg with Buyani Duma (aka Desire Marea), one half of the FAKA duo.

For FAKA, being visible is being activist and they exploit commodification to augment their visibility (Duma 2015). They use self-actualization through fashion and consumerism to remake normative reality and carefully crafted spectacles to create contemporary indigenous queer rituals. There have been three broad strands to their work so far: gallery-based performance pieces,

8 Hamblin and The Sistaaz Hood have revised this financial agreement since this interview, and now all profits from this work go towards The Sistaaz Hood project. 


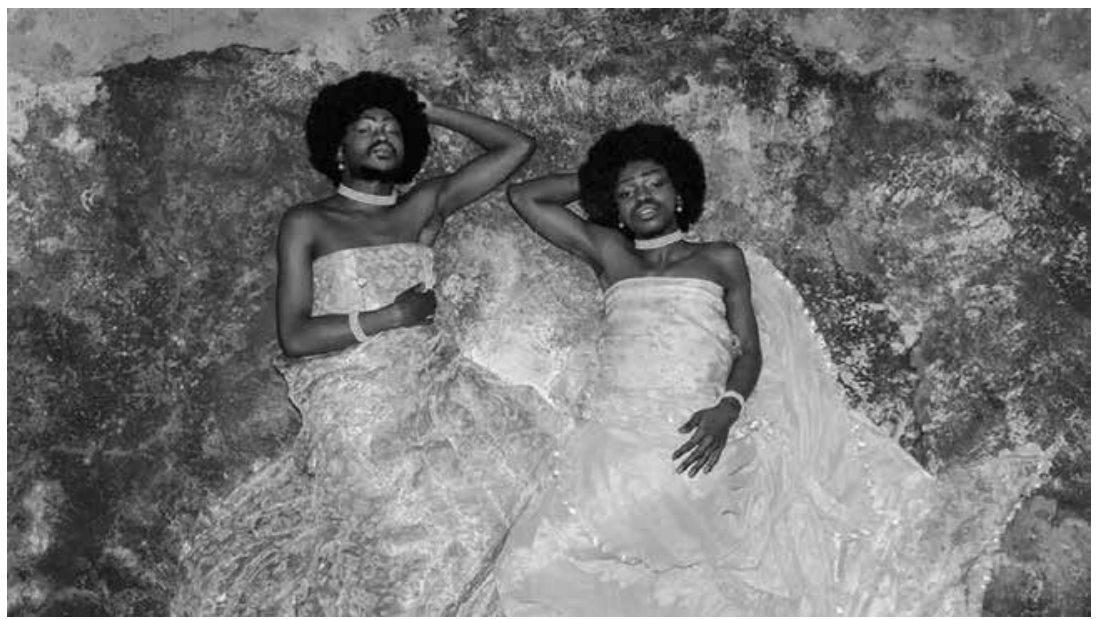

Figure 1.3. FAKA, 2016. Photo credit: Nick Widmer.

music videos, and heavily stylized fashion (self-)portraits. Their aesthetic sense is extremely powerful and unusual, partly in the way that they blend contemporary and traditional visual elements and partly in their embrace of the erotic as well as of their femininity. FAKA means 'to penetrate', but also 'to contribute to', so even within their name there is surprising mixture of irreverence and social responsibility.

South Africa is famous for its regional exceptionalism in Africa marked both by its 1996 constitution, which explicitly outlaws discrimination based on sexuality or gender, and the existence of gay marriage. ${ }^{9}$ However, despite this legal inclusion, there have been numerous cases of violent homophobic murder, 'signifying the continued social exclusion of those at the sexual margins' (Judge 2015: iii). Much queer visual activist work in South Africa has concentrated on the documentation of hate crimes and either supporting or challenging the criminal justice system in an attempt to better support the victims of hate crimes..$^{10}$ FAKA's artistic production on the surface is the antithesis of this kind of work. It is much more concerned with celebrating life, and fabulousness, than documenting death. Yet, it too is motivated by a desire to challenge both damaging gender norms and homophobia. FAKA's decision to be artists was based a belief 'that culture is a higher governing body than law when it

9 South Africa became the fifth country in the world to legalize marriage of same-sex couples in 2006. The debates around this reform, and the journey taken towards its institution are celebrated, documented, and analysed in Judge et al. (2008)

10 See, for example, the work done by Zanele Muholi with Inkanyiso, and by Iranti.org 
comes to power over bodies, ${ }^{\prime 1}$ an opinion echoed by Steyn and Van Zyl, who suggest that without challenging the gendered nature of social institutions, gender-based violence will persist, regardless of how well the criminal justice system works (2009: 12). In challenging normative gender constructions by unapologetically embracing their femininity and the social conservatism around sexuality (by being overtly sexual), FAKA hope to challenge both gender-based violence ${ }^{12}$ and homophobia. Here Duma explains this as follows:

we represent our generation, and our generation needs different things. Like, it's a whole different narrative now. It's more about issues of representation, and yes, the hate crimes are still there, but we sort of try to get to the root of things, because we wouldn't feel like there would be so much homophobia if sexuality wasn't so like frowned upon in our society. Because anything that even hints at sexuality is like completely expunged, and that's why AIDS, or HIV, was stigmatized for such a long time. (Duma 2015)

FAKA's performance piece Wait Lorraine (2015) is about refusing the stigma attached to sexuality. ${ }^{13}$ Wait Lorraine is partly an assertion of pride, but it is also an emphatic countering of the argument that homosexuality is un-African; an argument that structures much homophobia in South Africa (Ekine 2013). FAKA's work is both definitively queer, and definitively (South) African.

FAKA consciously position themselves as role models offering guidance to younger black South African queers. Borrowing from Pepper Labeija, ${ }^{14}$ Duma introduces himself as 'Desire Marea - legendary half mother of the house of FAKA'. The younger artists they profile on their website ${ }^{15}$ they refer to as 'Top Upcoming Legendary Children', and 'The House of FAKA', is 'a counterinstitution meant to shelter everybody, who is alienated by mainstream culture' (Duma 2015).

FAKA's desire to be famous is very much imbricated in their desire to model what Muñoz (2009) calls a 'critical utopia', and FAKA a 'reimagined

11 See Duma's talk at Creative Mornings Johannesburg, June 2016, https://www.youtube.com/ watch? $\mathrm{v}=\mathrm{kFkgN}$ PGdMM, accessed 12.02.19.

12 South Africa has extraordinarily high levels of gender-based violence, with more rapes committed per capita than any other country in the world (Anderson 2000: 789). Gqola argues that rape works to keep patriarchy intact (2015:21) and that it is a national culture, not just a behaviour attributable to a small minority of men (ibid.: 178).

13 https://www.youtube.com/watch?time_continue=181\&v=uzJyF1QIyrA.

14 A central figure from the New York ball scene of the 1980 .

15 www.siyakaka.com. 
existence for black queer people'. Duma, explaining the importance of the gay celebrity Somizi Mhlongo, equates visibility with activism:

[J] ust by being visible, I feel that that in itself is activism. [...] [T] here are so many people. And some are not actually fine artists, but it's queer visual activism. There's a South African called Somizi Mhlongo - he acted in Sarafina the musical, then in the 8os, he was the first black man I knew to be publicly homosexual (when I was a kid) and that was unheard of, and he did it with such grace, and he stayed true to himself. And he's been successful for so many years, he's been a role model. [...] [I]f Somizi didn't exist, we'd actually be in a different place, like in terms of society. Maybe my grandparents wouldn't be as exposed to knowing what a homosexual man is, that a homosexual man can be a talented performer on television. He can be a person who loves his mother, because he's been public about that as well, and he has a daughter as well, and the complexity is so humanized. (Duma 2015)

So, for Duma, Somizi's presence on national television provides much needed proof not only that queer people can exist, but that they can be valued (socially and economically) and that they are capable of having the kinds of loving family relationships that his grandparents regard as important. Somizi's public visibility both facilitates (in relation to his family) and affirms (in relation to himself) Duma's own queerness.

Many of the people that Duma cited as his queer activist heroes are celebrities or public figures. To him, they are activist in the sense that they are 'out', and therefore actively, daily, challenging dominant social norms, that talk of queerness as 'un-African' (Hoad 2007: xi; Gunkel 2010: 25), that require men (and women) to be gendered in a particular way, and that violently police the boundaries of heteronormativity. Currier (2012) and Tucker (2009) have both shown how queer South Africans strategically shift between visibility and invisibility to protect themselves. Duma's respect for queer black South Africans, who are unequivocally, permanently 'out' is partly about the fact that they are allowing the general public access to queer representations.

FAKA sees the art world as just one of the platforms that will help them access bigger and more diverse audiences in the long term:

Right now, our audience is not the audience we want, because our audience is mostly at art galleries, and it's a very concentrated niche audience. We so badly want to have mainstream impact. [...] [T] he art world is slowly becoming more open [...] but I guess the art world is also a business and 
they need to make money. So, it's sort of something you have to do on your own, independently as an artist, like put up your own structures that actually reflect that ideology of accessible art [...] with the help of the art world. We don't want to limit ourselves to fine art or anything like that. We want to be FAKA on television, we want to bring the truth there. We want to be FAKA in magazines. (Duma 2015)

Since this interview, FAKA's ambitions have in many ways been realized. In 2016, they were appointed as 'brand ambassadors' for Adidas. Even given the elision of culture and consumerism in contemporary South Africa (Nuttall 2011), it seems counterintuitive to be celebrating this as a victory for queer visual activism. However, the members of FAKA argues that they are consciously using the Adidas brand to promote themselves, and to subvert mainstream or normative representations. In an interview with the Mail and Guardian, a weekly newspaper in South Africa, Duma talks about using capitalism as a resource:

Capitalism gives us access to all the artefacts that can have a different meaning when subverted. Also, when you are at the forefront of a cultural phenomenon in a time when culture is gaining a lot of economic power, you will find people trying to commodify you. It is weird for us because the thing they would commodify is the very idea of our bodies, our identities basically. (Quoted in Bongela 2016)

Although Duma expresses some discomfort with being commodified by a brand, he sees it as inevitable, and goes on to talk about the fact that this is strategically useful in furthering not just their political project but their own brand. Adidas may be using FAKA to stay relevant, but FAKA is using them back, and is fairly confident that it is their own narrative that will win out as more interesting. Here Duma talks about the inevitability of collaboration between consumer brands and what Bongela (the Mail and Guardian journalist interviewing Duma) calls 'self-made internet stars':

You know, it is an inescapable reality. We grew up in a very consumerist black society and in many cases the choices concerning brands were very irrational, in a sense that we believed that the brands did something to us that made us 'better' or 'okay' or 'less black and poor'. I think that was a reality a lot of black youth were trying to escape: the fact of poverty. We believed brands had the power to change that narrative. We find it interesting now, to see brands scrambling for relevant black artists to 
change the narrative of the cultural bankruptcy of their brands. The Adidas campaign for us was more a story of representation and in a way, we had to have faith that that story would be more potent. (Quoted in Bongela 2016)

In 2018, FAKA's music track 'Uyang'Khumbula' was chosen by designer fashion label Versace to accompany the launch of their spring/summer 2019 collection. This particular success has great significance for FAKA because fashion and self-fashioning have been central to their self-actualization. Duma says that one of the things that brought himself and Ramaisa together was the mutual understanding that they 'didn't have the money to have certain things that make you matter these days'. Through performing FAKA, they are laying claim to that which has been previously denied to them. In the particular context of post-apartheid South Africa, their self-actualization through fashion and consumerism becomes analogous not only with a post-apartheid black freedom ${ }^{16}$ but also with a utopian enacting of their gender and sexuality that moves FAKA, and their audience beyond the present. Exemplifying the queerness that Muñoz characterizes in Cruising Utopia, as 'a structuring and educated mode of desiring that allow us to see and feel beyond the quagmire of the present' (2009:1).

\section{From Self-styling to Solidarity}

The literature on visual activism suggests a false dichotomy between two distinct forms - one emerging in Western Europe and America post the financial and economic crash of 2008, situated outside of the formal institutions of the art world, and linked to street protests, or activist campaigning, and often explicitly anti-capitalist (Demos 2016; McKee 2016a, 2016b; Sholette 2017). The other emerging in post-apartheid South Africa and closely linked to the fine art market and its associated institutions. Because much of the literature on visual activism is written by scholars from visual studies or art history, it tends to focus its analysis on the visual artefact rather than the practices that surround the production of this work, thus exacerbating the distinction between these two forms. This binary division is further emphasized by analysis that positions 'protest art' as authentic, and art based in institutions as inauthentic - because of its complicity with global capital (Demos 2016). The examples of Hamblin and FAKA's practice explored in this chapter both complicate and broaden existing understandings of visual activism and allow us to see similarities 
between two allegedly distinct forms of activism, both of which use art as 'a constitutive force in the building of social movements' (Holmes 2012). Like the exhibition discussed in Eğrikavuk's work (this volume) both artists recognize and utilize the convening power of their artistic practice. Their work creates a space of resistance which brings people together (Eğrikavuk, this volume).

Tulke's framing of political street art in Athens (this volume) as an 'aesthetics of crisis' also resonates with this work. Hamblin and FAKA's practice are driven by the representational marginalization of queer intersectionality in South Africa. Their work is partly a 'space for emotional processing' (Tulke, this volume) but in centring and valuing non-hegemonic identities they are also weaving 'a sense of political potentiality into the very fabric of everyday life' (ibid.).

Hamblin and FAKA are opportunistic in their use of available resources to support and amplify their work. Through the process of their visual practice, they create literal and symbolic capital which they use to build and support communities. Although there are clearly multiple tensions and contradictions raised by a model of activism that embraces an imbrication with art markets and consumer brands, there is no doubt that this work constitutes a form of protest. What we learn from these two examples of queer visual activism is that visual activism can be multisited and does not always present in an 'obvious' form. The relationship between activists and capital is often a complex and often contradictory one. Where, on the one hand, activism is seen as a route to economic freedom, on the other, refusing to engage with corporate capital may be seen not only as a privileged position but also as counterproductive to the visibility on which activism depends.

Through my reading of Hamblin and FAKA's work, I demonstrate how they use visual forms to document experiences that would otherwise be invisible in the public sphere, represent themselves as they wish to be seen, and expand the boundaries of gendered identities. Crucially, in both examples I have traced their move in their artistic practice from an individual project of self-styling to a solidarity with others that eventually constitutes a form of movement building.

\section{References}

Allen, Rika. 2009. 'Art Activism in South Africa and the Ethics of Representation in a Time of AIDS', Critical Arts 23(3): 396-415.

Anderson, Michelle J. 2000. 'Rape in South Africa', Georgetown Journal of Gender and the Law 1: 789-821. 
Berndt, John. 2007. From Weapon to Ornament: The CAP Media Project Posters (1982 to 1994). Cape Town: Arts and Media Access Centre.

Bongela, Milisuthando. 2016. 'FAKA: Making Living Performance Art That Flips the Script on Gender Norms'. Mail and Guardian (Johannesburg), 29 September.

Burk, Tara Jean-Kelly. 2015. Let the Record Show: Mapping Queer Art and Activism in New York City, 1986-1995. PhD thesis, CUNY Graduate Center.

Crenshaw, Kimberlé W. 1989. 'Demarginalizing the Intersection of Race and Sex: A Black Feminist Critique of Antidiscrimination Doctrine, Feminist Theory, and Antiracist Politics', University of Chicago Legal Forum 139: 139-167.

Currier, Ashley. 2012. Out in Africa: LGBT Organizing in Namibia and South Africa. Minneapolis: University of Minnesota Press.

Cvetkovich, Ann. 2001. 'Fierce Pussies and Lesbian Avengers: Dyke Activism Meets Celebrity Culture', in Feminist Consequences, ed. Elizabeth Bronfen and Misha Kavka, 283-318. New York, Columbia University Press.

Demos, T.J. 2016. 'Between Rebel Creativity and Reification: For and Against Visual Activism', Journal of Visual Culture 15(1): 85-102.

Duma, Buyani. 2015. Interview, Johannesburg, November.

Durrheim, Kevin, Xoliswa Mtose, and Lyndsay Brown. 2011. Race Trouble: Race, Identity and Inequality in Post-Apartheid South Africa. Natal: University of KwaZulu-Natal Press

Ekine, Sokari. 2013. 'Contesting Narratives of Queer Africa', in Queer African Reader, ed. Sokari Ekine and Hakima Abbas, 78-91. Dakar: Pambazuka Press.

Gqola, Pumla. 2015. Rape: A South African Nightmare. Johannesburg: Jacana.

Gunkel, Henriette. 2010. The Cultural Politics of Female Sexuality in South Africa. London, Routledge.

Hallas, Roger. 2012. 'Photojournalism, NGOs, and the New Media Ecology', in Sensible Politics: The Visual Culture of Nongovernmental Activism, ed. Meg McLagan and Yates McKee, 95-116. New York: Zone Books.

Hamblin, Robert. 2016. Interview, Cape Town, November.

Hayes, Patricia. 2011. 'The Form of the Norm: Shades of Gender in South African Photography of the 1980s', Social Dynamics 37(2): 263-277.

Hill Collins, Patricia, and Silma Bilge. 2016. Intersectionality. Cambridge: Polity Press.

Hoad, Neville. 2007. African Intimacies: Race, Homosexuality and Globalization. Minneapolis: University of Minnesota Press.

Holder, Alex. 2017. 'Sex Doesn't Sell Any More, Activism Does: And Don't the Big Brands Know It'. The Guardian, 3 February.

Holmes, Brian. 2012. 'Eventwork: The Fourfold Matrix of Contemporary Social Movements', in Living as Form: Socially Engaged Art from 1991-2011, ed. Nato Thompson, 72-93. New York, Creative Time. 
hooks, bell. 2014. 'Is Paris Burning?', in Black Looks: Race and Representation, 145-156. New York: Routledge.

Jewkes, Rachel. 2016. Gender-Based Violence (GBV) in South Africa: A BriefReview. Pretoria: CSVR.

Judge, Melanie. 2015. Violence against Lesbians and (Im)possibilities for Identity and Politics. PhD thesis, University of the Western Cape.

Judge, Melanie, Anthony Manion, and Shaun De Waal. 2008. To Have and to Hold: The Making of Same-sex Marriage in South Africa. Johannesburg: Jacana.

Khatib, Lina. 2013. Image Politics in the Middle East: The Role of the Visual in Political Struggle. London: I.B. Tauris.

Lilla, Qanita. 2017. Setting Art Apart:Inside and Outside the South African National Gallery (1895-2016). PhD thesis, Stellenbosch University.

Livingston, Jennie. 1990. Paris Is Burning [documentary film].

McKee, Yates. 2016a. 'Occupy and the End of Socially Engaged Art', eflux 72.

McKee, Yates. 2016b. Strike Art: Contemporary Art and the Post-Occupy Condition. London: Verso Books.

Mohanty, C.T. 1988. 'Under Western Eyes: Feminist Scholarship and Colonial Discourses', Feminist Review 30: 61-88.

Muholi, Zanele. 2009. Mapping Our Histories: A Visual History of Black Lesbians in Post-Apartheid South Africa, MA thesis, Ryerson University.

Muñoz, José Esteban. 1999. Disidentifications: Queers of Color and the Performance of Politics. Minneapolis: University of Minnesota Press.

Muñoz, José Esteban. 2009. Cruising Utopia: The Then and There of Queer Futurity. New York: New York University Press.

Nuttall, Sarah. 2011. 'Self-Styling', in Global Visual Cultures: An Anthology, ed. Zoya Kocur, 270-292. Chichester: Wiley-Blackwell.

Posel, Deborah. 2005. 'Sex, Death and the Fate of the Nation: Reflection of the Politicization of Sexuality in Post-Apartheid South Africa', Africa 75(2): 125-153. Posel, Deborah. 2010. 'Races to Consume: Revisiting South Africa's History of Race, Consumption and the Struggle for Freedom', Ethnic and Racial Studies 33(10): 157-175. Rand, Erin J. 2013. 'An Appetite for Activism: The Lesbian Avengers and the Queer Politics of Visibility', Women's Studies in Communication 36(2): 121-141.

Roberts, Allen. 2001. "Break the Silence": Art and HIV/AIDS in KwaZulu-Natal', African Arts 34(1): 36-49.

Seidman, Judy. 2007. Red on Black: The Story of the South African Poster Movement. Johannesburg: STE Publishers.

Sholette, Greg. 2017. Delirium and Resistance:Activist Art and the Crisis of Capitalism. London: Pluto Press.

Simelela, N.P., and W.D.F. Venter. 2014. 'A Brief History of South Africa's Response to AIDS', South African Medical Journal 104(3): 249-251. 
Southall, Roger. 2007. 'Ten Propositions about Black Economic Empowerment in South Africa', Review of African Political Economy 34(111): 67-84.

Steyn, Melissa, and Mikki van Zyl, eds. 2009. The Prize and the Price: Shaping Sexualities in South Africa. Pretoria: HSRC Press.

Sulla, Victor, and Precious Zikhali. 2018. Overcoming Poverty and Inequality in South Africa: An Assessment of Drivers, Constraints and Opportunities. Washington, DC: International Bank for Reconstruction and Development/The World Bank. Thomas, Kylie. 2013. 'Digital Visual Activism: A Profile of Inkanyiso', Feminist Africa 18: 79-81

Thomas, Kylie. 2014. Impossible Mourning: HIV/AIDS and Visuality after Apartheid. Johannesburg: Wits University Press.

Thomas, Kylie. 2017. 'Rage against the State: Political Funerals and Queer Visual Activism in Post-Apartheid South Africa', in Public Art in South Africa: Bronze Warriors and Plastic Presidents, ed. Kim Miller and Brenda Schmahmann, 265-281. Bloomington: Indiana University Press.

Thomas, Kylie. 2018. "Remember Marikana”: Violence and Visual Activism in Post-Apartheid South Africa', ASAP/Journal 3(2): 401-422.

Thompson, Nato. 2015. Seeing Power: Art and Activism in the $27^{\text {st }}$ Century. London: Melville House.

Tucker, Andrew. 2009. Queer Visibilities: Space, Identity and Interaction in Cape Town. Oxford: Wiley-Blackwell.

Wienand, Annabelle. 2012. 'Portraits, Publics and Politics: Gisèle Wulfsohn's Photographs of HIV/AIDS, 1987-2007', Kronos 38: 177-203.

Williamson, Sue. 1989. Resistance Art in South Africa. Cape Town: David Philip. Wilson, Sarah, and Elisabeth-Jane Milne. 2015. 'Visual Activism and Social Justice: Using Visual Methods to Make Young People's Complex Lives Visible across "Public" and "Private" Spaces', Current Sociology 64(1):140-156.

\section{About the Author}

Tessa Lewin is a doctoral candidate at the University of Brighton, where she is writing her thesis on queer visual activism in contemporary South Africa. She is also a Research Fellow at the Institute of Development Studies, where her work involves creative, visual and participatory research, teaching and communication. 


\title{
2 The Use of Visibility in Contentious Events in Northern Ireland
}

\author{
Katy Hayward and Milena Komarova
}

\begin{abstract}
Territorial space in Northern Ireland is often associated with certain communal and political identities. This is vividly demonstrated by traditional parades in local areas. Some parades become contentious because they pass through localities associated with very different communities. Often, contentious parades are met with protests, which can become violent. Based on ethnographic fieldwork on the contentious Protestant Orange Order parade through Ardoyne in North Belfast, we interpret contentious events not just in the usual terms of territorial struggles but as a quest for visibility. A focus on visibility as a field of social action, through which territories are established and contested, illuminates better the social relationships at work and the effects of their contestation at their nexus.
\end{abstract}

Keywords: visibility, parades, protest, conflict, Belfast

\section{Introduction: The Twelfth July in Ardoyne}

On the morning of Wednesday, 12 July 2017, there was a Protestant Orange Order parade from the Orange Lodge in Ballysillan in North Belfast. As it has done each 'Twelfth' for generations, the parade's route came down the Crumlin Road through Ardoyne (with its predominantly Catholic population) into Woodvale (with a predominantly Protestant population), before continuing on into Belfast city centre. Strict conditions were enforced on the parade as a result of the decision of the Parades Commission - the agency tasked with determining the rules for the conduct of parades,

McGarry, A., I. Erhart, H. Eslen-Ziya, O.Jenzen, U. Korkut (eds), The Aesthetics of Global Protest: Visual Culture and Communication. Amsterdam: Amsterdam University Press, 2020 DOI 10.5117/9789463724913_CHO2 
particularly those (such as this one) likely to be contentious. ${ }^{1}$ The Police Service of Northern Ireland (PSNI) enforced these conditions in a carefully light-touch way. Whilst a few officers in summer uniform of peaked cap and shirtsleeves interacted face to face with the leaders of the parade and its supporters, dozens of officers waited in police Land Rovers in streets adjacent to the Crumlin Road with riot gear at the ready.

The progress of the parade down the Crumlin Road was closely followed by a police helicopter overhead, by several journalists (including a TV crew from Belgium), and a sizeable group of supporters by phone who were waiting at the roundabout interconnecting Woodvale and Ardoyne. However, for the first time in years, something was missing: there were no protestors to meet the procession as passed through Ardoyne. Even more noticeable was the absence of violence in the area that evening - another 'tradition' that has evolved in connection with the contentious nature of the parade. Indeed, the Twelfth parade through Ardoyne has long been associated with riotous and violent behaviour. In 2011 - the year we first started observing the passing of the Twelfth feeder parade of three Orange Order lodges ${ }^{2}$ through Ardoyne - the news reported outbreaks of sectarian rioting and violence against the PSNI to an extent not seen for at least a decade (BBC 2011).

This chapter is based on research that originated with the Economic and Social Research Council (ESRC)-funded 'Conflict in Cities and the Contested State' project and has produced eight years of unbroken ethnographic fieldwork on contentious annual events in Belfast. It draws on data that includes field observations from different perspectives and locations: from alongside a marching band, to pressed up against a police line, to standing with protestors, to observing (via helicopter feed) from the distance of a PSNI Gold Command Room. Our methods included qualitative primary research based on ethnographic observation and interviews, including 'walking interviews' with a range of participants, involving local residents, Orange men, local politicians, police officers, and community workers. We have also conducted extensive desk research including analysis of media coverage of the events, analysis of official documents (particularly Parades Commission determinations) and photographic and video archives of the events in

1 The Parades Commission of Northern Ireland is an independent public body established in 1997 - after a period of growing tension and violence around contentious parades. Under the Public Processions (Northern Ireland) Act 1998, the commission is tasked with facilitating mediation between disputing parties regarding public processions and issuing determinations in respect of proposed public processions and protest meetings. Its determinations and, indeed, its legitimacy have been frequently challenged by both sides (Walsh 2015).

2 LOL no. 1932 Ligoniel True Blues, the Ballysillan LOL 1891 and the Earl of Erne LOL no. 647. 
question. This longitudinal qualitative methodology has been integral to the content of our findings and particularly to our ability to reframe our understanding of the significance and management of contentious events in Northern Ireland.

This chapter explores the thesis that understanding conflict around contentious events rests not only on police tactics, territorial containment or political compromise but also on appreciating the quest for visibility among actors involved. Visibility may be understood as a field of social action through which territoriality is established and relationships of power are contested and maintained. We see all actors in a contentious event such as an Orange parade through Ardoyne engaging in their own efforts to be 'visible' - not just to their own group but also to each other and to a wider, external audience. Drawing on Brighenti's (2010a, 2010b, 2010c) insights, we illustrate three forms of public visibility at work in this context: Spectacle, Recognition, and Control. A more comprehensive encounter with and accounts of types of visibility at work during a contested event will assist us to better comprehend the most effective means of defusing the friction around the visual regimes of protest.

\section{Contentious Parades}

The parading tradition in Northern Ireland has a long history (Bryan 200o). Parading on Twelfth July commemorates the 1690 victory of the Dutch King William of Orange at the Battle of the Boyne over the English (Catholic) King James II. It is the most significant commemoration in the annual calendar of Protestant unionists in Northern Ireland. ${ }^{3}$ Whilst predominantly associated with the Protestant community, parading has also been part of some Catholic traditions too, notably the Ancient Order of Hibernians and some republican groupings (Browne 2016). The parading tradition in Northern Ireland is a classic enactment of commemoration. Be it republican commemorations of the 1916 Easter Rising or the Apprentice Boys' commemoration of the siege of Derry, the parade is part of a ritual of collective memory. As such it can be understood as one means of solidarity formation, creating a sense of unity and collective consciousness through the shared performance of a ritual (Durkheim 2001).

3 According to the 2011 census, $48 \%$ of the population in Northern Ireland come from a Protestant background. Around $84 \%$ of them, according to the Northern Ireland Life and Times Survey of 2017, hold 'unionist' political aspirations, which is to say that they want Northern Ireland to remain part of the United Kingdom. This is in distinction from the predominantly Catholic nationalists in Northern Ireland, who would like to see Northern Ireland becoming part of a united Ireland. 
However, the use of collective memory formation and ritual also contains a particularly sharp political edge in the context of a divided society such as Northern Ireland. Political behaviour and belief are central to the use and construction of identity in such a performance of collective memory and solidarity (Ross 2007). This is why, as Jarman (1997) explains, the use of symbols and iconography in parades in Northern Ireland is not just intended to assert a particular form of cultural identity, but also to give a tangibility to deeply held, antagonistic political views. As such, parades are an integral form of sustaining mutual antagonism as well as entrenching cultural difference. This is particularly true when they pass through communities of a very different cultural and political tradition. Commemoration (and contestation in the form of protests at parades) strengthens group experience in relation to place, but it also opens it up to challenges, which are based on and exercised through local space. For such reasons, contention around parades appears to be a microcosm of wider political and communal tensions in Northern Ireland. Violence and disorder at such events are seen as significant indicators of risk for the wider political compromise in Northern Ireland, especially if the forces of law and order appear to be biased or unbalanced in their management of the event.

The annual occurrence of contentious parades and protests in Northern Ireland are typically explained as an expression/manifestation of the relationship between communal identity and territory, i.e. a manifestation of social territoriality. Therefore, they are seen as a struggle over territory (Cohen 2007). Although where and when parades and protests are performed is very important to their understanding, we suggest that it is not place itself that is of most importance in such events, but rather the way in which the practice and performance of parades and protests in particular spots produces certain visibilities for different participants and for the general public. This is because visibility, as argued by Brighenti (2010c), is itself central to the social production of space, to claiming and contesting territory, and to the broader production of the public sphere (and the associated relationships of power). Drawing on Brighenti's work, we see that events are made contentious by the type of visibility that participants in a contentious event are seeking and are given at any particular point.

This is a particularly useful lens through which to understand how contention increases and is ameliorated. The complexity of the matter is in part because there are several groups of persons that contribute to the performance and management of the event itself. This includes the marchers, the supporters of the parade, the protestors, the agitators, the observers (such as journalists), and, finally, the police. A better understanding of the 
type of visibility at work during a contentious event relating to the position and action of these groups will assist us to better appreciate the social effects of performances in such events. Our research has shown that the participants are astutely aware of and do consciously use various techniques and devices of visibility to communicate and interact with various audiences while claiming, contesting or resisting (ascribed) subject positions. As such, visibility is not simply a tool through which to (re)claim territory, but it could also be at the very centre of contestation itself, that is, it is what is being fought over. The necessity for visibility itself, in other words, can be understood as one of the reasons for the intractability of local contestation.

\section{Visibility}

In the introduction to this volume McGarry et al. describe protest as a performative operation of democratic power through which the democratic public 'demands recognition, embodies visibility, articulates a political voice, and communicates ideas/demands'. As such, protest is a performative act of public communication that aims to contest the existing power relations and 'the rules of the game' that may be dictated by those in positions of authority. More broadly speaking, as Gambetti affirms, '[T]he public sphere [is] a space of appearances where conflicts, identities, differences, communalities and power structures are compellingly revealed to a heterogeneous multitude [...]: a public is constituted performatively as the addressee of discourses and practices that brings [sic] it into being' [emphasis added] (2004: 2). Not only are human relations of inter-visibility essential to publicness, as the above suggests, but also publicness itself is innately performative. In order to communicate, publics need to make themselves and their claims visible and as such - recognizable - often through literal physical and spatial performances. Parkinson states: 'This is more than an empirical point about how people in the real world communicate; it is a theoretical point about the conditions of democratic communication' (2012:35). The public sphere as such is a space of communication through visibility.

Visibility itself, as noted by Brighenti (2010c: 186), is a complex social field of meaning, action and communication, which helps to separate 'the perceptible or noticeable from the imperceptible or unnoticeable'. It thus encompasses many other forms of 'managing attention and determining the significance of events and subjects' (Brighenti 2010a: $5^{2}$ ). As such, performative activities such as parading or protesting seek to draw attention away from alternative narratives and identities, rendering them less significant. 
In a similar manner, Ryan (this volume) sees visibility as a 'framing' device and a resource through which social movement activists and leaders seek to draw support for their actions and recognition of their identities. Even if this is achieved just for a brief and temporary period, this may be considered a symbolic and worthwhile 'victory' for a community that considers itself to be under threat or in conflict.

One level through which visibility operates is 'socio-technical', i.e. involving space, materiality and technology (Brighenti 2010c). Commonplace discussions in architecture, for instance, suggest that the built form shapes perception and cognition and can make spatial order appear 'natural' or 'unchangeable' through both concealing and revealing social relations (Dovey 2005: 291). Physical space, in other words, can work as a visibility device that gives shape to publicness, allowing for certain kinds of social action to 'take place' in certain localities and, as such, makes a crucial difference to the way that power relations work. For example, the extent of proximity is central, as Allen (2003:148) stresses, to the exercise of relationships of authority: 'the more direct the presence, the more intense the impact'. The same holds for coercive relationships, that most visible imprint of power, where the threat of force lasts only for as long as people feel constrained by its possibility.

Yet, space is not an inert container of social action. It is itself the outcome of social relations. As such, another level at which the field of visibility operates is the 'bio-political' (Brighenti 2010c), i.e. that of social practices, actions and interactions, down to the micro-level of the positioning of bodies and gestures. In this respect Brighenti (2010c: 123) notes that:

[P]ublic space on the ground is constantly made by acts of territorialisation, which are themselves processes made up of different thresholds and dynamics of visibility, carving the environment through acts of boundary-drawing.

Visibility as such is a way of 'prolonging' the territorial social relations (including power relations) inscribed in physical space by managing perception and attention. In short, Brighenti (2010a: 52 ) concludes, 'visibility lies at the intersection of the two domains of aesthetics (relations of perception) and politics (relations of power)'.

\section{Regimes of Visibility}

As a field of social action, visibility is strategic and relational: it is manipulated by social actors for different end goals, while its effects depend on the 
means and conditions in which it is generated. The effects themselves can be asymmetrical and these asymmetries, as Brighenti (2010a) suggests, are organized 'around regimes of visibility'. The author discusses three regimes of visibility - 'recognition', 'control' and 'spectacle' - taking care to stress that they are not mutually exclusive.

Visibility as 'recognition', which we briefly discussed above, is perhaps most commonly encountered in the fabric of everyday life. Looking at each other is where we constitute ourselves as 'subjects' (Brighenti 2010c). As Goffman (2005) further notes, acknowledging the visibility of others legitimises them as participants in a social situation. In the case of the parades and protests which we discuss in this chapter, this form of visibility captures the actively constructed 'identity work at play' which participants engage in. Here, 'the public square acts as a theatre where the individual and collective identities of protestors are performed' and 'ideas of democracy, including specific demands and grievances' are communicated (McGarry et al., this volume). Achieving visibility in the form of recognition is, therefore, not simply about constructing identity but is inherently an act of empowerment, particularly common to the repertoire of social movements (Honneth 1995). As Mirzoeff (this volume) states, the very exchange of glances 'in the non-enclosed encounter' is 'an apprehension of the claim of the other to the right to look'. The quest for visibility as a form of recognition is similarly discussed by Mercea and Levy (this volume) when referring to the pursuit of visibility by activists of Occupy Gezi on Twitter as a 'subaltern tactic' to reverse an asymmetry of power and engage 'into a struggle for recognition and participation'.

By contrast, visibility as social 'control' can be disempowering. Here social actors do not themselves 'struggle for recognition through visibility' but are 'obliged to be visible' (Brighenti 2010c: 49). An example of how visibility as control is constituted can be seen in contemporary surveillance practices. Drawing on Foucault's ideas on power and governmentality (Rose 1999), surveillance wages an impact on and possesses the power to alter one's actions and behaviour by virtue of the very knowledge or the suspicion of being observed. Contemporary professional surveillance knowledge, Brighenti (2010a) adds, intersects with, and even colonizes lay knowledge in the public domain. For example, in our research we have observed how the use of helicopter cameras by police on the day of a contentious event creates visibilities not open or accessible for either protestors or marchers. Policing decisions on the ground are often based on such privileged visibilities, and create a clear consciousness on the part of other participants that pre-existing agreements regarding how a parade and protest will be policed 
can be subject to momentary change. This consciousness often shapes the longer-term relationship that protagonists may have with the police and may infuse it with distrust. Yet neither as recognition nor as control is visibility linearly associated with empowerment or disempowerment. This is because the means through which visibility is produced opens up a range of possibilities for resistance or even unintended counter-effects.

An example of this in our case study is the response of the nationalist party Sinn Féin to the challenge of the Orange parades through Ardoyne. Sinn Féin has strong political support in Ardoyne and would consider itself to be the primary party representing not just nationalists in the local area but nationalists across the island of Ireland. With international focus on contentious events such as the parades through Ardoyne on the Twelfth, Sinn Féin gained a natural opportunity to be visible as well. One Parades Commission representative interviewee described their conundrum in this way:

If they're not on the streets placating, then the raw edge is the police and the people. [...] But if they are there and then they end up with too forward a role, then people will identify them as facilitating a parade or supporting and sponsoring police violence. ${ }^{4}$

There is a careful balance to be struck in visibility. And it is not always clear whether those who are seeking visibility as recognition will manage to avoid being subject to visibility as control. In seeking to become empowered through coordinating protests and through assuming a high-profile role on the day in obvious support for local residents, Sinn Féin could easily become accused of being manipulated and used by the police and even the Orange Order to facilitate the parade. What matters in this instance is the audience. Sinn Féin wants to be seen by the wider audience and the local residents as showing leadership, but it could be seen by critics within its community as demonstrating compliance. Mercea and Levy (this volume) also demonstrate this point clearly when showing that despite its initial success as a pursuit of recognition and participation, the Occupy Gezi movement's visibility on Twitter was soon reversed into becoming 'the basis for reflexive state surveillance'.

The final regime of visibility is perhaps the most straightforward, namely that of the 'spectacle'. The parades and protests that we discuss in this chapter are first and foremost forms of public ritual. At one level, they serve 
as illusory or ideological forms of unity (Durkheim 2001), which intensify collective experience in relation to territory (Koster 2003; Lukes 1975). In another way, crucially, by making a spectacle of themselves as they perform specific roles, social actors become visible to external audiences (Brighenti 2010c). The notion of spectacle is readily embedded in the performance itself. The performers' visibility is an easily understandable social exchange. 'During the spectacle, all gazes are morally authorized to direct themselves at the performer and to fix upon him/her' (Brighenti 2010c: 50). This is not just true of the participants in the parade in the case of our fieldwork. Protestors can also become performers who '[modify] the field of visibilities [...] by offering [themselves] to an audience's gaze' (Brighenti 2010c: 50).

Minute differences in the use of space, gestures, positions, cameras, for example, can all be exploited by performers who are safe in the knowledge that they are being watched, observed, and noticed. The strategic use of any and all of these devices for producing visibility feed into an exercise of power relations and can signal solidarity, resistance, compliance, challenges to authority or lack of legitimacy. As Allen (2008: 1617) suggests, 'the spacing and timing of people's interactions' can be mobilised as resources. Furthermore, as Parkinson (2012: 35) notes, ${ }^{5}$ the demands of our 'mediatized' age are such that political communication is under additional strain to become highly 'spectacular' by nature so that 'issues of staging, lighting, audience access, symbolism and interaction between actors are all important'. Thus, for instance, in our research both the police and local community workers often cited the presence of journalists at contentious events as 'inciting' observers and protestors to engage in conflict or even violent behaviour as a form of performing to external audiences.

\section{Visibility on the Crumlin Road on the Twelfth July}

In order to ascertain the role played by the quest for visibility in the performance of political positions in Ardoyne on Twelfth July, we hereby look at each one of five key groups: marchers/participants in the parade, supporters of the parade, agitators, protestors and police.

\section{Marchers in the parade: Making a spectacle, seeking recognition}

Those marching in the parade can come from several different groups. They may be Orange men or women marching with their Loyal Orange Lodge, or members of a marching band accompanying the lodge on the 


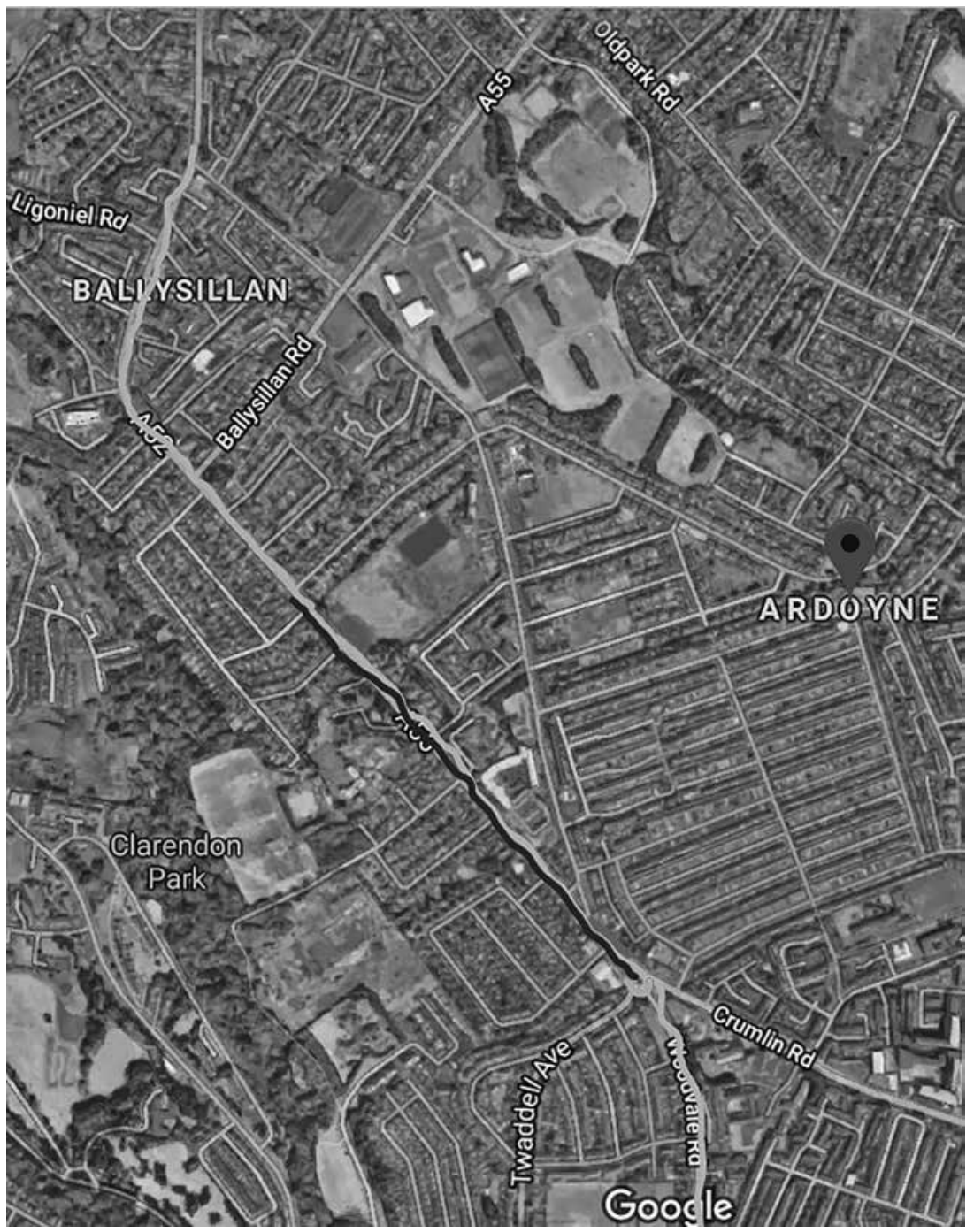

Figure 2.1. Map of Ardoyne from Google Maps. Map data $\bigodot_{2019}$ Google.

parade. Marching bands traditionally include pipes, flutes or drums. This is significant, because the Parades Commission often recommends that a single drum beat be played whilst the parade makes its way through a contested part of the route in order to avoid the risk of sectarian songs being played by a band. A third category of 'marchers' would be supporters who follow the parade down the route, usually up to a certain point. When a lodge submits an application to the Parades Commission for permission to parade down a route on a particular day and time (it must do this for each 
occasion), it is required to predict how many supporters will accompany the parade on the route.

At one level, the regime of visibility for the marchers is very obvious: the parade is a spectacle and their primary role is to perform as part of that spectacle. This is clearly true for the members of the Orange Lodge and, by association, of the bandsmen and women. Yet, something else is also going on in the case of their accompanying marchers: their presence is more than that of the performance of a collective ritual. Beyond creating a spectacle, they are looking for recognition. Our fieldwork suggests that marchers are highly conscious of the contentious nature of the event. This is evident in the conversations that are held (speculating about the size of the protest from the Ardoyne residents, for example); in visible displays that are used (for example, in the bed sheet hung on a fence along the parade route with the words ' $\mathrm{F}$ "ck your talk, we will walk'), including specially prepared T-shirts (one woman wearing a 'No 1 Likes Us We Don't Care' top in 2018); and in the management of the parade itself by stewards in collaboration with the police. The parade always stops at a certain point along the route, at the junction between Hesketh Road (leading directly to the few streets in the Ardoyne area known to have a predominantly Protestant populations) and the Crumlin Road (a major arterial road and the main parading route to the gathering point near the city centre) (fig. 2.1). At this point, the marchers wait - some new supporters join in but many more stop following the parade. From this position - a few hundred metres away from the roundabout where Ardoyne meets Woodvale - marchers can get a sense of the size of the crowd that awaits them: the police presence, the protestors and their supporters waiting in Woodvale (fig. 2.2). The police manage this waiting crowd of around a hundred people (the greater the friction, the greater the crowd) in a low-key way, using requests through band leaders and senior figures in the Orange Lodges present to ensure that marchers comply with the rules set by the Parades Commission. The rules that are relevant in this case would be the need to walk in the middle of the road (not the pavement) and the need for the parade to be within a certain size.

Such rules offer the marchers the possibility of demonstrating acts of resistance - showing that they see the parade as an opportunity for recognition and manifesting the use of cultural symbols (attire, flags), of sound (songs, humming), of space (walking close to the pavement), as well as more obvious acts such as jeering at the protestors or name-calling. Marchers are careful not to violate the rules as a collective act, knowing that it is likely to lead to much greater restrictions on them on the return parade or in future 


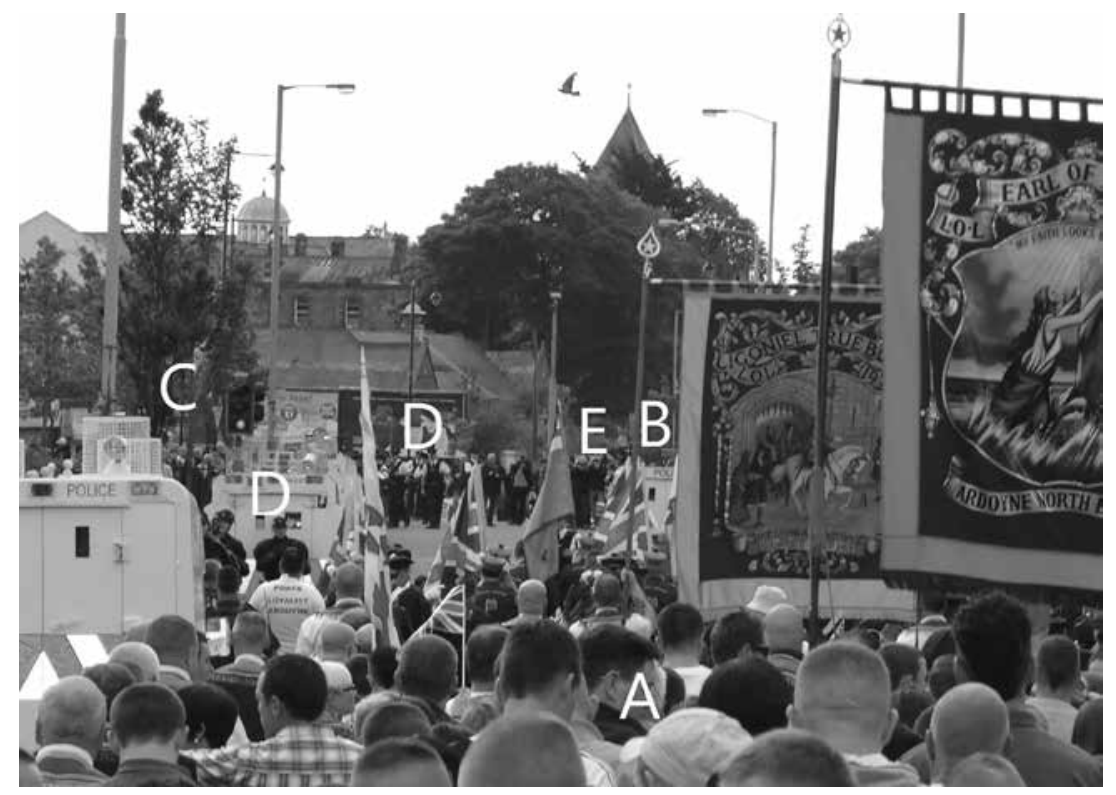

Figure 2.2. The Orange parade through Ardoyne on 12 July 2012, including the marchers (A), their supporters at Twaddell/Woodvale (B), the protestors (C), the police (D) and journalists (E). Image $\odot$ Katy Hayward.

years. In that sense, the 'civilized' morning parade is the clearest space for the manipulation of visibility to seek recognition.

A striking example of this came in 2011 when the parading procession was led, not by an Orange Lodge, but by a group of women holding a large banner with the words: 'Republicanism = Cultural Apartheid'. This was a direct retort to the large banner held by a republican group protesting the march the previous year, with the words 'Re-route sectarian marches'. Other marchers held smaller posters saying 'Respect our culture' whilst protestors' banners demanded: 'Respect our rights'. From an observers' perspective it was clear that marchers and protestors were using their visibility to both communicate with one another and to seek recognition - from each other and from the wider audiences of the highly mediatized event. This is a particular example of the importance of visual culture for political communication. By making their message visible, the paraders and protestors immediately expand the potential reach and impact of their claim.

Furthermore, marchers often seek to make their culture visibly different from those of the nationalist residents of Ardoyne, despite the rulings of the Parades Commission, which are deliberately restrictive with regard to the use of (potentially provocative) symbols. For example, the Parades 
Commission had originally ruled in 2011 that all flags should be furled as the parade passed the protestors in Ardoyne (in order to avoid the flags of loyalist paramilitary groups being displayed). After some harsh criticism from unionist Members of the Legislative Assembly (MLAs), the commission amended its determination to allow the union flag (as the national flag of the United Kingdom) to be unfurled. This was seen as an important concession, not least because nationalist residents in Ardoyne had hung the Irish tricolour (the national flag of the Republic of Ireland) from lampposts along the contested part of the parade route as an act of defiance. The marchers now had a means of direct riposte and they not only carried the Union Jack - the UK flag (sometimes as a shawl), but also wore the colours of the Union Jack (red, white and blue) in their clothing. A few individuals proudly displayed tattoos of the Union Jack on their arms and calves. Individuals' inventiveness when it comes to seeking recognition for their cultural identity is very evident on Twelfth July.

\section{Supporters of the parade: Seeking to bolster the marchers' quest for recognition}

The power of the spectacle of the parade is fuelled, of course, by the fact that it is witnessed. From early morning on the Twelfth July, roads and streets across Northern Ireland are lined with chairs and mini picnic tables as people secure their places on the pavement to get a good view of the parades. Busy highways are turned into parallel lines of red, white, blue and orange as people line the route. One unusual point about the Orange parade through Ardoyne on the Twelfth is that the witnesses of the spectacle and supporters of the parade are not able to stand on either side of the road for a distance of about 450 metres. As a consequence, the supporters of the parade from the southern side of Ardoyne are corralled at two exits off the roundabout - Twaddell Avenue and Woodvale Road.

The positioning of this group is very important as their presence and size has a direct effect on tensions during the parade. This was particularly notable during 2013, when tensions were particularly high given the flag protests by loyalists, which had caused civil disruption over the Christmas period before and resulted in the setting up of a loyalist protest camp at the top of Twaddell (Nolan et al. 2014). There was a heavy police presence, with police having been drafted in from England to boost the capacity of the PSNI. The number of supporters was much more than the previous year and the police moved the group to different locations behind the roundabout. Standing in the crowd, this adjustment of position had the effect of raising expectations that the parade was imminent, only for yet 
more waiting to follow. In the vacuum of communication, rumours were flying around about riots having broken out at the top of the parade. Such rumours were all the more wild and effective because of the fact that the supporters were unable to see the parade itself. The density of the crowd and the close cordon enforced by the police meant that a slightly claustrophobic atmosphere was evident.

It became increasingly important for the supporters to be visible and noticed. If the marchers were under fire further up the route, it was all the more important that they knew that a strong crowd of supporters were waiting for them. In this way, the supporters used their visibility to bolster the marchers' quest for recognition.

Another perspective on the role of supporters was gained for us the previous year, when we came down the route of the parade as part of the marching group itself. Hemmed into the road, lines of police either side, banners of Orange Lodges being held overhead - it was difficult as a marcher to get a clear glimpse of the protestors that were objecting the parade. Although the music of the bands had been silenced (as decided by the Parades Commission), what we could hear was the cheering and singing from the group of supporters waiting at the roundabout. The 'frisson of danger' that went with being part of the parade along a contested route and objected to by residents meant that the sense of celebration and triumph when welcomed by a crowd singing the famous Orange song 'The Sash' was enormous. ${ }^{6}$ The visibility of the supporters was, thus, directed not so much at the protestors, as one might expect, but at the marchers.

\section{Agitators: Exploiting visibility as control in order to show resistance}

Those involved in the negotiation and management of contentious events locally are usually people in positions of authority within their communities. This authority can derive either from their capacity of local residents, positions within traditional local institutions (churches, schools) or from their experience with political conflict (often such people are former combatants, political prisoners or paramilitaries). Yet, the very performance of contentious parades and protests represents not simply a testament to the authority of such figures but, increasingly, intra-communal challenges to

6 'The Sash' is a ballad commemorating the victory of King William III (known as William of Orange) in the Williamite-Jacobite War in Ireland in 1688-1691. 'The sash' refers to the regalia of the Orange Order, which is the fraternal institution established at the end of the eighteenth century to celebrate the victory of King William for Protestant ascendancy, particularly his victory at the decisive Battle of the Boyne on 12 July 1690. 
it. As such, contentious events have often been a visible manifestation of growing fragmentation within republicanism and challenges to the authority of Sinn Féin as the largest nationalist party.

It is therefore most accurate for us to report the activities of two types of protestors: the community residents' group (Crumlin Ardoyne Residents Association, CARA), which is loosely associated with Sinn Féin, and the hard-line group associated with dissident republicanism (Greater Ardoyne Residents Collective, GARC), which advocates more direct action to disrupt the parade. Whereas CARA is involved in behind-the-scenes negotiations with the police and those associated with the Orange parade, GARC criticizes this approach as too concessionary. The differences in approach were most starkly evident in 2009 when members of GARC sat on the Crumlin Road to block the route of the parade. Their forced removal by police officers generated the type of headlines and photographs that they had hoped for. This group recognizes that its members' visibility is a form of control by police and they seek to exploit this for their own political ends. Another act of resistance by GARC utilizing their members' visibility was holding its own parade whilst complying with the requirement to submit its intentions to the Parades Commission in advance. This allowed GARC a further means of exploiting visibility as control: it requested that its parade be on the Crumlin Road at exactly the same time as the returning Orange parade. This clearly set up a direct confrontation between the rights of both sides - not just on the road, but across the committee table of the Parades Commission, if not in their physical presence on the Crumlin Road at the same time.

For the most part, the tactics of GARC are to distract the police and supporters from the main legitimate protest by breaching the requirements of the Parades Commission vis-à-vis the use of space, particularly its ruling on where protestors should stand. By simply walking 20 metres away from the main protest towards the roundabout, GARC members immediately heighten their visibility. They are noticed not only by police but by journalists and by supporters of the parade itself.7 In this way, the 'visibility as control' being used by the Parades Commission is exploited ruthlessly to its full potential to 'agitate'. In 2011, when the GARC protestors attempted to move towards the roundabout, they were closely followed by police, journalists and human

7 We observed on several occasions how supporters of the parade took it upon themselves to draw the attention of the police to any potential breach of the Parades Commission's rulings by GARC. This is partly because the supporters' position, at the roundabout, allows easier view of potential 'breakaway' groups than the main body of protestors. In 2013 we witnessed an overenthusiastic group of supporters demand that the police question a young couple walking down the unapproved route beside the roundabout; they turned out to be bemused tourists. 
rights observers. The exclamation by one middle-aged woman from the breakaway group is telling: it was not an expression of defiance aimed at the police, but one of provocation aimed at their fellow republicans: 'Where are you, Sinn Féin?' The impression of resistance, the effect of agitation is where GARC seeks to distort the visibility of control.

\section{Protestors: Seeking to counter the marchers with their own quest for recognition}

Ironically, the visibility of the main protest group (CARA) risks being diminished by the activity of the agitators. We noted, when we were in the Gold Command Room in 2016, how the feed of the police helicopter over the site of the protest does not concentrate on CARA but on GARC. Whereas GARC uses space to full advantage (spreading out before the parade arrives, thinning out police lines by ensuring they are followed by police), CARA is much more contained. Their presence, immediately proximate to the parade, spread in a line just one-person deep, for a stretch of about 20 metres, is primarily to counter the marchers' quest for recognition with their own counter-quest. The protestors talk quietly among themselves and rarely address comments at the marchers (even when provoked). Instead, they communicate their message through the use of posters, knowing that this can project a message much more clearly to a much wider audience (through disseminating images on [social] media networks) than any chants or verbal exchanges. These posters have fairly consistent messages. It is noteworthy that in 2016 CARA held a large banner stating 'Resolution is possible'. The following year, they decided not to protest.

It is interesting now, after a long period of observation of this protest and interviews with the protestors, to see what effect their decision to become 'invisible' had on the contentious nature of the parade. After much behindthe-scenes negotiation in 2017, the Twaddell camp was finally dismantled. There was no official protest on the morning of the Twelfth, and the return parade complied with strict conditions and passed off peacefully. By refusing to stand protestors withdrew themselves as witnesses for the marchers' quest for recognition. In so doing, the parade returned to being primarily 'visibility as spectacle', with the principal audience being their own supporters.

\section{Police: Using visibility as control}

The final group of agents we consider in the management of this contentious event is that of the police. The police themselves are fully conscious that the performance of contentious events is the most immediate threat to their attempts to develop good relationships with local communities - particularly 
those in 'interface' areas. ${ }^{8} \mathrm{~A}$ police commander commented, for instance, that while promoting 'empathetic' and 'responsive' policing is both what the police aim to do and what 'interface' communities have come to expect from them, contentious events by their nature require the use of coercion, making it 'hard to convince people that you are there to police with the community. [...] So, when you're involved in that type of policing there's a risk that you continue to alienate people. 9 The complex maelstrom of power relationships involved in the negotiation, attempts at management and the policing of contentious events most directly thwart the development of community policing, based on stable and trusting community-police relationships locally and on police institutional legitimacy more broadly.

Our observations of the Twelfth Orange Order parade and the nationalist protests confirm that the PSNI does attempt to ensure that the visibility of the police is carefully choreographed so as to reduce tensions and the sense of surveillance and control that further exacerbates tensions in the local community. Small changes in the visibility of the police have been shown to make a big difference in defusing potential conflict. Such changes include: the clothing of the police (white shirt sleeves and soft caps rather than riot gear), the direction in which they face (i.e. not all towards the protestors, which gave the impression that they alone were the source of potential trouble), the number of police on the road (the vast majority are ensconced in Land Rovers adjacent to the route), and the speed with which they evacuate the area (as soon as the last marcher has crossed the other side of the roundabout, there is a line of police Land Rovers exiting the area at speed). Such efforts are positively commented on in our interviews, indicating that even the body positions of individual officers are both carefully watched and judged to have significance for defining who and what is seen as 'the problem' on the day. The shape and positioning of police lines and cordons are considered to display the police's degree of commitment to even-handedness and neutrality (Bryan 2006).

That said, over the past decade the use of cameras has also grown exponentially. There is the camera of the police helicopter overhead (so strong, we witnessed from the Gold Command Room, that it is possible to read the brand of a chocolate bar on the ground from 1,00o feet). There are also large

8 These are areas (usually working class) where Protestant and Catholic communities live side by side. In Belfast such areas have been the sites for a disproportionate amount of violence during 'the Troubles'; continue to witness regular outbreaks of sectarian disquiet; and to exhibit higher levels of social deprivation.

9 Interview with a district police commander, 21/09/2010. 
cameras facing in several different directions from tall poles on the top of an armoured police Land Rover, which is a very familiar vehicle in public order situations in Northern Ireland. In addition, individual police officers carry small handheld cameras which they clearly direct at certain groups. There are also CCTV cameras on lampposts and shop fronts and cameras in the hands of other subjects (marchers, supporters, protestors, journalists). Visibility as control is no longer exclusively in the hands of the police. With the increasing technologization of visibility as such, its use as control has become more subtle. Rather than keeping out of the eyeline of a particular officer, each individual marcher and protestor may be conscious that they are being watched and recorded, and thus their actions are potentially viewed by dozens if not hundreds of people. As it is, a contentious event such as this embodies an unusual melding of physical, territorial and temporal space together with a type of control that transcends the constraints of physical presence, territory and time. The critical point of commonality here is that of visibility. Any and all changes in the dynamics of visibility result in changes to the whole dynamic of the event.

\section{Conclusion}

It is appropriate to reflect at this point on the longitudinal form of qualitative research applied in this case. This was made possible by the uniquely cyclical (annual) rhythm and predictable spatial positioning of the events we study. As such, we were able to, and itself enabled us to pinpoint acts of visibility-production in the situational and sociopolitical dynamics of these events in Northern Ireland.

Interpreting parades and protests as primarily quests for visibility further enriches understandings of these events as performative struggles over territory, and as solidarity-boosting collective rituals. From a practical perspective, a focus on visibility helps develop a more thorough and detailed appreciation of the shifting dynamics of power relationships in their dependence on spatial, material, technological and performative means of production. It demonstrates that contentious events serve as direct stages for intra- (as well as inter-) communal power struggles (opposition to and contestation of political authority) and the crucial role that space and performativity play both as media and as resources of these power relations. The three models of visibility that Brighenti (2010c) speaks of - recognition, control and spectacle - are clearly not mutually exclusive. In our case study at every one moment of time the three were present. They also have 
particular potency in a 'post-conflict' context. We have shown here how in a sensitive and sometimes volatile environment, the use of visibility by different agents is a very useful tool for understanding why some actions have the effect of increasing conflict while others defuse it.

In our case study, we have witnessed the transition over time from a fairly violent and tense event to a fairly routine and mundane one. We do not assume that the problem of the contentious Orange parade through Ardoyne has been resolved. As a predictable event and a highly symbolic tradition, the parade will always be vulnerable to exploitation by those who wish to demonstrate resistance or to seek recognition. That said, it is notable that the contention on the day has been dramatically reduced simply by the tit-for-tat quest for visibility being made much more one-sided: if there are fewer witnesses, then the act immediately becomes less powerful or important. Moreover, being a witness also makes one a subject, that is, the attention of the gaze of others are on one. In realizing this and actively averting visibility, actors have the opportunity to regain the type of agency that they had feared was impossible under such police presence and cultural provocation.

On the one hand, therefore, this reveals the use of visibility as a major vehicle for the flux and flow of power relationships. In particular, it can help explain why events, interactions and social actors can be rendered either socially relevant or insignificant. From a conceptual point of view, on the other hand, our focus on parades and protests as contestation over visibility itself (rather than as struggles over territory), stresses an understanding of social territoriality that decouples it from physical space. This idea builds on Brighenti's suggestion that 'territory is better conceived as an act or practice rather than an object or physical space' (2010b: 53). What counts, therefore, is 'the relationships among people that are built through space and inscribed in it' (2010b: 55). As such, the contentious events that we study must be understood as acts of inscription etching territorial patterns of social and political relationships onto physical space.

\section{References}

Allen, John. 2003. Lost Geographies of Power. Oxford: Blackwell.

Allen, John. 2008. 'Pragmatism and Power, or the Power to Make a Difference in a Radically Contingent World', Geoforum 39(4): 1613-1624.

BBC. 2011. 'Belfast Riots: Appeals for Calm after Night of Violence', BBC.com, 12 July. http://www.bbc.co.uk/news/uk-northern-ireland-14130190. Accessed 12.06.19. 
Brighenti, Andrea Mubi. 2010a. 'Democracy and Its Visibilities', in Surveillance and Democracy, ed. Kevin. D. Haggerty and Minas Samatas, 51-68. London: Routledge. Brighenti, Andrea Mubi. 2010b. 'On Territorology: Towards a General Science of Territory', Theory, Culture \& Society 27(1): 52-72.

Brighenti, Andrea Mubi. 2010c. Visibility in Social Theory and Social Research. Basingstoke: Palgrave Macmillan.

Browne, Brendan. 2016. 'Choreographed Segregation: Irish Republican Commemoration of the 1916 Easter Rising in "Post Conflict" Belfast', Irish Political Studies 31(1):101-121. Bryan, Dominic. 2000. Orange Parades: The Politics of Ritual, Tradition and Control. London: Pluto Press.

Bryan, Dominic. 2006. 'The Anthropology of Ritual: Monitoring and Stewarding Demonstrations in Northern Ireland', Anthropology in Action 13(1): 22-32.

Cohen, Saul. 2007. 'Winning While Losing: The Apprentice Boys of Derry Walk Their Beat', Political Geography 26(8): 951-967.

Dovey, Kim. 2005. 'The Silent Complicity of Architecture', in Habitus: A Sense of Place, ed. Jean Hillier and Emma Rooksby, 283-296. Aldershot: Ashgate.

Durkheim, Émile. 2001. The Elementary Forms of Religious Life, trans. Carol Cosman. Oxford: Oxford University Press.

Gambetti, Zeynep. 2004. 'The Conflictual (Trans)formation of the Public Sphere in Urban Space: The Case of Diyarbakir', EUI Working Papers, RSCAS No. 2004/38. http://cadmus.eui.eu/bitstream/handle/1814/2780/04_38.pdf;sequence=1. Accessed 13.06.19.

Goffman, Erving. 2005. Interaction Ritual: Essays in Face-to-Face Behavior. New Brunswick, NJ: Aldine Transaction.

Hajer, Maarten A. 2005. 'Setting the Stage: A Dramaturgy of Policy Deliberation', Administration and Society 36(6): 624-647.

Hajer, Maarten A. 20o9. Authoritative Governance: Policy-making in the Age of Mediatization. Oxford: Oxford University Press.

Honneth, Axel. 1995. The Struggle for Recognition: The Moral Grammar of Social Conflicts. Cambridge: Polity Press.

Jarman, Neil. 1997. Material Conflicts: Parades and Visual Displays in Northern Ireland. Oxford: Berg.

Koster, Jan. 2003. 'Ritual Performance and the Politics of Identity: On the Functions and Uses of Ritual', Journal of Historical Pragmatics 4(2): 211-248.

Lukes, Steven. 1975. 'Political Ritual and Social Integration', Sociology 9: 289-308. McGarry, Aidan, Itir Erhart, Hande Eslen-Ziya, Olu Jenzen, and Umut Korkut. 2019. 'Introduction: The Aesthetics of Global Protest: Visual Culture and Communication', in The Aesthetics of Global Protest: Visual Culture and Communication, ed. Aidan McGarry, Itir Erhart, Hande Eslen-Ziya, Olu Jenzen, and Umut Korkut. Amsterdam: Amsterdam University Press. 
Nolan, Paul, Bryan Dominic, Clare Dwyer, Katy Hayward, Katy Radford, and Peter Shirlow. 2014. The Flag Dispute: Anatomy of a Protest. Belfast: Queen's University. https://pure.qub.ac.uk/ws/files/13748797/The_Flag_Dispute_report_PRINTED. pdf. Accessed 13.06.19.

Parkinson, John. 2012. Democracy and Public Space: The Physical Sites of Democratic Performance. Oxford: Oxford University Press.

Rose, Nikolas. 1999. Powers of Freedom: Reframing Political Thought. Cambridge: Cambridge University Press.

Ross, Marc Howard. 2007. Cultural Contestation in Ethnic Conflict. Cambridge: Cambridge University Press.

Walsh, Dawn. 2015. 'Northern Ireland and the Independent Parades Commission: Delegation and Legitimacy', Irish Political Studies 30(1): 20-40.

\section{About the Authors}

Katy Hayward is Reader in Sociology, and a Fellow of the Senator George J. Mitchell Institute for Global Peace, Security and Justice at Queen's University Belfast. A political sociologist, her research expertise centres on processes of conflict and conflict transformation on the island of Ireland. Among her recent publications are the co-edited book Dynamics of Political Change in Ireland (2017) and a co-edited (with Niall Ó Dochartaigh) special issue of Nationalism and Ethnic Politics on the subject of 'Nationalism and Organized Violence' (2013).

Milena Komarova is a Research Officer at the Centre for Cross Border Studies, Armagh, and a Visiting Research Fellow at the Senator George J. Mitchell Institute for Global Peace, Security and Justice, Queen's University Belfast. She holds a PhD in Sociology from Queen's University Belfast (2008). Her research work traverses the fields of conflict transformation, border and urban studies, including the interplay between conflict and everyday life practices and spaces in cities, and the effects of Brexit on the UK-Ireland border. Among her more recent publications is "You Have No Reason to Access": Visibility and Movement in Contested Urban Space', in Ethnographies of Movement, Sociality and Space. Place-making in the New Northern Ireland, ed. M. Komarova and M. Svašek (Berghahn, 2018). 



\title{
3 Maybe, We Will Benefit from Our Neighbour's Good Fortune: An Exhibition on Collectivity, Community, and Dialogue in Turkey
}

\author{
Işıl Ĕgrikavuk
}

\begin{abstract}
Deriving from the Gezi Park protests, this chapter focuses on an art exhibition that took place in Istanbul in 2017, which was realized under the 'Aesthetics of Protest' project. Looking at past examples of community art practices, this exhibition proposes to think of collectivity as a form of resistance and frames how aesthetics of protest can be traced to artistic work in order to provide solidarity and empowerment. Working with different art and environmental collectives, the exhibition questions the idea of 'neighbourhood' and 'neighbourliness' and searches for ways of sustaining hope and solidarity through the aesthetic values of the Gezi Park protests and in an artistic practice. This chapter conceptualizes the process of the exhibition and its artistic research process.
\end{abstract}

Keywords: art, collectivity, exhibition, community, artistic research, dialogue

\section{Neighbourhood: From House to a Park}

I am the member of a generation, who grew up in Turkey of the 199os in a non-gated condominium without any security guards or walls. In that Anatolian city called İzmit, each of our neighbours at the time, their children and even the children of their children, knew one another; they knew even the smallest details of each other's furniture and what was cooking for dinner in each house every night. It was a time when you cooked something, you

McGarry, A., I. Erhart, H. Eslen-Ziya, O.Jenzen, U. Korkut (eds), The Aesthetics of Global Protest: Visual Culture and Communication. Amsterdam: Amsterdam University Press, 2020 DOI 10.5117/9789463724913_CHO3 
would give one plate to your nearest neighbour 'because it would smell good and they might like to have it too', would say our mothers. When you gave the food, you would also leave your plate with your neighbour and soon find out that your plate would return in a few days with some freshly cooked and delicious food on it. That was the exchange of the day.

Years later, when I came to Istanbul and started to live in an apartment, I realized I had only law offices as neighbours, whose owners I never met. My flat was protected by an alarm system that made me feel like my head would explode each time it went off by accident. I had one neighbour whose name I knew, as well as the building superintendent who pounded on the ceiling from downstairs every now and then when I was making too much noise. Still, I tried. I clearly remember one day giving a bowl full of soup to my neighbour just like the old times, yet my plate never made its way back.

\section{The Process into Gezi Park Protests}

The example above encapsulates the change that not only Istanbul but many Turkish cities have gone through in the last 20 years, especially whilst the AKP (Justice and Development Party) government has been in power. The AKP, during its sixteen years of rule, has 'aggressively embedded neoliberalism in neo-authoritarianism' which 'prioritized the governance of urban landscapes and adopted urban transformation as a technique for consolidating neo-authoritarianism' (Akçalı and Korkut 2015: 77). Such a neoliberal urban understanding transformed not only public spaces, but has also weakened the social fabric of the city, rendering feelings of community and neighbourhood a thing of the past, as many neighbourhoods were demolished 'to build highways and high-rises, eventually pushing the working class to peripheral areas' (Akçalı and Korkut 2015: 81). Thus, the idea of being neighbours evolved from people having a strong sense of sharing and being part of a community into being isolated and hiding from one another. Older traditions that encouraged mutual trust and sharing and provided a sense of community became almost extinct all over Turkey, most specifically in Istanbul, which is populated almost by almost 15 million people.

Yet, in May and June 2013, something unexpected and groundbreaking happened. Known as the Gezi protests, it started with a small crowd of protestors coming together as a reaction to the government's announcement of the destruction of Istanbul's centrally located Gezi Park (see McGarry et al., introduction). However, 'what began as a simple environmentalist protest grew rapidly and spread across the country as a result of police brutality faced 
by the small group of activists' (Batuman 2015: 1). In a few days, thousands of people had gathered in the park and at Taksim Square, located right at its exit. The protests soon spread to other cities, such as Ankara, Adana, İzmir, and Eskişehir, as well as many others. In only a few days an environmentalist protest turned into 'a major civil uprising against the government in which the most chanted slogans were "Down with the government!" and "Shoulder to shoulder against fascism!"' (Türkmen-Dervişoğlu 2013).

As much as it was a protest arena, the park quickly became a place where people started to inhabit as well, echoing the occupation repertoire of recent protests in New York, Hong Kong and São Paolo, amongst others. In a few days, Gezi Park was transformed into a neighbourhood, a social microcosm of the nation where thousands of people gathered by day and hundreds slept by night. The park became almost like a town, with its freshly built squares, monuments, communal eating places, and even small signs that identified each passageway or corner (such as the 'LGBT Street' or 'Çapulcu [Marauder] Corner' (see Tulke, this volume). The term çapulcu was especially a significant word because the then Prime Minister Recep Tayyip Erdoğan had attributed it to the protestors, who in return quickly 'internalized this term and made it a nickname for themselves' (Öğün Emre et al. 2013: 7). Similar to this creative twist on the meaning of the word çapulcu, the Gezi microcosm adopted many other creative practices. Many of these practices involved collective cooking, eating and distributing food, an open library, a free-speech station, a mock-marriage hall, as well as dancing, music and performances.

One of these performances, referred to as 'Standing Man' by the media, was started by dancer and choreographer Erdem Gündüz and 'was taken up quickly by a large number of followers' (Verstraete 2015: 122), later becoming one of the most celebrated and iconic images of the Gezi protests. In his performance, Gündüz stood facing the Atatürk Cultural Center, which was then the main theatre, opera and ballet house of Turkey, on which a flag showing Turkey's founding father, Mustafa Kemal Atatürk, was hanging. Gündüz's passive act of standing drew the attention of passers-by, and 'this humble gesture of non-violent action' (Verstraete 2015:122) soon turned into a major protest. Similar to 'Standing Man', there were other creative and collective practices taking place in- and outside the park. One of these examples was 'rainbow stairs', which was an anonymous act of painting public stairs in the cities with the colours of the rainbow. The choice of rainbow colours 'obviously referred to advocacy of LGBT communities in Turkey and was a great instance of solidarity between different groups of people' (Germen 2015: 18). It was also a clear declaration of visibility 
and belonging in a public space for this marginalised community. This performative gesture became almost a battle between the people and the municipality, which immediately moved to repaint the stairs grey, only to find the next day that the stairs had been painted with rainbow colours again. These acts signify how the Gezi protests were inspiring different communities in Turkey to assert their presence and demand recognition - to be seen and to be included.

In addition to all these creative acts, a very common and everyday practice in the park was centred around cooking, eating, and sharing food. While among the leftist groups, 'distribution of food free of charge reflected the ideology of sharing and equal distribution of resources' (Haksöz 2015: 7), such sharing was also adopted especially by an anti-capitalist Muslim group during Ramadan. Breaking their fast in the park together with other protestors (known as yeryüzü sofrasi, or 'Mother Earth meals'), this act of sharing a religious ritual with others 'destabilized the conservative AKP government's claim to be the sole representative of religious practices' (Ağartan 2018: 211). Furthermore, it also reaffirmed the importance of food for building solidarity and community cohesion.

Witnessing many of these events personally intrigued me for two reasons. First of all, many of these examples were extremely similar to what I had studied years ago as an art student in terms of their creative potential. Yet secondly, what fascinated me more was that they passed beyond the borders of the art institutions and were collectively experienced by thousands of people, who possibly had no previous contact with arts or artistic practice. As stated by Verstraete (2015: 122), some referred it, in a somewhat essential claim, as 'Turkish people becoming familiar with performance art for the very first time'. As an artist, I could make a link between the protests in the park to certain artistic practices, for example, found objects such as pepper gas cans being on display in the park as if they are in a museum. Just like a ready-made object in art meant that an object could gain another meaning by being shifted from its original context and placed in another, these gas canisters had lost their functional purpose (to disperse the protestors) and instead became artefacts that capture and communicate the brutality of the government and an expression of excessive state power.

Similarly, a construction vehicle belonging to the municipality and originally used for the reconstruction of the park area was painted bright pink by the artist collective KABA HAT, and thereon was turned into a playful sculpture on which people took selfies. Another highly participatory act in the park was the open library serving as a free donation and pick-up point for books in the park. Thus, the park became a space where solidarity, 
participation and dialogue became visible, and this became known as 'Gezi spirit'. At the very same time, all these practices invoked a very strong sense of community and solidarity among heterogeneous groups and attempted to bring back sentiments of community and the close neighbourliness of the past. Yet, this reminder of the past did not necessarily mean romanticizing the earlier days. Rather, the park became a place where new aesthetics of protests were crafted and displayed through fast-pace, dynamic and fluid forms every day.

Still, one can ask, What are the new aesthetics of protest? How does one define them? What I refer to here as 'aesthetics' is not a Kantian feeling of pleasure that an aesthetic encounter (see Ryan, this volume) or a 'visceral sign of underlying harmony' produce (Kester 2004: 29). I am rather taking 'dialogue' and 'dialogical aesthetics' as keywords, which will be discussed in the next sections. While doing that, I am also aware that it may appear as an attempt to situate a political uprising in Turkey solely in a context of Western contemporary art theory. However, what I am trying to do here is to determine whether it is possible to form links between socially engaged or participatory art practices and Gezi protests, and to interpret what these common frameworks might uncover about the Gezi protests.

As part of the Arts and Humanities Research Council (AHRC)-funded 'Aesthetics of Protest: Visual Culture and Communication in Turkey' (hereafter 'Aesthetics of Protest') project, in 2017, I curated an exhibition on the theme of neighbourhood and community. The exhibition sought to communicate and sustain the principles and ideas of the Gezi Park protests through collective artistic expression.

\section{Post Gezi: Changing Feelings, Spaces of Resistance}

When I joined the 'Aesthetics of Protest' team to develop and curate an exhibition on the project theme, I knew clearly what I did not want to do. The exhibition was scheduled for 2017, exactly for four years after the Gezi protests, in a dramatically different political environment, one characterized by increased authoritarianism. I suspected that the hope and idealism engendered by the Gezi protests had given way to a different understanding of people's relationship with the state, but also with each other. In the subsequent years, the park had survived, but both the physical and political atmosphere around it had changed. Taksim, the cultural centre of Istanbul had turned into a giant shopping area attracting tourists; Erdoğan was no longer the prime minister but the president following the 2014 elections, 
which brought 'a period of extreme polarization, full of uncertainties and tensions' (Özbudun 2014). Moreover, a failed coup had taken place in the country, leading to a continuing 'state of emergency', allowing 'the Turkish government to restrict or ban gatherings and censor the media' as well as to purge 'hundreds of thousands of people from civil service, shutting down critical media organizations, and arresting tens of thousands of suspected members of the opposition' (Eagan 2018). The optimism and hope embedded in the Gezi spirit, which had emerged in 2013, had not translated into positive political and economic changes. As a result, many people like me, who were the regular inhabitants of the park during the protest, somehow felt a bit deceived; perhaps a bit tired as well, and isolated. The hope and optimism of the park protests had been suppressed by the increasing authoritarianism of the government and, gradually, many people had fallen into a grudging acceptance of the status quo.

Yet, in terms of collective production and solidarity, it was still possible to see the traces of the Gezi protests continuing - though not in Gezi Park, but in other public spaces. The Gezi protests had started as a result of a resistance against the demolition of the park, and had quickly morphed into a political outcry articulated by many disaffected groups. However, there was still a need to protect the existing green spaces of the city as the "AKP-led urban transformation had entailed "grounding neoliberalism" in the material environment' at the cost of the natural environment (Akçalı and Korkut 2015: 82). Branding its projects 'Çılgın Projeler' (Crazy projects), the AKP government continued to initiate major infrastructural projects pursuing 'increasing self-entitlement to privatize public assets' (Iğsız 2013), including public (and green) spaces.

Still, there were opposition voices. One of the well-known collective projects involving community gardens was against the demolition of Yedikule Vegetable Gardens in the Fatih district of Istanbul. These plots comprised $85,000 \mathrm{~m}^{2}$ area of fertile urban farm that has been cultivated since the Ottoman times by the Istanbul metropolitan municipality. If destroyed, 'the traces of a unique eco-system of houses, barns, gardens and resources of Ottoman agricultural technology [could] have been erased' (Cihanger and Durusoy 2016: 132). As a reaction, a growing group of gardeners, ecological activists, artists and journalists collaborated to secure the gardeners' rights to continued use of the land and to conserve the area. Other similar acts included the Kuzguncuk Garden and Roma Garden in Cihangir in Istanbul. Beyond Istanbul, especially in the Black Sea region, locals protested against pervasive hydroelectric plants and other power plants, as well as copper mines, which operated at the expense of the environment. Hence, they 
organized against the 'commoditization of urban and environmental common purposes' (Özgökçeler and Sevgi 2016: 507). In the Black Sea province of Artvin, for example, protestors staged protests, blocked roads and set up tents, thus earning the moniker 'junior Gezi' from Erdoğan. Such persistent collective environmentalism certainly was using the repertoires of Gezi, yet had a distinct communal favour in the sense that 'the main focus of resistance here was the mine' (Özgökçeler and Sevgi 2016: 505).

As the environmental protests continued all around Turkey, it was possible to see a similar collective spirit and solidarity through artistic productions as well. Gezi was long gone, yet a group of artists and academics, who had come together under the group name of Turuncu Çadır (which translates as 'Orange Tent', literally referring to the orange tent that had become a meeting point for artists during the protests in Gezi Park), were continuing to meet and debate every week in person or online in Facebook groups. Following this, in 2014 and in 2015, some 84 artists came together for an exhibition entitled Stay with $M e$, in which they reflected on the memories, findings and traces of the Gezi protest. Organized by the artist-run-space Apartment Project, the exhibition took place in Istanbul, Berlin, Amsterdam and Bremen, respectively. The manifesto of the exhibition summarized the feeling that many people were sharing at the moment: 'This [the Gezi protests] was the hope itself. It was spirit of solidarity, struggle, standing side by side. Then [...] nothing changed. We closed back into ourselves. Now, we are just left tired. Is it possible to remember this hope?'2 In the exhibition, each artist created a notebook to document, re-enact or comment on their experience from the time of the protest. This was not just remembering what was long gone, but rather an attempt to keep it alive through physical documentation.

Yet, four years after, how would it be possible to remember the feeling of hope? And, most critically, how could an exhibition achieve that? How could an exhibition attempt to bring back the vanishing spirit of solidarity and communal support that was so dominant in the Gezi Park protests? As an artist as well as the appointed curator of the exhibition, I felt that an exhibition to foreground the 'Aesthetics of Protest' project should not repeat or reflect on yet again what happened in the park since this would only be a failed attempt to mimic the past. Therefore, rather than looking back, I chose to contribute to the legacy of the Gezi protests, exploring continuing

1 https://www.citylab.com/equity/2017/o7/making-room-for-nature-in-erdogans-istan$\mathrm{bul} / 534678 /$, accessed 15.04.19.

2 http://berlin.apartmentproject.org/projects/stay-with-me/, accessed 15.04.19. 
artistic and communal production. Thus, emerged the idea for Maybe, We Will Benefit from Our Neighbour's Good Fortune, an exhibition on collectivity, community and dialogue. Drawing on the ideas of 'participatory and community art practices', I decided to work with artist collectives, and engage them to produce new works on the theme of community, neighbourhood and collectivity, which was something we had all experienced thanks to the principles and ideas of the Gezi Park protests. The hope was to move beyond frustration with the events unfolding in Turkish politics and instead to reinvigorate those sentiments and aspirations that emerged so vividly in the Gezi protests. It was a call to bring back the lost values of traditional neighbourliness through communal artistic production.

\section{Dialogical Aesthetics}

In order to create the theoretical framework of the exhibition, I started to look into theories and practices of art that revolve around social relations. In the 1990s and early 200os, the French curator Nicholas Bourriaud's term 'relational aesthetics' (1998) was an often-debated approach in contemporary art, which foresaw that social relations could become the centre of an artwork. In his collection of essays under the same name, Bourriaud drew attention to the art of the 1990s, which, he claimed, takes 'as its theoretical horizon the realm of human interactions and its social context, rather than the assertion of an interdependent and private symbolic space' (Bourriaud 1998: 14).

Although Bourriaud's concept of 'relational aesthetics' (1998) has left a stamp on the period, he was still much criticized by other writers. Notably, art historian Claire Bishop was critical of the essentializing tendency to see a community as a single entity that looked at things from the same perspective, and artworks which she described as creating a 'fictitious whole subject of harmonious whole community' (Bishop 2004: 79). Departing in her argument from those found in Ernesto Laclau and Chantal Mouffe's book Hegemony and Socialist Strategy: Towards a Radical Democratic Politics (1985), Bishop suggested that antagonism was essential in a functioning democratic society so that confrontations could provocatively serve as an opening within the democratic public sphere. Referring to Bourriaud's proposed idea of relations occurring in the gallery space between a group of art dealers or like-minded art lovers, she suggested that it might be interesting to think what would happen if the gallery space was invaded by people who were genuinely seeking asylum. 
Moving from Bishop's comments, I began to consider: How can art become instrumental in opening up a democratic sphere with various identities, voices and representations while building up communities with a strong sense of collectivity? How can it allow different voices yet constitute a community? These questions led me into exploring community art practices and collectivity, and thinking of these as transformative tools. Surely the idea was not new; other people such as the famous German artist and teacher Joseph Beuys had once described the term 'social sculpture' as a socially engaged art that would 'mould and shape the world in which we live' (Beuys 2010: 9). Beuys had also claimed that everyone is an artist. This did not mean that everyone was a painter or a sculptor, but every human being would be participating in the future social order through art, which could have revolutionary characteristics.

Moreover, the artist Suzanne Lacy has also long been working with Beuys's questions and asking how artists could 'become catalysts for change' and 'reposition themselves as citizen-activists' (Lacy 1994: 8). As an artist, Lacy was also engaged in work in collaboration with the public, and in pointing to different social and political issues since the 1970s. Her work Three Weeks in May (1977), in which she and a group of women made maps indicated where rapes occurred in public spaces in Los Angeles, became instrumental in making these cases heard in the public space by a plethora of performances.

Through looking at these artists' work, I found myself engaging with the dialogical practices of art in creating communities. The art historian Grant H. Kester formulated the term 'dialogical aesthetics', where he wrote aesthetic experience was created as a 'condition and character of dialogical exchange itself' (Kester 2004: 4). According to Kester, by creating a dialogue between different segments of communities in societies, artists could enable us to 'speak and imagine beyond the limits of fixed identities and official discourse' (Kester 2004: 2). Kester's ideas on dialogical exchange was extremely critical as for me as it reflected the spirit of Gezi - a space where people from different class, groups and segments could come together and stand side by side as argued above. 'The plurality of people with different political, religious, ethnic, social, cultural, sexual tendencies yet all pursuing the same notion of freedom was very striking' (Germen 2015: 18), to illustrate Claire Bishop's 'antagonism', which did not define community as a single identity but rather a group of people with different perspectives. Hence, taking Kester and Bishop as my references, I built an exhibition that I hoped would sustain and nourish the community, collaboration, participation and dialogical aspects of the spirit of Gezi, as well as revive the feeling of communal support and solidarity. 


\section{Maybe, We Will Benefit from Our Neighbour's Good Fortune: An Exhibition on Collectivity}

The saying 'Maybe, we will benefit from our neighbour's good fortune' (Komşuda pişer, bize de düşer) in Turkish involves a slight double entendre. It means that the positive circumstances and good fortune of those around us will also hold for us. It also signifies the act of exploiting and creating opportunities for oneself from the good fortune of others. I thought that this old saying, despite the changing dynamics of neighbourhoods in big cities, could present an opportunity to pursue questions by way of an exhibition: Can the new aesthetics of political protests provide the lost values of traditional neighbourliness and at the same time constitute acts of resistance? Can collective production and communality, and a concept of neighbourhood formed around such an understanding, constitute a counter-stance towards oppressive politics? These were the questions that started my research for the exhibition.

As mentioned previously, I am taking dialogue and dialogical aesthetics as a key point in defining aesthetics of protests. But can we consider every dialogue as a democratic conversation? In her article 'An Introduction to Community Art and Activism', Jan Cohen-Cruz points that not every community art practice may stem from or lead to a democratic turn. She specifically speaks about Lenin's embrace of festivals and parades and Hitler's Nuremberg party rallies to celebrate the values of the Third Reich. Seeing these two examples as a terrifying example of mass art's capacity to be used to any ends, Cohen-Cruz writes, 'those rallies stand as a cautionary tale about the dangers of coercive community-based art, actually controlled from above' (Cohen-Cruz 2002: 2). According to her, although it involves a group of people, it would not be possible to speak of a democratic role in these parades, as they are controlled from a higher position.

Having these questions in mind, I set off to create an exhibition space where heterogeneous groups of people could come together and have a dialogue in which, the works, their creators and the participants could have equal roles instead of a top-to-bottom relationship. Just as the Gezi protests had brought various groups together to exist in the same space almost like neighbours with different ideologies, I wanted to bring different groups of artists and audiences together in the space, yet also allow room in the space for any possible contradictions.

With these questions in mind, I searched for collectives, which included artistic, ecological and academic groups working in Istanbul and beyond, which were also engaged in ideas of community engagement 
and neighbourliness. I should underline that the exhibition did not only consist of artistic projects, but also projects and workshops involving the environmental, gastronomic, and theoretical discussions framing them. By working with art and ecological collectives, I hoped that the exhibition would, instead of remembering Gezi, reflect and further the ideas of Gezi into another platform in the light of an exhibition.

\section{The Works}

During this research process, I met with many artist, non-artist and academic collectives that were working across different mediums together. Out of these meetings, and through many dialogues on the exhibition's theme, I decided to focus on three art collectives: Dadans (Istanbul), HAH (Istanbul), and Pelesiyer (Ankara). Each were producing works together for different periods of time. I asked each collective how they reflect upon their own collectivity, how they perceived 'neighbourhood' and what they would like to produce in the light of the theme of the exhibition.

Through the process, I regularly met all the collectives to discuss their process and to exchange ideas. I also interviewed each collective on how they perceived collectivity and how it influenced their work. As an artist, I also knew how difficult it could be to produce a piece of work, especially in an art market where a single signature could be worth of millions. I asked each collective how they viewed being a collective. For Dadans, collectivity was 'something exponentially increasing both in terms of enthusiasm and in terms of the quality of the work ${ }^{3}$ and therefore it was quite motivating. For $\mathrm{HAH}$, which was a group of six people, collectivity was also a question they often asked themselves: 'What can we bring out from standing side by side instead of being a single subject?'4 And for Pelesiyer, a collective of four people who met at art school, it 'was being a single entity like a human being. 5 These interviews later became part of the exhibition together with another film, which spoke about the curatorial process.

For the final works in the exhibition, Dadans took on the topic of listening to one's neighbour through the walls and constructed a performance. Members of Dadans placed a drinking glass on the body on another member and described the memories emanating from the body part where the glass

3 http://www.aestheticsofprotest.com/digital-galleries/, accessed 12.03.19.

4 İbid.

5 Ibid. 


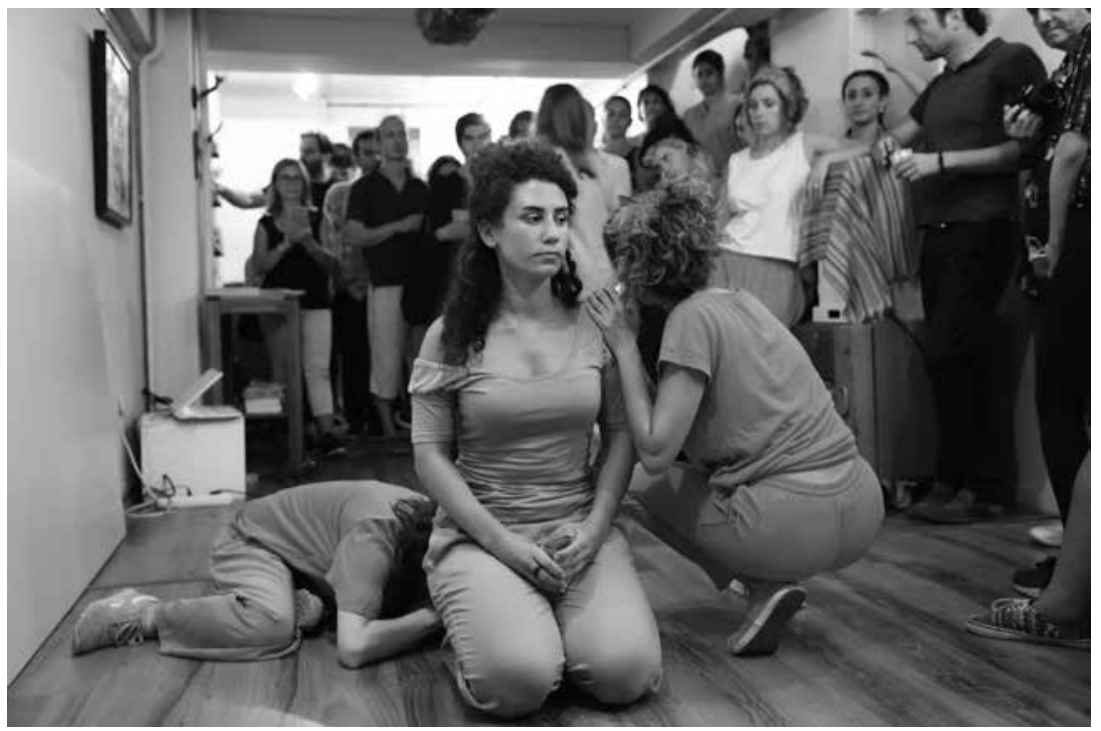

Figure 3.1. $\mathrm{HAH}$, Without Encountering, site-specific installation.

was placed. After that, they placed the glasses on the bodies of randomly selected audience members and asked them to do the same. As the audience members started to speak, the room became a place where very personal and mostly body-related experiences and stories were shared among the audience. The performance thus became an open dialogue, where one could open up private memories, yet without necessarily waiting to be answered.

HAH and Pelesiyer also created participatory works. HAH came up with an installation covering almost an entire floor in which small pieces of paper and pencils were hung from the ceiling. On each piece of paper one found either a question or an answer. Participants were asked to complete the work by either answering a question or writing a new question for the next person. Some of the written questions were: 'Do you consider the stray dog or cat on the street more of your neighbour than your actual neighbour?', 'Is your best friend also your neighbour?' and 'What would unhappiness be if it was a space?' Answers included: 'I used to have a chicken when I was a child. It was called Çanta (Bag). I really miss it' and 'The answer is more difficult than existence. It depends on where you are at at the moment.' Thus, the final installation became a continuous dialogue process between people who did not know each other and who communicated and exchanged ideas only through their writing, making the piece literally the signifier of dialogical aesthetics. 


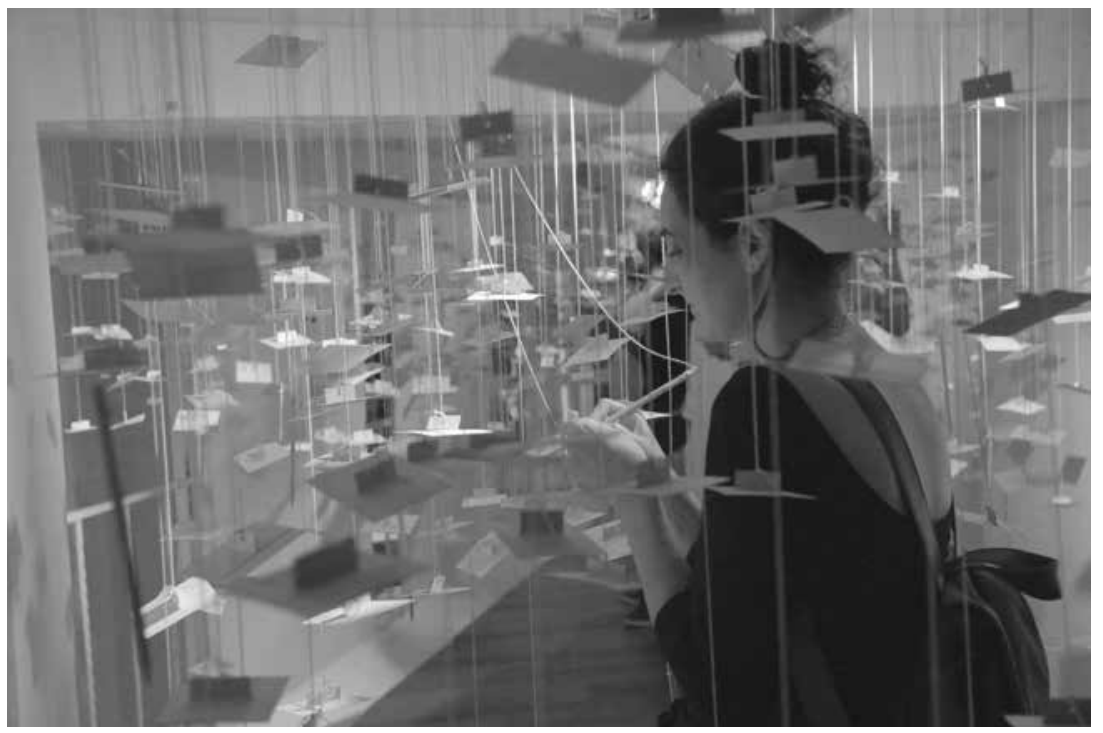

Figure 3.2. Dadans, Playing House, performance.

Finally, Pelesiyer made an eatable artwork, for which members of the collective collected flour from their neighbours in Ankara in advance of the Istanbul workshop and made a 1.5 meter-long loaf of bread that was quickly consumed during the opening event. This was quite a critical work for the exhibition as it reflected the whole process of making and sharing food together in the park. The fact that the final outcome (the bread) was consumed on the opening night by the visitors was also a bonding experience for everyone. In Dadans's performance, the oral stories were shared; in HAH's installation, the writings were shared; and in Pelesiyer's it was an item of food that brought everyone together.

The exhibition did not only include artworks. I wanted to use the space to include other means of production, sharing and discussion revolving around art, ecology and food. With this in mind, I met with the members of the Istanbul Permaculture Collective, who were interested in the theme of the exhibition. Together with them, we decided to organize two DIY workshops to take place during the exhibition, one focused on cultivating one's own garden at home, and one on making one's own bread with organic ingredients. During the opening exhibition, we also cooked and shared two giant pots of rice and beans with the visiting audience, thus literally sharing what we produced.

There were two other collectives who contributed to the framework with different perspectives. The first, Artık Işler, a video collective, screened 
their work The Waste of Istanbul, which made us consider the relationship between collective production and collective waste. The second significant collective involved was Birbuçuk, a group of culture professionals who practice dialogue as a form of artistic production: they organize talks as their works. Together with other experts they invited, we organized an open discussion one day around a lunch table on the politics of food. This was our closing event and it wrapped up the whole exhibition. We ate, listened, spoke, discussed and left the space with not just the memories of our dialogues but with ideas on how to move forward. This was exactly the spirit of Gezi, a collaborative experience where you could form dialogues with people from all over the country, participate in forums, eat together at the same table, and be interactive and creative. As I mentioned earlier, our idea was never to repeat what happened in Gezi or show its documents, but indeed to sustain its spirit and ideas with new forms. We realized this through the exhibition.

Before I turn to my reflection on the exhibition, I would like to make two points about the location of the exhibition space. After a long search, we decided to hold the exhibition in a non-profit space, one dedicated to furthering the interests of its neighbourhood and very open to inviting and working with people living there. Thus came our connection to the Halka Art Project, an art space on the Asian side of Istanbul, which was very much dedicated to community art projects and was the right location for us due to its openness to raise, work on and collaborate on issues regarding the needs of the local community. Finding an exhibition space on the Asian side of Istanbul was also important for a second reason. The fifteenth Istanbul Biennial was taking place that year on a similar theme, 'A Good Neighbour, ${ }^{6}$ and it was mainly taking place on the European side of the city. This contrast - and perhaps 'neighbourliness' - made the two exhibitions stand side by side both thematically and geographically.

\section{Reflection}

This chapter is written almost one year after the exhibition and in a very different political context. On 24June 2018, Turkey voted, yet again, to return Erdoğan as president, which marks 'the official break with a parliamentary democracy that Turkey has maintained for over half a century, giving way to a presidential republic' (Eagan 2018). Right before the elections, on 30 May

6 http://15b.iksv.org/agoodneighbour, accessed 12.05.19. 
2018, Istanbul's iconic Atatürk Cultural Center, which acted as one of the focal points of the Gezi protests, was demolished. ${ }^{7}$ Exactly opposite of this space, a new mosque is being built as the new cultural icon of the Taksim area, significantly marking the change happening both symbolically and physically. Yet, in such an area of continuous oppression and precarity of human rights, how can one continue to speak of resistance, or rather, can resistance ever take shape of different forms of protest? By embracing the aesthetics of socially engaged, participatory and dialogical art forms, I tried to build an exhibition that would sustain the ideas of Gezi protest in the form of artistic works, and thus see whether we could in this way continue to sustain the ideas of hope and solidarity.

Evaluating the outcome of an exhibition or its effects on community is neither a quantitative or qualitative task, therefore it is hard to judge by academic methods. As Tom Finkelpearl (2014: 6) writes, in talking about participatory art and its aesthetics, it can be even more difficult while 'agreeing on aesthetic criteria remains particularly difficult in the light of the diversity of practices and the fact that the aesthetic, ethical, and social values can be diametrically opposed'. Sometimes, a work of art could also be re-evaluated or gain new meaning after several years.

The case of Maybe, We Will Benefit from Our Neighbour's Good Fortune was certainly an exhibition towards building a community producing, sharing, discussing and consuming artistic, ecological, dialogical and culinary experiences. By taking the ideas of dialogue-based, participatory art practices, and linking them to an environmentally conscious political protest and its values such as collaboration and collectivity, we tried to see whether it would be possible to sustain these values in an artistic context and thus sustain hope for the future. Even though the qualitative outcome was never a goal, more than a thousand participants visited the exhibition, around a hundred people joined our workshops and discussions, and there was even more visibility on social media. In an environment where freedom of expression is extremely limited and the right to protest is almost banned, the exhibition searched for ways of sustaining hope and solidarity through the aesthetic values of Gezi and in artistic practice. Even though the acts of cooking, eating and gardening may seem like simple daily tasks, in an atmosphere of censorship, they served as tools for the artists and participants to come together and support each other in a safe exhibition space.

7 http://www.hurriyetdailynews.com/photo-iconic-culture-center-in-istanbul-demolished-132655, accessed 12.05.19. 
When it comes to an actual change of political climate, it is hard to make a clear judgement on what will happen soon. As artists, academics, and culture professionals continue to work with what they have, they also face harsher changes and implementations. In such an age of precarity, it seems unlikely to expect grand gestures as protest. Still, could the sole act of coming together through art collectives be considered as resistance? And what if these acts also come together and grow, just like the hundreds of people standing on a square together? Can we create new communities with new values and at the same time be neighbours again in full solidarity? As hopefully similar practices continue to exist, such questions will unfold in time.

\section{References}

Ağartan, Kaan. 2018. 'Politics of the Square: Remembering Gezi Park Protests Five Years Later', New Perspectives on Turkey 58: 201-217.

Akçalı, Emel, and Korkut, Umut. 2015. 'Urban Transformations in Istanbul and Budapest: Neoliberal Governmentality in the EU's Semi-Periphery and Its Limits', Political Geography 46: 76-88.

Batuman, Bülent. 2015. "Everywhere Is Taksim”: The Politics of Public Space from Nation-building to Neoliberal Islamism and Beyond', Journal of Urban History 41 (5): 881-907.

Beuys, Joseph. 2010. What Is Art? Conversation with Joseph Beuys, ed. with essays by Volker Harlan, trans. Matthew Barton and Shelley Sacks. London: Clairview Books.

Bishop, Claire. 2004. 'Antagonism and Relational Aesthetics', October 110: 51-79.

Bishop, Claire. 2012. Artificial Hells: Participatory Art and the Politics of Spectatorship. London: Verso.

Bourriaud, Nicholas. 1998. Relational Aesthetics. Dijon: Les Presses du réel.

Cihanger, Duygu, and Elifnaz Durusoy. 2016. 'Historic Landscape vs. Urban Commodity? The Case of Yedikule Urban Gardens, Istanbul', Megaron 11(1):125-136.

Cohen-Cruz, Jan. 2002. 'An Introduction to Community Art and Activism'. https:// library.upei.ca/sites/default/files/an_introduction_to_community_art_and_activism_cohen_cruz.pdf. Accessed 16.05.19.

Eagan, Eleanor. 2018. 'Erdogan's Latest Move towards Autocracy', Open Democracy, 24 May. https://www.opendemocracy.net/eleanor-eagan/erdogan-s-latest-movetowards-autocracy. Accessed 17.10.18.

Finkelpearl, Tom. 2014. 'Participatory Art', in Encyclopedia of Aesthetics, ed. Michael Kelly. Oxford: Oxford University Press. http://arts.berkeley.edu/wp-content/ 
uploads/2015/03/Participatory_Art-Finkelpearl-Encyclopedia_Aesthetics.pdf. Accessed 25.03.19.

Germen, Murat. 2015. 'Istanbul Gezi Park Resistance Movement as Public Engagement in the Making of Place'. Procedia - Social and Behavioral Sciences 184: 13-21.

Haksöz, Cengiz. 2015. 'Eating in Gezi, Devoured by Gezi: Food and Resistance in Istanbul Gezi Park Protests', in Another Brick in the Barricade: The Gezi Resistance and Its Aftermath, ed. Harun Aksu and Güneş Koç, 55-78. Bremen: Wiener Verlag.

Hinderliter, Beth. 2009. Communities of Sense: Rethinking Aesthetics and Politics. Durham, NC: Duke University Press.

Iğsız, Asl. 2013. 'Brand Turkey and the Gezi Protests: Authoritarianism, Law and Neoliberalism.' Jadaliyya, 12 July. http://www.jadaliyya.com/Details/29078/ Brand-Turkey-and-the-Gezi-Protests-Authoritarianism,-Law,-and-NeoliberalismPart-One. Accessed 25.03.19.

Kester, Grant H. 2004. Conversation Pieces: Community and Communication in Modern Art. Berkeley: University of California Press.

Lacy, Suzanne. 1994. Mapping the Terrain: New Genre Public Art. Seattle: Bay Press. Öğün Emre, Perrin, Barış Çoban, and Gülüm Şener. 2013. 'Humorous Form of Protest: Disproportionate Use of Intelligence in Gezi Park's Resistance', paper presented at Politsci' 13 Political Science Conference, Istanbul, Turkey, 31 October-2 November. https://www.academia.edu/5114875/Humorous_form_of_protest_Disproportionate_use_of_intelligence_in_Gezi_Parks_Resistance.Accessed 25.07.18.

Özbudun, Ergun. 2014. 'The 2014 Presidential Elections in Turkey: A Post-election Analysis'. Open Democracy, 20 October. https://www.opendemocracy.net/ergun$\% \mathrm{C}_{3} \%$ B6zbudun/2014-presidential-elections-in-turkey-postelection-analysis. Accessed 25.03.19.

Özgökçeler, Serhat, and Hüseyin Sevgi. 2016. 'Cerattepe: As an Explanandum of the Common Faith', Journal of International Social Research 9(45): 501-507.

Simanowitz, Stefan. 2018. 'Defending Journalism in Turkey's Climate of Fear', Open Democracy, 2 May. https://www.opendemocracy.net/stefan-simanowitz/ defending-journalism-in-climate-of-fear. Accessed 25.03.19.

Türkmen-Dervişoğlu, Gülay. 2013. 'Gezi: The Park That Shook up Turkey', Open Democracy, 3June. https://www.opendemocracy.net/gulay-turkmen-dervisoglu/ gezi-park-that-shook-up-turkey. Accessed 25.03.19.

Verstraete, Peter. 2015. 'Still Standing? A Contextual Interview with "Standing Man”, Erdem Gündüz', in In der Welt der Proteste und Umwälzungen:Deutschland und die Türkei, ed. Yasemin Dayioglu-Yücel, Michael Hofmann, and Seyda Ozil, 121-136. Göttingen: V\&R Unipress. 
About the Author

Işıl Eğrikavuk is an artist whose work focuses on performance art and community art practices. She has been an Assistant Professor at Berlin University of Arts since October 2017. Her current $\mathrm{PhD}$ research investigates artistic acts, performance and collectivity in relationship to political protests. For the 'Aesthetics of Protest' project, she curated an exhibition in Istanbul in 2017 titled Maybe, We Will Benefit from Our Neighbour's Good Fortune. 


\title{
4 Political Street Art in Social Mobilization: A Tale of Two Protests in Argentina
}

\author{
Holly Eva Ryan
}

\begin{abstract}
Separated by almost two decades, the large-scale social mobilizations known as El siluetazo and El argentinazo have been understood by some scholars as watershed moments in Argentine politics. At these times of heightened political contestation, it has been possible to observe a dissolution of the status quo and the emergence of new or alternative political paradigms. Less recognized, however, is the central role that 'the aesthetic' has played within such processes of political transformation. By focusing on the spectacular outpouring of street art that accompanied these two protest events, the chapter aims to illuminate some of the analytical gaps and grey areas that exist between art, aesthetics and social movement studies today.
\end{abstract}

Keywords: street art, Argentina, aesthetics, social mobilization, affect, performativity

\section{Introduction}

Consider these two vignettes.

The year is 1983 and Argentina has been in the grips of a brutal dictatorship for seven years. Up to 3o, oоo have been forcibly 'disappeared" and there is

1 During Argentina's period of military rule, lasting from 1976 to 1983, the security forces abducted (forcibly disappeared) around 30,000 people, many of whom are still unaccounted for (Amnesty International 2018).

McGarry, A., I. Erhart, H. Eslen-Ziya, O.Jenzen, U. Korkut (eds), The Aesthetics of Global Protest: Visual Culture and Communication. Amsterdam: Amsterdam University Press, 2020 DOI 10.5117/9789463724913_CHO4 
virtually no familial or friendship network that has not been touched by loss. Foryears, public manifestations of resistance have been declining due to the seeds offear and mistrust successfully sown by the governing regime. One of the few remaining symbols of active resistance is the haunting presence of the mothers of the 'disappeared', who march weekly on the Plaza de Mayo, calling silently for the safe return of the sons and daughters that have been taken from them. On 21 September, coinciding with a public opposition march mobilized by the Mothers, hundreds of life-sized paper bodies appear in the Plaza de Mayo. The scene is saturated with silhouettes representing the 'disappeared'. Hundreds of people of all ages pour into the square to create their own silhouettes - of mothers, brothers, fathers, daughters, all snatched away - and, for a temporary period, the plaza becomes a liberated zone where porteños (residents of Buenos Aires) overcome their fears and band together to make a visual call for their 'reaparición con vida' (return alive and well).

The year is 2002 and Argentina is reeling from a spectacular economic and political collapse. The country has just defaulted on its $\$ 155$ billion public debt, output is falling rapidly, inflation is reaching new highs, cash and credit are unavailable for consumers and businesses alike, and government after government has tried and failed to resolve the situation. ${ }^{2}$ Tensions are mounting, in the halls of power and on the streets. The walls of Buenos Aires are flooded with hastily graffitied inscriptions and crudely cut stencils; common refrains include (the now emblematic) 'Que se vayan todos'(Throw them all out) 'Violencia es robar'(Violence is robbery) and 'Congreso traidor' (Traitor Congress). Perhaps most poignantly, protestors invoke the memory of the Dirty War with allusions to the year ' $19766^{3}$ and the phrase, 'Nunca mas, bancos'(Never again, banks).

Each of these episodes recalls a moment in recent Argentine political history where the streets and squares of the country's capital, Buenos Aires, have provided the setting for a sudden and remarkable outpouring of political street art. Separated by some nineteen years, these episodes are testimony to the pervasive utility of street art as a mode of protest. For the purposes of this chapter, street art is understood to include murals, wheatpastes, graffiti,

2 The extent of Argentina's debt and the dramatic unfolding of the country's 2001/2002 economic collapse has been well documented and extensively discussed by economists and political scientists (see, for example, Blustein 2005; The Economist 2002; Levey et al. 2014).

3 This is a reference to the 1976 military coup and the period of violence that it ushered in. 
stencils and other ad hoc painted expressions found outdoors. Street art is considered a mode of protest in the sense that it is one manner through which political messages or sentiments are expressed and communicated to governments and publics. Messages or sentiments are defined as political to the extent that they illuminate, challenge or otherwise engage with the existing constellations of power within society. From the early twentieth century, street art has been used by individual and collective non-state actors to announce and denounce, educate and inform populations in both urban and rural areas. These kinds of expressions are by no means new. And yet, in recent years, they have seen a manifold increase all across the globe, often emerging against the backdrop of popular protests and political uprisings (see Tulke, this volume). At these junctures, where activism and aesthetic practice combine and collide in impulsive and sometimes unexpected ways, scholars should take pause to examine and ask questions about what exactly is going on: What prompts such a sudden 'outpouring' of street art? How can we best understand the dynamics that bring individuals to the street? And what, if anything, is unique about street art as a form of political expression and claim-making?

In pursuit of answers to these kinds of questions, we might logically turn our attention towards social movement theory (SMT), defined as the interdisciplinary assemblage of works from political science, sociology, cultural and organizational studies that explore the causes and consequences of social mobilization, activism and protest. But perhaps surprisingly, mainstream SMT has been relatively slow to make inroads and advances in the area of art activism and aesthetics. This is due in part to the lingering prevalence of methodological rationalism and structuralism that limit the scope of visual and aesthetic analysis. As this chapter will argue, the political importance of street art cannot be understood through a purely rationalist lens. Taking the two episodes from Argentina referred to above as cases in point, it seeks to demonstrate how an approach grounded in 'practical aesthetics' can better enable researchers to understand how street art impresses on individuals and environments, how it functions, and what it produces in relation to protest events.

\section{Social Movement Theory and the Structuralist/Rationalist Bias}

Studies of social mobilization have proliferated since the 1960 s as theorists have rallied to adapt and develop new tools for understanding major protest events, including the 'Paris Spring' of 1968 (see Tarrow 1993), mobilizations for civil rights and black power in the United States (see Morris 1986), and 
transnational anti-war demonstrations in the 1970s (see McAdam and Su 2002). New and different lenses for the analysis of these moments and movements were proposed on either side of the Atlantic. In the United States, the resource mobilization (RM) framework placed an emphasis on the variety of material and ideational resources that must be brought together for movement success as well as the importance of the links and networks that exist both within the movement and beyond it for developing unity, cohesion and support (McCarthy and Zald 1977). Political process theory (PPT) approaches aimed for a more extensive conceptualization of the political environments that movements face and, in particular, promoted a thoroughgoing assessment of the structure of 'political opportunities' that could accelerate or constrain political action. Meanwhile, in Europe, new social movement theory emerged to highlight the discontinuities between older Marxian and vanguardist models of political action as a response to economic grievances, and the new and sometimes decentred movements of the post-industrial era with their focus on identity, culture and lifestyle (Melucci 1994).

Since the 1990s the lines between these different theoretical schools and approaches have become increasingly blurred as they have been variously adapted and appropriated by a new generation of scholars eager to make sense of a fast-evolving landscape of local, national and transnational protest activity that simultaneously pushes at the boundaries of the political and cultural status quo. A tacit consensus has emerged around the use and utility of certain conceptual tools inherited from RM and PPT, which include mobilizing structures, political opportunities, and framing processes. Whilst each of these conceptual advances has provided useful insights into how, why, and when mobilizations occur and gather pace, the argument presented below is that the prevalence of rationalist and structuralist biases in mainstream social movement theory obscure certain practices and processes of power, resistance, and change from its field of vision.

The term 'rationalism' is used here to describe an epistemological position that regards human reason as the paramount source and means for gathering and testing of knowledge. Rationalists tend to place a great deal of emphasis on the ideas of progress, universality and truth. Each generation is able to advance beyond the previous one through the exercise of human reason and a gradual accumulation of knowledge, bringing them ever closer to an assumed truth. In pursuit of that goal, the human intellect can and must overcome emotional impulses; scientific knowledge can and must overcome the temptation to custom and superstition. The pursuit of knowledge and truth must not rely upon the sensory but rather upon intellectual and deductive processes. 
In order to explain the prevalence of rationalism within today's social movement theory, it is necessary to wind back the clock and examine RM and PPT not as abstract processes of theory generation but rather as political acts of counter-framing. Prior to the 196os, the major formulations used to examine and explain social mobilization were mass society theory, relative deprivation, and collective behaviour theory. These approaches variously pointed to sudden increases in individual grievances that had been generated by the 'structural strains' of rapid social change. As Jenkins $(1983: 528)$ notes, 'while specific hypotheses varied, these traditional theories shared the assumptions that movement participation was relatively rare, discontents were transitory, movement and institutionalized actions were sharply distinct, and movement actors were arational if not outright irrational'. Engaged in close observation, if not participation in, of the social movements of the 196os and after, scholars of RM and PPT objected to these characterizations of protestors as lacking agency and rational capacity. These new perspectives instead 'emphasized the continuities between movement and institutionalized actions, the rationality of movement actors, the strategic problems confronted by movements, and the role of movements as agencies for social change' (ibid.).

Structuralism refers to the tendency to focus on the material conditions and broader social, economic or political forces that operate to contain and shape the actions and activities of social movement actors. Goodwin and Jasper (1999) famously referred to structuralism as 'a winding snarling vine' that weds social movement theory to forms of analysis that are tautological, inadequate or just plain wrong. Their argument suggested that structuralist analyses impose a kind of universalist straight jacket onto circumstances, processes and events that are both dissimilar and contingent. It is possible to detect echoes of both rationalism and structuralism in many of the major works on resource mobilization, political opportunity, and framing.

Mobilizing structures are described by Sidney Tarrow (1998: 123) as the various elements that 'bring people together in the field'. Whilst there are innumerable factors that could help to cement bonds between individuals and groups in society, such as ideology, ritual, culture, collective memory or emotion, Tarrow (1998) focuses more specifically on models of organization, looking at the relative merits of hierarchical versus more horizontal membership structures within and between movements and non-profits. Other works in this area have tended to pay close attention to material factors like financial resources, size of pre-existing or overlapping membership bases (Zald and McCarthy 1979). The focus here is on the number of 
bodies that make up an assemblage rather than the feelings or sensations of commitment, anger or hope that might be shared among them.

Most works on political opportunity has focused heavily on the structure of regimes and cohesion of elite politics. Tilly (2008: 179) argues that 'regime openness, coherence of the elite, stability of political alignments, availability of allies, repression and facilitation, and [the] pace of change in those elements define [the level of] opportunity and threat for potential claimants'. Meanwhile, McAdam (1996) outlines the following four main dimensions of political opportunity: (1) the relative openness or closure of the institutionalized political system; (2) the stability or instability of that broad set of elite alignments that typically undergird a polity; (3) the presence or absence of elite allies; and (4) the state's capacity and propensity for repression. However, these approaches largely overlook the mediating presence of different ideologies and belief systems as well as situated experiences - of classed, raced and gendered discrimination, for example - that can affect how political processes are perceived, how risks are calculated and how they are felt or internalized by different groups of actors. Also neglected in this literature are the ways in which the manipulation or transformation of physical environments themselves can affect the individual and group behaviour, variously invoking fear and mistrust or collectivity and confidence.

Neal Caren (2007) describes 'framing' as one of the ways that scholars have attempted to bring agency back in to the conversation about social movements. Receiving the most thoroughgoing exposition by scholars Snow and Benford in the 1990s, the concept of 'framing' has been used to describe the ways that movement activists and leaders construct their actions and identities in order to draw support. Inspired by the work of the social theorist Erving Goffman, 'framing' describes different strategies that are pursued with the aim of reaching new audiences, galvanizing existing supporters and extending the resonance of protest demands. The success or resonance of a frame is said to rest on its measures of credibility and salience: Are the claims understood to be legitimate and do they have a basis in real world experience? How well do they match up with the priorities, values and ambitions of their target audiences?

To the extent that art within social movements has received attention from mainstream social movement scholarship, it has largely been under the rubric of framing, where cultural innovations and aesthetic practices have been understood as a part of conscious and rationalized strategies to mobilize support (Adams 2002). Interestingly however, even Goffman's original discussion of what he termed 'impression management' reserved 
a role for what we might call embodied behaviours or non-rationalized actions. As Goffman put it, '[s]ometimes the traditions of an individual's role will lead him to give a well-designed impression of a particular kind and yet he may be neither consciously nor unconsciously disposed to create such an impression' (Goffman 1959: 6). The underlying takeaway for social movement theorists interested in manifestations of art that occur in and around sites of protest is that although art can evidently help to market, promote or resist a particular cause, not every animating and/or aesthetic action undertaken during processes of social mobilization is meticulously planned, or consciously executed.

Taken together, these criticisms demonstrate some obvious blind spots or omissions from mainstream social movement analysis as it relates to art within social mobilization. Quite notably, many of these gaps and omissions could be usefully addressed through a greater cross-fertilization of ideas and concepts drawn from practical aesthetics. The proposal for a keener 'aesthetic sensibility' in SMT, as articulated more fully below, can be seen as an added dimension in the wider emotional and cultural 'turn' that has been taking place in social movement studies, spearheaded by scholars such as James Jasper, Jeff Goodwin, Francesca Polletta, Bert Klandermans and Hank Johnston (see Johnston and Klandermans 1995; Jasper 1998, 2008; Goodwin et al. 2009).

\section{An Aesthetic Sensibility for SMT?}

The term 'aesthetics' comes from the Greek word 'aesthesis', which refers to sensory perception. Until very recently, the field of aesthetic inquiry in the Western philosophic tradition has been dominated by questions about beauty and taste in art. Aesthetic philosophers have been occupied with endeavours to derive standards and principles for making proper aesthetic judgements, based on the notion that the aesthetic constitutes an autonomous realm of value that should remain shut off from the social concerns, moral considerations and/or power relations that are encountered in everyday life. In this view, which has among its forebears seminal works such as Kant's Critique ofJudgement and Schiller's On the Aesthetic Education of Man, artistic expression is understood to be, according to Kant, 'purposive without a purpose' (cited in Belfiore and Bennett 2008: 178). The value of art is not tied to any prior function; it is to be appreciated for its own sake.

However, this 'autonomist' view has increasingly been called into question. Aesthetic philosophers, including Noël Carroll $(1996,2001)$, have broken with tradition by arguing for the acknowledgement of multiple realms of value for 
the arts. Moreover, in recent years, an increasing number of social scientists and art historians have taken up an interest in the ways that images and sounds work over individuals and collectivities to elicit responses that have implications for social and political practice. Hence, where some scholars still use the term 'aesthetics' to denote an autonomist reading, others refer to the aesthetic as a field of knowledge through which power and resistance can operate (Rancière 2004; Panagia 2009; Bleiker 2009; Bennett 2012). This more 'practical' understanding and application of aesthetics tends to underline the interconnection between art, image-making and the sociopolitical sphere, including the ways in which artistic expression, popular culture and embodied sensory encounters of various kinds interact with - even alter - the prevailing landscape of power and possibility.

Roland Bleiker's Aesthetics and World Politics (2009) provides a useful starting point for thinking practically about aesthetics. In this book, he offers up a distinction between 'aesthetic' and 'mimetic' approaches to studying the social world (and in his case global politics). He uses the term 'mimetic' to describe research methodologies that aspire to represent events and processes as realistically and authentically as possible. Inspired by rationalist-positivist social science, these approaches attempt to act as a mirror unto the social world and come as close as possible to a singularity of truth and meaning. The trouble with such approaches is that there is a continuous impulse to try and close down on doubt and to clear up all ambiguity through research in order for us to tell a neat, linear and bounded tale - whether one of resistance or oppression, continuity or change. However, it is important to acknowledge what we may lose when we try to impose singular meanings on events and/or rationalize away the ambiguities. In the first instance, we remove the opportunity for the reader to participate actively in the creative process by drawing on her/his own stock of knowledge and experience to help understand phenomena. In the second instance, scholarly practices of storytelling become manifestations of power in themselves that can promote a single vision, standpoint or experience - at the expense of others.

For these reasons, Bleiker promotes a more nuanced aesthetic approach or sensibility for social scientists. Such an aesthetic approach entails a much higher level of sensitivity to what one sees and discovers in the world, including an alertness not just to one's thoughts and cognitions but also to the intuitions and alternative forms of knowing that are generated when we experience an event or process. Hence, 'aesthetics refers not only to practices of art - from painting to music, poetry, photography, and film - but also, and above all, to the type of insights and understandings they facilitate' (Bleiker 
2018). These are the affects, feelings and embodied responses that we might not have quite the right words to pin down in our everyday language and discourse, and that remain somehow in excess of language and therefore always clouded in some level of ambiguity. To have an aesthetic sensibility then is to be attuned to the ways in which visual, aural, and tactile encounters with objects, spaces or indeed other bodies can engage the senses in ways that produce (political) effects. It is to tip the balance back towards the study of 'affect rather than reason, judgement rather than fact, sensation rather than intellectualism' (Moore and Shepherd 2010: 299) in order to generate a wider analytical and methodological toolkit. Crucially, aesthetic sensibility is to expand the territories of what we can know, and how we can know, about political events and processes.

Considering this theoretical debate with particular reference to the production and experience of street art, we can then think about a number of ways that an 'aesthetic sensibility' can revise and extend SMT. By paying closer attention to the expressive, embodied and performative elements of street art production and reception, it is possible to shed new light on sources and processes of individual transformation and wider political change.

\section{Silhouettes, Stencils, and Aesthetic Sensibility: Argentina Revisited}

This section extends two the vignettes that appeared at the beginning of the chapter. By offering further contextual information and analysis it endeavours to demonstrate how and in what ways an aesthetic sensibility aids our understanding of the dynamics and processes at play in these street art outpourings.

\section{El Siluetazo}

By the early 1980 os small cracks had started to show in the machinery of the Argentina's brutal dictatorial regime. From 1981, the Mothers of the Plaza de Mayo (Asociación Madres de Plaza de Mayo) - several of whom had themselves disappeared - had been calling on human rights organizations and others to participate in annual marches of resistance, which were also gaining increasing coverage abroad. In 1982, Argentina's defeat to Britain in the Malvinas/Falklands War signalled a weakening of the regime and encouraged civil society actors to cautiously intensify their criticism of the dictatorship. Nonetheless, the climate was still one of severe repression and fear. Garreton (1992) explains that while 'fear' is inherent in human society and forms a fundamental part of the human psyche, within Latin America's military regimes, authoritarian elements worked to cultivate a 'politically 
determined fear', one that shaped not only the type of relation that existed between state and society but also between citizens and neighbours who came to distrust one another. This kind of fear was cultivated in a number of ways, including the use of outright violence, the insidious 'removal' of opposition members and sympathizers from society, veiled threats and hushed murmurings about clandestine torture centres as well as a total and suffocating silence around the fates of 'the disappeared'. Fear was also reinforced through aesthetic and visual cues: unmarked Ford Falcons crawling menacingly along the roads; city plazas eerily devoid of celebration, collectivity, and voice; naked - sometimes mutilated - corpses washing up on the desolate banks of the Rio del Plata, where the mouth of the river meets the churning Atlantic.

In 1983, during the planning stages of their third annual march of resistance, the Mothers of the Plaza de Mayo received an unusual proposal from three visual artists: Rodolfo Aguerreberry, Julio Flores, and Guillermo Kexel. Sometime earlier, the three artists had come across a poster image by Jerzy Skapski, which had been featured in the 1978 edition of The Courier, an international magazine compiled by UNESCO. Skapski was a Polish artist whose work dealt with the theme and memory of the Holocaust. The poster in question placed 24 rows of human silhouettes of different sizes and shapes against a black background, together with the caption: 'Every day at Auschwitz brought death to 2370 people, and this is the number of figures represented above. The concentration camp at Auschwitz was in existence for 1,688 days and this is the exact number of copies of this poster printed. Altogether some four million people died at the cam'. Aguerreberry, Flores and Kexel became captivated by the idea of scale that had been so exactingly articulated in Skapski's work. And, similar to Skapski, they sought to devise visual representations that could call heightened attention to the staggering number of human bodies that had been fatally harmed in repugnant acts of political violence and genocide. One of the artists, Julio Flores, explains that 'The objectives were to reclaim through representation, the lives of the disappeared [...] to create a graphic that would shock the Government through its physical scale and its formal development, and to create something so unusual as to renew the attention of the media and cause a provocation that would last many days before leaving the streets' (Flores 2004, cited in Museo de Arte Contemporáneo de Rosario 2009).

Initially, the artists devised a work of enormous scale - the aim was to fill an exhibition space with hundreds, even thousands of life-sized silhouettes, as many as could fit - using visual spectacle to drive home the message of just how many individuals had been 'disappeared'. They hoped to realize this 
plan at an Esso Foundation-sponsored exhibition on 'objects and experiences' that had been planned in Buenos Aires (Longoni 2007). However, that event was eventually suspended due to the Malvinas/Falklands War. Failing to find an institution with either space or willingness to take on a work that called out the military in such dramatic, scalar fashion, the artists turned to the Mothers of the Plaza de Mayo and appealed to them to help stage a public art intervention as a part of the Third Annual March for Resistance.

The Mothers agreed to help execute the planned intervention, but they also sought to enforce certain aesthetic and symbolic principles of their own. As an example, Longoni (2007) writes that the Mothers opposed the idea of placing silhouettes horizontally on the ground because these could be more readily associated with the image of death than life. For the Madres, the call for 'aparece con vida' (appearance with life) was paramount to their campaign. Since the regime had refused to release any information on the whereabouts or circumstances of those 'disappeared', there remained a trace of hope that some might be alive. For many of the women, this emotional and affective component was a vital ingredient to their struggle. The faint glimmer of possibility that their sons and daughters were alive was something that sustained them and compelled them to return to the plaza week after week even in the face of fear and repression. ${ }^{4}$ As one of the Mothers, Margareta de Oro, articulates in an interview with Josephine Fisher (1989: 156), 'You only become conscious when you lose something. When the Mothers first met we used to cry a lot and then we began to shout and demand, and nothing mattered anymore except that we should find our children.'

Together, the three visual artists and the Mothers pre-prepared a large number of silhouettes on madera paper and collected paints, brushes and rollers. Not having full biographical details of all of those disappeared, nor the time to adequately personalize the images, the artists and Mothers opted to impose a certain aesthetic uniformity on the silhouettes. They created a life-sized stencil and then ran black paint over it, producing - initially - 1,500 identical silhouettes that might represent any one of the disappeared such as fathers, sons, daughters, friends, or neighbours (Longoni 2007; Longoni and Bruzzone 2008).

On 21 September, the artists and the Madres descended on the Plaza de Mayo with their materials. They began pasting up the life-sized figures on walls and gates and trees. They began producing more silhouettes on the

4 In 1977, three of the founding members of the Mothers of the Plaza de Mayo and two French nuns, who had supported the Mothers' efforts were 'disappeared'. 


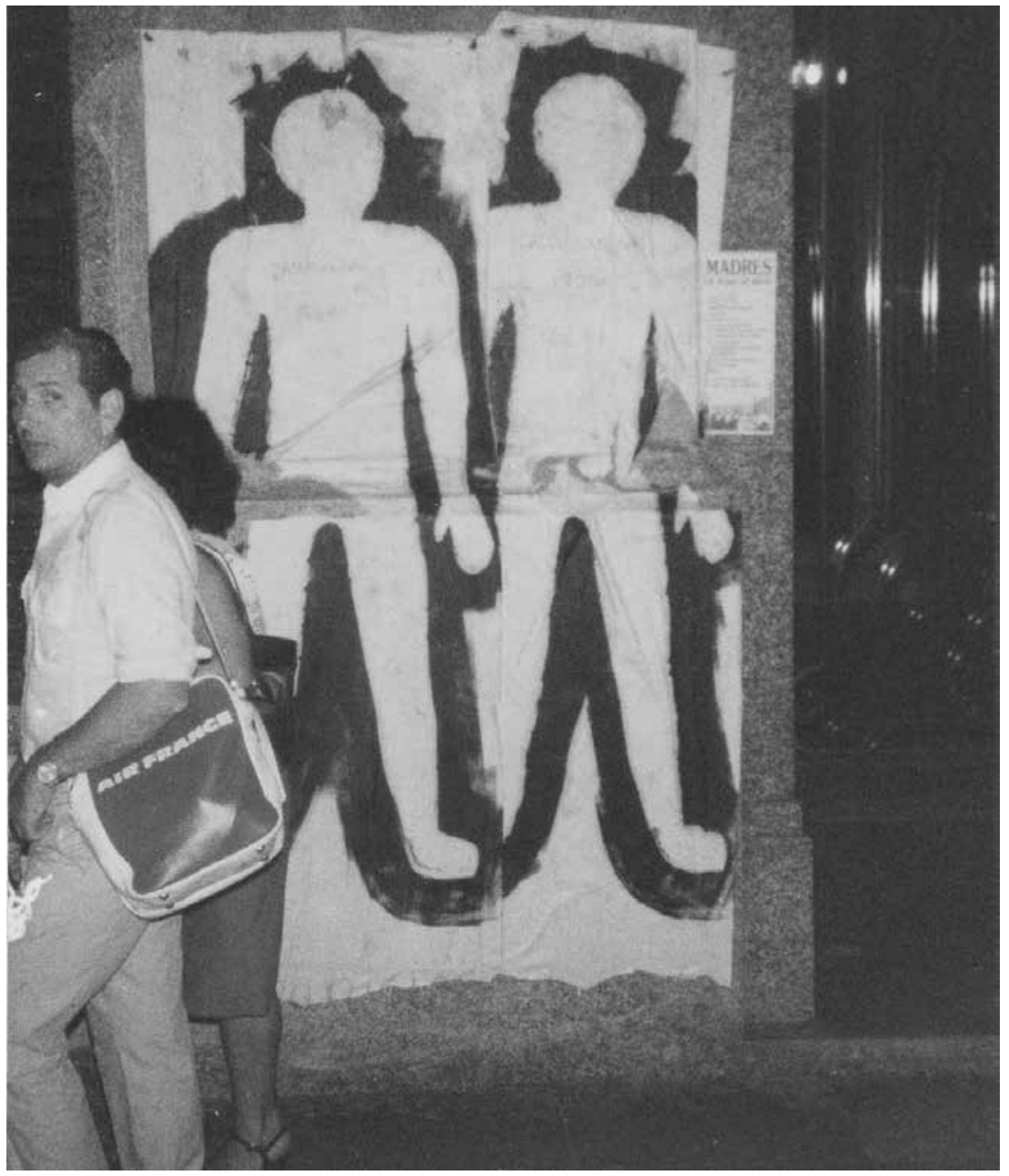

Figure 4.1. First Siluetazo, 20-21 September 1983. Two silhouettes on an urban wall. The two silhouettes have identifying labels but the image is blurred and the names are hard to distinguish. Photograph courtesy of Edward Shaw.

ground, hoping that others would join them. And so, they did. Within hours, 'the Plaza turned into an improvised and gigantic workshop' (Longoni 2007). The fervour of fellow activists, who had gathered for the march, as well as those of the passers-by exceeded their expectations by far. The initial plans to create uniform bodies were crushed by the spontaneous initiatives of members of the public, who adapted pre-prepared figures or traced new ones in order to better represent the physical traits of their own disappeared relatives. Longoni notes that Grandmothers who joined the march 'pointed 


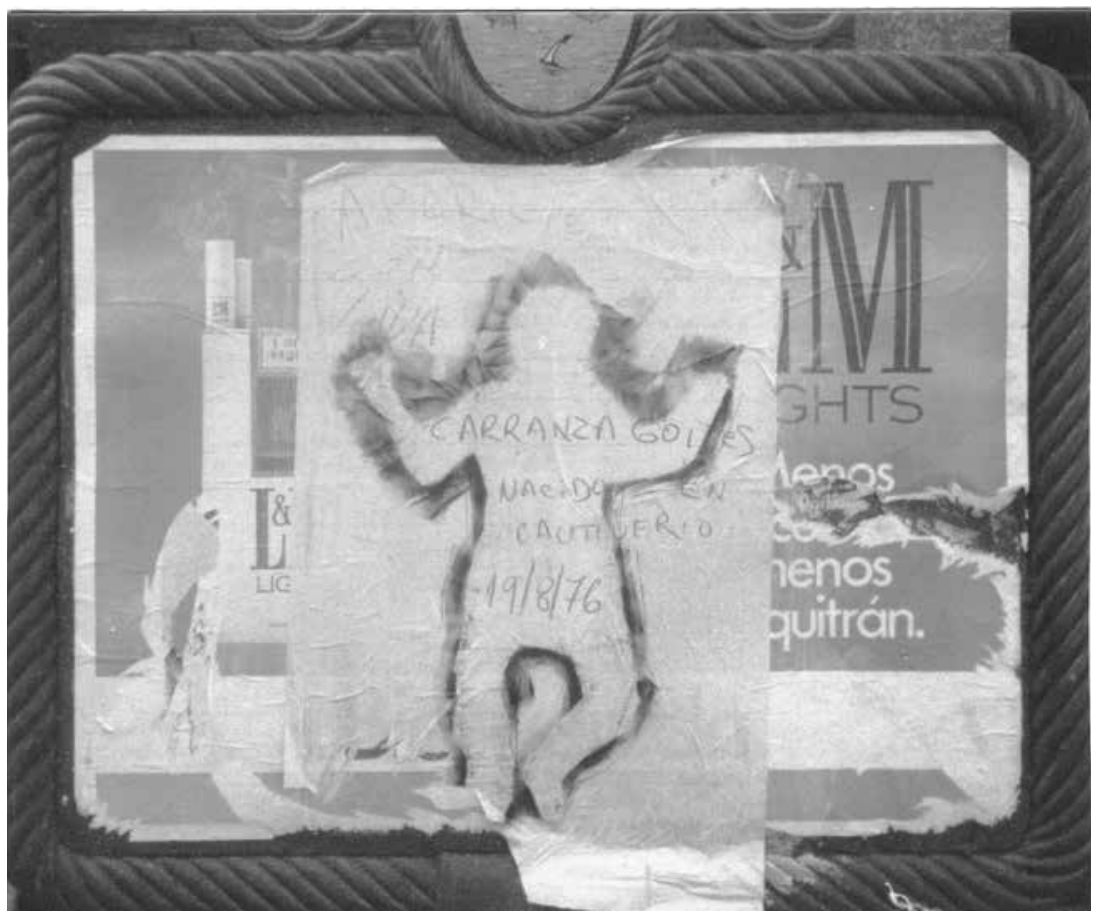

Figure 4.2. First Siluetazo, 20-21 September 1983. Silhouette of a baby/toddler on an urban wall. This silhouette represents a child born in captivity, Carranza-Goites, born on 19 August 1976. Photograph courtesy of Edward Shaw.

out that children and pregnant women should also be represented [and so] Kexel tied a pillow to his stomach and his body profile was sketched for the silhouette. His daughter served as a model for the silhouette of a child. Babies were drawn freehand'. The workshop ran until the early hours of the next day, with children lending their bodies to be traced in representation of missing youngsters and adults cooperating to help one another represent the 'absented' bodies of their friends, colleagues, family members. The result was an unparalleled visual spectacle, which has since become inscribed in the collective memory of the nation through re-enactments and exhibitions (Godoy Vega 2014; Argentine Ministry for Education 2011).

Marking a temporary pause or break in the urban visual landscape and repressive atmosphere maintained by the regime, El siluetazo recaptured the public space of the Plaza de Mayo so powerfully that the action was repeated across other locations in Buenos Aires in the months to follow. This was at least partly due to the easy replicability of the silhouettes. However, the ubiquity of loss was also crucial in fuelling these ongoing actions. Longoni 
(2007: 3) summarizes that El siluetazo's 'remarkable impact was due not only to its mode of production (the demonstrators lent their bodies for hundreds of artists to outline their contours, which in turn came to stand for each of the disappeared) but also to the effect achieved by the crowd of silhouettes whose voiceless screams addressed passers-by from the walls of downtown buildings the following morning. Longoni here attributes a performative power to the silhouettes. They did not merely mirror or describe the prevailing political conditions. Rather the presence of these bodies had a constitutive force. As more and more people took up the opportunity to produce figures that represented their lost loved ones, the more that the true extent of state brutality revealed itself. Similarly, the more people that participated in the action, the more the others felt emboldened to do the same. In this way, El siluetazo went a long way towards breaking the pact of silent complicity with the regime, encouraging a widespread public acknowledgement of the atrocities of the Dirty War (1976-1983) and opening up political space for critique of the junta.

The artist Leon Ferrari, who participated in El siluetazo, reflects that the event was 'formidable not only politically but also aesthetically'. He relates this to

the number of elements that went into play: an idea proposed by artists, carried out by the masses without any artistic intention. It is not as if we got together for a performance, no. We were not representing anything. It was a production of what everybody felt, whose material was inside the people. It did not matter if it was art or not. (Ferrari, cited in Longoni 2007)

As Ferrari's comments indicate, El siluetazo produced an unanticipated rupture of the strategic by non-rationalised sentiment. Beginning with a carefully planned protest action, silhouette production soon took on a life and course of its own, so much so that as Aguerreberry attested 'within half an hour of reaching there we could have left the Plaza because we were not needed for anything' (ibid.). Members of the public had taken ownership of the intervention and transformed it into something that more adequately served their immediate emotional needs. In as far as the action was carried out by the masses as an expression of 'what everybody felt' the episode was powerfully cathartic. Moreover, the event itself marked a sudden and dramatic turning point in public perceptions about the political environment, the balance of opportunities and threats for activism. The sudden outpouring of anti-regime sentiment helped to tip the general mood of suspicion and fear amongst porteños. The visual materialization of so 
many bodies - of paper and flesh - on the streets signalled a newfound confidence among the populace. In so doing, it foreshadowed the restoration of democracy, renovation of public space. Most importantly, it hastened the end of the political and artistic asphyxia which had characterized the years of the Dirty War (Ryan 2017).

\section{El argentinazo}

The spectacular economic crisis which befell Argentina in 2001/2002 has received extensive academic and coverage and has been subject to much academic debate (see Levey et al. 2014). The root of that crisis can be traced back at least as far as the early 1990s and the policies adopted by President Carlos Menem and his minister for the economy, Domingo Cavallo. After decades of military rule, Menem had inherited a languishing economy. Between 1976 and 1989, GNI per capita had shrunk by more than 1\% per year. Two bouts of hyperinflation and several banking collapses had destroyed domestic and international confidence in the peso. By the start of the 1990s, Argentines preferred to use US dollars for big purchases such as houses, cars, etc. The wealthy simply moved their assets abroad. As a way of remedying this situation and curbing capital flight and hyperinflation, Economy Minister Domingo Cavallo decided to peg the value of the Argentine peso to the dollar on a one-to-one basis. This move had the effect of stabilizing the currency, but it also limited the government's scope to manage the economy in response to external events. Towards the late 1990s, Argentina found itself increasingly uncompetitive in some of its major export markets, but unable to devalue its currency as a solution. Falling export revenues were compounded by problems of government borrowing and overspend as well as rising costs of living, the latter of which resulted at least in part from the privatization of major utilities providers under Menem.

By 2001 Argentina had a huge external debt and few options for raising the necessary funds to service it. As news of the country's precarious economic situation reached investors around the world, they promptly began pulling out their cash. Argentines did the same, withdrawing some $\$ 15$ billion from the banks between July and November of that year. In order to stop the country's banks from liquidating, Cavallo imposed a cap of $\$ 1,000$ a month on domestic bank withdrawals. Known as the 'corralito', this ceiling dealt a deadly blow to smaller scale businesses and the informal service economy, which functioned primarily on cash-based transactions. With unemployment spiralling, limited access to cash for essential purchases and further austerity on the horizon, Argentines took to the streets in mass mobilizations up and down the country. These mass mobilizations were 
collectively referred to as 'El argentinazo'. A culmination of frustrations and anger on the part of ordinary Argentine citizens, the social mobilizations themselves articulated no concrete long-term political agenda or strategy. ${ }^{5}$ The rallying cry was the simple yet evocative: 'Que se vayan todos' (Throw them all out). It was an impassioned indictment of the entire political class.

As social tensions mounted in the latter half of 2001, the walls of Buenos Aires, in particular, became flooded with hastily graffitied inscriptions; spontaneous and fervent outbursts against the politicians: 'Fuera politicos' (Out, politicians) and 'Fuera Congreso' (Out, Congress). Others recalled previous failures of government to uphold the social contract: most poignantly, protestors invoked the memory and betrayal of the Dirty War with allusions to the year ' 1976 '. Alongside these inscriptions, a series of stencilled images emerged in the urban landscape. Some stencillers, like the duo Vomito Attack, attempted to project a clear anti-capitalist/anti-consumerist message through their interventions. Their appropriation of the 'Puma' logo, shot with bullets and streaming with blood, is one example of this.

However, despite being repeatedly depicted as part of a 'grassroots democratic movement' (see Lyle 2007), the political cohesion, ideological unity and sense of purpose of other individual stencillers and stencil collectives was not initially all that clear. Several practitioners have attested that prior to the crisis they would not have considered themselves activists at all: 'none of us were political activists. [In fact] none of us had ever really painted in the streets' (GG, BSASSTNCL 2011, cited by Ryan 2017). Rather than identifying an explicit political aim, ideology or strategy, many of the stencillers instead allude to an engulfing energy or 'mood' that exploded during the crisis and took them outdoors to paint:

It was in the air. [...] You would see all the people in the streets and think I just have to do something. (GG, BSASSTNCL 2011, interview with the author)

I lived downtown and everything was happening all around me. [...] [T] he City was in the mood. It was hot and no one had any money. (NN, cited by Lyle 2007)

In 2002, I started seeing on my way to work, one stencil, the next day another, and with each passing day it looked like the walls were made of mutating

5 Although it must be noted that these mobilizations later spawned forms of collective and horizontal organizing in abandoned factories, via neighbourhood assemblies and community kitchens/workshops (see Sitrin 2006, 2012). 
colours. [...] I asked myself why people would do this [i.e. spend time and money painting pictures on the walls of the city]. [...] Without ever finding the answer to that question, I cut a stencil, I bought a spray can, and that night I went out to paint. (StencilLand 2011, interview with the author)

For many of the stencillers, a political position or consciousness is something that only emerged and crystallized during the process of making and doing street art. Through the practice of expression and experimentation with colours, themes, styles, and slogans, and through the course of interacting with other stencillers on the streets they have eventually formed more decisive political ideas and attachments. In this respect, it is fair to say that the process of street art production could play a role in the constitution of political identity and subjectivity.

Chandra Morrison (2008) similarly recounts interviews with Argentine stencil makers whose motivations to come out in the street were initially articulated in terms of a sensed need to produce, to actualize, to participate, or 'to do something' in wake of the crisis. This impulse to act and to actualize a 'feeling' through artistic expression is something ill-explained by reference to rationalist/structuralist modes of social analysis. As Sara Ahmed (2001: 11) highlights, emotions 'do things' both inside and outside of the body. Emotional encounters can 'align individuals with communities - or bodily space with social space - through the very intensity of their attachments'. Artistic or aesthetic expression as an expression of feeling is one step in the mediation and emergence of these attachments; it becomes part of the process through which affective intensities are recognized as particular emotions and made socially or politically meaningful. Street art production within and against the backdrop of social mobilizations can therefore be understood as something more than a medium for conveying narrowly conceived and/or propagandist messages. Street art production can and should be understood as a psycho-social and performative process that can help individuals and communities to renew their social attachments and make sense of situations and phenomena.

Beyond the anti-consumerist messages of Vomito Attack, the subject matter of the stencils ranged from the ironic and playful to the surrealist and the absurd. In one stencil, 'an image of the sinking Titanic appeared to link the prospects for the Argentine economy to that of the ill-fated ship. The accompanying phrase "se cayó el sistema" [the system is down] invoked the computer speak, often heard in Argentina's banks as well as other service outlets where processing equipment routinely failed to operate, leading to long queues of hot, disgruntled customers' (Lyle 2007, cited by 
Ryan 2017). In another, the face of former US President George W. Bush was crowned with a pair of Mickey Mouse ears and accompanied by the slogan 'Disney War'. In a similar mischievous style, StencilLand's 'El David', translated Michelangelo's statue of David the giant-slayer into a stencil and placed a kettle and gourd of yerba mate - a popular traditional tea drunk in Argentina - in his hands. The iconography of this stencil might be readily interpreted as an expression of Argentine national sovereignty vis-à-vis the 'Goliath' of the global capitalist system, the United States or international financial institutions. Yet, when questioned about his works, StencilLand refutes the idea that there is a fixed message or ideal 'take away':

[B]ehind each of my images is a much darker or twisted story. [...] I do not intend to relay a message, I do not expect that the viewer 'understands' my ideas exactly; that is not my goal. The main target of my stencils is me. I enjoy the different stages of the process: sketching ideas in a notebook, taking a design from the PC, cutting the templates and then painting. Commonly this combination is what I enjoy. It may be the case that my work leaves a taste of dissent, but it is rather something internal, perhaps my own self-criticism [and] that is transformed into an 'engine' which brings me back to continue designing. (Author's translation)

Running contrary to the more 'mimetic' analyses of collective action frames, which tend to suggest that political art will 'resonate' only if it delivers a clear and empirically verifiable message about an injustice of some kind, StencilLand gestures towards a deliberate ambiguity. The concept of ambiguity refers to an uncertainty of meaning in which several different interpretations of a word, phrase, event, image or composition are possible. The presence of ambiguity in street art is something that invites the viewer into the creative process. It encourages the viewer to look for some of the answers for them self. In so doing, it can not only engage the onlooker on an aesthetic level. It can also work in a full circle to foster and elicit critical thinking, helping to raise political consciousness without presenting the viewer with a ready-made political paradigm. In this respect, the use of playful, ambiguous stencils can be seen as a reflection of the profound depth of the political crisis embodied in the phrase 'Que se vayan todos'. All the ready-made political paradigms had been trialled and failed. Street artists like StencilLand, through their interventions in the public space, called on citizens to break with existing repertoires and frameworks for understanding and rather offered them a cue to find new political and social meanings within and among themselves. 


\section{Conclusion}

El siluetazo and El argentinazo occurred in the same urban landscape of Buenos Aires, separated by nearly two decades during which the newly democratized political system in Argentina produced sequential governments committed to the neoliberalization of the economy. El siluetazo occurred during the final phases of the brutal Argentine dictatorship. It was prompted by artists' and activists' desires to confront and call attention to the scale of state-sponsored violence and the failure of the regime to uphold citizens' fundamental rights. El argentinazo meanwhile expressed a collective sense of indignation at an elite political class which had emerged from the ashes of the dictatorship, instituted harsh economic adjustments at the behest of the international financial institutions and ultimately steered the country into an intractable crisis. In both cases, there was an 'outpouring' of artistic and creative content in public spaces, lending a strong visual character and presence to the protests. In both cases, initial actions in Buenos Aires were followed by copycat actions in other major Argentine cities.

By revisiting these two episodes of street art 'outpouring', this chapter has attempted to demonstrate the pervasive political utility of street art over time and illuminate some of the analytical gaps and grey areas that exist within the extant scholarship on art, aesthetics and social mobilization. In particular, it aims to push beyond reductive rationalist accounts of the role of art in social movements, instead arguing for an approach that is better attuned to the complex and sometimes unpredictable interplay of affect and performativity that shapes the aesthetics of protest(s). This complexity is well evidenced in the example of El siluetazo. Here, a meticulous plan for a particular kind of action and visual output was distorted and amplified by the sheer intensity of collective desire for the reaparición (reappearance) of the disappeared. As activists produced more and more silhouettes, the true scale of state-sponsored terror began to materialize in an eerie visual form. Without words and without sound, the silhouettes' presence served as a public and inescapably damning indictment of the junta. The collaborative mood fostered by those coming together to draw the silhouettes also played a role in shifting perceptions of danger attached to collective organization and political action. Thus, the episode as a whole can be regarded as a performative one, helping to erode the fear and suspicion that the military government had so effectively cultivated as a means of controlling the Argentine population and suppressing democratic practice. The more recent example of stencils produced in the aftermath of the 2001 economic crisis further revealed some of the indeterminacies and contingencies involved 
with the analysis of art in social mobilization. Interviews conducted with several of the most prominent stencillers of the period reveal a group whose political opinions were far from fully formed at the outset of the crisis but whose commitments were gradually constituted through expressive, creative and communicative acts involved with the production of stencils. Finally, exploring the work of StencilLand, the chapter also highlighted the unlikely utility of ambiguity within street art. Namely, the ways that surreal, playful juxtapositions can help to spur critical thinking and raise political consciousness without imposing a particular ideology or creed on the viewer.

\section{References}

Adams, Jacqueline. 2002. 'Art in Social Movements: Shantytown Women's Protest in Pinochet's Chile', Sociological Forum 17(1): 21-56.

Ahmed, Sara. 2001. 'Communities that Feel: Intensity, Difference and Attachment', in Affective Encounters, ed. Anu Koivunen and Susanna Paasonen, 10-25. Turku: University of Turku Press.

Amnesty International. 2018. 'Enforced Disappearances'. https://www.amnesty. org/en/what-we-do/disappearances/. Accessed 12.03.19.

Argentine Ministry for Education. 2011. 'Educación y memoria - 24 de Marzo: Día de la Memoria por la Verdad y la Justicia: Construcción de la memoria’. http:// educacionymemoria.educ.ar/primaria/category/construccion-de-la-memoria/ index.html. Accessed 12.03.19.

Belfiore, Eleonora, and Oliver Bennett. 2008. The Social Impact of the Arts. Hampshire: Palgrave Macmillan.

Bennett, Jill. 2012. Practical Aesthetics: Events, Affect and Art after 9/11. London: I.B. Tauris.

Bleiker, Roland. 2009. Aesthetics and World Politics. London: Palgrave Macmillan.

Bleiker, Roland. 2018. 'Aesthetic Turn in International Relations'. Oxford Bibliographies, 27 June. doi:10.1093/OBO/9780199743292-0236. Accessed 12.03.19.

Blustein, Paul. 2005. And the Money Kept Rolling In (and Out). New York: Public Affairs. Caren, Neal. 2007. 'Political Process Theory', in Blackwell Encyclopedia of Sociology, ed. George Ritzer. London: Blackwell.

Carroll, Noël. 1996. 'Moderate Moralism', British Journal of Aesthetics 36(3): 223-239.

Carroll, Noël. 2001. Beyond Aesthetics: Philosophical Essays. Cambridge: Cambridge University Press.

The Economist. 2002. 'Argentina's Collapse: A Decline without Parallel', The Economist, 28 February. https://www.economist.com/special-report/2002/02/28/adecline-without-parallel. Accessed 12.03.19. 
Fisher, Jo. 1989. Mothers of the Disappeared. Cambridge, MA: South End Press.

Garreton, Manuel, Antonio. 1992. 'Fear in Military Regimes: An Overview', in Fear at the Edge: State Terror and Resistance in Latin America, ed. Juan E. Corradi and Patricia W. Fagen, 13-25. Berkeley: University of California Press.

Godoy Vega, Francisco. 2014. 'Restaging in Order to Activate Living Memory', L'internacionale, 19 November. Available from: http://www.internationaleonline. org/opinions/39_restaging_in_order_to_activate_living_memory, Accessed 12.03.19.

Goffman, Erving. 1959. The Presentation of Self in Everyday Life. Garden City, NY: Anchor Press.

Goodwin, Jeff, and James M. Jasper. 1999. 'Caught in a Winding, Snarling Vine: The Structural Bias of Political Process Theory', Sociological Forum 14(1): 27-54.

Goodwin, Jeff, James M. Jasper, and Francesca Polletta. 2009. Passionate Politics: Emotions and Social Movements. Chicago: University of Chicago Press.

Jasper, James. M. 1998. 'The Emotions of Protest: Affective and Reactive Emotions in and around Social Movements', Sociological Forum 13(3): 397-424.

Jasper, James. M. 2008. The Art of Moral Protest: Culture, Biography, and Creativity in Social Movements. Chicago: University of Chicago Press.

Jenkins, J. Craig. 1983. 'Resource Mobilization Theory and the Study of Social Movements', Annual Review of Sociology 9(1): 527-553.

Johnston, Hank, and Bert Klandermans, eds. 1995. Social Movements and Culture. London: Routledge.

Levey, Cara, Daniel Ozarow, and Christopher Wylde. 2014. Argentina since the 2001 Crisis: Recovering the Past, Reclaiming the Future. London: Springer.

Longoni, Ana. 2007. 'El Siluetazo (The Silhouette): On the Border between Art and Politics', in Sarai Reader o7: Frontiers, ed. Monica Narula, Shuddhabrata Sengupta, Jeebesh Bagchi, and Ravi Sundaram, 176-186. Delhi: Centre for the Study of Developing Societies. http://archive.sarai.net/files/original/oo6ea358 66a5aado475949b419c63462.pdf. Accessed 12.03.19.

Longoni, Ana, and Gustavo Bruzzone. 2008. El Siluetazo. Buenos Aires: Adriana Hidalgo.

Lyle, Erick. 2007. 'Shadows in the Streets: The Stencil Art of the New Argentina', in Realizing the Impossible: Art against Authority, ed. Josh MacPhee and Erik Reuland, 76-103. Edinburgh: AK Press.

McAdam, Doug. 1996. 'Political Opportunities: Conceptual Origins, Current Problems, Future Directions', in Comparative Perspectives on Social Movements, ed. Doug McAdam, John D. McCarthy, and Mayer N. Zald, 23-40. Cambridge: Cambridge University Press.

McAdam, Doug, and Yang Su. 2002. 'The War at Home: Antiwar Protests and Congressional Voting, 1965 to 1973', American Sociological Review 67(5): 696-721. McCarthy, John D., and Mayer N. Zald. 1977. 'Resource Mobilization and Social Movements: A Partial Theory', American Journal of Sociology 82(6): 1212-1241. 
Melucci, Alberto. 1994. 'A Strange Kind of Newness: What's "New" in New Social Movements?', New Social Movements: From Ideology to Identity, ed. Enrique Laraña, Hank Johnston, and Joseph R. Gusfield, 101-13o. Philadelphia: Temple University Press.

Moore, Cerwyn, and Laura J. Shepherd. 2010. 'Aesthetics and International Relations: Towards a Global Politics', Global Society 24(3): 299-309.

Morris, Aldon D. 1986. The Origins of the Civil Rights Movement. New York: Simon and Schuster.

Morrison, Chandra. 2008. 'Do-It-Yourself: Stencil Art, Generational Media, and (A) Political Engagement in Buenos Aires', paper presented at the Society for Latin American Studies Annual Conference.

Museo de Arte Contemporáneo de Rosario. 2009. El siluetazo. http://www.macromuseo.org.ar/coleccion/artista/e/el_siluetazo.html. Accessed 12.03.19.

Panagia, Davide. 2009. The Political Life of Sensation. Durham, NC: Duke University Press.

Rancière, Jacques. 2004. The Politics of Aesthetics: The Distribution of the Sensible, trans. Gabriel Rockhill. London: Continuum.

Ryan, Holly Eva. 2017. Political Street Art: Communication, Culture and Resistance in Latin America. London: Routledge.

Sitrin, Marina. 2006. Horizontalism: Voices of Popular Power in Argentina. Edinburgh: AK Press.

Sitrin, Marina. 2012. Everyday Revolutions: Horizontalism and Autonomy in Argentina. London: Zed.

Tarrow, Sidney. 1993. 'Social Protest and Policy Reform: May 1968 and the Loi d'orientation in France', Comparative Political Studies 25(4): 579-6o7.

Tarrow, Sidney. 1998. Power in Movement: Social Movements and Contentious Politics. Cambridge: Cambridge University Press.

Tilly, Charles. 2008. Contentious Performances. Cambridge: Cambridge University Press. Zald, Mayer N., and John D. McCarthy. 1979. Social Movement Industries: Competition and Cooperation among Movement Organizations. Oxon: Taylor and Francis.

\section{About the Author}

Holly Eva Ryan is a Lecturer in the School of Politics and International Relations at Queen Mary University of London. Her research is situated at the intersections of international politics, social movement studies, and aesthetics. 


\title{
5 Archiving Dissent: (Im)material Trajectories of Political Street Art in Istanbul and Athens
}

\author{
Julia Tulke
}

\begin{abstract}
In Athens and Istanbul, two cities that have emerged as epicentres of protest within the broader conjuncture of contemporary political mobilization across the Mediterranean, the transformative potential of political street art has become particularly evident. Staging a dialogic encounter between the two cities, this chapter examines how in each case interventions into public space as well as their circulation in the digital realm create, according to Can Altay, 'hybrid space[s] of resistance' that sustain political performances both grounded in the real world and beyond. Attentive to the resonances as well as the differences between the two cities and their respective political configurations, I reflect on manifestations of political street art in the context of contemporary social movements.
\end{abstract}

Keywords: protest, political street art, urban space, right to the city, Athens, Istanbul

\section{Introduction}

As contemporary social movements have come to rely increasingly on visual and performative registers of protest (McGarry et al., this volume; Weibel 2015; Doerr et al. 2013; Firat and Kuryel 2010), political street art has emerged as one of the most important modes of fostering and disseminating a shared aesthetics of resistance. ${ }^{1}$ Whether graffitied slogans or large murals, stencils

1 Following the work of Lyman G. Chaffee and its adoption by Holly Eva Ryan, I here take up the term 'political street art' as a broad and inclusive concept that encompasses all self-authorized

McGarry, A., I. Erhart, H. Eslen-Ziya, O.Jenzen, U. Korkut (eds), The Aesthetics of Global Protest: Visual Culture and Communication. Amsterdam: Amsterdam University Press, 2020 DOI 10.5117/9789463724913_CHO5 
or posters, creative interventions into public space have the potential to stage meaningful encounters between city dwellers and the urban landscape they inhabit, inscribing alternative histories and possibilities into the very surface of the city. A careful and situated reading of political street art can in turn offer critical insights into the social composition, grievances, and affective ambiance of a given moment of protest (see Ryan, this volume). As political scientist Lyman G. Chaffee argues in his formative 1993 book Political Street Art: Popular Tools for Democratization in Hispanic Countries: 'Street art, in essence, connotes a decentralized, democratic form in which there is universal access, and the real control over messages comes from the social producers. It is a barometer that registers the spectrum of thinking, especially during democratic openings' (ibid.: 4).

In Athens and Istanbul, two cities that have emerged as epicentres of protest within the broader conjuncture of contemporary political mobilization across the Mediterranean, the transformative potential of political street art has become particularly evident, signalling towards a productive connection between space, politics, and creative intervention. The 2013 Gezi Park uprising in Istanbul was accompanied by a surge of political street art as protestors took to the walls of the city to express their mounting discontent, and claim the urban landscape as a site of participatory democratic encounter. Similarly, the city of Athens witnessed a proliferation of political street art in alignment with the anti-austerity movement that formed in response to the complex state of crisis that Greece has been subjected to since 2010. In both cases, protestors not only performatively engaged the material landscape of the city through paint and paper, 'animat[ing] and organiz[ing] the architecture' in an effort to create an embodied public (Butler 2015: 71). As slogans, posters, stencils, and murals were photographed, shared, and circulated through social media infrastructures, these interventions also came to resonate beyond their immediate context as part of a mobile, transnational political aesthetics. $^{2}$

interventions into public space, including (but not limited to) 'posters, wallpaintings, graffiti, and murals' (Chaffee 1993: 4).

2 Following the trajectory laid out by the editors, the term 'aesthetics' is here used not in the sense of a normative (Kantian) judgement of visual qualities, but rather as a political category as described by Jacques Rancière: 'It is a delimitation of spaces and times, of the visible and the invisible, of speech and noise, that simultaneously determines the place and the stakes of politics as a form of experience. Politics revolves around what is seen and what can be said about it, around who has the ability to see and the talent to speak, around the properties of space and the possibilities of time' (2004: 8). 
Staging a dialogic encounter between Athens and Istanbul, this chapter examines how in each case interventions into public space as well as their circulation in the digital realm create 'hybrid space[s] of resistance' (Altay 2015: 203) that sustain political performances both grounded in the real world and beyond. Attentive to the resonances as well as the differences between the two cities and their respective political configurations, I reflect on manifestations of political street art in the context of contemporary social movements, paying close attention to their material oscillation between physical and digital space.

I will begin my inquiry with a general discussion of the spatial politics of street art within the framework of 'right to the city' activism. Following this conceptual framework, I move towards my case studies. A close reading of one specific site in Athens - the memorial for Alexis Grigoropoulos and Berkin Elvan - will serve as my point of departure, establishing the two cities as part of a shared aesthetic landscape of protest. The following two sections will offer brief descriptions of political street art in Istanbul and Athens, attending to both current manifestations and historical precedents. Pulling both cases back together, the final section will then trace material and immaterial trajectories of political street art in Athens and Istanbul and consider some of the broader questions of materiality, erasure and circulation they bring forth.

\section{Reclaiming the City and Beyond: The Spatial Politics of Street Art}

As a medium whose significance is fundamentally dependent on its claim to public space, political street art must be understood as part of a broader ecology of 'right to the city' activism (Tulke 2013: 12; see also Zieleniec 2016). Coined by the French theorist Henri Lefebvre, the 'right to the city' denotes the right of urban citizens to collectively participate in the creation of cities according to their own needs and desires - a notion that has gained considerable currency in contemporary city-based social movements (Harvey 2012: 4). The concept relies on an understanding of space as mutable and socially constructed, a product of the dialogic interaction between institutions, planning paradigms, and city dwellers. According to Lefebvre, this social production of space assumes the shape of a triad, consisting of spatial practice (espace perçu), the organizing principle of a society, representations of space (espace conçu) expressed in patterns of planning and design, and representational space (espace vecu), the lived and imagined everyday experience of urban dwellers (Lefebvre 2009). Urban space is thus at the 
same time deeply permeated by power relations and technocratic governance, but also open to appropriation and reinterpretation; the unstable trialectic of spatial production constantly produces ruptures in the urban fabric that have the potential to become strategic sites of appropriation for marginalized actors.

Based on this understanding of space, the political significance of street art as a cultural practice unfolds on three interrelated levels. ${ }^{3}$ On the most basic level, all self-authorized works of street art, regardless of their explicit intent or underlying political motivation, represent a semantic intervention into the visual configuration of the city that implicitly contests dominant notions of what urban space should look like, questioning public ownership and representational regimes. On a more concrete level, street art may become politically significant through its encrypted messages and the strategic contextualization by the artist. Finally, as the work on the wall circulates beyond the embodied performance of the artist (Pabón-Colón 2018: 20) it also generates alternative channels of communication and fosters meaningful encounters between urban dwellers and the material landscapes they inhabit - a function that is potentially amplified when photographic traces of political street art are circulated digitally.

Political street art is thus never merely a static representation of its given sociocultural context but has the potential to actively transform urban space and reimagine everyday life by inscribing alternative histories and possibilities into the very surface of the city. The imperative for social transformation is always already latent in any visual expression or performance in public space, constituting what social theorist Michael Warner would call acts of poetic world-making, that is, 'all discourse and performance addressed to a public must characterize the world in which it attempts to circulate, projecting for that world a concrete and liveable shape, and attempting to realize that world through address' (Warner 2002: 81). It follows that analyses of political street art must always operate dialectically, engaging with methodologies that are object-based - looking at visual artefacts and the historical, political, and affective narratives and iconographies they contain - as well as in ones that attend to the performative, affective, and embodied aspects of the practice (see Ryan, this volume).

3 My typology of the political significance of street art, first laid out in Tulke (2013), is influenced by and indebted to a number of interdisciplinary contributions to the emerging field of graffiti and street art studies, most notably, Baudrillard (1993), Chaffee (1993), Deutsche (1992), Dickens (2008), and Schacter (2014). 


\section{From Alexandros to Berkin: Memory, Space, and Belonging}

At the heart of Exarcheia, the 'anarchist fortress' (Vradis 2012: 88) of Athens, lies Tzavella Street, a pedestrian road measuring the length of three blocks, enclosed by walls densely saturated with posters, slogans, and portraits of struggle, all of which appear to trace back to one corner. Here, at the intersection of Tzavella and Mesologgiou, two black plaques are mounted onto the thick layers of paint and paper (fig. 5.1). The one on the left shows the photo of a young boy in a black sweatshirt, his gaze inquisitively directed back at the photographer. Next to his likeness, an inscription in Greek letters reads: 'Here, on 6 December 2008 without any purpose, the innocent child's smile of fifteen-year-old Alexandros Grigoropoulos was extinguished by the bullets of unrepentant murderers.' To his right, another plaque is adorned with the photograph of a teenage boy seemingly in the midst of a demonstration, a red scarf wrapped around his mouth and nose, his hands forming victory signs in the air. Next to the image, first in Greek, then in English, is written:

Berkin Elvan. During the June Uprising in Istanbul, fourteen-year-old Berkin Elvan was seriously wounded by police [...]. He received a head injury from a tear gas canister and was in a coma for 269 days. Every day there were actions to announce his situation to the world. When he died, three million people took part in his funeral. [...] Alex and Berkin are symbols of the struggle. Their memory lives on in our struggle!

The impromptu memorials dedicated to the deaths of Alexandros Grigoropoulos in Athens 2008 and Berkin Elvan in Istanbul 2014 not only index two of the most important moments in the recent political history of both cities, they also connect them across spatial and temporal boundaries through a shared iconography of protest. Due to the uncanny (and unfortunate) similarities in the circumstances of the two incidents - both boys were killed at the hands of police at about the age of fifteen during times of political rupture - protestors in Athens and Istanbul have performatively woven together their image in solidarity and support of each other's struggle (Taş and Taş 2014b: 343).

The killing of Grigoropoulos on 6 December 2008 in Athens - the selfidentified anarchist was shot during a scuffle with two police at the very site of the memorial - launched the biggest uprising in the post-dictatorial era (Vradis 2009). Riots erupting out of the urban core of Exarcheia unfolded along pre-existing structures and geographies of resistance, and over the 


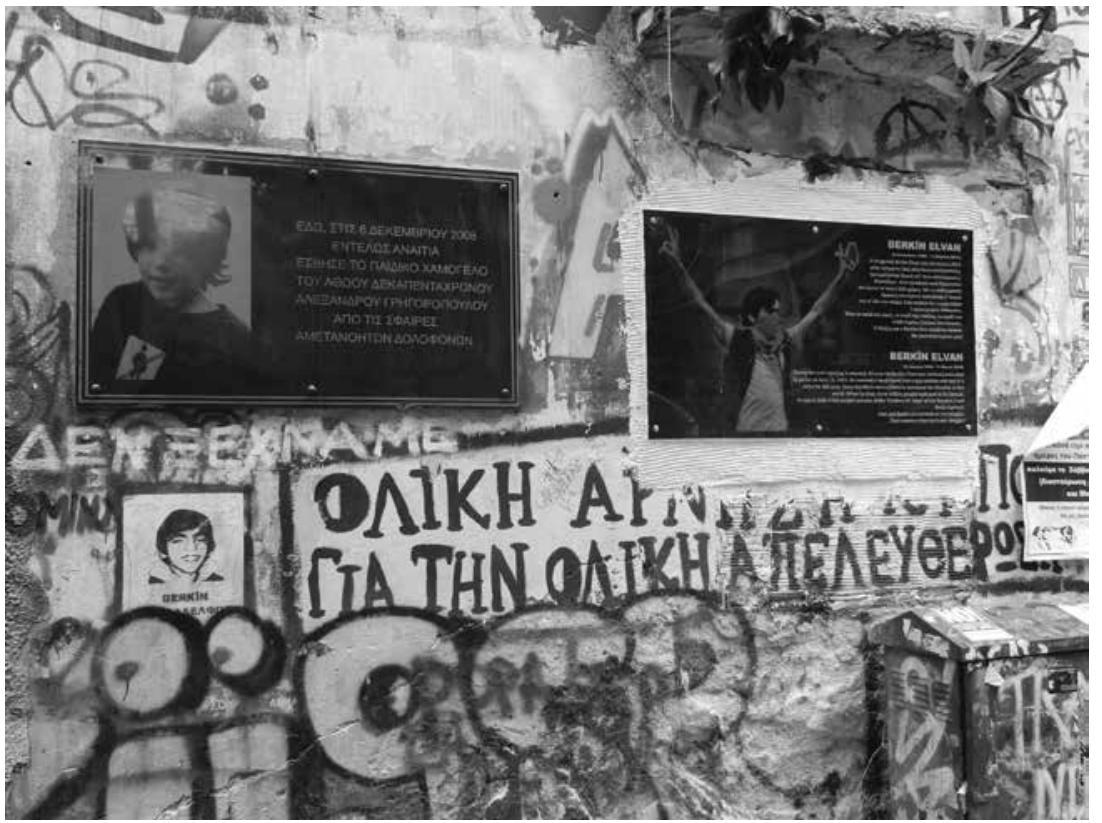

Figure 5.1. Memorial for Alexandros Grigoropoulos and Berkin Elvan in AthensExarcheia, 2015. Photography by the author.

course of a few days spread to include the whole city. Demonstrations and clashes continued well into 2009. The repertoire of the uprising did not only include rioting and protest marches, but also creative modes of spatial occupation, notably political street art. The walls of the city emerged as a space for negotiating collective responses to the death of Grigoropoulos. Expressions of anger and outrage, mostly assuming the form of anarchist and anti-police slogans, were joined by displays of mourning and memorialization (Stavrides 2017). While the uprisings of 2008 and 2009 eventually receded, the 'December spirit' and aesthetics forged during those months carried over into the anti-austerity movement that gathered momentum during the following years. The angry and raw slogans of 2008 and 2009 expanded into a complex visual economy, which I have elsewhere described as 'aesthetics of crisis': a palimpsest of poetic scribbles, portraits of protest and struggle, and expressive depictions of everyday life under the prolonged state of emergency (Tulke 2013, 2016).

Whereas in Athens it was the death of Alexis Grigoropoulos that sparked an uprising, several years later the Gezi Park movement in Istanbul was already in motion when Berkin Elvan sustained the injury that eventually took his life. He was out buying bread during the protests when he was struck 
in the head by a tear gas canister. ${ }^{4}$ As one of several 'martyrs' of the Gezi uprising, Elvan became one of the most recognizable icons of the movement, his name and image painted on banners and surfacing repeatedly on city walls in Turkey and beyond (Gruber 2017).

While it is not my intention here to offer a detailed reading of Alexis Grigoropoulos and Berkin Elvan as icons of protest, I recognize in the wall memorial described above a meaningful point of departure for reflecting on political street art in Athens and Istanbul. Not only does it explicitly establish a connection between the two cities, it also illustrates the potential of political street art to imbue public space with new meanings and transformative potentials. Mounting the memorial of Alexis at the site of his killing serves to sustain the spirit of resistance at its very point of origin, keeping the struggle visible beyond the temporal boundaries of the actual uprisings. It also prompts questions of collective belonging and ownership of public space as Exarcheia is reclaimed as a site of mourning and resistance, but 'as a space for meeting and 'doing' life in the city, [rather than] a place of death for its inhabitants' (Makrygianni and Tsavdaroglou 2011: 45). The later juxtaposition of a memorial for Berkin Elvan in the same space emphasizes the continued relevance and resonance of Alexis' death within a transnational landscape of protest and struggle, gesturing towards a political aesthetics rooted in mutual solidarity in which affectively imbued images are both deeply embedded into space, but also attain new meanings through constant circulation. Departing from the image of Berkin and Alexis, the following two sections will trace the emergence and significance of political street art in contemporary Athens and Istanbul.

\section{Of Tear Gas and Penguins: The Political Street Art of the Gezi Park Uprising}

When in summer 2013, a small environmental protest against the destruction of Istanbul's Gezi Park for the sake of a monumental project of neoliberal urban renewal exploded into the most forceful uprising of modern Turkish history (Aytekin 2017: 192), political street art immediately emerged as one of the most powerful mediums of expression for the protestors. Spreading laterally from Taksim Square, which quickly manifested as the focal point of protests and finally a ten-day occupation, slogans and stencils densely

4 The narrative of the 'innocent boy' has been actively contested, as both the police and Erdoğan have accused Elvan of being affiliated with violent terrorist groups (see BBC 2014). 


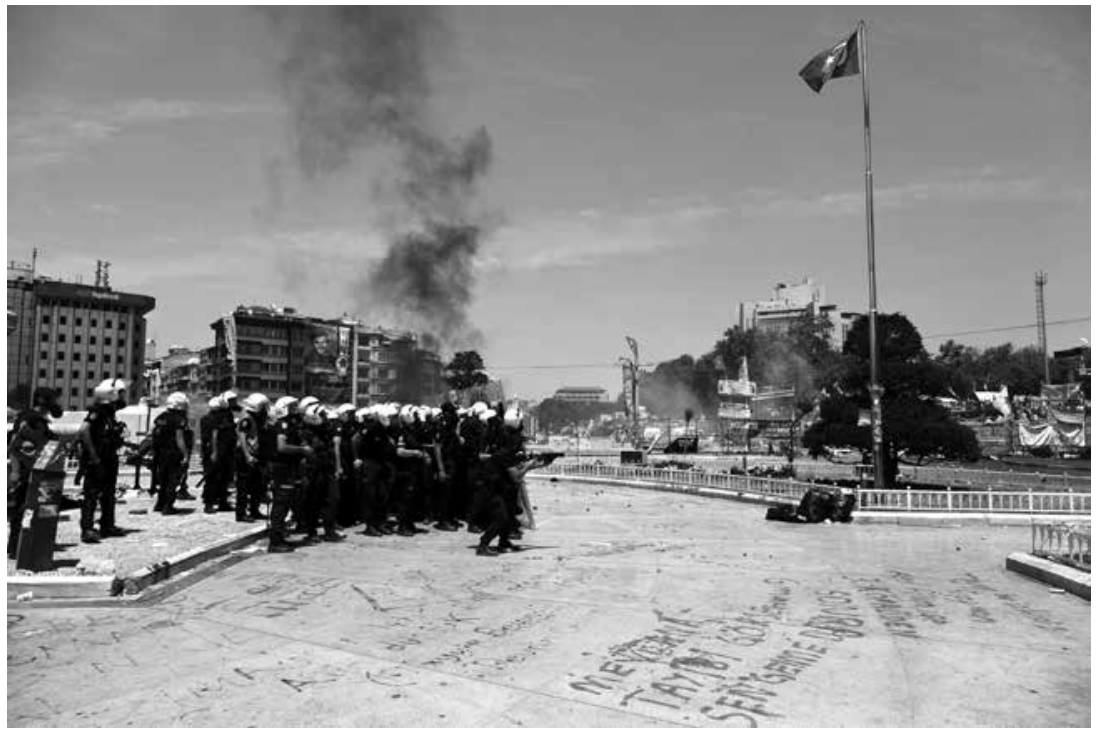

Figure 5.2. Graffiti slogans on the floor of Taksim Square during the Gezi protests, 11 June 2013. Photograph by Eser Karadağ via https://flic.kr/p/eJQdsv.

covered the walls and floors of central Istanbul within just a matter of days (see figure 5.2), collectively laying a claim to public space, acting as what art historian Christiane Gruber has called highly visible agents for resistant place-making' (Gruber 2018: 84). Barricades that were erected around the square using appropriated materials such as bricks, police barriers, and burned out trucks, equally became canvases for political expression (Ertür 2016).

Early on, the mobilization had to contend with heavy police repression, resulting in a broad solidarization of Turkish society:

Public places were occupied in 79 cities; police used 3,000 tons of pressurized water and 150,000 tear gas grenades to disperse the protestors. As a result, six protestors and a police officer lost their lives and around 7,500 people were injured - 200 severely; the number of people taken into custody exceeded 3,00o. (Aytekin 2017: 192)

As has been widely documented, the cultural practice of political street art, mostly assuming the shape of anonymous inscriptions, flourished in response to this exceptional level of state opposition, a hallmark of what would be dubbed the 'Gezi spirit' - a new type of collectivity based on 'the enactment of solidarity rather than a collective identity' (McGarry et al., 
this volume). This spontaneous street-level discourse thrived on a distinct use of tactical humour (Kaptan 2016: 568). Rather than posting collective demands, or performing their allegiance to specific political ideologies, protestors subverted and parodied the status quo through witty messages. Countless slogans mocked the excessive use of tear gas by the police force, proclaiming: 'Oh, Biber!' (biber being the Turkish word for tear gas); 'Dude, this gas is awesome!' (Bu gaz bir harika dostum!); 'Another serving of gas, please' (Bir porsiyon gaz, luften); 'Bro, you are really making us tear up' (Polis kardeş gerçekten gözlerimizi yaşartıyorsunuz); 'If we were scared of gas, we wouldn't fart' (Gazdan korksaydık osurmazdık); or 'Tear gas beautifies' (Biber gazi cildi güzellestirir) (see Kaptan 2016; Morva 2016; Gruber 2013; Bektas 2013). Other slogans made light of the inadequate response by the then prime minister (now the president) Recep Tayyip Erdoğan to the Gezi Park movement. After he pejoratively referred to the protestors as çapulcu (marauders), the term was immediately appropriated and inspired several wall writings, the most prominent of which was 'Every day I'm çapuling.' Similarly, Erdoğan's dismissal of the protestors as marjinal (marginal) members of Turkish society triggered a slogan as a response: 'Marginal is your mother, Tayyip!' (Marjinal anandır, Tayyip!) (Gruber 2018: 88). In another strategic act of appropriation, protestors elevated the penguin to an icon of resistance after CNN Turkey had aired a penguin documentary instead of reporting on the unfolding struggle at Gezi Park at a moment where violent clashes between protestors and police were covered extensively by international media. Stencils and murals of penguins, at times joined by inscriptions such as 'Antarctica Resists' (Antarktika Direniyor), came to occupy the city walls as a humorous reminder of the inadequate coverage of Turkish national television.

The majority of the humorous slogans were written in Turkish, often containing subtle intertextual references to national culture and history. Others relied on Anglophone cultural texts. 'Tayyip, winter is coming' or 'Down with Lannister' (Kahrolsun Lannister), for example, gesture towards the popular fantasy TV series Game of Thrones, implying an aesthetic connection between the medieval power struggles depicted in the series and the demeanour of Erdoğan. Others yet play on phonetic resonances between the Turkish and English language. 'The Incredible Halk' was a popular slogan that capitalized on the similarity between the Turkish halk (people) and the Marvel comic book character Hulk.

Several authors have examined this political humour of the Gezi Park protests through the work of linguist Mikhail Bakhtin, and particularly his concept of 'carnivalesque humour' (Tunali 2018; Kaptan 2016). Carnival, for 
Bakhtin, denotes a 'social space in which social and political hierarchies are temporarily suspended and people are liberated from social sanctions' (Kaptan 2016: 571-572). In this reading, seemingly benign humorous slogans and images have the capacity to produce ruptures in the status quo that are imbued with a sense of possibility of change.

Alongside expressions based in humour and wit, the walls of Istanbul also sustained more sombre messages, many of which were written in response to the excessive police repression protestors were confronted with. One popular slogan resurfacing repeatedly in several areas of the city read: 'Don't forget the police beat the people here last night' (Egemen 2015). As violent clashes claimed the life of several protestors - five young men were killed during the early weeks of the uprising alone - another visual discourse emerged paying tribute to the so-called Gezi martyrs (Gezi şehitleri) through stencils, stickers, and murals (Gruber 2017). Other icons that would frequently resurface on the walls of Istanbul included the 'woman in the red dress', modelled after a viral photograph taken by Reuters photographer Osman Orsal of a young woman in a red dress defiantly standing her ground despite getting sprayed with tear gas by police from an extremely short distance.

While the proliferation of political street art in Istanbul is often perceived to be a contemporary development, Turkey has a rich historical lineage of 'oppositional aesthetics' (Taş and Taş 2014a) that traces back to the 1968 student movement. Going out to write on walls (yaziya cikma) was an integral part of the protest repertoires of political groups at the time. In fact, '[b]efore the military coup in 1980, all the street walls in big cities such as Istanbul and Ankara were covered with political posters and graffiti' (Taş and Taş 2014a; see also Taş and Taş 2014b: 329-330). Particularly, the work of the Atelier of Revolutionary Posters, formed at the Middle East Technical University in Ankara during the 1968 student movement has been extensively documented. In 2008 Yllmaz Aysan himself a founding member of the collective, published an essay collection devoted entirely to work of revolutionary poster-makers at the time.

However, it is not only the political practice of appropriating public space creatively that has several historical precedents, but also the use of humour as a medium of dissent. As activist Ali Bektas has noted, the Gezi humour can be traced back to satirical magazines published during the 1970s:

Faced with the iron fist and gaze of military rule, these magazines developed a way of criticizing power under the cover of satire. [...] Noteworthy 
is that most of these magazines have their offices in Taksim and are intertwined with the cultural life of those streets. (Bektas 2013: 14; see also Altay 2015: 202)

In a similar vein, the Turkish folk hero Nasreddin Hoca has been cited as a point of reference for the protestors' sense of political humour. Set in thirteenth-century Anatolia, popular stories featuring the figure of Nasreddin Hoca provide a model in which 'the hierarchical social structure between the powerful and powerless [is turned] upside down, by ridiculing and despising authority figures such as tyrants, despotic sultans, and kings' (Kaptan 2016: 575).

\section{Aesthetics of Crisis: Political Street Art in Athens}

In the city of Athens, fuelled by a forceful anti-austerity movement that has formed in response to the ongoing crisis, political street art has gained enormous significance as an unsanctioned medium of public expression, rendering the city "one of the most "stained" and "saturated" [...] in the world' (Pangalos 2014: 154). Due to a lack of municipal funding, street art is only sporadically removed from the walls of the city, allowing it to sprawl unhindered and, even on highly representative public buildings, to remain visible for long periods of time (Pangalos 2014: 162). The resulting dense accumulation and elongated lifespan of public artworks have allowed for elaborate dialogues and interactions to unfold on the walls of the city over time. Ruptures created in urban space by disinvestment, austerity, and years of political struggle constantly produce new surfaces and spaces - boarded-up urban ruins, abandoned construction sites, vacant shop windows, and decaying billboards - that have become highly significant sites for creative appropriation. Moreover, the proliferation of street art is catalyzed by the un- and underemployment of large parts of the productive population, particularly the young and highly educated, which has set free a vast amount of creative potential and fostered a creative renewal in both formal and informal cultural production (Tziovas 2017).

As the context of crisis and austerity permeates all aspects of everyday life in the city, it also fundamentally shapes the form and content of the artworks that can be found on the walls of Athens. According to sociologist Myrto Tsilimpounidi, 'street art becomes a visual history of non-hegemonic voices [...] that points towards the wider sociopolitical tensions in the era of austerity and crisis' (2015: 72). The walls of the city are thus transformed 
into a living archive of the current historical conjuncture, and at the same time becoming a site for imagining new political possibilities.

Other than Istanbul, where anonymous slogans dominate the visual field, political street art in Athens encompasses a broad spectrum of formal approaches, from graffitied slogans and stencils, to paste-ups, posters, and large-scale murals. The thematic range of artworks is similarly complex. Confrontational messages written by activists affiliated with the anarchist, antifascist, and squatter movements coexist with more poetic textual interventions. Iconic portraits of gas mask-clad protestors sit next to powerful depictions of the urban precariat. Collectively these works constitute an unfolding visual body and ongoing dialogue that is constantly being rewritten. Artworks are animated and imbued with significance only through interaction with one another and with the urban dwellers that make their everyday lives among them. They offer no stable belonging. Rather, they inscribe a multitude of alternative imageries and positionalities into the urban fabric, thereby, claiming public space as a significant site for negotiating the crisis as a context for everyday life.

Several authors have traced and analysed different aspects of Athenian street art vis-à-vis the discursive and material landscapes of the crisis (see Boletsi 2016; Stampoulidis 2016; Alexandrakis 2016; Tsilimpounidi 2012, 2015; Avramidis 2012). In my own work, I have argued that what distinguishes the political street art of Athens is the prevalence of expressive depictions of human figures, which are mobilized as a site of display for the everyday effects of crisis and austerity (Tulke 2019). Such artworks depart from representations of the crisis as an abstract and disembodied economic dynamic that are characteristic of most mainstream media depictions, framing it instead as a deeply corporeal experience. By directing the viewer towards the body visibly rendered in vulnerable states - fragmented, injured, and imbued with affective negativity - they also prompt questions about subjectivity in/of crisis.

A mural painted in Exarcheia by street artist WD, for instance, shows the body of a sleeping man spanning the entire width of an apartment building. His legs are defensively drawn towards the body, while his hands are folded and directed upwards as if in prayer. There is a distinct heaviness, a certain weight to his posture, which is only emphasized by lines of dripping paint at the bottom of the piece. He is quite literally dissolving. His weathered face rests without emotion. To the left a small inscription reads: 'Dedicated to the poor and homeless here and around the globe' - a powerful commentary on the humanitarian dimension of the crisis as well as the need for transnational solidarity (see Kaika 2012). 
By making visible the shared affective condition of the crisis, political street art in Athens opens it up for interrogation. Through realistic portrayals of the corporeal and affective impact of crisis and austerity on everyday life, artists and activists claim the walls of the city as a space for emotionally processing the continuous state of exception. The task of dealing with this deeply felt precarity is typically relegated to the privacy of the domestic sphere, as demanded by what Athena Athanasiou calls the truth regime of crisis and austerity, that is, 'not only do people have to engage in a daily struggle against economic hardship and humiliation, but they are also called upon to bear all this without any sign of outrage or dissent' (Butler and Athanasiou 2013:149). By visualizing this collective vulnerability of the everyday in public space, works of street art may eventually become a meaningful basis and resource for political solidarity and community formation.

Much like Istanbul, there are several historical precedents for the contemporary proliferation of political street art in Athens, which architect Konstantinos Avramidis attributes to the city's 'turbulent past and its tolerant citizens' (Avramidis 2012: 4). Although such lineages are not consistently documented, evidence can be found scattered throughout popular culture and archival bodies. The work of documentary film-maker Alinda Dimitriou offers an unusually explicit account of the significance of political writing for resistance movements throughout the twentieth century. Between 2009 and 2012 Dimitriou directed a three-part series of oral history-style documentaries that chronicled the role of women in political activism between the 1940 s and 1970s. As the protagonists tell their stories of disobedience, struggle, and detention they often recall strategically engaging in wall writing as a political practice, either to communicate and coordinate with other underground groups via a sort of encrypted language or to spread subversive messages of encouragement, hope and strength to their fellow people. Particularly in the first film of the series, Birds in the

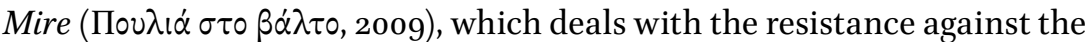
occupation of Greece by Nazi Germany, women gleefully recount sneaking out after curfew to scrawl slogans such as 'Liberty or Death' on the walls of Athens. Similar to Istanbul, political street art is deeply woven into the fabric of collective memory and continues to reverberate through the present aesthetics of protest with slogans, vocabularies and aesthetic references excavated from history and adapted to the current context. ${ }^{5}$

5 Similar historical resonances have emerged in the case of Argentina, where political street art created during the 2001 crisis 'invoked the memory and betrayal of the Dirty War, with allusions to the year "1976"' (Ryan, this volume). 


\section{Conclusion: (Im)material Trajectories and Hybrid Spaces of Resistance}

Though distinct in its respective formal and thematic articulations, the political street art of Athens and Istanbul described above forms part of a broader, transnational project of radical political imagination, sustained by a relationship to the social world that is poetic and performative rather than mimetic and representational. Autonomous interventions into public space - be they humorous scrawls or expressive murals - weave a sense of political potentiality into the very fabric of everyday life. Contingent encounters between city dwellers and the walls that they inhabit may then carry this political ambience over into collective forms of solidarity and resistance (Butler 2015). Yet, although political street art is fundamentally site-specific, encounters with it are not limited to the material landscape of the city. Photographs of the walls of Athens and Istanbul circulate through digital space by the thousands, posted and collected on social media where they are compounded into mobile archives of creative protest. When presented in this manner, artworks are generally stripped of their specific spatial embedding - information about location, significance of location, scale, and surrounding artworks are rarely provided and generally left to the viewer to decipher. Photographs of political street art may yet function as potent tools of political mobilization as they document the visual emergence of social movements and enable their work to circulate transnationally (Vatikiotis and Yörük 2016: 2). Indeed, my own engagement with the walls of Istanbul relies entirely on its extensive digital documentation.

Digital traces of political street art become particularly important in cases where its already ephemeral material presence is subject to censorship and erasure. In contrast to Athens, where artworks are for the most part left to freely accumulate in public space, in the wake of the Gezi Park uprising Istanbul has seen active campaigns directed against political wall writing. As early as June 2013, with active protests still ongoing, maintenance crews descended upon Taksim Square and the surrounding streets. As geographer Kyle T. Evered observed at the time, they

cleaned debris, sowed grass and flowers in the park, and painted most surfaces, vertical and horizontal. New graffiti would appear each night and workers returned each day; the district looked progressively more like a document undergoing extreme redaction than restoration. (2018:2)

In an effort to exert a sense of control over public space and collective memory, public service workers covered the city in 'patches of institutional 
beige, blue, grey, green, and yellow' (Evered 2018: 2), betraying just how seriously the government took the presence of political street art. Protestors, of course, were quick to register the irony of the situation, countering: 'Until you run out of grey paint!' (Gri boyaniz bitene kadar!). Five years later, at the writing of this book chapter, no instances of political street art hailing back to the Gezi movement appear to have survived in the streets of Istanbul. With censorship and state control tightened in light of the attempted 2016 military coup, political street art is, for the time being, being effectively suppressed. Photographs showing the walls of Istanbul during the Gezi Park uprising that still circulate through the digital realm, in this context, take on a new significance as artefacts of collective memory that gesture towards a spirit of resistance still latent in the urban landscape, buried under layers of paint. This dynamic interplay of the physical and digital spheres, in Istanbul as in Athens, constitutes a 'hybrid space of resistance' (Altay 2015: 203) that has the potential to sustain political performances both grounded in the real world and networked beyond.

As political street art is gaining traction as an interdisciplinary field of study, the questions of materiality, erasure, and circulation that emerge from the two case studies discussed in this chapter point to the need for more complex methodological and conceptual approaches. For although there is a growing body of empirical work offering sophisticated analyses of content and production of political street art within different political contexts (Campos et al. 2019; Ryan 2017; Tolonen 2016; Tsilimpounidi 2015; Hamdy and Karl 2014; Waldner and Dobratz 2013; Borriello and Ruggiero 2013), such accounts rarely address the material and immaterial trajectories different works assume as they are archived, copied, shared, erased, and remade over time. Approaching the complex (im)material trajectories of contemporary political street art, as Lachlan MacDowall has suggested in his research on the image-sharing platform Instagram, requires recalibrating the notion of 'the street' in a way that addresses its dual role 'as a set or backdrop for the production of digital content and a site of globally connected political action' (MacDowall 2017: 232). Methodologically, this means shifting towards lateral modes of engagement that document and analyse how traces of political street art move through time and space, accumulating into living archives of dissent across material and digital worlds. With contemporary social movement theory shifting increasingly towards aesthetic and performative modes of inquiry - as the editors of this volume suggest - such nuanced readings of political street art can offer broader insights about how protestors articulate a shared expression of visual dissent in times of political crisis. 


\section{References}

Alexandrakis, Othon. 2016. 'Indirect Activism: Graffiti and Political Possibility in Athens, Greece', Cultural Anthropology 31(2): 272-296.

Altay, Can. 2015. 'A Public Presence versus Greed, Brutality, and Control', in Global Activism: Art and Conflict in the $27^{\text {st }}$ Century, ed. Peter Weibel, 200-206. Cambridge, MA: MIT Press.

Avramidis, Konstantinos. 2012. "Live Your Greece in Myths": Reading the Crisis on Athens' Walls', Professional Dreamers Working Paper 8. http://www.professionaldreamers.net/_prowp/wp-content/uploads/Avramides-Reading-theCrisis-on-Athens-walls-fld.pdf. Accessed 13.02.19.

Aysan, Yılmaz. 2018.'68 Afişleri: ODTÜ Devrimci Afış Atölyesinin Öyküsü [Posters of '68: The story of the Atelier of Revolutionary Posters at METU]. Istanbul: Metis. Aytekin, E. Attila. 2017. 'A "Magic and Poetic" Moment of Dissensus: Aesthetics and Politics in the June 2013 (Gezi Park) Protests in Turkey', Space and Culture 20(2): 191-208.

Baudrillard, Jean. 1993. 'Kool Killer, or the Insurrection of Signs', in Symbolic Exchange and Death, 76-84. London: Sage.

BBC. 2014. 'Berkin Elvan: Turkish PM Accuses Dead Boy of Terror Links.' BBC, 15 March. https://www.bbc.com/news/world-europe-26594922. Accessed 13.02.19. Bektas, Ali. 2013. This Is Only the Beginning: On the Gezi Resistance ofJune 2013. Self-published pamphlet.

Boletsi, Maria. 2016. 'From the Subject of the Crisis to the Subject in Crisis: Middle Voice on Greek Walls', Journal of Greek Media \& Culture 2(1): 3-28.

Borriello, Luca, and Christian Ruggiero, eds. 2013. Inopinatum: The Unexpected Impertinence of Urban Creativity. Rome: Inopinatum Study Center on Urban Creativity.

Butler, Judith. 2015. Notes toward a Performative Theory of Assembly. Cambridge, MA: Harvard University Press.

Butler, Judith, and Athena Athanasiou. 2013. Dispossession: The Performative in the Political. Cambridge:John Wiley \& Sons.

Campos, Ricardo, Andrea Pavoni, and Yannis Zaimakis, eds. 2019. Street Politics in Critical Times: Street Art, Graffiti and Visual Protest across the World. New York: Berghahn. Forthcoming.

Chaffee, Lyman G. 1993. Political Protest and Street Art: Popular Tools for Democratization in Hispanic Countries. Westport: Greenwood Press.

Deutsche, Rosalyn. 1992. 'Art and Public Space: Questions of Democracy', Social Text 33: 34-53.

Dickens, Luke. 2008. “Finders Keepers”: Performing the Street, the Gallery and the Spaces In-Between', Liminalities: A Journal of Performance Studies 4(1): 2-30. 
Doerr, Nicole, Alice Mattoni, and Simon Teune, eds. 2013. Advances in the Visual Analysis of Social Movements. Bingley: Emerald Group.

Egemen, Mehmet Sinan. 2015. Graffiti, Hegemony, Empty Signifier: Curious Case of \#DirenGezi. MA thesis, Istanbul Bigli University.

Ertür, Basak. 2016. 'Barricades: Resources and Residues of Resistance', in Vulnerability in Resistance, ed. Judith Butler, Zeynep Gambetti, and Leticia Sabsay, 97-121. Durham, NC: Duke University Press.

Evered, Kyle T. 2018. 'Erasing the Place of Dissent: Inscriptions and Eliminations of Gezi Park Graffiti', AREA: Royal Geographical Society 51(1): 1-11. https://doi. org/10.1111/area.12439.

Firat, Begüm Özden, and Aylin Kuryel, eds. 2010. Cultural Activism: Practices, Dilemmas, and Possibilities. Amsterdam: Rodopi.

Gruber, Christiane. 2013. 'The Visual Emergence of the Occupy Gezi Movement.' Jadaliyya, 6 July. http://www.jadaliyya.com/Details/28971/The-Visual-Emergence-of-the-Occupy-Gezi-Movement,-Part-One-Oh-Biber. Accessed 13.02.19.

Gruber, Christiane. 2017. 'The Gezi Martyrs and Visual Resistance in Turkey (Part 1): “They Are Among Us"', Mizan, 1 June. http://www.mizanproject.org/the-gezimartyrs-and-visual-resistance-in-turkey-part-1/. Accessed 13.02.19.

Gruber, Christiane. 2018. 'Gezi Graffiti: Shout-Outs to Resistance and Rebellion in Contemporary Turkey', in Scribbling through History: Graffiti, Places and People from Antiquity to Modernity, ed. Chloé Ragazzoli, Ömür Harmanşah, Chiara Salvador, and Elisabeth Frood, 83-94. London: Bloomsbury Academic.

Hamdy, Basma, and Don Karl aka Stone, eds. 2014. Walls of Freedom: Street Art of the Egyptian Revolution. Berlin: From Here to Fame Publishing.

Harvey, David. 2012. Rebel Cities: From the Right to the City to the Urban Revolution. London: Verso.

Kaika, Maria. 2012. 'The Economic Crisis Seen from the Everyday: Europe's Nouveau Poor and the Global Affective Implications of a "Local" Debt Crisis', City: Analysis of Urban Trends, Culture, Theory, Policy, Action 16(4): 422-430.

Kaptan, Yesim. 2016. 'Laugh and Resist! Humor and Satire Use in the Gezi Resistance Movement', Perspectives on Global Development and Technology 15:567-587.

Lazzarato, Maurizio. 2012. The Making of the Indebted Man: An Essay on the Neoliberal Condition. Los Angeles: Semiotext(e).

Lefebvre, Henri. 2009. The Production of Space, trans. Donald Nicholson-Smith. Malden, MA: Blackwell.

MacDowall, Lachlan. 2017. '\#Instafame: Aesthetics, Audiences, Data', in Graffiti and Street Art: Reading, Writing and Representing the City, ed. Konstantinos Avramidis and Myrto Tsilimpounidi, 231-249. London: Routledge.

Makrygianni, Vaso, and Haris Tsavdaroglou. 2011. 'Urban Planning and Revolt: A Spatial Analysis of the December 2008 Uprisings in Athens', in Revolt and Crisis 
in Greece. Between a Present Yet to Pass and a Future Still to Come, ed. Antonis Vradis and Dimitris Dalakoglou, 29-57. Oakland: AK Press.

Morva, Oya. 2016. 'The Humorous Language of Street Dissent: A Discourse Analysis of the Graffiti of the Gezi Park Protests', European Journal of Humour Research 4(2): 19-34.

Pabón-Colón, Jessica Nydia. 2018. Graffiti Grrlz: Performing Feminism in the Hip Hop Diaspora. New York: NYU Press.

Pangalos, Orestis. 2014. 'Testimonies and Appraisals on Athens Graffiti, Before and After the Crisis', in Remapping 'Crisis': A Guide to Athens, ed. Myrto Tsilimpounidi and Alywyn Walsh, 154-176. London: Zero Books.

Rancière, Jacques. 2004. The Politics of Aesthetics, ed. and trans. Gabriel Rockhill. London: Bloomsbury Academic.

Ryan, Holly Eva. 2017. Political Street Art: Communication, Culture and Resistance in Latin America. London: Routledge.

Schacter, Rafael. 2014. Ornament and Order: Graffiti, Street Art and the Parergon. Surrey: Routledge.

Stampoulidis, Georgios. 2016. 'Rethinking Athens as Text: The Linguistic Context of Athenian Graffiti during the Crisis', Journal of Language Works 1(1): 10-23.

Stavrides, Stavros. 2017. 'The December 2008 Uprising's Stencil Images in Athens: Writing or Inventing Traces of the Future', in Graffiti and Street Art: Reading, Writing and Representing the City, ed. Konstantinos Avramidis and Myrto Tsilimpounidi, 164-176. Oxon: Routledge.

Taş, Hakki. 2017. 'Street Arts of Resistance in Tahrir and Gezi', Middle Eastern Studies 53(3): 802-819.

Taş, Tuĝba, and Ộuzhan Taş. 2014a. 'Contesting Urban Public Space: Street Art as an Alternative Medium in Turkey', in Alternative Media and Participation, ed. Beybin Kejanlioglu and Salvatore Scifo. Istanbul. http://www.costtransforming-audiences.eu/system/files/alternative\%2omedia\%2oand\%2o participation-19-02-14.pdf. Accessed 13.02.19.

Taş, Tuĝba, and Oĝuzhan Taş. 2014b. 'Resistance on the Walls, Reclaiming Public Space: Street Art in Times of Political Turmoil in Turkey', Interactions: Studies in Communication and Culture 5(3):327-349.

Tolonen, Jonna. 2016. Visage of Madrid: Illegal Graffiti as a Part of Spanish 15-M Protests. PhD thesis, University of Helsinki.

Tsilimpounidi, Myrto. 2012. 'Athens 2012: Performances “in Crisis”, or What Happens When a City Goes Soft', City: Analysis of Urban Trends, Culture, Theory, Policy, Action 16(5): 546-556.

Tsilimpounidi, Myrto. 2015 “If These Walls Could Talk”: Street Art and Urban Belonging', Laboratorium 7(2): 71-91. 
Tulke, Julia. 2013. Aesthetics of Crisis: Political Street Art in Athens in the Context of the Crisis. MA thesis, Humboldt University of Berlin.

Tulke, Julia. 2017. 'Visual Encounters with Crisis and Austerity: Reflections on the Cultural Politics of Contemporary Street Art in Athens', in Greece in Crisis: The Cultural Politics of Austerity, ed. Dimitris Tziovas, 201-219. London: I.B. Tauris. Tulke, Julia. 2019. 'Figuring Crisis: The Performative Politics of Street Art in Contemporary Athens', City: Analysis of Urban Trends, Culture, Theory, Policy, Action. Forthcoming.

Tunali, Tijen. 2018. 'The Art of Resistance: Carnival Aesthetics and the Gezi Street Protests', ASAPJournal 3(2): 377-400.

Tziovas, Dimitris, ed. 2017. Greece in Crisis: The Cultural Politics of Austerity. London: I.B. Tauris.

Vatikiotis, Pantelis, and Zafer F. Yörük. 2016. 'Gezi Movement and the Networked Public Sphere: A Comparative Analysis in Global Context', Social Media + Society 2(3): 1-12.

Vradis, Antonis. 2009. Greece's Winter of Discontent, City: Analysis of Urban Trends, Culture, Theory, Policy, Action 13(1): 146-149.

Vradis, Antonis. 2012. 'Wri(o)ting Cities: Some Candid Questions on Researching and Writing on Urban Riots', in Writing Cities, Vol. 2: Distance and Cities: Where Do We Stand?, ed. Gunter Grassner, Adam Kaaa, and Katherine Robinson, 88-94. London: LSE.

Waldner, Lisa K., and Betty A. Dobratz. 2013. 'Graffiti as a Form of Contentious Political Participation', Sociology Compass 7(5): 377-389.

Warner, Michael. 2002. 'Publics and Counterpublics', Public Culture 14(1): 49-90.

Weibel, Peter, ed. 2015. Global Activism: Art and Conflict in the $27^{\text {st }}$ Century. Cambridge, MA: MIT Press.

Zieleniec, Andrzej. 2016. 'The Right to Write the City: Lefebvre and Graffiti', Environnement Urbain/Urban Environment 10: 1-37.

\section{About the Author}

Julia Tulke is a PhD student in the Graduate Program in Visual and Cultural Studies at the University of Rochester, NY. Her work focuses on material landscapes of urban crisis as sites of cultural production and political intervention. In this context, she has conducted extensive research on street art and graffiti as mediums of expression and dissent in the context of an ongoing ethnographic fieldwork project in Athens, Greece. 



\title{
6 The Introvert's Protest: Handwriting the Constitution and the Performance of Politics
}

\author{
Interview with Morgan O'Hara by Aidan McGarry
}

\begin{abstract}
This interview explores the relationship between performance, art and protest, using the example of the project 'Handwriting the Constitution'. The chapter is an interview with the founder of this global artistic and performative project. It examines how protest is expressed in diverse ways and the importance of carving out public and private spaces for protest. Whilst protest is invariably seen as a dramatic event with people taking to the streets to demonstrate, this chapter challenges our understanding of how silent protest can be a powerful tool to express a political voice. It locates the act of protest in handwriting key document in quiet collective spaces.
\end{abstract}

Keywords: handwriting; performance, art, rights, protest, introvert

In January 2017, as the inauguration of Donald Trump neared, New Yorkbased artist, Morgan O'Hara felt the need to protest. As a concerned artist, she had marched many times, but this particular moment seemed to call for something else. She wanted stay clear of the campaign's toxic excesses, and take action silently. On 5 January she woke up with the idea of copying the US Constitution by hand. While she often hand copies texts as part of her art practice, she hadn't thought much about the Constitution before. She only knew she wanted to do it, and to do it with others in a public space. On Inauguration Day she went to the New York Public Library with a small suitcase of pens, a few sharpies, paper, and copies of the Constitution. She brought old notebooks, half-used drawing pads and loose sheets to share with anyone that might show up. She began writing.

McGarry, A., I. Erhart, H. Eslen-Ziya, O.Jenzen, U. Korkut (eds), The Aesthetics of Global Protest: Visual Culture and Communication. Amsterdam: Amsterdam University Press, 2020 DOI 10.5117/9789463724913_CHo6 
To date she has organized over 85 sessions around the world. 'Handwriting the Constitution' has been taken up in many states in the United States, as well as in France, Italy, Israel, Germany, the Netherlands, Taiwan, Macau, Hong Kong, Poland, and Portugal. In each case, people handwrite their chosen documents written to protect human rights, which could be a constitution, a bill of rights or the Universal Declaration on Human Rights. On the $70^{\text {th }}$ anniversary of the UN Declaration on Human Rights, Aidan McGarry also organized an 'Introvert's Protest' at the Netherland's Institute for Advanced Study in Amsterdam on 10 December 2018.

Morgan O'Hara is an artist. Her work can be found in the permanent collections of the Metropolitan Museum of Art in New York, the National Gallery in Washington, DC, the British Museum and elsewhere. Aidan McGarry spoke with her about the 'Handwriting the Constitution' project, protest, and politics. Morgan's project is a creative, democratic and participatory exercise and she encourages others to organize their own sessions wherever they live. For more, see the project website: https://www. handwritingtheconstitution.com/.

\section{AMG: You describe your project 'Handwriting the Constitution' as an introvert's protest? What does this mean to you?}

$\mathrm{MOH}$ : Well, it is an example of protesting, which is silent and pretty much immobile, as opposed to the kinds of protests, which were happening at the time of Trump's inauguration, or have traditionally been done where people go out and march, chant slogans, or yell or wave banners. All of those are quite extrovert activities, which I have done in the past, but this situation got me to thinking about what an introvert could do. I thought this action had to be something quiet, something silent, but active. I don't know exactly where the idea came from but I woke up one day and it was in my head to handwrite the Constitution and it made me smile because an introvert can write something, can read something and it can still be an act of protest.

I soon realized I had to do it in a public place so I decided to do it at the Rose Reading Room at New York Public Library. It's quiet, it's peaceful, and everyone who is in there is concentrated. I felt I could do this private protest introspectively in a public place. I think it would have been performative whether I had done it with other people or not, just because it was an action I was doing and it had its own parameters. A friend of mine asked if she could publicize it on Facebook and initially I wasn't sure as I was concerned that it might change the quality or it could be distracting but I decided to 
embrace it. So, I prepared extra materials in case more people turned up. At the first session, I was writing for an hour on my own, then two people I know turned up and then seven people I hadn't met before arrived. We were soon all handwriting the Constitution together.

Do you think there is a performative quality to the writing or what purpose does the action of writing serve?

The action is very important. Writing is very different from reading and typing. When you write something out it somehow gets into your head and your body in a more profound way. I think drawing serves the same function. I don't own handwriting and I don't own the Constitution. I just happened to put them together at a key moment. The combination of the two is very powerful. It's definitely performative even when I am there alone because when I am there I feel visible as I am the only one writing. In addition, it is my intention to do this publicly as a performance. It is a private action consciously made public.

When you hand copy the Constitution and you have to deal with the words, one by one, you can feel the different battles that were going on to create this document, the compromises, you can feel the polarization of things. It's a really good example of people with strong views hammering out something together. And I feel that is something we have lost now. Right now, people just want to find more people who think the same way they do and there isn't a debate. This is not the whole purpose of the United States and you get a feel for that when you write out these documents. The same is true for constitutions of countries around the world and international human rights standards, like the UN Declaration on Human Rights.

Doing this does not solve any of the problems that we have, I am very aware of that. But it does calm people down and when you are calmer, your decision-making process is better so that is why I am still doing it.

\section{And it is just the US Constitution?}

No. I am interested in handwriting any documents which have been written in defence of human rights. I have written out the UN Declaration of Human Rights in Taiwan when I was working there. It didn't make sense to write the US Constitution in that situation. Some of the participants in Taiwan chose to handwrite the Declaration, alternating paragraphs in both Chinese and English. 


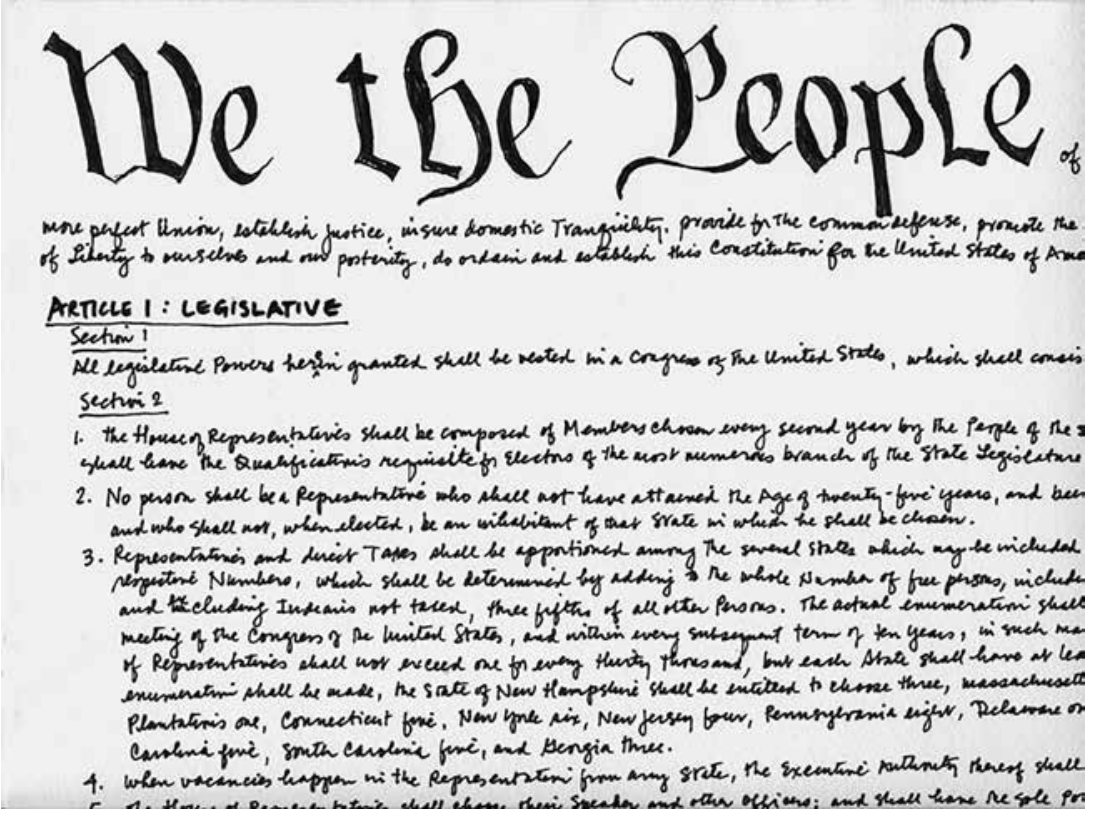

Figure 6.1. 'We the People'.

How does it feel to engage in this collective process as an individual?

It's a very special thing when you are sitting around the table and 20 people are hand copying the same document. It's like you don't have to look at it but you can feel it. It's the feeling of having a good meal with friends; it's a nice feeling.

I had the pleasure of organizing a session in Amsterdam at the Netherlands Institute for Advanced Study. It was for the $70^{\text {th }}$ anniversary of the Universal Declaration of Human Rights and we had 35 people writing out the document start to finish in English, Dutch, Spanish and Chinese. It was an amazing experience to have everyone sitting around performing the same action in quiet concentration, and afterwards many participants told me that they liked the activity because it was 'quiet dissent' and 'peaceful resistance'.

The best way to describe it is to call it introvert's activism. We need to keep inventing more ways to protest what we need to protest, in non-violent ways because the non-violent ways are the ones which are effective. 
In the testimonies of the participants I have read and listened to they talk about how handwriting the Constitution anchors them. How is this possible?

I'm not sure how this works, but it definitely does. It has a calming effect. It's like reminding yourself that rights exist and that you have rights at a time when everything else is falling apart. It is the grounding; this is the earth on which we stand, the fact that we have these rights and they have been defended time and again through all these different documents. And when you are in a time of crisis, these documents remind you that you have a right to live in peace, to live unmolested, to live in harmony.

I am surprised that people immediately think it is art. I have not mentioned this when describing the project. I am an artist, so I suppose people think it is art. Actually, I don't care what it is called as long as we do it.

That is what is so interesting about this project. Many people think of rights as an abstract ideal but all laws come alive when you invoke them or they are violated. So, they are dead letters on a page but there is something in this project when you write them out, they are being invoked, they are made to be alive, they are not just abstract words arranged on a document. Their meaning is much more significant. Doyou think that the project is political?

Yes. I have never identified myself as a political activist and I am surprised by the discussions I get into because of this. I have to learn a lot because people ask me questions about history and the documents. For me it has become an intellectual as well as a conscious and creative process.

It would be interesting to see this project manifest in different places. There are places where rights are under attack, like in Hungary, Turkey, Russia, Poland, and increasingly in the USA. And there are places where the squeezing of rights is more latent. That's why it is interesting 'Handwriting the Constitution' is happening in Germany, as we think of Germany as a stable democracy but rights are constantly being squeezed and ignored. Therefore, it is good to have this, as a reminder of what you have and what you have a right to.

There's a wonderful word in Italian when you have had enough of something, you say 'Basta!' which is exactly as it sounds. Enough! I take this idea-wordfeeling to indicate that we have had enough with these encroachments on our rights. There has been so much in US politics, which has been uncivilized and crude, not to mention illegal, and many worse things are happening in 
many places around the world. Collectively, we need to remind ourselves of our dignity and our rights and insist that they be respected.

So, yes, 'Handwriting the Constitution' is political, yes, it's introspective and yes, it's performative. All three. It is also a silent action, which has the potential to be transformative. I hope that in 2019 and beyond more and more people will participate and will feel empowered through this simple action.

If you have been inspired by Morgan's project here is some information about how to get involved either as a participant or an organizer.

If want to learn more about the project, see the project website: https://www. handwritingtheconstitution.com/. The website has details of upcoming sessions where you can take part as a participant.

\section{HOW TO SET UP YOUR OWN HANDWRITING SESSION}

1. Email the details of your event to handwritingtheconstitution@gmail. com (when, where, and which document you will be handwriting) and you will receive a personalized invitation as an optimized pdf. You may suggest a background colour.

2. Send this invitation to friends, colleagues, and anyone in your community you think might be interested.

3. Download copies of the constitution of your country, the Universal Declaration of Human Rights or any other document protecting human rights and print copies for your group.

4. Bring pens and paper for your fellow handwriters.

5. When everyone is writing, stay with your own concentration and writing. Let people be.

6. When the session is finished, share photographs of your event online using the hashtag \#handwritingtheconstitution and/or email the best ones to handwritingtheconstitution@gmail.com.

Questions may be directed to Morgan O'Hara at handwritingtheconstitution@gmail.com.

\section{About the Authors}

Morgan O'Hara is a New York-based artist. She is recipient of grants from the Pollock-Krasner Foundation, the Gottleib Foundation, the Leon Levy 
Foundation, the David and Rosamond Putnam Travel Fund, and the Milton and Sally Avery Foundation. Her work is in the permanent collections of many institutions around the world including China, the United States, the Netherlands, and the Czech Republic. She began the 'Handwriting the Constitution' project (www.handwritingtheconstitution.com) in 2017.

Aidan McGarry is a Reader in International Politics at the Institute for Diplomacy and International Governance at Loughborough University, London. His research focuses on social movements, protest, political voice, and marginalized communities (www.aidanmcgarry.com). He is the author of four books, including Who Speaks for Roma? (Continuum, 2010) and Romaphobia: The Last Acceptable Racism in Europe (Zed, 2017). He was Principal Investigator of an Arts and Humanities Research Council (AHRC)funded project 'Aesthetics of Protest: Visual Culture and Communication in Turkey' (www.aestheticsofprotest.com) from 2016 to 2018. In 2018-2019 he is a EURIAS/Marie Curie Fellow at the Netherlands Institute for Advanced Study in Amsterdam, where is writing a book on political voice. 



\section{Part II}

Visual Activism and Digital Culture 



\title{
7 Photography and Protest in Israel/ Palestine: The Activestills Online Archive
}

\author{
Simon Faulkner
}

\begin{abstract}
This chapter will explore two key ways that photography plays a role within the aesthetics of protest. This will be done through a discussion of a small number of photographs of political demonstrations selected from the online archive of the Israel/Palestine-based photographic collective Activestills. The photographs discussed in the first section of the chapter present evidence of people carrying photographic images within demonstrations. While the second section deals with examples of the how photography has been used to document the immediate scene of protest for distant spectators. After these discussions of particular examples from the archive, the chapter concludes with a more speculative discussion of the Activestills archive itself.
\end{abstract}

Keywords: Visual activism, online archive, protest, photography, Palestine, Israel

\section{Introduction}

This chapter explores two key ways that photography plays a role within the aesthetics of protest. This will be done through a discussion of a small number of photographs of political demonstrations selected from the online archive of the Israel/Palestine-based photographic collective Activestills. ${ }^{1}$

1 The term 'Israel/Palestine' is used to designate the unresolved political geographical construct that was formerly called Mandate Palestine, but is now constituted by the state of Israel within its 1949 borders and the occupied and besieged territories of the West Bank and Gaza Strip.

McGarry, A., I. Erhart, H. Eslen-Ziya, O.Jenzen, U. Korkut (eds), The Aesthetics of Global Protest: Visual Culture and Communication. Amsterdam: Amsterdam University Press, 2020 DOI 10.5117/9789463724913_CHO7 
The photographs discussed in the first section of the chapter present evidence of people carrying photographic images within demonstrations. While the second section deals with examples of the how photography has been used to document the immediate scene of protest for distant spectators. ${ }^{2}$ After these discussions of particular examples from the archive, the chapter concludes with a more speculative discussion of the Activestills archive itself.

For the purposes of the chapter, the aesthetics of protest is understood to encompass those aspects of protest that relate strongly to the senses, especially vision. This encompasses the ways that protesting bodies assemble within space, the ways they interact and move, how they dress, and the performances they enact. This immediate aesthetics of protest also entails the things that protestors carry: banners, placards, three-dimensional props, and images, including photographs, hence the discussion in the chapter of participants in demonstrations holding and showing photographs. But the aesthetics of protest is also wrapped up with the ways that protest is mediated. The aesthetics of protest is consequently understood to be both a matter of how protest appears to co-present observers and how the appearances of protest can be viewed through technically produced images. Jim Aulich defines this relationship between the immediate and mediated aspects of the aesthetics of protest as being one between 'the aesthetic form of the protest in the present' and 'the aesthetic of the trace of the demonstrations in analogue and digital media'. For him, ' $\mathrm{t}$ ] he "phenomenon" and its "image" are in an entangled relationship' (Aulich, this volume).

In the case of photography, the mediation of protest can occur through the work of photographers, who define themselves as activists producing images for publication and distribution within social movements (Memou 2013: 70-76, $79,81)$. But these images are often also intended for wider distribution. The Civil Rights movement in the United States, for example, 'cultivated teams of professional "movement photographers", whose work was intended to make up for the perceived shortcomings of mainstream photojournalism (Berger 2010:110). While the South African photographic collective Afrapix worked 'in concert with the liberation movement' (Cedric Nunn, quoted in Newbury 2009: 241) to supply photographs of the struggle against Apartheid to the international press. The photographic mediation of protest also occurs through the work of ostensibly 'non-political' photojournalists, when they document photogenic protest events. For example, the Southern Christian

2 The photographs discussed in the chapter were selected either by using place names to search within the archive, or in the case of some photographs of people carrying photographs during demonstrations, by searching within the archive using the terms 'photograph'. 
Leadership Conference sought to provoke a violent official response to their protests in Birmingham, Alabama, in 1963 on the correct assumption that this violence would be reported through mainstream photojournalistic images in the North American and international press (Berger 2010; Johnson 2007; McAdam 2000). Such press photographs, although produced for commercial purposes, can still serve the needs of protestors to gain publicity for their struggle and can therefore be understood as visual extensions of the immediate aspects of the aesthetics of protest.

These uses of photography relate to the political question of visibility, which is at the heart of the aesthetics of protest. As Andrea Brighenti observes, 'Visibility lies at the intersection of the domains of aesthetics (relations of perception) and politics (relations of power)' (Brighenti 2007: 324), meaning that politics is largely a struggle over visibility: over what and who can be seen, and in what ways. This is why Jacques Rancière states that 'politics is a question of aesthetics, a matter of appearances' (1999: 74). This is because, in his terms, the established political order is 'an order of the visible' that works to make sure particular things can be seen and others not (Rancière 1999: 29). Protest challenges this order by bringing people and their plights into the field of vision, entailing 'the introduction of a visible into the field of experience, which then modifies the regime of the visible' (Rancière 1999: 99). As pointed out above, the visibility of protest is both a matter of direct visual experience and of images. Though it is the latter that seems to be a more important consideration when it comes to relationships between photography and the aesthetics of protest. Visibility through the media, including photography, has been a crucial political stake for protestors at least since the mid-twentieth century (Cottle 2008; Faulkner 2013).

But if we are to understand the place of photography within the aesthetics of protest, it is necessary to be sensitive to the specificity of the aesthetics of photography itself, defined by its two-dimensionality, its pictorial framing of visible reality and the way that it captures a moment in time (Shore 2010; Price 1994). It is also necessary to understand what photography does, both technically and in terms of what people think it can do. Thought about in relation to both the use of photographs within demonstrations and its use as a means of visually mediating protest, its principle function is the technical capture and transportation of appearances across time and space (Berger and Mohr 1982: 92). After all, photographs are two-dimensional artefacts that carry the framed appearances of the things they depict and as such can be disseminated through different technical means. 
By framing and freezing the visible world, photographs also ascribe significance to what they depict. Their underlying message is that what they show is important to see. This ascription of significance to an appearance through photography is the result of the agency of the photographer. Hence, John Berger's observation that the simplest message of a photograph is 'I have decided that seeing this is worth recording' (Berger 2010: 179). This significance is also affirmed by the agency of others, who use photographs they have not necessarily taken, for example, by showing them in demonstrations or by uploading them to social media platforms. But photographs also have a kind of agency of their own defined by their capacity to transport appearances and bring things into visibility in contexts, where they would not otherwise be seen. Photographers and other human agents utilize this capacity to produce an aesthetics of protest that involves showing the appearances of events that usually occur in the past and elsewhere.

This understanding of photography as a technology that deals in the capture and transportation of appearances does not involve an assumption that photographs have a 'truthful' relationship to what they show. Rather, veracity is understood as a key element of the socially embedded 'idea' of photography (Gitelman 2006: 7-8; Gitelman 2014: 84). Veracity is what we have made photography mean, not its essential condition. What this means, in general terms, is that the primary function of photographs within the aesthetics of protest is as documents that are taken to attest to the realities they depict. These photographs have other affective qualities and symbolic functions, but these aspects of photography are enmeshed with or built upon their function as documents. Consequently, the suggestion is that photography generally contributes to the 'political voice' of protest (see the introduction to this volume) on the basis of its documentary function.

Activestills mobilize the idea of photography as a veracious medium that has the power to show that which is general unseen, when they state: 'The collective believes in the power of images to shape public attitudes and raise awareness on issues that are generally absent from public discourse or presented in a misleading way by the media' (Activestills 2015). This general concern with the potential of photography to bring issues into political visibility prompted the foundation of Activestills in 2005 - by the Israeli photographers Oren Ziv, Keren Manor, and Yotam Ronen, and the Argentinian photographer Eduardo Sauteras - in response to the popular struggle that developed that year in the Palestinian village of Bil'in in opposition to the construction of a section of the West Bank Barrier on village land. The aim of the collective was to contribute to this struggle through their presence at demonstrations and through the production and dissemination of photographs. 
Since 2005, Activestills has expanded and diversified its membership (to include Palestinian photographers) and responded to a wide range of ongoing political struggles. Their practices have involved the photographic documentation of demonstrations and other forms of resistance, and the distribution of these photographs through street exhibitions as well as through political blogs, social media and their own website. The Activestills archive is an aspect of these distributive practices and crucial to their concerns to provide visibility for political struggles against state violence and repression. The members of the collective freely contribute their photographic images to the archive, while also retaining individual rights to these images. This means that the archive exists in a state of relative independence from the practices of the individual photographers who have made it possible. As such, the archive is a collection of photographic documents of particular struggles and at the same time a complex aesthetic form in itself that is part of a wider set of aesthetics practices relating to dissent within Israel/ Palestine.

\section{Photographs Carried in Demonstrations}

Participants in political demonstrations carrying and showing photographic images is not a new phenomenon. In September 1963 members of the Congress of Racial Equality in the United States carried a large photograph during a demonstration in Washington, DC, against the Ku Klux Klan bombing of the $16^{\text {th }}$ Street Baptist Church in Birmingham, Alabama that same month. This photograph showed the wreckage outside the church after the bombing, which killed four young black girls. The organization Women Strike for Peace used posters bearing photographs of injured children during a demonstration against the Vietnam War at the Pentagon in 1967. While in 1970, the Art Workers Coalition produced a poster for use in anti-Vietnam demonstrations that showed a colour photograph of the Mai Lai massacre (Lippard 1990: 27-28). In all of these instances, photographs were used as documents that exemplified the violence that demonstrators opposed. This use of photographs in demonstrations emphasizes what Lisa Gitelman calls the 'know-show function' of documentary forms (Gitelman 2014: 1-4) through the performative showing of the images as evidence. This showing of the photographs combines a claim to truth with a moral imperative. The demonstrators seek to use the photographs as a means of showing the reality of violence committed elsewhere enabling a form of knowing that underpins the assertion that such situations should come to an end. Again, 
photographic evidence is used as a kind of political 'speech' or 'voice' (see the introduction to this volume).

Other photographic images carried during political demonstrations, such as the portraits of 'disappeared' loved ones used by Mothers of the Plaza de Mayo in Argentina or by activists calling for an inquiry into 'Bloody Sunday' in Northern Ireland (Herron and Lynch 2006), have served a largely mnemonic function. This is also the case with an image in the Activestills archive, which depicts the carrying of a large framed portrait of Mustafa Tamimi, who was mortally wounded by an Israeli soldier during a demonstration in the West Bank village of Nabi Saleh in January 2012. The majority of the examples from the Activestills archive to be discussed in this section involve the use of photographs during demonstrations for evidential purposes rather than for the purpose of remembrance. ${ }^{3}$ However, as will be seen, there are some examples that involve the use of photographs for the combined purposes of showing evidence and engaging in a kind of remembrance.

A number of photographs in the archive show close-ups of Israelis in Tel Aviv in July 2006 protesting against the Israeli bombardment of Lebanon during the conflict between Israel and Hezbollah that occurred in July and August that year. These demonstrators hold images of injured Lebanese children or of Lebanese families mourning dead relatives. This showing of images of the injured or the dead is very similar to the use of photographs in opposition to the Vietnam War. In both cases, the demonstrators show photographic images in opposition to violence deployed by their own state against distant others. The photographs are used to bridge the spatial distance between Tel Aviv and Lebanon, which also involves the experiential distance between a space of peace and a space of conflict. Thought about in these terms, the photographs function as a means of bringing something into visibility in space where such things are generally not seen. Again, the showing of these photographs in the Tel Aviv demonstration mobilizes photography's know-show function, which is based on its association with veracity and the moral force that derives from its claim to truth. On top of this, the demonstrators also exploit the affective power of photographic images of violence. Something especially powerful, when it comes to images of the effects of violence on children. In doing this the demonstrators mobilize photography to enhance their claim to political visibility as Israelis

3 Meir Wigoder has also discussed photographs from the Activestills archive that show demonstrators holding and showing photographs in terms of the way that the images become 'performative' in the immediate context of the demonstrations and become the focal points for 'communities of touch' (Wigoder 2016). 
who oppose their government's violent policy towards Lebanon. Here the aesthetics of protest involves the combination of a group of people assembled in public space with the appearances of the situations depicted in the images they hold.

Somewhat different are photographs in the archive that relate to the 'unrecognized' Bedouin village of Al Arakib in the Negev Desert north of Beersheba. Israeli authorities destroyed the village in July 2010, in the first of what became a protracted series of official demolitions in response to subsequent attempts by the villagers to rebuild their homes. Members of Activestills photographed the village prior to and during the demolition in July 2010. Oren Ziv in particular developed a working relationship with the villagers. ${ }^{4}$ He printed out copies of the photographs he took of the initial destruction of a number of homes in Al Arakib prior to July 2010 and gave these to the villagers, who used them in a demonstration in Tel Aviv in May 2010 against the proposed destruction of the entire village. Ziv also provided the villagers with further photographic prints of the July demolition, which were displayed in a protest tent established on the site of the former village a number of days after the demolition and also used in subsequent demonstrations. Photographs by Ziv and Yotam Ronen held in the archive depict the carrying of Ziv's photos of the initial destruction of homes in Al Arakib during the May 2010 demonstration in Tel Aviv.

One photograph in particular shows two Bedouin men, one on the left with a megaphone and the other holding an image of the rubble of a destroyed home. In this example, the showing of the photograph appears to function both as a documentary means of attesting to the demolition of a building in the recent past and as an image that is indicative of something that will happen again if the proposed destruction of the whole village is not stopped. Although the showing of the photograph involves the spatial transportation of an appearance from the Negev to Tel Aviv, the photograph is predominantly used in relation to a temporal axis that relates it both to the past and the potential future.

Different again was the use of Ziv's photographs of the destruction of Al Arakib during demonstrations on the former village site. These demonstrations occurred on 30 July, a number of days after the demolition and later on 9 August 2010. There was also a further demonstration that involved the use of the photographs on the first anniversary of the demolition in

4 Information about Oren Ziv's activities in Al Arakib was derived from an interview with the photographer conducted by the author in Tel Aviv, 17 August 2015. 
2011. The carrying of these photographic images of the destruction of Al Arakib during demonstrations at the site of the former village foregrounded the temporal rather than the spatial transportation of appearances. The images that the demonstrators hold depict the same location, where they are demonstrating. Photographs in the archive of the demonstration on 30 July 2010 show villagers holding images of bulldozers demolishing houses and of the police arresting members of the village community. Photographs of the demonstration on 9 August 2010 similarly show the villagers holding images of bulldozers flattening parts of the village and also the ruins of former habitations after their destruction. By holding these pictures during demonstrations at the site of the demolished village, the past is brought into dialogue with the present. The images that the villagers carry in the demonstrations are documents of an event that happened in the past, but they are not just that. Through their use during the demonstrations, they become tokens of loss. They represent the homes and communal existence that have been destroyed.

However, this is not a total loss. The village and its way of life could be rebuilt, as the villagers began to do after the first and each subsequent demolition. Thought about in these terms, the photographic images carried in the demonstrations functioned as both documents of actual events and also as tokens or icons of what was at stake in the villagers' political struggle. A struggle that would decide between two very different trajectories: on the one hand, destruction, displacement, and loss and, on the other, the reconstruction of the village and its communal life. Although the photographic images carried in the demonstrations depicted the destruction of the village by the state, they also showed what had been lost at the very moment it was being destroyed. In the absence of other photographic representations of former village life, it seems that the residents of Al Arakib had to use the Activestills images to both protest against the actions of the state and to stand-in for what they wanted to regain.

In the examples discussed in this section, protestors held printed photographic images with the aim of showing them to co-present spectators. However, it is also reasonable to suggest that the performance of the act of showing these images was itself intended to be photographed. Consequently, the showing of photographs within demonstrations was itself intended to produce further aesthetics in the form of images of the showing of these images. The use of photographs in the immediate context of the demonstration was meant to be mediated, so that the appearance of the performance of showing visual evidence could itself be transported to distant others. 


\section{Photographic Amplifications of Protest}

The Activestills photographs of the carrying of photographic images within demonstrations, discussed in the preceding section, also attests to the more general use of photography as a means of documenting protest events. The following section will focus on this larger function of photography as a means of mediating and amplifying protest. Amplification is understood here to refer to ways that protest is given greater 'reach' (Bailo and Vronicu 2017: 1663) and visibility through mediation. As suggested in the introduction, the visual mediation of protest is a significant aspect of the aesthetics of protest, when it comes to questions of political visibility (see also the introduction to this volume). The photographic amplification of protest is based on both the capacity of photography to transport appearances and the processes through which photographic images are themselves transported.

In general terms, photographic amplification occurs when people with cameras, present at the scene of protest, take photographs of other people marching, carrying objects or engaging in direct action. As noted, this is the case when protestors carrying and showing photographic images are themselves photographed performing such actions. These photographs can then be distributed in different ways and potentially viewed by spectators at varied degrees of spatial and temporal distance from the original protest situation. Amplification can also involve the further distribution and reuse of images by spectators themselves or lead to other responses such as the performance of further acts of protest. These points affirm Judith Butler's observation that visual mediation involves the extension of 'the scene or the space' of political protest (Butler 2012: 129). Yet, the visual extension of the scene of protest through photography is paradoxical, involving the creation of a sense of visual access for the spectator to an event that is not directly visible to them, while at the same time emphasizing the separation that exists between the original event and the image that the spectator actually views (Faulkner 2016b). As Jean-Luc Nancy observes, an image presents 'a world that we enter while remaining before it' (Nancy 2005: 5). The aesthetics of the photographic mediation of protest consequently involves tensions between proximity and distance, and between access and separation, but nevertheless enables the visual amplification and visibility of protest beyond the immediate vicinity and duration of a protest event.

The current domination of photojournalism by digital technologies enables the rapid communication of photographic images. Professional photojournalists can send images from the field to picture agencies and news wires almost instantaneously. These organizations can then make 
these images quickly available to clients for rapid publication online or in print. But the current period is also marked by the use of camera-phones and cheap DSLR cameras by direct participants in protest events. These 'amateur' or 'citizen' photographers can upload their images to social media platforms and other websites while demonstrations are still in progress. Other users can then view and re-circulate, or re-upload these images. What this suggests is a contemporary situation in which photographs of protest can be distributed at different temporal rates - immediately, or with differing amounts of delay - but in which these images are generally distributed much more rapidly than in the past. This enables photographic images to function in more direct and embedded and concurrent ways as part of the sensible experience of protest.

The Activestills archive is full of images of the kind under discussion here. As noted in the introduction, the collective was initially formed in 2005 in response to the protests in the Palestinian village of Bil'in against the West Bank Barrier. The members of the collective have continued to photograph the protests in Bil'in up to the present. Their photographs have been used to amplify these protests in different ways. Village activists used the photographs of the struggle on their no longer active website (bilin-village.org). Such photographs were also used on left-wing websites and blogs such as Digital Intifada and +972 Blog as well as on Activestills' own social media accounts. The collective also organized exhibitions of their photographs of the struggle in Bilin. Their first collective action involved the organization of a street exhibition of a grid of sixteen A3 paper prints of photographs of the demonstrations in Bil'in presented in different locations in Tel Aviv in early 2006 (Faulkner 2016a). This exhibition can be understood straightforwardly to involve the transportation of appearances from Bil'in across the Green Line (the 1949 ceasefire line) to the very different context of Tel Aviv. Activestills viewed the display of images on the street as an important way of bringing generally unseen aspects of the occupation into the Israeli public's field of vision.

Other exhibitions were organized in Bil'in itself as part of demonstrations to mark the second and tenth anniversary of the beginning of the village's struggle against the barrier. These exhibitions displayed the protests back to participants, showing them what they had achieved and reinforcing the culture of resistance within the village. Here the photographs shown in the exhibitions produced a form of amplification that was internal to the protest movement itself, rather than extending the scene of resistance beyond its immediate physical space. Photographs of these exhibitions in Bil'in held in the Activestills archive show members of the village community pointing at 
the photographs, perhaps recognising themselves or others. The images in these exhibitions functioned mnemonically in relation to the maintenance and reproduction of the struggle, constituting a publicly visible archive of this struggle over two or ten years respectively. The staging of the exhibitions in Bil'in also involved Activestills performing a form of solidarity with the villagers. In this sense, the photographic images used in the exhibitions were records of the protests - embodying the know-show function that defines photographs as documentation - and at the same time functioned symbolically in terms of the notion of 'joint-struggle' between Palestinians and Israelis that informed the Bil'in protests.

It is also interesting for this discussion to consider a particular set of images within the archive that relate to the amplification of a demonstration that occurred in Nabi Saleh on 28 August 2015. Nabi Saleh is a small village with roughly 500 inhabitants, located near Ramallah, adjacent to the Israeli settlement of Halamish, which was established on village land after the June War in 1967. Between 2010 and 2016 activists within the village community staged weekly Friday demonstrations in opposition to settlers from Halamish seizing a village owned spring. These demonstrations usually began with a procession from the centre of the village down the road towards the spring, which would be blocked by the Israeli military, resulting in a series of confrontations that spread out across the hillside opposite the settlement. Photographers and video activists often attended and documented the protests both for the photojournalism industry and for political purposes. Members of Activestills attended the demonstrations in Nabi Saleh on a regular basis from their inception, resulting in a relatively large number of photographs in the archive that are searchable under the village name. As has been the case with Bil'in, activists in Nabi Saleh have been able to gain considerable media attention for their struggle, including in international publications such as the New York Times Magazine (Ehrenreich 2013).

The following incident in question exemplifies this media attention. On this particular Friday, the weekly demonstration had dispersed across the hillside between Nabi Saleh and Halamish, when a soldier seized twelveyear-old Mohammed Tamimi, the son of prominent village activists Bassem and Nariman Tamimi, on the pretext that he had been throwing stones. Mohammed was wearing a plaster cast on his left arm, which was also in a sling. His cries attracted photographers and other demonstrators to his location. What ensued was a short confrontation between the soldier holding Mohammed down and other female members of the Tamimi family, who managed to release the boy, all the while with a line of photographers in front of them taking pictures. Amongst those taking photographs of 
this incident were the Palestinian photojournalists Abbas Momani and Mohammad Torokman, who worked respectively for the news agencies Agence France Presse and Reuters. Their photographs were widely published in the international press and broadly distributed on social media.

The photographs taken by all the photographers present at this event can be divided into two iconic scenarios: the first involving a struggle between an armed adult soldier and a boy, whose incapacity to resist the soldier was reinforced by the presence of the plaster cast on his arm, and the second showing Palestinian women and girls overpowering the soldier and compelling him to release the boy. The latter photographs include images that depict the soldier having a mesh ski mask torn from his head and his fingers bitten. Consequently, the photographs can be interpreted in terms of a set of compelling oppositions between the occupier and the occupied, and the oppressor and the resistor. It is reasonable to suggest that it was these connotations that led to the broad distribution of the photographic images of this incident.

The Activestills archive does not contain Momani and Torokman's commercially circulated photographs of the confrontation between members of the Tamimi family and the soldier. The archive does, however, contain ten photographs of the incident taken by the Palestinian freelance photojournalist Muhannad Saleem, who distributes some of his photographs through Activestills and their regular photographic feature on $+972 \mathrm{Blog}$. The presence of Saleem's photographs in the archive allows for this specific incident in Nabi Saleh to be discussed in the context of the chapter, in that these photographs constitute an element of the complex and dispersed existence of the incident as an amplified media phenomenon.

Most of the photographs in the Activestills archive relating to the protests in Nabi Saleh show the regular repertoire of these demonstrations and as such are representative of the standard relationship between both professional and activist photographers and the Friday demonstrations in a number of Palestinian villages in the West Bank that have developed over the last decade. Photographers generally document the routines of these demonstrations. Yet, at the same time, the professional photojournalists especially hope to capture exceptional pictures arising from unusual incidents within these events. Such images have a strong commercial value within the news industry. The photographs under discussion are a good example of this. But they also carry a strong political resonance for anti-occupation activists. They attest in particularly loaded ways to the processes of oppression and resistance that define relations between the Israeli state and Palestinians living under occupation. 
What is most interesting about this particular case is that the photographic amplification of the confrontation between the Tamimis and the soldier resulted in a diverse range of interpretations of these photographs. From an anti-occupation perspective, the photographs resonated with understandings of the highly unequal power relations between the Israeli occupier and Palestinians while also showing the momentary overturning of this relationship of domination. However, from a right-wing Israeli point of view the photographs were evidence of quite different things. The photographs were read in terms of the notion of 'Pallywood', a popular right-wing neologism that combines the words 'Palestinian' and 'Hollywood', to imply that documentary representations of the oppression of Palestinians under Israeli rule involve the industrial scale manufacture of fictions comparable to Hollywood movies. In line with this thinking, the photographs were interpreted in relation to what was understood as the Tamimi family's record of 'staging' confrontations between themselves and the Israeli army to create publicity for their cause. For example, images uploaded to Twitter contested the authenticity of Mohammad Tamimi's broken arm, suggesting that it had been faked to heighten the impact of what was effectively a stage-managed event performed for the cameras. For example, a montage image uploaded to Twitter with the title 'Palestinian Propaganda Exposed' contrasted press photographs of Mohammad Tamimi being held down by the soldier from the 28 August incident with images of Mohammad wearing a plaster cast on one of his arms during an earlier demonstration. This combination of images was intended to demonstrate that this arm cast had been switched from his right to his left arm and was therefore not indicative of a genuine injury. This reframing of the photographs as representations of an inauthentic 'Pallywood' scene in fact led some international newspapers to redefine their initial online reporting of the incident (Tomlinson and Mullin 2015). What is also important to understand about this reframing of the photographs of the incident in Nabi Saleh is that it was not intended to challenge the veracity of photography per se, but to contest the interpretation of these particular photographs as images of Israeli oppression and Palestinian resistance. The charge of 'Pallywood' was meant to interrupt the relationship between showing and knowing that these specific photographs were generally understood to entail.

The photographs of female members of the Tamimi family overpowering the soldier in particular were also framed in Israel as evidence of the perceived vulnerability of Israeli soldiers doing their jobs while serving in the West Bank under rules of engagement that supposedly limited their ability to defend themselves against Palestinian attack. This understanding of the 


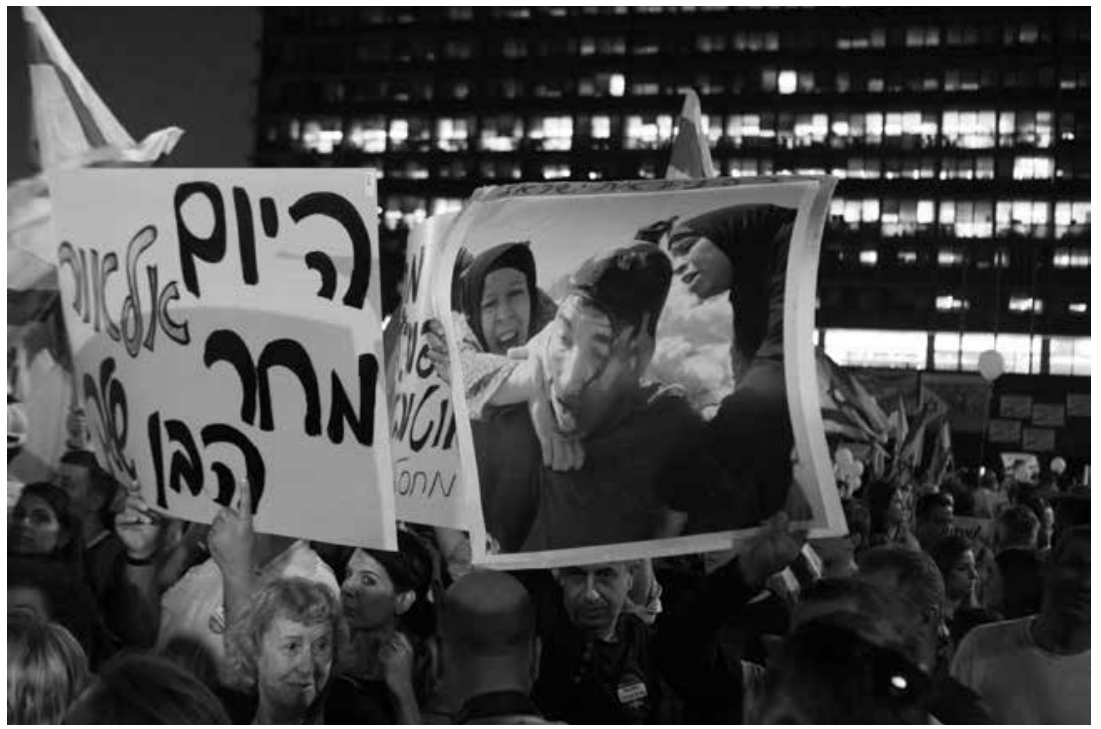

Figure 7.1. Oren Ziv, 'Protest calling for the release of Israeli soldier Elor Azaria, Tel Aviv, Israel, 19.4.16', 2016. Reproduced with permission of Oren Ziv/Activestills.

meaning of the photographs resulted in the staging of a counterdemonstration on the road near Halamish in support of the Israeli army in Nabi Saleh on Friday 4 September, a week after the initial incident. 5

A closely cropped version of one of the photographs showing the Israeli soldier being accosted by two female members of the Tamimi family was also used in a demonstration months later in Tel Aviv on 19 April 2016 (see figure 7.1). This demonstration was organized in support of the Israeli soldier Elor Azaria, who had been arrested on a charge of murder in March 2016 after fatally shooting an already incapacitated Palestinian man in the head in Hebron. One of the demonstrators held a large print of the photograph at the top of which was written in Hebrew 'This is what Israel looks like', ${ }^{6}$ suggesting that the image was being used to show how Israeli soldiers and the Israeli military were being humiliated. This use of the photograph of the Nabi Saleh incident indicates that for some Israelis the images of this confrontation had a generic meaning informed by certain perceptions of Israeli victimhood. This example also indicates that the forms of visibility gained for protestors through the photographic amplification of their actions

5 This counterdemonstration can be seen from a distance at the beginning of Israeli artist and video-activist David Reeb's video of the protest from Nabi Saleh on that day (Reeb 2015).

6 My thanks to Oren Ziv for translating this slogan. 
is something that is often contested. Although the images produced for the photojournalism industry can benefit protest movements, the resulting images can also be appropriated and given contrary meanings by those who do not share the protestor's political view.

\section{Conclusion}

This chapter has involved the use of the Activestills archive as a source of photographic evidence for discussions of two significant ways that photography has been deployed in relation to protest in Israel/Palestine: the carrying and showing of photographic images during demonstrations and the use of photography to extend the visibility of protest beyond its immediate spatial and temporal limits. The discussion of these subjects has been informed by understandings of photography as a means of capturing and transporting appearances and as a form of documentation that works through what Lisa Gitelman calls the know-show function that defines all documentary forms. But what of the Activestills archive itself? Can the archive be discussed separately as something that has a place within the aesthetics of protest?

Vered Maimon and Shiraz Grinbaum have argued that the key characteristic of the Activestills archive is its 'openness to perpetual updating and rewriting' as members of the collective upload new images of protests as they happen (Maimon and Grinbaum 2016: 34-35). For them, this makes the archive 'an archive of the present, vibrating with political potency and urgency as it constantly displays, circulates, and reframes the precariousness of its subjects and their images of relentless protest' (Maimon and Grinbaum 2016: 35). This approach to the archive is in keeping with the aim of the collective to be responsive to current political struggles. It also makes clear the difference between the Activestills archive and more traditional archival collections that relate primarily to the past. However, this approach also downplays the significance of the majority of the images held in the archive that do not depict very recent events.

In contrast to Maimon and Grinbaum's definition of the Activestills archive as an 'archive of the present', it is worth considering the value of the archive as something that documents the struggles of the past. This is worthy of consideration on the understanding that current political struggle always involves a relationship to dissent in the past. Palestinian national struggle in particular involves a collective consciousness of the unresolved historical injustice of the Nakba (catastrophe) of 1948 and also collective memories of 
resistance to dispossession and occupation that have been shared across generations. This means that Palestinian struggle is not simply about the immediate present, but more precisely about the present as a continuation of the resistance and steadfastness (sumud in Arabic and Palestinian political parlance) of the past. Thought about from this perspective, the Activestills archive gains a value as a collection of images that can enable the viewing of struggles as they develop over time. Moreover, the archive has value as a repository of visual evidence of ongoing protest in a wider political context within which struggle has been constant, but also fleeting and subject to forgetting. This is particularly significant, given the deliberate destruction and looting of archives relating to Palestinian national struggle by the Israeli government (Sela 2017) as part of what Baruch Kimmerling has called the 'politicide' of the Palestinians (Kimmerling 2003).

The discussion in the preceding section noted the street exhibitions staged in Bil'in by Activestills as part of demonstrations to mark the second and tenth anniversaries of the beginning of the struggle in the village. These exhibitions involved the bringing together of images of protest from different moments so that the history of community's own resistance could be shown back to them. As such, the exhibitions demonstrate a potential function of the archive as a source for visual histories of struggle that could be fed back into cultures of protest in the present. If one searches within the archive using the place-name 'Bi'lin', this results in the identification of 2,259 photographs that go back to $2005 .{ }^{7}$ These photographs depict a wide range of scenarios, including demonstrations, direct actions, creative activism, stone-throwing, injuries, arrests, village invasions, prisoner releases, and the funerals of community members killed during the demonstrations. The photographs also document the changing conditions of protest within Bil'in, starting with images of demonstrations at a time when the barrier was yet to be built on village land up to the current situation where the original fence system has been moved further away from the village and replaced by a concrete wall. Such a rich and accessible collection of images of a single struggle is a rare resource that could have as yet undefined uses in relation to further acts of protest in the future.

This discussion returns us to the subject of the photographic amplification of protest discussed in the preceding section. The discussion of this subject involved an understanding that, in the case of photography, the aesthetics of protest is not just a matter of the immediate spatial and temporal context of protest, but also of how photographs are used to mediate and extend 
this context. The crucial question here is how far can this extension of the scene of protest be understood to go? If the photographic amplification of protest is part of the aesthetics of protest, then is there a temporal cut-off point when this no longer applies? The suggestion being articulated here is that this is not the case and that photographs of past protest can continue to contribute to the aesthetics of protest long after they were taken and first circulated. Think, for example, of the cultural longevity of images of the Civil Rights movement. These images have continued to have a cultural 'life' both in terms of broader social understandings of dissent and in relation to subsequent protest movements that have mobilized these images from the past as means of ascribing significance to their own actions (see Vis et al. in this volume). Is this a way that images of protest in the past held in the Activestills archive could function in the future? This is not something that can be predicted. However, reflecting on this matter allows for the consideration of the role of photography within the aesthetics of protest beyond both its use in the immediate context of protest and as a means of amplifying protest in its initial aftermath. This suggests that any further study of the role of photography in relation to the aesthetics of protest should be open to thinking about how photography as a tool can extend the aesthetic presence of protest over much longer periods of time than one might at first consider.

\section{References}

Activestills. 2015. 'About Us', Activestills website. http://activestills.org/about.php. Accessed 31.03.19.

Bailo, Francesco, and Ariadne Vronicu. 2017. 'Hybrid Social and News Media Protest Events: From \#MarchinMarch to \#BusttheBudget in Australia', Information, Communication, and Society 20(11): 1660-1679.

Berger, John. 1972. 'Understanding a Photograph', in Selected Essays and Articles: The Look of Things, 178-182. Harmondsworth, Middlesex: Penguin.

Berger, John, and Jean Mohr. 1982. Another Way of Telling. London: Writers and Readers Publishing.

Berger, Maurice. 2010. For All the World to See: Visual Culture and the Struggle for Civil Rights. New Haven: Yale University Press.

Brighenti, Andrea. 2007. 'Visibility: A Category for the Social Sciences', Current Sociology, 55(3): 323-342.

Butler, Judith. 2012. 'Bodies in Alliance and the Politics of the Street', in Sensible Politics: The Visual Culture of Nongovernmental Activism, ed. Meg McLagan and Yates McKee, 117-137. New York: Zone Books. 
Cottle, Simon. 2008. 'Reporting Demonstrations: The Changing Media Politics of Dissent', Media, Culture and Society 30(6): 853-872.

Ehrenreich, Ben. 2013. 'Is This Where the Third Intifada Will Start?, New York Times, 17 March.

Faulkner, Simon. 2013. 'Images and Demonstrations in the Occupied West Bank', JOMEC Journal:Journalism, Media, and Cultural Studies 4. https://jomec.cardiffuniversitypress.org/articles/abstract/10.18573/j.2013.10254/. Accessed 31.03.19.

Faulkner, Simon. 2016a. 'Contentious Displays: Activestills' Street Exhibitions', in Activestills: Photography as Protest in Palestine/Israel, ed. Vered Maimon and Shiraz Grinbaum, 74-87. London: Pluto Press.

Faulkner, Simon. 2016b. 'Images at a Distance', Regarding Spectatorship website. http://www.regardingspectatorship.net/images-at-a-distance/. Accessed 31.03.19.

Gitelman, Lisa. 2006. Always Already New: Media, History, and the Data of Culture. Cambridge, MA: MIT Press.

Gitelman, Lisa. 2014. Paper Knowledge: Toward a Media History of Documents. Durham, NC: Duke University Press.

Herron, Tom, and John Lynch. 2006. 'Like "Ghosts Who'd Walked Abroad”: Faces of the Bloody Sunday Dead', Visual Culture in Britain 7(1): 59-77.

Johnson, Davi. 2007. 'Martin Luther King Jr.'s 1963 Birmingham Campaign as Image Event', Rhetoric \& Public Affairs 10(1): 1-25.

Kimmerling, Baruch. 2003. Politicide: The Real Legacy of Ariel Sharon. New York: Verso. Lippard, Lucy. 1990. A Different War: Vietnam in Art. Seattle: Real Comet Press.

Maimon, Vered, and Shiraz Grinbaum. 2016. 'Introduction', in Activestills: Photography as Protest in Palestine/Israel, ed. Vered Maimon and Shiraz Grinbaum, 28-38. London: Pluto Press.

McAdam, Doug. 2000. 'Movement Strategy and Dramaturgical Framing in Democratic States: The Case of the American Civil Rights Movement', in Deliberation, Democracy, and the Media, ed. S. Chambers and A. Costain, 117-133. Lanham: Rowman \& Littlefield.

Memou, Antigoni. 2013. Photography and Social Movements: From the Globalisation of the Movement (1968) to the Movement against Globalisation (2001). Manchester: Manchester University Press.

Nancy, Jean-Luc. 2005. The Ground of the Image. New York: Fordham University Press.

Newbury, Darren. 2009. Defiant Images: Photography and Apartheid South Africa. Pretoria: Unisa Press.

Price, Mary. 1994. The Photograph: A Strange, Confined Space. Redwood City, CA: Stanford University Press.

Rancière, Jacques. 1999. Disagreement: Politics and Philosophy. Minneapolis: University of Minnesota Press. 
Reeb, David. 2015. Nabi Saleh 4.9.15 [video], YouTube, 4 September. https://www. youtube.com/watch?v=qHHytzcL-Z8. Accessed 08.11.18.

Sela, Rona. 2017. Looted and Hidden: Palestinian Archives in Israel [video]. Vimeo. https://vimeo.com/213851191. Accessed 31.03.19.

Shore, Stephen. 2010. The Nature of Photographs: A Primer. London: Phaidon.

Tomlinson, Simon, and Gemma Mullin. 2015. 'Questions Raised over Shocking West Bank Image of boy with a Broken Arm Being Held at Gunpoint by an Israeli Soldier after Girl, 13, Seen Biting Attacker Is Revealed as Prolific "Pallywood Star", Daily Mail, 28 August. https://www.dailymail.co.uk/news/article-3214441/ Remarkable-moment-young-girl-bites-Israeli-soldier-two-women-overpowerputs-Palestinian-boy-broken-arm-headlock-gunpoint-clashes-West-Bank.html. Accessed 31.03.19.

Wigoder, Meir. 2016. 'Communities of Touch: Photography's Spaces of Appearance', in Activestills: Photography as Protest in Palestine/Israel, ed. Vered Maimon and Shiraz Grinbaum, 196-203. London: Pluto Press.

\section{About the Author}

Simon Faulkner is a Senior Lecturer in Art History and Visual Culture at Manchester School of Art, Manchester Metropolitan University. His recent individual research has focused on relationships between visual practices and the Israeli-Palestinian conflict. This research has addressed a range of artistic and photographic work, and has been particularly concerned with the ways that visual images are used for political purposes within the divided geography of Israel/Palestine. This work has resulted in a number of publications, including the book Between States (Black Dog Publishing, 2015), developed with the Israeli artist David Reeb. Since 2014, he has also been a member of the Visual Social Media Lab, the work of which focuses on researching social media images. 



\title{
8 Drones, Cinema, and Protest in Thailand
}

\author{
Noah Viernes
}

\begin{abstract}
The drone is defined within the duality of indifference and depersonalization, but also elevates a specific technology of seeing above fluid expressions of collectivity. This chapter addresses the drone as a mechanical device and figurative analogy of clarification that helped to organize ideological divisions into an objective narrative of the 2014 military coup d'état in Thailand. To critique these droned hierarchies, I draw upon Jacques Rancière's conception of the 'politics of aesthetics' to address independent Thai cinema as a regime of 'fictionality' where the personalization of protest returns. The fictionality of Prapat Jiwarangsan and Danaya Chulphuthipong, two Thai film-makers, reconfigures the field of protest by extending its duration into an expanded realism of post-coup oppression and resistance.
\end{abstract}

Keywords: aesthetics, drone theory, cinema, Thailand, coup d'état, personalization

\section{Introduction}

Between 2006 and the 2014 coup d'états, political disagreements in Thailand were stretched across Bangkok in cinematic cuts between radical, progressive, and conservative forces competing for a place in the timeline of historical moments. The most dominant among them, the Bangkokconcentrated Yellow Shirts, built their reputation upon a street presence that ushered in the 2006 coup d'état, and drew upon this experience to promote the 2014 coup d'état that remains in place the time of writing. Represented as hostile antagonists in dominant media channels, a coalition of rural

McGarry, A., I. Erhart, H. Eslen-Ziya, O.Jenzen, U. Korkut (eds), The Aesthetics of Global Protest: Visual Culture and Communication. Amsterdam: Amsterdam University Press, 2020 DOI 10.5117/9789463724913_CHo8 
outsiders and urban dissidents known as the Red Shirts fought back to sustain a series of progressive changes that had, ironically, been achieved under the neoliberal populist prime minister, Thaksin Shinawatra. In the scopic regime of tanks, snipers, and assassinations between 2010 and 2014, the Red Shirt opposition was diffused. The opposition was further divided by post-coup re-education camps, radio station closures, the restrictions of martial law, and military-drafted constitutional articles. This chapter reflects upon visual manifestations of protest in order to move beyond existing binaries in Thailand. First, I treat dominant media tropes, especially in drone camera captures of the 2013-2014 protests, as a channelling of voices across a hierarchy of screens. Second, I demonstrate how two independent Thai films, The Asylum (2015) by Prapat Jiwarangsan and Night Watch (2015) by Danaya Chulphuthipong, recover silenced voices in their personalized disruption of media conventions.

These two short films highlight the emergence of a protest cinema because they incorporate a 'fictionality' that disrupts how bodies often appear. Positioned in a rural forest and an alienated space of the city, the characterization of seeing, hearing, and speaking extends protest beyond dominant screens. At the height of the conflict, the state mediums that captured street-based movements changed, from television and traffic cameras to technologically updated drones, but remained focused on the visual antagonisms that territorialize the event in images of disorder. This dominant protagonist-antagonist fiction worked towards a desire for consensus by foreclosing the space of politics in the vocabulary of mobs and what E.P. Thompson described as the 'spasmodic view' (Thompson 1971: 76). For the political theorist Jacques Rancière, speaking from the elevated perception of known politicians or common narrative tropes means being 'caught in a structure of the visible where everything is on show and where there is thus no longer any place for appearance' (Rancière 1999: 103). Consequently, the primacy of one regime of visibility relies on the presupposition of the evacuation of other voices from the screen. This logic of national or state representation is always a miscount of bodies that can only be recovered through what Rancière calls the 'partition of the sensible', i.e. a disruption of 'the distribution of places and roles, and the systems for legitimizing this distribution' (Rancière 1999: 28). For Thailand, dissidence did not end in the wake of the 2014 coup, but worked from a space of exile and discouragement that I address below in the possibility of an independent camera. I begin with drone cameras that captivate attention through a technological superiority analogous to the objective eye of the state. These cameras ensure that the viewer recognizes who and what matters, 
while 'independent' films fictionalize the space of protest as personalized departures where the possibility of disagreement remains.

\section{Theories of the Drone}

Between 2013 and 2014, a technologically advanced regime of images came to dominate the representation of the Thai polis in Bangkok. Unlike the horizontal redirections of modernist urban public culture like the Democracy Monument (Dovey 2001: 273), these heavily Twittered, Facebooked, and YouTubed perspectives framed the nation from new vantage points. New to the scene of protest perspectives, a bird's-eye/God's-eye view of Bangkok hovered above in the form of 'quadcopter' citizen drones buzzed through the sky to record the escalating protestor numbers and the violent clashes. Down below, official CCTV traffic cameras recorded unexpected explosions that interrupted protest movements. But the triviality of drone cameras drew out numerous perspectives around the claim to truth, objectivity and responsibility, and invited the viewer into a screen that captured all sides. The distanced gaze overlooked the affective intensity of social movements even as it framed an erratic anger towards injustice. On the screen, the People's Democratic Reform Committee (PDRC) comprised an urban mass that wore Yellow Shirts in previous editions of Bangkok protest in the past decade. They sought the end of the so-called 'Thaksin regime', an action that protestors chalked across a protest zone as if it was meant for a cinematic establishing shot. Across town, in another drone capture, the United Front for Democracy against Dictatorship (UDD), or the Red Shirts, assembled in a stadium near the nation's largest university to defend their vote. The sea of red looked more like a sporting event, like a blimp shot that eludes the unsightliness of the city. Tom Conley (2003) writes how these bird's-eye-view shots place spectators into a fantasy of 'panopticism' (2003: 216), safe from the details down below because billboards and advertisements stand out most. From drone to drone, the assembly of the people was visualized in the promotional culture of two sides heading towards confrontation. As Janjira Sombatpoonsiri remarks of the time, "[p]ublic assembly spiraled out of control, resembling a scene of civil war' (2017: 111).

It is precisely when the polis seems to be breaking apart that cameras piece it back together as total representation. On the one hand, a drone calls for security through surveillance and is replayed in the cinematic cuts between hostility to solidarity. But the distance between the camera and the spectator conceals the 'manning' of this overhead perception. The virtual immersion of the spectator at a safe remove from the scene formulates 
several questions about the mediums of protest images. First, where does the drone come from? Friedrich Kittler (1999) argued that militarization played a key role in the organization of technology, a point that can be linked to the contemporary function of a 'citizen' drone in Bangkok protests as much as the deployment of drone as a weapon in the War on Terror. 'Media determine our situation' (Kittler 1999: xxxix), he wrote, emphasizing how technology transitions from war to everyday life. In A Theory of the Drone, Grégoire Chamayou reinforces this technological collusion. The drone emerges from a dream 'to construct a bodiless force, a political body without human organs' (2015: 221). He is referring to a transition from a collective sovereignty that internalizes an image of the people to a mechanical apparatus that hovers above them. But what happens when citizens deploy technology against the state? On 11 June 2013, some months before the Bangkok protests began, Turkish police shot down a citizen drone as it framed the tear-gassing of Taksim Square. In Forbes magazine, Michael Peck (2013) described the incident as a global confrontation between state abuse and citizen-made visual cultures attempting to increase transparency. It is hard to know when exactly the transition to this 'objective' drone began and, specifically, when the politics of protest was narrowed to two sides captured in this vertical reality. In November 2011, a 'talented handyman' sent a RoboKopter drone into the airspace of a Polish Independence Day parade to capture the escalating confrontations between the extreme right-wing nationalists and antifascist protestors (Lambert 2013: 61). From the Euromaidan protests to the far-right violence in Charlottesville, Virginia, in 2018, the remote eye of the drone hovers in the sky as an objective party establishing the boundaries of division and debate.

In the Thai case, protest drones responded to a practical concern among videographers entering a precarious field of violence. In his journal entries about the 2010 Red Shirt protests, Claudio Sopranzetti (2012) observed that a large gathering of videographers is a sign of danger driven by a need to capture hostility. Because the polarity of division is never resolved, visual evidence is preferred. Could it be that perceptions of the body politic would change, if we consider how this public evidence converses with other personalized cameras? How might we think protest as an assemblage of projections, images, and frames assembled more around aesthetic dimensions than state tropes? My response is rooted in the post-coup strategies of dissidence in Thailand, especially those confronted by the polarizing distance of politics under dictatorship. Better-known protest strategies confront dictatorship publically, either through mass movements such as the Yellow Shirts or the Red Shirts, or, more recently, through decentralized anti-coup groups, such 


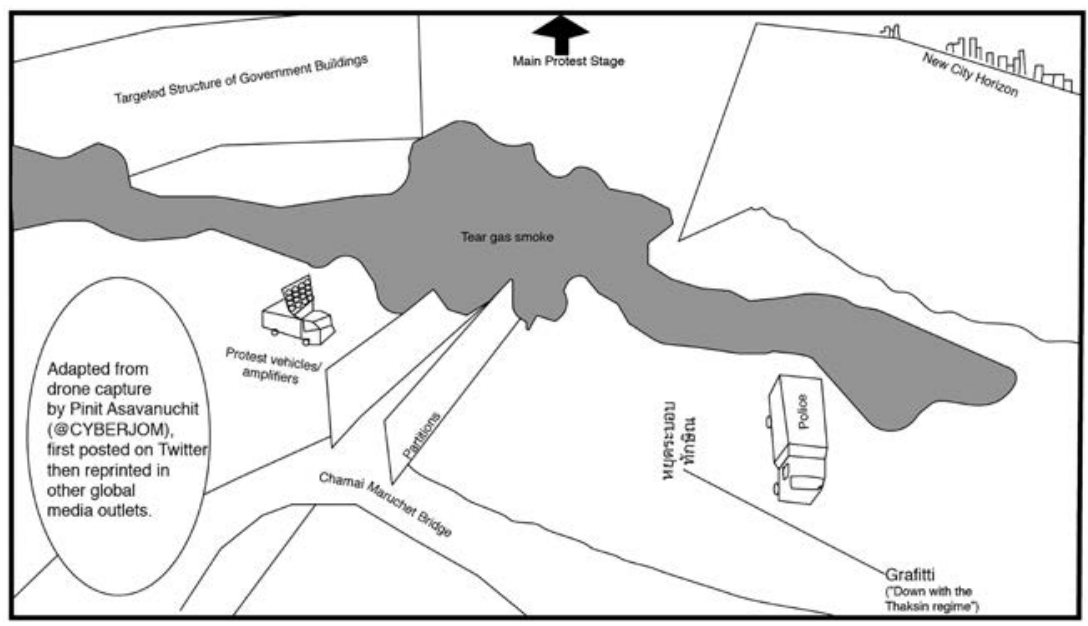

Figure 8.1. Drone Space. Self-sketch of a drone capture.

as Resistant Citizen, whose tactics range from public assembly on mass transit lines to music videos. The latter groups not only inspire an extended duration of protest beyond the official timeline of national events, but also trigger me to search for other manifestations of protest in Thailand today. As dictatorship persists, the space of departure from the public realm expands. In these departures, protest becomes a parallel space for complicating the prominence of true images with an affective imagination of resistance that takes over during the waiting period.

\section{The Militarized City}

I argue that any capture of sides is simultaneously ideological and aesthetic in that the objectivity and technological superiority of drones is undercut by the convergence of recording and seeing; as if 'overlooking' is somehow disembodied from protest. In the above image, smoke emanates from the tear gas canisters during a confrontation at Chamai Maruchet Bridge, where the Network of Student and People to Reform Thailand (NSPRT) - a security wing of the pro-military PRDC - negotiate a police cordon along the route to the nearby Government House. The PDRC escalated its disagreement with the 'populist' government in an all-out street assault as a seemingly objective drone opens new perspectives of the conflict to public view. The drone is depersonalized and alienated, removed from the street as a neutral observer of two opposing sides. This objective position renders the technology perfect for a gaze depopulated of personalities. In fact, this way 
of looking perpetuates the continuity of some rational order in what Peter Adey (2010) calls the 'aerial gaze': i.e. a view that evacuates subjectivity. 'Now, and from above, the eye is neither clouded with subjectivity nor distracted by feelings; it is calculated, it is truthful' (ibid.: 86). By conditioning the perception of protest from above, the 'gaze is filtered' into a readable plan with the potential to further the regime of control of the subjects down below. Even though the sounds of a drone, Adey emphasizes, feed the perceptual and 'affective atmospheres of fear' (ibid.: 172), the fear is displaced to off-screen zones of a coming military dictatorship. We hear these sounds in a video posted on Twitter by Pinit Asavanuchit (@CYBERJOM), but the message is silently channelled in references amplified elsewhere. 'Down with the Thaksin regime' is chalked across the pavement to mobilize our attention towards the government of his sister, Yingluck Shinawatra, as the perpetrator of disorder. Just as institutions work from the top down, so too does the God's-eye view rely on generalization. The low angles of the street might tell a different story. But why does this one prevail?

On one hand, the drone is novel and new, unlike any previous framing of Bangkok protests. The drone glides neutrally along Phitsunalok Road with a field of view that frames key actors: a police van, the government house, a security wall to protect it, the protestors attempting to breach it, and the preserved landscape of a modern bureaucratic core that reinforces dominant representations of the political alongside the skyscraper city that does not appear here. The horizon bends with the fish-eye lens that allows the drone to partially immerse in dreamy clouds of tear gas before turning towards the more populated demonstration stages. The video, entitled Chamai Clash at Dusk (Asavanuchit 2013b), is far less melodramatic than the drone operator's subsequent posts. CU against Amnesty Bill 5 Nov 2013 (Asavanuchit 2013a), for instance, engages the upbeat orchestration of an American frontier biopic and intertitles, such as 'Lecturers, staff, students and alumni rally together' in order to fold a prestigious organization into the moral order of protest. I am more interested in how it converts protest into a new form of objectivity at the expense of personality. What happens when the dominance of a technological image stands for all and no one at the same time?

The drone is the culmination of how cities coincide with 'pixels' and 'actions' since, according to Nicholas Mirzoeff (2015), political activism must become 'visual activism' if it is to communicate in contemporary terms. But often, the camera angles condition our seeing without the reminder that we were not there. On one side, a government, bolstered by the presence of riot police, seeks to hold on to power in the face of the well-organized PDRC. 
Over 150,000 people began to occupy several parts of the city at the beginning of November 2013 to intensify their grievances against the Yingluck government. The protestors were especially angered by the Amnesty Bill passed suspiciously through the House of Representatives in the early morning hours of 1 November 2013, which would have paved the return of Thaksin from exile. For Yingluck's Pheu Thai (For Thai) Party, the Amnesty Bill was originally planned as a conciliatory concession to military leaders and government officials who ordered the 2010 crackdown on the United Front for Democracy against Dictatorship (UDD) protests. But the protestors emphasized the persistence of a 'Thaksin regime' to suggest that even the military coup on 19 September 2006 could not prevent his ability to influence domestic politics. The PDRC reignited an alliance of sporadic middle-class street provocateurs and conservative, royal, and heritage-minded nationalists (Tejapira 2006; Winichakul 2008). Thai protest thus appeared as a split between these forces of the extreme right and the antagonism of a rural/ urban alliance of Thaksin-aligned neoliberal populists.

Years earlier, there were no drones to frame the Red Shirts' protest against the appointment of the urban and conservative Democrat Abhisit Vejajiva. During these 2010 protests, the emergent social media followed a similar narrative escalation by amplifying two ideological positions in dominant media outlets. The televised appearances of government security officials aligned with local radio broadcasts of a Redshirt 'mob', while hotel lobby posters played to global fears of 'rebel cities' (Harvey 2012) that must be pacified according to the prerogatives of global tourism and investment. The attempt to visualize disorder in the promotion of militarized security is precisely where disruption becomes political. Rancière writes that 'the organization of bodies as a community and the management of places, powers, and functions' (1999: 99) require constant policing of who is counted (or visualized) as part of the political body. In this distribution of sensibility, protest is the claim to visibility of 'those who have no part' in official counts, surveys and images of the political body. On Flickr, Bunika Chatakul's (2010) post of an overturned military vehicle on 11 April 2010 was neither the loudest nor exemplary of the event's main characters. Channelling a contemporary form of 'photographic amplification' (see Faulkner, this volume) we read the morning after tear gas, live fire, and the government's failure to remove Red Shirts from the city's 'heritage' district in a caption that reads 'and nothing will ever be the same'. Of course, nothing will be the same for all those who count themselves in a disrupted image of an overturned military vehicle with 'tyrant' spray-painted in red alongside numerous other graffiti tags. The photograph does not attest to a victory of the Red Shirts, but 
manifests the multiple modes of confrontation in a multimediated city. In the expanded duration of a photograph, a political subjectivity emanates; the very subjectivity that Adey (2010) finds to be evacuated from the objectivity of the drone. Inscriptions of political subjectivity are a necessary component of relocating protest from public phenomenon to the extended duration of personal experience (Al-Saleh 2015; Bordowitz 2003; Mason 2012).

Civil war in Thailand directly translates as 'war in the middle of the polis' (songkhram klang meuang), which aptly expresses why divided cities rely on a visual culture of truth and frames that appear as objective. For Bangkok, the zoomed-out drone framed the coming militarization as inevitable when it cut to street-level media. In one example from early December 2013, the PDRC-led Network of Students and People for Reform of Thailand (NSPRT) attacked buses along the route to a Red Shirt counter-protest. Passengers were forced to remove their shirts and other 'red' items. Street fights ensued, bombs were detonated, and a PDRC leader was assassinated in his motorcade. The PDRC called on the government to take responsibility for these deaths, as the army's highest-ranking general and current PM, Prayuth Chan-ocha, proposed to mediate a dialogue between the two groups. On 8 December, Yingluck dissolved the government and set elections for 2 February 2014. But in the final PDRC push, protestors returned to the streets under the name Shutdown Bangkok, Restart Thailand. As they shut down government ministries and blocked most polling stations, the 2 February election devolved into sporadic armed street battles.

Zoomed out, drones missed the perspectives of the street. Zoomed in, disorder promoted security. This multimediated sensibility climaxed in the official channels of television because this is where representation could be policed in mass media-friendly generalizations. On the evening of 22 May 2014, the end point of the PDRC protests, army general Prayuth Chan-ocha assured television audiences that Thailand would 'quickly return to a normal state' (klap su sa-pha-wa po-ka-ti doi raew). The perception and anticipation of a normal state is a sensibility that can only be reproduced through a mediated regime of policing. The police are, first, an order of bodies that defines the allocation of ways of doing, ways of being, and ways of saying, and sees that those bodies are assigned by name to a particular place and task; it is an order of the visible and the sayable that sees that a particular activity is present and another is not, that this speech is understood as discourse and another is noise (Rancière 1999: 29).

A police order ensures that the spaces and times of national protest unfold according to dominant conventions: dialogue, debate, announcements, declarations or conversation among those certified to do politics. 
But policing also means qualifying an argument through moral tropes. The PRDC broadcasts, like those of the military at the time of the 2006 coup, were framed as a minority of so-called 'good people', through the visual repetition of a centripetal centre - the well-educated capital city, loyal disciples of the king, the sacrificial protest leader (many who had resigned from their governmental positions to lead the street protests), and so on. These broadcasts were designed to organize and order the political body, so that military necessity could be justified along the pretext of security. In the absence of a clear leader, the political body becomes a legitimation mechanism for security thinking. To secure the truth is to channel some images at the expense of others. To secure an area is to lay claim to it within a sovereign field that opens during moments of institutional crisis. When convention falls apart, the military seizes power.

\section{Cinema}

The above discussions of drones, civil war, and political instability inspire two directions for this analysis of social movements. The linking of media is inevitably global. The evolution of a medium is often political. Social movements rely on the presence of cameras to mark the immediacy of time in visions of anger, disagreement, and some bipolarity in an unbalanced body (Bordowitz 2004). In 'The Pixelated Revolution', Rabih Mroué (2017) illustrates a perfect scenario of this tension in the confrontation between the low-resolution visual culture of demonstrators and the violence of the state as concealed in official Syrian media. To think through this scenario, Mroué imagines protestor film-making as an emergent global cinema that challenges prior conventions of realism in visual culture (e.g. as a critical rejoinder to the handheld film-making of the Dogme 95 manifesto that revolutionized independent film at the turn of the century). He decides to read the pixelated digital videos of the Syrian revolution to devise a manifesto capable of leading demonstrators to an 'establishment phase' where an anxious handheld aesthetic might, someday, shift towards a more fixed position. But for now, what counts is that their realism might impact our vision, and that the image-as-protest might play a larger role in how we link our eyes to cameras. Mroué cites his experience of the Lebanese Civil War when images should have counted as evidence against the amnesty of the early 199os that exonerated criminals. The pixelated images do not replace laws, but exist as a protest against the police order of the state that stabilizes their status quo in tripods, television, and moral tropes. Their shots are not meant to immortalize a moment or an event, but rather a 
small portion of their daily frustration, fragments of a diary that might one day be used in the writing of an alternative history (Mroué 2017:484).

We must, as Mroué insists, consider the challenge of each medium to its time in the recovery of what we know is happening off-screen. In the case of early 199os 'democratization' in Thailand, for instance, William Callahan (1998) wrote of the significance of post-event photographic exhibitions in crystallizing an official narrative of democratic change, while Annette Hamilton (1993) and Alan Klima (2002) wrote of the open-ended format of the blank videotape for rendering transparent the violence of the military - as crackdowns could not be aired on television. As duration, the mechanical reproduction of images inevitably brackets disagreement inside the frame of black-and-white photographs, radio waves, television, bootlegged video, social media and now drones. Mroué's point is that cinema, too, must maintain its commitment to protest as an aesthetic manifestation of collectivity. As dimly lit subjects in darkened landscapes, we might also refer to this politics in the context of what Özge Özdüzen calls 'DIY citizenship' (see Özdüzen, this volume).

With the return of the military in the 2014 coup, tension built in the space between analogue and digital technologies, for example, in the shutdown of radio stations and the seizure of data to implicate 'subversive' activity. Prapat Jiwarangsan's 2015 short film The Asylum, released one year and three months after the coup, is set in this context and links its protest to the alienating exile of military rule. In the film, a Karen immigrant boy from Myanmar and a middle-aged woman pass time together in a northern Thai jungle. For Thai cinema, the jungle exists as a multidimensional reference to exiled demonstrators of the 1970 s who fled to join a Communist insurgency. It is also a recurring space of reflection on marginality and dehumanization (for instance, in the films of Thailand's most well-known independent film-maker, Apichatpong Weerasethakul). Here, the aesthetics of protest relies on the characterization of how these characters share this space of exile as a consequence of militarization. The boy is here as a consequence of another military regime, and relegated to the condition that Giorgio Agamben calls 'bare life' by the policing of the nearby border. He passes time by throwing stones into a nearby pond. The scene recalls Agamben's work, specifically, because there is a boundary marker in the frame that aligns the forest with the Italian political theorist's reference to 'the camp' as a space where citizens are reduced to expendable bodies. While Bangkok streets appear on TV and citizen drones, the provinces do not. So too is the forest an exceptional space, i.e. 'a space in which sovereignty exists but the law does not, a territory in which actions [of the state] are neither legal nor 
illegal' (Agamben 2007: 53). Nearby, the woman recites a monologue from an imaginary Red Shirt radio station that, in real life, has been shut down in the new regime's attempt to conquer the territory north of Bangkok.

Here, the film's aesthetics of protest is the recovery of bodies that attest to the incompleteness of the Thai political image. Prapat's camera disrupts this image in what Rancière (2004: 37) cites as the space of 'fictionality' that challenges 'everything silent and the proliferation of modes of speech and levels of meaning'. This fictionality does not preclude truth, but rethinks bodies beyond the conventions of a militarized image. In treating the connection between fiction and realism, Rancière (2018: 237-238) underscores fiction's political function in the 'expansion' of 'random moments' into the lives of characters that rarely find their place in the dominant chronicles of historical moments. On 22 May 2014, the day of the twelfth successful Thai military coup, an anti-military media activist, who works under the pseudonym 'Daeng', dumped his hard drive into a river in fear that it could be used to incriminate him under the newly imposed martial law (Lee and Darin 2014). While Daeng's digital archive of regional stories are decomposing in rust, the problem is also that media stories are being forgotten and while images of the oppressed are normalized, not by our own ignorance but in their redundancy (Sontag 1973; Shapiro 2008). From Thailand's rural north-east to the Muslim south, militarization and martial law escaped the kind of coverage captured in the accumulated images of Bangkok protests. In one story, Daeng reported that a ten-year-old child was kidnapped in order to compel a dissident relative, an area radio DJ, to report to the military. The Asylum references all of these stories, in the attempt to recover bodies in images of Thai protest, but also to promote the conditions of possibility for other associations.

The Thai title of The Asylum is Dork Rak (Crown flower), which stands for a radio station closed down after the 22 May 2014 coup. While closures to rural radio stations for political reasons were not uncommon, the declaration of martial law institutionalized the repression with the exceptional conditions of national division. The ruling National Council for Peace and Order (NCPO) anticipated the end of martial law in promulgating an interim constitution on 22 July 2014, which contained the flexible Article 44 that incorporated emergency powers for the purpose of 'national security.' Defiantly onscreen, Varanee Tapanya appears in her forested exile to let the audience know that she's reporting live 'as usual', even as the boundary-marked forest and contemporaneous political context recalls the disrupted radio. It is 12 February 2015 and she has received a phone call to dedicate Pai Pongsathorn's local 'luk thung' folk song 'Wanna See You in My Dream' to three people. The song 
hints towards a dream world designed to escape the disenfranchisement of politics that aligns with a nearby bench designated as a space of waiting. So, too, are these rural audiences collectively waiting in the post-democratic imaginary. The film cuts to a young Karen boy, Ah Tay, as he throws rocks into a nearby pond. Matching the action, the camera follows the trajectory of the rocks into the pond where they sink into murky brown water. This is the space where Nietzsche located 'frog perspectives', to oppose the desire to 'paint' an objective truth that is, at best, murky (Nietzsche 2002: 6). The camera dwells in the murky water to break the narrative dependence on clarity that does not comport with their realism. The soundscape seems to accentuate the involuntary gravity of a drowning victim, or the gaze of an underwater search team. We cut back to the radio DJ's monologue as she facilitates another song dedication, and then back to a medium-shot of rocks breaking the surface of the pond. In the cut between the world above and the world below, the sound design stands out as the difference between a multiplicity of voices - from a radio DJ to the resonance of forest animals - and the indecipherability of underwater frequencies. These sounds align with multiple camera shots as parts of a 'state' in the immersive sensibility of martial law. In a move from reportage to dramaturgy, Varanee amplifies her voice through the open field of poetry in her final remark:

Courage is from within

Turn your dreams into power

So to speak, life is similar to a blanket

That is shorter than our height

To cover the shoulders,

The tip of your toes will be exposed

But to cover the toes

It will slip off from your shoulders

So what could we do to sleep soundly under this blanket?

We just have to change our sleeping posture

Try lying on the side with knees bent

You can now cover yourself up in the warm blanket all night long

Our lives are not perfect

But it's good enough

If you can adapt yourself to the imperfections of life

Troubles and dead ends ruin your dream slowly

Sadness doesn't come from others

It's your heart that carries that weight

No one gets everything they want 
Yet no one gets nothing at all

For those who lost today

Stand up straight for tomorrow

The poem expresses the off-screen temporality that partitions so-called political action from waiting, a fixed picture of protest juxtaposed with the formlessness of adaptation that prompts an aesthetic turn. Varanee is now imagined in the same kind of exile given to the Karen boy as she gathers a hand full of rocks and tosses them into the river. For progressive audiences of independent Thai film, the poem surely recalls a similar assemblage of verses read in a voice-over at the end of Apichatpong Weerasethakul's contemporaneous film Cemetery of Splendour (2015). In both cases, a narrator vocalizes the poverty of political representation where the main protagonists shine as bright as the sun. In darkness, only dreams can ensure the persistence of personal visions.

The former prime minister, Thaksin Shinawatra, in the months after the 2014 coup, advised his Red Shirt followers to 'play dead' until elections (Webb and Temphairojana 2015). But years have passed without them. Military promises of an election 'one year and three months' from the seizure of power was then pushed to 'no later than' February 2019 (Hariraksapitak 2018). Movement between the government repression of the Red Shirts in 2010 and 2014, and the prolonging of military rule, does not make narrative sense. But in the abstractions of The Asylum, a space of exile is also a space of protest where oppositional strategies are reformulated, and dominant protagonists subverted.

While the province of The Asylum projects an exiled space of waiting, Danaya Chulphuthipong's Night Watch (2015) provokes the viewer to consider the violence of continuity. The film cuts across the divergent temporalities of militarization where, through a common Bangkok neighbourhood frame, a personalized camera captures the evening landscape of 22 May 2014 coup d'état. Whereas The Asylum projects a pastoral space of exile beneath the shadowy canopy of the jungle, the nocturnal activities of Night Watch unfold from a domesticated urban view where speed and the mechanical lights of the city ensure the continuity of labour even during the interruptions of military intervention. The establishing shot is one of many windows in a vertical city where workers are surrounded by, and alienated from, other workers who evaporate in the flow of media. In prior protests, the Red Shirts were emblematic of the mobility of a working class, whereas the PDRC protest ignored these horizontal structures in vertical appeals to a hierarchy of appointed 'good people' (Radcliffe 2014). 


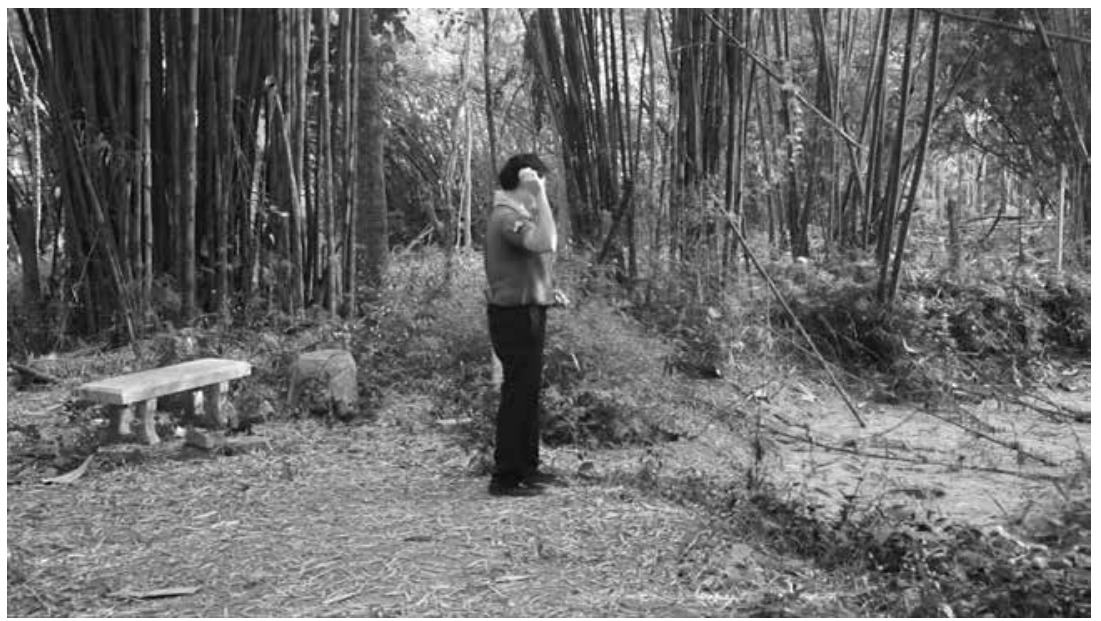

Figure 8.2. Throwing stones scene from The Asylum (dir. Prapat Jiwarangsan, 2015).

The scene moves from establishing shot to a televisual channel-switching sequence that juxtaposes military announcements and comical talk shows. The erasure of protest claims in the hierarchy of media can be read in what Raymond Williams (1989: 133) calls 'televisuality' because this form of information is, we find, a disposition of control: 'We can switch on and off for particular programmes but in some ways the programmes are conceived as a whole and they're often received as a continuity.' This controlled stream, Williams (2003: 91) goes on to argue, is not unlike a city in the sense that appearances converge in the 'planned flow' of the state. Danaya disrupts this continuity by cutting to the ground, the bottom of the vertical hierarchy, where two 'flashlight' shots emanate from the darkness as inversions of the bird's-eye view. The first shot projects a snail emerging from its shell, which escapes the conventions of realism in the more personalized framing of 'latent' power. The film then cuts to a toad that jumps off-screen where protest is converted into disappearance. Hanna Rose Shell (2012) explains that a 'camouflage consciousness' emerges around a will to disappear, especially when cameras assume the taxonomic function of clarifying subjects (from the human to the inhuman) in larger claims to truth. Like camouflage, this kind of film departs from the threat of publicity in the development of its own forms of visibility.

Unlike the 'quadcopter' drones raised above the city, these short films do not portend neutrality. In fact, Night Watch protests the time of the coup through the ominous pulse of a low-pitch audio drone sample. As a cinematic form of negation, the sonic drone is not uncommon in Thai film. 


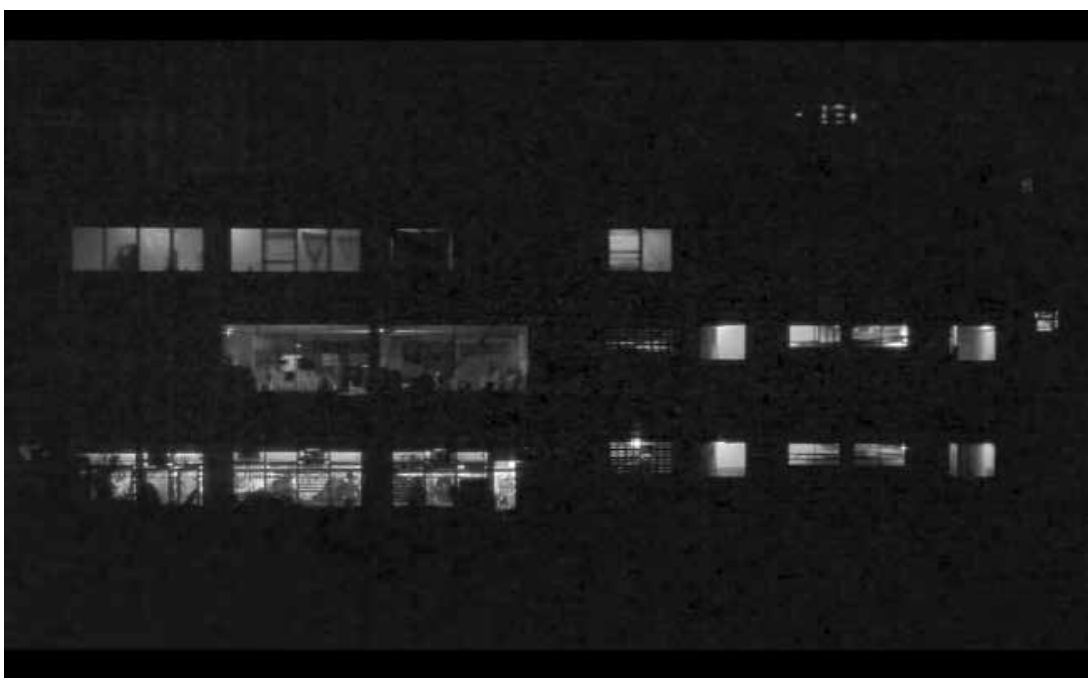

Figure 8.3. The continuity of work during a military coup, from Night Watch (dir. Danaya Chulphuthipong, 2015).

It surfaces in a scene banned from Apichatpong Weerasethakul's Syndromes and a Century (2006) in the aftermath of the 2006 coup, and a scene where memories of the 6 October 1976 protest dematerialize in the digitized global city in Anocha Suwichakornpong's By the Time It Gets Dark (2017). The Thai Ministry of Culture demanded that Nontawat Numbenchapol remove this kind of drone sample to lift a ban on his documentary critique of the Preah Vihear border dispute in Boundary (2013). In Night Watch, these sounds are especially resonant as the colour-coded flickering of red, white, and blue lights flash upon the continuous activities of nearby workers. Sounding the colour scheme of the national flag associates the symbolic trinity of nation, religion, and monarchy with forces that legitimize the coup. Whereas this distribution of sensibility extends into the representational coding of Red Shirts and Yellow Shirts, or 'good' people and 'corrupt' people, the representation of political voice is deformed by noise. Noise reverberates as a critical rejoinder to the impending silence of martial law, Article 44, Article 112, or any other harmonies of the state.

\section{Conclusion}

Political representation is often discussed under the presupposition of a complete image (or count) of sides. The protest drone is an analogy of this 
completeness, but also a recent technological novelty that records protestors with the machine-like precision of objectivity. Drones reinforced the appearance of a body pulled apart as a public plea for military intervention reinventing, even decentralizing, the historic state-led appropriation of radio and television. The drone is also the guise of neutrality in a spectator-led cinema of attractions, but this time linked to the mapping of hostile space and a need for narrative dénouement in an obvious story. The aesthetics of protest, like fiction - though no less real, is far less clear than the representation of protest. The fictionality of Thailand's post-coup cinema disrupts the representation of an ordered debate and interrogates who counts as a political voice during periods when laws are suspended and reformulated according to official perceptions. Consequently, film is an important protest aesthetic for remapping possible positions and sensory dispositions that always remain incomplete. While states prefer to see two sides in search of harmonious consensus, Prapat Jiwarangsan and Danaya Chulphuthipong deform the conventions of cinema and reconsider the relationship between visibility and audibility underlying militarization in Thailand. This contribution is highly significant for imagining the communities of protest to come, since this expanded duration of opposition is reformulating who and what counts as a relevant voice.

\section{References}

Adey, Peter. 2010. AerialLife: Spaces, Mobilities, Affects. Malden, MA:Wiley-Blackwell. Agamben, Giorgio. 2007. Profanations. New York: Zone Books.

Al-Saleh, Asaad. 2015. Voices of the Arab Spring: Personal Stories from the Arab Revolutions. New York: Columbia University Press.

Asavanuchit, Pinit. 2013a. CUagainst Amnesty Bill 5 Nov 2013 [video], YouTube, 12 December. https://www.youtube.com/watch?v=IRKjK_QmxXo. Accessed 31.03.19.

Asavanuchit, Pinit. 2013b. Patha chamai phlob kham [Chamai clash at dusk] [video], YouTube, 1 December. https://www.youtube.com/watch?v=5tInPbosw 3 U. Accessed 31.03.19.

Bordowitz, Gregg. 2003. 'My '8os: My Postmodernism', Artforum 41(7).

Bordowitz, Gregg. 2004. The AIDS Crisis Is Ridiculous and Other Writings, 1986-2003. Cambridge, MA: MIT Press.

Callahan, William. 1998. Imagining Democracy: Reading 'the Events of May' in Thailand. Singapore: Institute of Southeast Asian Studies. 
Chamayou, G. 2015. A Theory of the Drone. New York: The New Press.

Chatakul, Bunika. 2010. Morning After [photograph], Flickr, 12 April. http://www. flickr.com/photos/bunika-snaps/4595427518/. Accessed 31.03.19.

Conley, Tom. 2003. 'The City Vanishes', in After-Images of the City, ed. Joan Ramon Resina and Dieter Ingenschay, 209-224. Ithaca: Cornell University Press.

DeCaroli, Steven. 2007. 'Boundary Stones: Giorgio Agamben and the Field of Sovereignty', in Giorgio Agamben: Sovereignty and Life, ed. Matthew Calarco and Steven DeCaroli, 43-69. Stanford: Stanford University Press.

Dovey, Kim. 2001. 'Memory, Democracy and Urban Space: Bangkok's "Path to Democracy"', Journal of Urban Design 6(3): 265-282.

Fox, William L. 2009. Aereality: On the World from Above. Berkeley: Counterpoint Press.

Hamilton, Annette. 1993. 'Video Crackdown, or the Sacrificial Pirate: Censorship and Cultural Consequences in Thailand', Public Culture 5(3):515-531.

Hariraksapitak, Pracha. 2018. 'Thai PM Now Says Election to Be Held No Later Than Feb 2019', Reuters, 27 February. https://www.reuters.com/article/us-thailandpolitics/thai-pm-now-says-election-to-be-held-no-later-than-feb-2019-idUSKCN1GBoQS. Accessed 31.03.19.

Harvey, David. 2012. Rebel Cities: From the Right to the City to the Urban Revolution. New York: Verso.

Kittler, Friedrich. 1999. Gramophone, Film, Typewriter. Stanford: Stanford University Press.

Klima, Alan. 2002. The Funderal Casino: Meditation, Massacre, and Exchange with the Dead in Thailand. Princeton: Princeton University Press.

Lambert, Léopold. 2013. The Funambulist Pamphlets, Vol. 5: Occupy Wall Street. New York: Punctum Press.

Lee, Alexandra, and Catherine Darin. 2014. 'Martial Law in Thailand's Northeast Creates Common Cause between Pro-democracy, Community Rights Groups', Prachatai, 20 December. http://www.prachatai.com/english/node/4624. Accessed 31.03.19.

Mason, Paul. 2012. Why It's Kicking OffEverywhere: The New Global Revolutions. New York: Verso.

Mirzoeff, Nicholas. 2015. How to See the World. New York: Basic Books.

Mroué, Rabih. 2017. 'The Pixelated Revolution', in Former West: Art and the Contemporary after 1989, ed. Maria Hlavajova and Simon Sheikh, 477-488. Cambridge, MA: MIT Press.

Nietzsche, Friedrich. 2002. Beyond Good and Evil, ed. Rolf-Peter Horstmann and Judith Norman. Cambridge: Cambridge University Press.

Peck, Michael. 2013. 'Now Police Are Shooting Down Drones', Forbes, 26 June. 
Radcliffe, Jack. 2014. 'The "Thaksin Regime" vs. the "Good People", Asian Correspondent, 26 December. https://asiancorrespondent.com/2014/12/the-thaksinregime-vs-good-people/. Accessed 31.03.19.

Rancière, Jacques. 1999. Disagreement. Minneapolis: University of Minnesota Press.

Rancière, Jacques. 2004. The Politics of Aesthetics. London: Continuum.

Rancière, Jacques. 2018. 'Auerbach and the Contradictions of Realism', Critical Inquiry 44: 227-241.

Rose Shell, Hanna. 2012. Hide and Seek: Camouflage, Photography, and the Media of Reconnaissance. Cambridge, MA: MIT Press.

Shapiro, Michael J. 2008. Slow Looking: The Ethics and Politics of Aesthetics: Jill Bennett, Empathic Vision: Affect, Trauma, and Contemporary Art (Stanford, CA: Stanford University Press, 2005); Mark Reinhardt, Holly Edwards, and Erina Duganne, Beautiful Suffering: Photography and the Traffic in Pain (Chicago, IL: University of Chicago Press, 2007); Gillo Pontecorvo, director, The Battle of Algiers (Criterion: Special Three-Disc Edition, 2004)', Millennium:Journal of International Studies 37(1): 181-197.

Sombatpoonsiri, Janjira. 2017. 'The Policing of Anti-government Protests: Thailand's 2013-2014 Demonstrations and a Crisis of Police Legitimacy', Journal of Asian Security and International Affairs 4(1): 95-122.

Sontag, Susan. 1973. On Photography. New York: Picador.

Sopranzetti, Claudio. 2012. Red Journeys: Inside the Thai Red-Shirt Movement. Chiang Mai: Silkworm Books.

Subhatra Bhumiprabhas, Pravit Rojanaphruk, and Pennapa Hongthong. 2006. 'Public Stages Its First Protest', The Nation (Thailand), 23 September. http:// www.nationmultimedia.com/2006/og/23/headlines/headlines_30014455.php. Accessed 31.03.19.

Tejapira, Kasian. 2006. 'Toppling Thaksin', New Left Review 39 (May/June).

Thompson, E.P. 1971. 'The Moral Economy of the English Crowd in the Eighteenth Century', Past \& Present 50: 76-136.

Webb, Simon, and Pairat Temphairojana. 2015. 'Thaksin Tells Thailand's Red Shirt Opposition: "Play Dead ... for Now"', Reuters, 20 September. https://www.reuters. com/article/us-thailand-politics/thaksin-tells-thailands-red-shirt-oppositionplay-dead-for-now-idUSKCNoRKo2F20150920. Accessed 31.03.19.

Williams, Raymond. 1989. Raymond Williams on Television: Selected Writings, ed. Alan O'Connor. New York: Routledge.

Williams, Raymond. 2003. Television: Technology and Cultural Form. New York: Routledge.

Winichakul, Thongchai. 2008. 'Toppling Democracy', Journal of Contemporary Asia 38(1): 11-37. 


\section{About the Author}

Noah Viernes teaches visual culture and social movements as an Associate Professor in the Global Studies Program at Akita International University in Akita, Japan. He is working to complete a documentary film on the Thai-Malay poet Zakariya Amataya and writing about the work of Thai film-maker Apichatpong Weerasethakul. He is from Honolulu, Hawaii. 



\title{
$9 \quad$ Bearing Witness to Authoritarianism and Commoning through Video Activism and Political Film-making after the Gezi Protests
}

\author{
Özge Özdüzen
}

\begin{abstract}
This chapter examines the intersection of politics and the culture of visual media to delineate the ways in which activists/artists have coped with increasing authoritarianism in Turkey following the Gezi Park protests. The study relies on in-depth interviews and participant observation with video activists and film-makers as well as textual analysis of recent films and videos with an aim to capture the political voice and ongoing creative resistance in urban centres since 2013. By clustering recent videos and films together in the light of their aesthetics of protest against the Islamist and neoliberal authoritarianism of the AKP (Justice and Development Party), the chapter investigates how creative communities used 'visual commons' to engage in democracy, relate to politics in an increasingly authoritarian setting, and deal with urban issues.
\end{abstract}

Keywords: Gezi Park, creative resistance, authoritarianism, video activism, documentary activism, visual commons

\section{Introduction}

In the last decade, political image and alternative media outlets have set the visual scene of Turkey. Documentaphobia (Bernstein 1994; Sönmez 2015) and videophobia rely on audiences' fears of direct visual exposure to social and political facts, especially based on 'an expository mode of filming including the voice of God narration' (Nichols 1983). Although such overarching phobias

McGarry, A., I. Erhart, H. Eslen-Ziya, O.Jenzen, U. Korkut (eds), The Aesthetics of Global Protest: Visual Culture and Communication. Amsterdam: Amsterdam University Press, 2020 DOI 10.5117/9789463724913_CHo9 
provide a factual framework for the production and circulation of activist media in Turkey, creative resistance and spatial strategies are still common traits of political film-making and video activism. This chapter examines the intersection of politics and the culture of alternative visual media to delineate the ways in which activists/artists have coped with and bore witness to increasing authoritarianism in Turkey in the aftermath of the Gezi Park protests. The study, by focusing on the political voice in recent activist films and videos from Turkey, aims to portray the ongoing creative resistance of activist/artists since 2013. It gives a glimpse of how creative communities engage in democracy and deal with ecological and urban issues through videos and films. The chapter will further discuss how the AKP (Justice and Development Party) governments in power, their neoliberal and Islamist urban control (Akçalı and Korkut 2015; Ozduzen 2018, 2019) and media and Internet regulation (Yeşil 2018) have created a generation of visual activists foregrounding a new type of aesthetics of protests in which 'the visibility of protest is both a matter of direct visual experience and of images' (see Faulkner, this volume).

Recently, videos and political films became two 'commons' in authoritarian Turkey in that their makers and audiences engaged in ecological citizenship over spaces and visual material. Commoning is 'a way of pointing out that resources should be owned and managed collectively as shared/common goods. The concept of commons is not limited to urban commons (Bromley 2008; Harvey 2012), but extend to knowledge, social, intellectual, cultural or musical commons' (Bruun 2015: 154). Video activists and political film-makers in Turkey aim to witness, record and disseminate various social movements and resistances on social, economic, political and cultural injustices by producing and circulating visual commons. Butler (2015:11) argues that 'only when bodies assemble on the street, in the square, or in other public (including virtual) space, they exercise a plural and performative right to appear and instate the body amid the political field, which delivers a bodily demand for a liveable set of economic, social and political conditions against induced forms of precarity'. In capturing the bodily demands of activists, the most important aspect of the aesthetics of videos and films in question is the camera's relation to the protest space, the position of the activists' bodies within the frame and the bodies of the recording video-makers/film-makers within the political field, thus constituting a public space between the digital and the material (McGarry et al., this volume).

The chapter rests on the argument borrowed from McGarry, and restate the quote that 'politics is not produced solely by the vocalised claims or 
demands of protestors but by their action, and sometimes their inaction, thus the aesthetics of protest reveals how democracy is constituted through performance or images' (McGarry 2017: 2). For this, first, I will look at how video/ film activists cope with direct state violence on streets or indirect forms of state violence, particularly censorship following the Gezi Park protests. Second, I will address how the videos and films capture and document visual and creative attempts to constitute democracy in contemporary Turkey such as the Occupy Gezi and No! campaigns against Tayyip Erdoğan's presidency ${ }^{1}$ as well as the aspects of Kurdish struggle. ${ }^{2}$ Within this framework, in this chapter, I will focus on the censored films and popular activist videos mostly relying on the testimonies of their makers through in-depth interviews. In my spatial ethnographic research in 2013-2014 and 2016-2017 within cultural spaces in Istanbul that mimicked the Gezi experience, I also followed the circulation contexts of videos/films and had access to their makers. The film-makers include Reyan Tuvi (the director of Love Will Change the Earth, 2014), Ayşe Çetinbaş3 (the producer of Bakur, directed by Çayan Demirel and Ertuğrul Mavioğlu, 2015) and Kazım Öz (the director of Zer, 2017), as well as the video activists Fatih Pınar, İmre Azem, Kazım Kızıl from Kamera Sokak, and Güliz Sağlam from Videoccupy and the Women for Peace Initiative. The censorship of Love Will Change the Earth at the International Antalya Film Festival (IAFF) in 2014 along with the censorship of Bakur a year later at the International Istanbul Film Festival (IIFF) signalled a new era for cultural and political regulation in Turkey. The chapter also captures a newer case of censorship, namely Zer, in 2017 at the IIFF.

In-depth interviews and participant observation for this research commenced in 2014 during the Documentarist film festival, followed by my participation in other politically engaged screenings and festivals from 2015 to 2017. I chose the research participants based on the reception contexts of their films and videos. The sample of video activists represents the well-known figures of the activist video scene in Turkey

\footnotetext{
1 Campaigns against the constitution change comprised of many political organizations, including the main opposition party CHP, the pro-Kurdish party HDP, and other left-wing groups, commenced in February 2017.

2 The conflict between the Turkish state and the PKK (Kurdistan Worker's Party) began in 1984, which resulted in the loss of over 100,000 people and had major social, political, and economic consequences. The PKK has been involved in armed conflict with the Turkish state to create a Kurdish state and later to build Kurdish autonomy. 'Amongst the legal parties, the HDP is the last to represent Kurds and compete under adverse circumstances' (Grigoriadis 2016: 40).

3 Cetinbas represents Bakur as the film's producer because one of the directors had a severe heart failure right before the censorship of Bakur.
} 
and film-makers and producers, whose films on various rights movements were censored by RTÜK (Radio and Television Supreme Council) between 2014 and 2017. Following the Gezi protests, I also collected and downloaded popular activist videos on social movements in Turkey. I collected data on censorship and circulation of films through politically engaged cinema and media collectives and organizations that I took part, including SIYAD (Turkish Film Critics Association). The first part of the chapter delineates the specific authoritarianism of the AKP period (2001-present), while the following section investigates aspects of video and documentary activism between digital and physical activism. The ensuing two sections examine the voices of video/film-makers and protest aesthetics of videos and films.

\section{Turkey's Slide towards Authoritarianism}

Coming into power as a 'moderate Islamic' party following the financial crisis in 2001, the AKP governments have evolved into an authoritarian governing rule, especially since their second term in power in 2007. According to Korkut and Eslen-Ziya (2017:2), 'the more moderate AKP government consolidated its power and merged with the state, the more authoritarian it became to reproduce the semi-democratic centre in a religious conservative form'. While relying on 'a high degree of political recentralization, operating in conjunction with a neoliberal macroeconomic programme' (Tansel 2019: 321), AKP erected a loyal business class along with its implications for regime change (Esen and Gümüşçü 2018: 350). AKP's regime change has operated not only with the help of state institutions such as local authorities (Tan 2018), where the abovementioned aspiring class is a part, but also with the involvement of religious civil society (Islamist newspapers, communities, associations) and mainstream media.

AKP increasingly constructed a competitive authoritarian regime (Iğsız 2015; Esen and Gümüşçü 2016) following the Gezi protests, which has broader implications for the cultural fabric, including the production and circulation of media. 'Competitive authoritarian systems' (Levitsky and Way 2012) are 'ruled by democratically elected charismatic leaders, who resort to aggressive political discourses that mobilize 'genuine nations' against 'old elites' and divide the remaining world into friends and foes. Political parties create consent, service their clients and replace more independent institutions and state agencies' (Öktem and Akkoyunlu 2016: 470). Increasingly after the Gezi protests, the then Prime Minister Erdoğan's speeches and actions reinforced the existing divisions in society such as the Sunni and Alevi, Turk 
and Kurd, çapulcu and non-çapulcu. ${ }^{4}$ In this context, society has become more polarised while many cultural institutions have been complicit in the top-down changes. For Eraydin and Taşan-Kok (2014:123), the state has become less democratic over the years, especially regarding AKP's aggressive responses to any protest and social mobilization, exemplifying heightened police surveillance, the arrest of journalists, and the use of physical force, which instil fear and discourage organized social response.

\section{DIY Visual Activism between Digital and Physical Activism}

DIY and user-generated media circumvent mainstream news media, which generally either ignore or disseminate a distorted coverage of protest movements (Thorson et al. 2013: 425). The result is that 'ordinary people, including residents, tourists, soldiers, activists, insurgents and terrorists can bypass established editorial and censorial filters and turn their personal record of an event into a public testimony that disrupt "official" perspectives' (Andén-Papadopoulos 2014: 754). Additionally, "unlike "traditional" forms of digital activism such as denial-of-service actions or online petitions' (Yang 2016: 14), video activism has a distinctly narrative character. The production of videos in public spaces opens discussions on the functions of activists' bodies as a source of narrative. Video activists' bodies and cameras transform into 'narrative tools', along with the produced photos and videos.

In most activist videos, audiences do not observe the video activists' body within the frame, but feel the shakiness of the camera, hence, their body movements. Also, their voices interact with other activists or the police, which determine their involvement in the virtual space of the video and the physical space of resistance. The proximity to protest violence makes these amateur recordings an extraordinary 'resource for understanding the subjective experience of ordinary people, who find themselves on the front line of revolutionary struggle' (Snowdon 2014: 401). While some of the videos and films in question are highly professional, especially in terms of editing, some of them like the videos of Videoccupy and Kazım Kızıl, represent amateur recordings. What makes their aesthetics similar is activists' spatial use of filmic spaces with their bodies in physical protest spaces such as eating, praying or listening to music altogether in parks during the protests (Love Will Change the Earth/the video of Videoccupy), cooking or playing

4 Erdoğan used the term çapulcu (marauders) to describe the Gezi protestors, which was deconstructed by the protestors, taking the meaning 'fighting for your rights'. 
volleyball together in the 'guerrilla camps' (Bakur) or being collectively taken into custody on a random street (Kizıl's video).

Video activism did not start with the Gezi protests in Turkey, but the protests generated an unprecedented number of YouTube videos, recording events within the occupied Gezi Park and other public spaces and reinforcing the sense of sharing and solidarity, whilst consolidating activists' understanding of DIY citizenship. Activist communities created their DIY networks of offline media such as film festival communities (Ozduzen 2018) or online media networks such as Facebook groups of the park forums e.g. Resist Kadikoy and online bulletins such as 'The Parks Are Ours' (Akçalı 2018). These forms of media activism emerged out of a young, urban movement with a high ecological and environmental awareness to generate a more sustainable future and find creative ways of disseminating their discontent with the political regime.

While Istanbul transformed into a video city during the Gezi protests (Jenzen et al., this volume), it has long been a 'cinematic city' (Brundson 2012), a home for various film industries from Yesilcam ${ }^{5}$ to New Turkish Cinema. Istanbul's 'film identity' has changed in the 2000 s primarily due to the emergence of an international 'New Turkish Cinema'. Since 1996 (Erdoğan and Göktürk 2001; Suner 2010), it has entered an era defined by its 'artsy' stylistic and narrative features and its independent infrastructure of production and distribution. Economic liberalization was an important reason behind 'the revival in the film industry in the 1990s, which also transformed creative industries, including a booming art scene' (Öz and Özkaracalar 2017: 67). Increasing numbers and impact of film festivals and alternative exhibition avenues have also played fundamental roles in Istanbul's shifting film identity, particularly in comparison to the remnants from the historical film cluster in Beyoglu (Öz and Özkaracalar 2017: 79-83). This could be related to top-down urban regeneration programmes, including the loss of large-format movie theatres.

In response to the authoritarianism of AKP, the influence of leftist and alternative outlets has increased in the 2000s and 2010s. Meanwhile many mainstream festivals and media platforms conformed to the silencing mechanisms of the regime by, for instance, shutting down their documentary sections as was the case with IAFF following their censoring of Love Will Change the Earth. It is important to note what counts as a political

5 The Yeşilçam film industry (mostly melodramas, comedy and action films) is the 'Turkish Hollywood' active from the 1950 s to late 1980s, which was extremely popular across Turkey unlike any other era. 
voice both as films and film festivals during periods when laws are suspended and reformulated according to official perceptions (see Viernes, this volume). While some mainstream avenues covertly complied with the ideologies of the state, Karaca (2011:156) identifies how contemporary art from Turkey over the past fifteen years has largely centred on political works regardless. The explicitly political image dealing with the social and political predicaments has become a major currency in the circulation of art and 'the way silencing mechanisms work and are addressed leads to a high visibility of censorship and visible responses' (Karaca 2011: 179-180). Although censorship is not a new phenomenon as Kurdish films have been widely censored, the Gezi protests and the popularity of the pro-Kurdish party HDP amongst Kurdish and Turkish publics in the early 2010 s have triggered a new wave of censorship.

\section{Glimpses from Video Activism in Turkey}

For years, Istanbul has been the centre of video and media activism, including Fatih Pınar, İmre Azem and Videoccupy. However, most existing collectives chose Izmir and Ankara as their headquarters, which accounts for the regional spread of media activism and shifting place-making practices of video and visual activists vis-à-vis the authoritarian urban politics in Istanbul. Azem's documentary Ekümenopolis, ${ }^{6}$ a landmark of activist film/ documentary, portrays photographic images and footage from the construction projects such as the Third Bridge and the Marmaray in Istanbul that have massacred the last remaining forests, and focuses on not only experts' opinions but also people's resistance against the top-down urban renewal projects. Azem (interview by author, August 2017) talks about how he has dealt with authoritarianism:

I started making videos for Diken following the Gezi protests to capture ongoing social movements to give voice those people, whose voices were unheard, and portray what wasn't shown on mainstream media. My first video was on the anniversary meeting of Hrant Dink's assassination. I also made videos on [incursions into] labour rights in 'New Turkey'. For instance, when ten workers were killed at Torunlar Centre's construction site in Istanbul after an elevator carrying them plunged to the ground in 2014, I went there to record on-site resistance and violence. Furthermore, I

6 Ekümenopolis: Ucu Olmayan Şehir (video), YouTube, 2012, https://www.youtube.com/ watch? $v=$ maEcPKBXVoM\&t=376s, accessed 14.03.18. 
travelled outside of Istanbul. For instance, I went to Soma in 2014 following the coal mine fire with a death toll of 301 miners to show the suffering and potential resistance.

Azem participated in the DIY ecologic citizenship by creating videos on various issues from labour rights to assassinations. Similar to other research participants, Gezi protests became a trademark moment in his understanding of visual activism. When I met him in 2017, he was coming out of a meeting of activists, architects and urban planners at the TMMOB (Union of Chambers of Turkish Engineers and Architects), which has been an active party to urban social movements. To capture the changes in his ways of combating the authoritarian state, I focus on two videos on Pride in Beyoglu in different years after the Gezi protests. Pride $2014^{7}$ was among the most crowded pride walks in the history of Turkey. The video highlights the colours, clothes, bands of the LGBTI+ communities on Taksim's streets in June 2014 by using close-ups of LGBTI+ activists, combined with long and medium-shots of marching and dancing crowds.

Following 2014, the pride walks have forcefully been prohibited, partly with an excuse that they coincided with Ramadan. Far-right groups, along with the government, threatened the LGBTI+ groups and recused to religious discourses, related to the holy month of Muslims in order to bolster public support for their violent attacks. Referring to ambiguously defined religious practices as an excuse has become a general authoritarian pattern to suppress left-leaning and liberal groups by the AKP government. While Pride was prohibited, LGBTI+ communities continued to go out in Taksim, which has been the original location of Pride since 2007. The video from 2014 shows this as resistance by mainly using long shots to capture the density of crowds, whereas the video from $2017^{8}$ mostly consists of an interview with an LGBTI+ activist as the walk could not take place due to heavy police intervention. On the recorded interview, audiences can discern that the police forces were on a witch hunt, constantly passing by and running after those alleged 'suspects' in front of the camera. Both videos unfold the ways that the bodies of protestors utilize public spaces in different ways when authoritarianism encroaches on everyday life in different levels, which radically transforms the costumes, objects and voices within the frame. The touchstone of the video from 2014 is the vivid use of colours, revealed through the LGBTI+ individuals' costumes. However, the camera

7 Pride Taksim (video), Vimeo, 30 June 2014, https://vimeo.com/99517268, accessed 14.03.18.

8 Pride Taksim (video), Vimeo, 26 June 2017, https://vimeo.com/223111378, accessed 14.03.18. 
also captures greyness of concrete buildings and the dire blackness of police uniforms in 2017.

During my fieldwork in 2017, Azem introduced me to Fatih Pınar. Pınar's most recent and most popular videos on YouTube were made during the curfew in Turkey's Kurdish region in 2016, which represent some of the rare footage from the AKP's recent war in the region. One of these videos ${ }^{9}$ depicts Sur (a district of Diyarbakır) after the curfew, which lasted three months and destroyed the whole neighbourhood. It relies on the testimony and memories of witnesses, namely people who had first-hand knowledge of executions and torture carried out by the Turkish state during the curfew. Thus, it runs counter to the state-sanctioned 'truth' about terrorism in the region and represents the political voice of those who suffer from state violence. It features the testimony of a mother who lost her daughter due to police violence during curfew. The video does not treat residents of Sur 'as objects of political subjugation or victims but shows the ways in which they became voluntary subjects of knowledge and purposeful subjects aware of their own voices' (Spence and Avc1 2013: 299). Similar to other videos that came after the Gezi protests, this video does not capture crowds, but features individuals' stories and memories of state violence and therefore becomes the voice of agents who are not afraid to express their grief against the authoritarian practices of the state. Pinar (interview by the author, February 2018) recounted how he copes with increasing state violence as follows:

Following the Gezi protests, there has been a variety of processes of resistance from Soma ${ }^{10}$ to Validebağ. ${ }^{.1}$ I recorded the social movements and made videos during the curfews in Kurdish towns and neighbourhoods without self-censoring. If Ahmet $S_{1} \mathrm{k}^{12}$ is on trial and there is a protest, I record it even if I don't circulate it instantly. However, social movements on the streets are in decline. Yet, activism is not only about street movements. There is so much to do now as the impact of authoritarianism has

9 Sur after the Curfew (video), YouTube, 9 February 2016, https://www.youtube.com/ watch? $\mathrm{v}=\mathrm{VJsfBpvvUJY}$, accessed 14.03.18.

10 In May 2014, 300 mine workers died in Soma (north Aegean Turkey) due to a mine explosion, leading to strike and protests.

11 Validebağ Volunteers (1995) were formed by neighbourhood residents against Validebağ Woods' commodification and organized petitions and demonstrations. Their widest social movement, called 'Validebag Resistance' and commonly referred to as 'Small Gezi', took place in 2014 when the government wanted to build a mosque in the woods.

12 A journalist who was jailed for a year in 2011-2012 and another year in 2017-2018. Now he is an MP of the pro-Kurdish party HDP. 
increased. For instance, I made a short video for the first day of trials of Academics for Peace ${ }^{13}$ and circulated it. Now there is so much resistance around courts.

In the aftermath of making and circulating these videos, Pinar continued with recording cases such as Ahmet Şık's trial but has not been active in circulating them due to his feeling more 'unsafe' as he recounted to me. In 2018, he was looking into independent funds to facilitate his act of visual commoning as media outlets were not employing him anymore.

In addition to Pınar and Azem as more professional activists, during and following the Gezi many collectives, including 'ordinary' people, have transitioned into what Andén-Papadopoulos (2014: 754) calls 'citizen camerawitnesses', defined as 'camera-wielding political activists and dissidents that put their lives at risk to produce public testimony and mobilize global solidarity through the affective power of the visual'. These videos record activists' and police's practices, but the camera identifies with protestors during police interventions. Hence, audiences view events from the activists' perspective. One of the most well-known video collectives during the Gezi period was Videoccupy. Güliz Sağlam from Videoccupy (interview by the author, December 2018), who has also collectively produced and circulated videos as part of the Women for Peace Initiative to highlight the testimony of women in the Kurdish region, expressed the evolution of their 'citizen camera-witnessing' and the ways she resisted the authoritarian state:

Videoccupy met in Gezi Park and recorded everyday life in the park and street protests. Everyone in the collective took the initiative to record events and circulate them instantly. After the occupation was over, we didn't use the same name but some of us formed Vidyo Kolektif and mostly followed women's struggles. In May 2016, when I was recording the Gezi protests' anniversary, police took my camera and asked me to delete some footage, which put me off from recording, but I recently made a video of the 8th of March for the Taz newspaper, which is diasporic media based in Germany.

Like other film and media communities that used the park as a physical space of DIY media activism, such as film festival circuits (Ozduzen 2018),

13 The Academics for Peace represent over 2,000 academics from Turkey who signed a petition in January 2016 to end AKP's violence in the Kurdish region. They have since been brought to court and been fired from their jobs. Some were taken into custody and four of them were imprisoned. 
video activists encountered each other and organized into action by using protest camps as their base. Videoccupy created 'visual commons' and recorded everyday life in protest camps, such as concerts, gatherings, police interventions, communal dinners or Friday prayers. The most viewed video of the Videoccupy is the police intervention at Gezi Park on 22 June $2013 \cdot{ }^{14}$ Like other videos on state violence, the shaky camera is the landmark of its aesthetics. Bolstering its shaky existence, the camera does not focus on an individual story but captures the movements and bodies of mass numbers of people. It showcases the ways crowds attempt to run away from persistent police violence and chaos on the streets. Rather than narrating individual stories, these videos benefit from the cacophony of voices, multiplicity of spaces, and consistent movement/action.

While Videoccupy is a single-event focused initiative and remained as a symbol of the Gezi protests, Camera Street prevailed in subsequent social movements, following a diversity of resistances around Izmir, including ecological movements, such as the anti-coal movement in Yirca. ${ }^{15}$ The chosen video of Camera Street ${ }^{16}$ shows the momentary instance of how video activists are taken into custody along with other activists. In these moments, the camera captures the ongoing, fast-pace dynamic on the streets, which exemplifies the everyday effects of authoritarianism. Abusive power of the police, implemented through threats and physical assaults, is a growing trend in that police forcefully ask activists to erase their recorded witnessing as it was the case with two of my participants, Sağlam and Kazım Kızıl (Camera Street). Video activists still utilize visible technological tools to record ongoing state violence even when they are increasingly subject to state violence, exemplified by the detention and arrest of Kizıl. In one of Kızl's videos, the moment police violence target him and other activists are showcased.

While Kizll was filming other people's detention at the boycott in Izmir, he ended up filming his own detention. During this incident, audiences see Kizll's camera and hear his conversation with the police. The video originally intends to record other activists on site, but eventually the audience hears and sees the video activist, as the camera unintentionally captures his own body movements and personal experience of state violence. Kizıl

14 Police Intervention at the Taksim Square 22.06.13 (video), YouTube, 23 June 2013, https://www. youtube.com/watch?v=V4pyzFeIHJo, accessed 14.03.18.

15 A Turkish village where 6,0oo olive trees were destroyed to construct a coal-fired power plant.

16 Kazım Kızıl's Detention (video), Facebook, 13 February 2015, https://www.facebook.com/ kazimkizil/videos/10152762090042857/, accessed: 14.03.18. 
was taken into custody once more on 17 April 2017 along with six other activists. Although Kizıl, who was recording a protest related to plebiscite results, presented his press card to the police, he was taken into custody and arrested on 21 April 2017 on charges of 'insulting the president'. Effectively operating as lèse majesté, the insult clause has become a ludicrous reason for journalists, activists and academics to be sacked, censored and arrested. Kizll (interview by the author, March 2018) tells the story of Camera Street and his ongoing visual activism:

Camera Street started as the Izmir branch of Gezi's DIY media. We have met each other once in every two weeks since then although we are not that active now. As the social movements on the streets lessened, our collective has also dispersed. To change this trend, we need to go beyond documenting state violence on the streets and focus on other issues, such as political prisoners, refugees, women's or children's issues or the economic crisis.

Increasing authoritarianism has also opened a room for a discussion on how to transcend formulas of Occupy activism. Rather than solely following street movements, video collectives capture the routes of refugees, labour rights and court cases. However, video activists could not follow political prisoners inside the court houses as cameras and phones were not allowed. To combat mechanisms of institutional exclusion, some activists drew sketches from the courthouses to visually narrate the situation, such as the drawing of Zeynep Özatalay from the courthouse where two hunger strikers, namely Nuriye Gülmen and Semih Özakça, were on trial in September 2017. There is a forceful passage from video activism to pre-digital activism even if visual activism is persistent.

\section{Filmic Activism against Censorship}

Similar to the forceful prohibition of activist videos, the complicity of film funds and mainstream film festivals have limited the production and circulation of politically engaged films. However, this also led to finding alternative locations and strategies. Similar to the police's behaviour towards the video activists Sağlam and Kızıl, Love Will Change the Earth was forcefully censored at IAFF in 2014. Although it was scheduled to be screened upon the decision of the preliminary jury and was previously screened and awarded at the Documentarist film festival, it was excluded from the IAFF's programme with an excuse that the subtitles included 'a swear word' targeting the president 


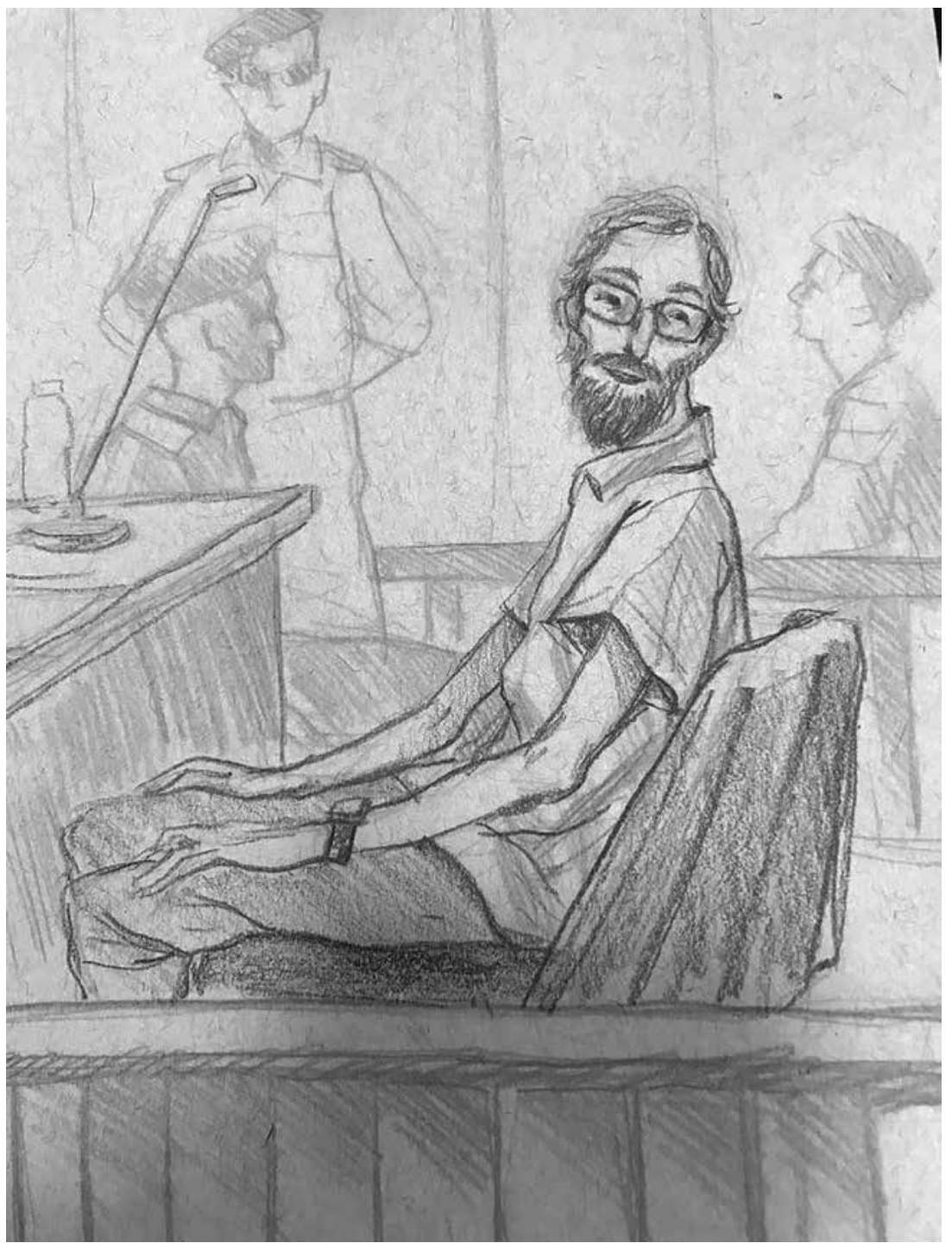

Figure 9.1. Özatalay's drawing of Semih Özakça. This image became a touchstone of digitally shared posts on the hunger strike of Özakça and Gülmen.

of Turkey. The censorship was implemented, citing Articles of 125 and 299 of the Turkish Criminal Code, which prohibit 'insulting' the unity of Turkey and its president, namely, Erdoğan. However, the documentary focuses on the practices of Turkey's disconnected populace, including a plethora of activists, such as youth, nurses, Alevites, and Kemalists, who fought to reclaim Gezi Park and thereby challenged the authoritarian politics of the government. 
In contrast to the film's tone of coexistence and presentation of multiplicity of political voices, its censorship at the IAFF brought stigmatization of and isolation on the part of the director and the documentary selection committee. Likewise, the initial festival screening of Bakur also took place at the Documentarist film festival in the following year (June 2015). These two screenings reflected ongoing right struggles, whilst initiating intersectional bonds between audience members against the re-homogenizing agenda of the government. Three months prior to being censored at the IAFF, the screening of Love Will Change the Earth in Documentarist film festival in June 2014 was filled with symbolic slogans and discussions of Gezi protests. Despite the indirect forms of violence, Reyan Tuvi (interview by the author, March 2018) continued producing media: 'I bypass wider mechanisms of censorship by participating in News Watch in Diyarbakir or by making another film. Doing what you can do is the best way to defeat censorship.' The fact that Tuvi has become part of News Watch in the Kurdish region in the aftermath of the arbitrary detention and imprisonment of Kurdish journalists accounts for the increasing convergence of media and cinematic activism in Turkey.

Upon the imprisonment of Kurdish journalists, Kurdish newspapers had to almost shut down in 2016. In order to reinvigorate Kurdish-language journalism, News Watch hosted voluntary activists. These kinds of vernacular alliances were a direct outcome of the Gezi protests, as with Tuvi, who told me that she took the uprising as a point of departure in her subsequent political action. In 2017, she completed her new film No Place for Tears, which is an observational documentary portraying local people's everyday life practices in Maheser village. The village lies at the border between Turkey and Syria, facing the Kurdish town Kobane, which was then under the siege of the Islamic State. The documentary provides glimpses of how residents sheltered their neighbours whilst watching the war happening in front of their eyes. Tuvi's engagement with the resistance during the war in the Kurdish regions of Syria and Turkey for her documentary and participation in News Watch foregrounded her visual activism and stance against mainstream festivals and media amidst the ongoing state violence.

While the screening of Love Will Change the Earth took place prior to its censorship at the IAFF, the first screening of Bakur at the Documentarist film festival followed its censorship at the IIFF. The screening on 15 June in 2015 in Şişli municipality's Cultural Centre started with 'Biji berxwedana Kobane $^{17}$ slogans by the audience members, representing solidarity with 
the ongoing Kurdish resistance against the Islamic State in Kobane in Northern Syria. This screening took place when Kurdish guerrillas ceased using guns and pulled back to cross-border zones; therefore, it was yet again a 'special' moment for the Kurdish 'problem' in Turkey. The documentary is based on the first-hand testimony of lower- and higher-ranked guerrillas during the "peace process"18 when it was possible for the film crew to enter guerrilla camps in south-eastern Turkey. Bakur illustrates instances of how guerrillas resisted the state, such as their daily exercises or community gatherings and felt strange having to leave behind their camps during the peace process. Its tone relies on an account of the 'human' aspect of the Kurdish armed forces in a bid to challenge the demonising discourse of the mainstream media.

Once the film was censored at the IIFF, audiences established their own meeting venues at parks in Istanbul and Ankara, especially at Abbasağa Park. The structure of the 'censorship forum' at Abbasağa Park allowed various actors to speak out about censorship to counter the official view. Film critics, audiences, intellectuals, and film industry workers, including one of the directors of Bakur, Ertuğrul Mavioğlu, spoke about the need to create a network of solidarity and initiate new alliances. The producer Ayşe Çetinbaş (interview by the author, July 2017) expanded on the connections and functions of the Abbasağa censorship forum as a place where communities defied and defeated censorship:

On the day the censorship happened, we invited film-makers to a restaurant and initiated the email group 'Against Censorship'. Simultaneous with our film's screening, Nadir Öperli's film was to be screened at the IIFF. They were waiting for our sign and upon the censorship of Bakur, they withdrew their films and boycotted the IIFF. Then the IIFF fell apart - the juries withdrew, ceremonies were cancelled, and the films were not screened. What we gained were the censorship march and the forum at Abbasağa Park, which were at the intersection of the Gezi protests and Kurdish resistance.

Gezi brought together different actors on the streets. Demirel and Mavioğlu decided to make Bakur in the occupied protest camp of Gezi Park. The park became an avenue connecting a journalist (Mavioğlu) and a film-maker

18 The peace process between the PKK and the Turkish state started in 2009. However, after the pro-Kurdish party HDP got $13 \%$ of the votes in the elections on 7 June 2015, the AKP restarted the war in the Kurdish region of Turkey as Kurdish forces impeded their potential victory. 
(Demirel) to make the film on guerrilla camps in the Kurdish region. As Çetinbaş's comment also shows, Gezi was not only a romantic reference, but it also functioned as a point of departure for activists and audience members to continue to use its practices, such as the forum structure employed in Abbasağa Park.

More recently, Kazım Öz also had to deal with censorship in creative ways. On 11 April 2017 the government rescinded the screening license for his fictional film Zer, which narrates the story of a diasporic Kurdish young man, Jan, on a journey from New York (his home) to Turkey (his ancestors' home), following the passing away of his grandmother. Through the story of Jan and his grandmother, the film recalls the 1938 massacre of Kurds in Dersim and the eradication of the event from Turkey's official history. At the film's premiere, Öz showed black screens in place of the censored scenes that depicted the history and culture of Dersim. Written on each of these blackened scenes were the words: 'You cannot watch this scene because the General Directorate of Cinema of the Turkish Ministry of Culture and Tourism deemed it inconvenient.' Öz (interview by the author, November 2017) addressed the whole process of censorship and his way of dealing with authoritarianism in the culture and politics of Turkey in this way:

When the ministers initially saw the film, they authorized it with the black scenes, but they had no clue that I was going to disclose their censorship of those scenes. The film finally got to an audience at the IIFF with the ministry's name all over it, which led them to censor the whole film. Even with this difficulty, however, the film continued its journey.

When I went to the screening on 11 April 2017, the biggest room of the Atlas movie theatre was full of a crowd that clapped and cheered during each scene with the disclosed name of the censoring body. In the aftermath of this radical screening, the film was re-censored and had to continue its journey through Turkey and Europe under the strict surveillance of the Turkish state. Thus, both the text and context of the film run as a counternarrative to the state-sanctioned truth about struggles in the region in the past and today.

\section{Concluding Remarks}

In combining textual and contextual analysis, the chapter presents a unique case study by clustering recent videos and films together in the 
light of their aesthetics of protest and creative resistance against AKP's Islamist and neoliberal authoritarianism. These videos and films bring along the subjective experience of activist bodies in public spaces during and following the Gezi protests and they point to the creativity and resilience in activists' resistance against state violence in an increasingly authoritarian setting. Following the physical violence or censorship, rising audience attention to these videos and films also turned them into visual commons, whilst their directors and producers were at the forefront of dissident publics. In this chapter, I define these acts of resistance as creative because the visual material and their makers (1) do not engage in conventional forms of protest, such as marching, but employ their visual presence and voice to come into prominence, and (2) use the bodies of video activists and other activists as a source of narrative. Furthermore, these acts of resistance are not just creative in their nature; they are also aesthetic, especially because they constantly find new digital or bodily ways to question the politics of the state and conventional Occupy activism.

While the early videos and films in 2013 and 2014 present crowds of dissident voices and bodies, recent ones since 2015 rely more on prescheduled interviews with activists and the presence of the police is much more increased within the frame. In the increasingly videophobic and documentaphobic state ideology relying on their fears of the visual versions of facts going viral in our digital era, my informants used fewer vivid colours and followed more dangerous routes to produce and circulate videos and films while utilizing alternative avenues such as Documentarist film festival or the Labour Film Festival or Kurdish media. These ongoing strategies at times fall short as they cannot prevent media censorship and regulation, but the testimonies here account for the willingness of creative communities to resist and fight back with their cameras and bodies, even if the outcomes are not yet 'successful'. While the interview material may seem to have captured a sense of optimism, authoritarianism continues to dominate Turkish politics. Authoritarianism, however, does not block, but, in fact, it encourages visual and creative resistance to diversify by using international platforms such as diasporic media or by turning to pre-digital activism, such as drawing from within courthouses, which broaden the horizons for the future of social and political change. Based on this framework, the chapter points out that 'protest by videos, films and visuals' bears witness to the atrocities committed by authoritarian regimes, which also feed our understanding of repertoires of protests and their aesthetics in similar regimes during the Arab Spring and beyond. 


\section{References}

Akçalı, Emel. 2018. 'Do Popular Assemblies Contribute to Genuine Political Change? Lessons from the Park Forums in Istanbul', South European Society and Politics 23(3): 323-340.

Akçalı, Emel, and Umut Korkut. 2015. 'Urban Transformations in Istanbul and Budapest: Neoliberal Governmentality in the EU's Semi-Periphery and Its Limits', Political Geography 46: 76-88.

Andén-Papadopoulos, Kari. 2014. 'Citizen Camera-Witnessing: Embodied Political Dissent in the Age of "Mediated Mass Self-communication", New Media \& Society $16(5): 753-769$.

Bernstein, Matthew. 1994. 'Roger and Me: Documentaphobia and Mixed Modes', Journal of Film and Video 46(1): 3-20.

Bromley, Daniel W. 2008. 'Resource Degradation in the African Commons: Accounting for Institutional Decay', Environment and Development Economics 13(5):539-563.

Brundson, Charlotte. 2012. 'The Attractions of the Cinematic City', Screen 53(3): 209-227.

Bruun, Maja. 2015. 'Communities and the Commons: Open Access and Community Ownership of the Urban Commons', in Urban Commons, ed. Christian Borch and Martin Kornberger, 163-18o. London: Routledge.

Butler, Judith. 2015. Notes toward a Performative Theory of Assembly. Cambridge, MA: Harvard University Press.

Eraydin, Ayda, and Tuna Taşan-Kok. 2014. 'State Response to Contemporary Urban Movements in Turkey: A Critical Overview of State Entrepreneurialism and Authoritarian Interventions, Antipode 46(1): 110-129.

Erdoğan, Nezih, and Deniz Göktürk. 2001. 'Turkish Cinema', in Companion Encyclopedia of Middle Eastern and North African Film, ed. Oliver Leaman, 533-573. London: Routledge.

Erdoğan, Nezih, and Dilek Kaya. 2002. 'Institutional Intervention in the Distribution and Exhibition of Hollywood Films in Turkey', Historical Journal of Film, Radio and Television 22(1): 47-59.

Esen, Berk, and Sebnem Gumuscu. 2016. 'Rising Competitive Authoritarianism in Turkey', Third World Quarterly 37(9): 1581-16o6.

Esen, Berk, and Sebnem Gumuscu. 2018. 'Building a Competitive Authoritarian Regime: State-Business Relations in the AKP's Turkey',Journal of Balkan and Near Eastern Studies 20(4): 349-372.

Grigoriadis, Ioannis N. 2016. 'The People's Democratic Party (HDP) and the 2015 Elections', Turkish Studies 17(1): 39-46.

Harvey, David. 2012. Rebel Cities: From the Right to the City to the Urban Revolution. New York: Verso Books. 
Iğsız, Aslı. 2015. 'Palimpsests of Multiculturalism and Museumization of Culture Greco-Turkish Population Exchange Museum as an Istanbul 2010 European Capital of Culture Project', Comparative Studies of South Asia, Africa and the Middle East 35(2): 324-345.

Karaca, Banu. 2011. 'Images Delegitimized and Discouraged: Explicitly Political Art and the Arbitrariness of the Unspeakable', New Perspectives on Turkey 45:155-183.

Korkut, Umut, and Hande Eslen-Ziya. 2017. Politics and Gender Identity in Turkey: Centralised Islam for Socio-Economic Control. London: Routledge.

Levitsky, Steven R., and Lucan A. Way. 2012. 'Beyond Patronage: Violent Struggle, Ruling Party Cohesion, and Authoritarian Durability', Perspectives on Politics 10(4): 869-889.

McGarry, Aidan. 2017. 'The Aesthetics of Protest: Performing Protest through Voice, Solidarity, and Space', paper presented at the Aesthetics of Protest workshop, at Cosmos (The Centre on Social Movement Studies), Scuola Normale Superiore, Florence, Italy, December.

Nichols, Bill. 1983. 'The Voice of Documentary', Film Quarterly 36(3): 17-30.

Öktem, Kerem, and Karabekir Akkoyunlu. 2016. 'Exit from Democracy: Illiberal Governance in Turkey and Beyond', Southeast European and Black Sea Studies 16(4): 469-480.

Öz, Özlem, and Kaya Özkaracalar. 2017. 'The Reemergence of Istanbul's Film Industry: A Path-Dependence Perspective', New Perspectives on Turkey 56:61-85.

Ozduzen, Ozge. 2018. 'Cinema-going during the Gezi Protests: Claiming the Right to the Emek Movie Theatre and Gezi Park', Social \& Cultural Geography 19(8): 1028-1052.

Ozduzen, Ozge. 2019. 'Spaces of Hope in Authoritarian Turkey: Istanbul's Interconnected Geographies of Post-Occupy Activism, Political Geography 70: 34-43.

Smith-Nonini, Sandy. 2007. 'Conceiving the Health Commons', in The Global Idea of 'the Commons', ed. Donald Macon Nonini, 115-135. New York: Berghahn.

Snowdon, Peter. 2014. 'The Revolution Will Be Uploaded: Vernacular Video and the Arab Spring', Culture Unbound:Journal of Current Cultural Research 6(2): 401-429. Sönmez, Necati. 2015. 'Belgesel Korkusu: Documenaphobia', Bianet, 15 April. https:// bianet.org/bianet/siyaset/163813-belgesel-korkusu-documentaphobia. Accessed 31.03.19.

Spence, Louise, and Aslı Kotaman Avcı. 2013. 'The Talking Witness Documentary: Remembrance and the Politics of Truth', Rethinking History 17(3): 295-311.

Suner, Asuman. 2010. New Turkish Cinema: Belonging, Identity, Memory. London: I.B. Tauris.

Tan, Evrim. 2018. 'Quo Vadis? The Local Government in Turkey after Public Management Reforms', International Review of Administrative Sciences. https://doi. org/10.1177/0020852317752268. 
Tansel, Cemal B. 2019. 'Reproducing Authoritarian Neoliberalism in Turkey: Urban Governance and State Restructuring in the Shadow of Executive Centralization', Globalizations 116(3): 320-335.

Thorson, Kjerstin, Kevin Driscoll, Brian Ekdale, Stephanie Edgerly, Liana Gamber Thompson, Andrew Schrock, Lana Swartz, Emily K. Vraga, and Chris Wells. 2013. 'YouTube, Twitter and the Occupy Movement: Connecting Content and Circulation Practices', Information, Communication \& Society 16(3): 421-451.

Yang, Guobin. 2016. 'Narrative Agency in Hashtag Activism: The Case of \#BlackLivesMatter', Media and Communication 4(4): 13-17.

Yeşil, Bilge. 2018. 'Authoritarian Turn or Continuity? Governance of Media through Capture and Discipline in the AKP Era', South European Society and Politics 23(2): 239-257.

\section{About the Author}

Özge Özdüzen is currently British Academy's Newton International Postdoctoral Fellow in the Institute for Diplomacy and International Governance at Loughborough University London. Previously, she was a visiting postdoc at the Center for Middle Eastern Studies in Lund University, funded by the Swedish Institute. Özge completed her PhD in the media department at Edge Hill University in 2016. Her research interests lie in protest spaces, urban and political communication, digital polarization, and video activism. 


\title{
10 Music Videos as Protest Communication: The Gezi Park Protest on YouTube
}

\author{
Olu Jenzen, Itir Erhart, Hande Eslen-Ziya, Derya Güçdemir, \\ Umut Korkut, and Aidan McGarry
}

\begin{abstract}
This chapter explores the relevance of the protest song as political communication in the Internet era. Focusing on the prolific and diverse YouTube music video output of the Gezi Park protest of 2013, we explore how digital technologies and social media offer new opportunities for protest music to be produced and reach new audiences. We argue that the affordances of digital media and Internet platforms such as YouTube play a crucial part in the production, distribution and consumption of protest music. In the music videos, collected from Twitter, activists use a range of aesthetic and rhetorical tools such as various mash-up techniques to challenge mainstream media reporting on the protest, communicate solidarity, and express resistance to dominant political discourse.
\end{abstract}

Keywords: protest, music, Gezi Park, video activism, social media

\section{Introduction}

Today music is an established part of political communication (Street 2012). Yet, music is often marginalized in the theorization of politics. The use of music is one of the ways social movements 'gain a hearing to serve as vehicles of cultural change' (Taylor and Van Dyke 2004: 279) and among other cultural products, music 'facilitate[s] the recruitment and socialization of new adherents and help movements maintain their readiness and capacity for collective action' (Edwards and McCarthy 2004: 126). Music

McGarry, A., I. Erhart, H. Eslen-Ziya, O.Jenzen, U. Korkut (eds), The Aesthetics of Global Protest: Visual Culture and Communication. Amsterdam: Amsterdam University Press, 2020 DOI 10.5117/9789463724913_CH10 
is an increasingly pivotal part of political communication across many political spheres, from election rallies to NGO media campaigns and street protests. Although some would argue that the heyday of the protest song is over (Lynksey 2010; Manuel 2017), the fact that the Gezi Park protests of 2013 in Turkey produced an extraordinary number of protest songs and music videos suggests that the protest song as political communication is still relevant in the Internet era. ${ }^{1}$ Challenging the view that 'the context in which protest music once thrived is no longer present' (Manuel 2017, in Kutschke et al. 2017:12), we propose that if we look at protest music online, we would see a thriving production. Particularly, if we look at the case of the Gezi Park protest, a wealth of creativity is evident with its diverse YouTube video output, combining music and image to challenge the mainstream media message about protest (and protestors), to communicate what the struggle is about, and eventually to connect wider publics to the local protest.

Research on digital activism, social media and protest has mainly focused on social media as a tool for sharing information regarding activities and for raising awareness of a protest (Bennett and Segerberg 2012). Less attention has been given to aesthetics and creativity. In this chapter, we explore the aesthetics and function of music videos as a specific protest expression and as a form of digital activism. This research, focusing specifically on YouTube videos that have been circulated on Twitter during the Gezi Park protests, forms part of the larger Arts and Humanities Research Council (AHRC)-funded 'Aesthetics of Protest' project which has explored visual protest culture and communication. ${ }^{2}$ The protest music video, we argue, draws on already established genres of video activism such as witness documentation (Askanius 2013), rally call, and political remix videos (Conti 2015), which, when combined with a musical soundtrack, communicates across intellectual and emotional registers (Mirzoeff 2015).

Using the highly mediated Gezi Park protest in Istanbul in 2013 as a case study, the chapter explores how digital technologies and social media offer new opportunities for protest music to be produced and reach new audiences. We argue that the affordances of digital media and Internet platforms such as YouTube play a crucial part in the production, distribution and consumption of protest music. Focusing on the specific intersection

1 An impressive catalogue of music dedicated to, or inspired by, Gezi was produced. It encompassed many genres, from traditional Turkish folk to hard rock, rap and pop. See, for example, the 'Artists in Resistance' blog or the 'Çapulcu Şarkılar' playlist on Bandcamp, with over 140 songs.

2 See the 'Aesthetics of Protest' project, https://www.aestheticsofprotest.com, AHRC Reference: $\mathrm{AH} / \mathrm{No04779/1.}$ 
of digital media and protest music, we seek to demonstrate how, in the format of music videos, activists use mash-up techniques, remixing images and music to reframe media images already in the public domain with the aim to raise awareness of police brutality, communicate solidarity and express resistance to dominant political discourse. By doing so they give new meaning to both images and music and contribute to a reorientation of protest to include online audiovisual outputs by individual producers. Many of the music videos in our data set employ sophisticated methods of combining sound, lyrics, and visual material to make specific rhetorical points or to provoke new interpretations, either by turning the lyrics into a commentary on the images or using specifically chosen images to give new meaning to a well-known song. We also argue that activists tap into pre-existing popular culture notions of an authentic political voice, such as the association of rap music with social protest, a tactic that also has the potential to reach new audiences and build solidarity.

Examining why protestors deploy particular aesthetics and how these are mediated and understood across social media we looked at different forms of creative political expressions as 'communication which have the potential to inspire and mobilize people to action' (McGarry et al., this volume). Quite soon on in our analysis of data collected via Twitter, it became apparent that we were dealing with a wide array of creative outputs, including photography, digital visual art, comics, poetry and music videos. Looking at the music videos separately, we could discern many different styles and genres of music. This in itself not only tells a story about the richness of the creative output, but also illustrates that the Gezi Park movement was made up of people of diverse backgrounds, ages, cultures, and tastes. The crowds, which consisted of diverse, even conflicting identities, united against what they called the 'authoritarian rule' (Erhart 2014: 1728) and mobilized around 'concerns for detrimental urban policies and for the environment' (Atak 2013: 19). During the protests, nationalists, Kurds, Kemalists, socialists, feminists, vegan activists, anti-capitalist Muslims, LGBTQI groups, and white-collar workers stood 'shoulder to shoulder against fascism' (Erhart 2014: 1725) and resisted together (Arat 2013). In light of this, we ask how do music videos operate to mobilize and unite the movement musically and as a multimodal form of online communication? How do the videos amplify the movement's critiques to reach a wider audience? And what does the online music video format offer to activists today?

Music can permeate protest in many different ways. Bianchi (2018) illustrates the function of music performances in the park and in the streets as part of the protest. Building on these insights, this chapter focuses 
specifically on Gezi Park protest music videos on YouTube. We argue that these videos not only offer opportunities for the music to reach beyond live performances, and thus extend the momentum of the movement, but also perform distinct corrective responses to mainstream media representations. They subvert the dominant message by remixing images and music in new and creative ways. Therefore, availing such music videos on YouTube requires us to look at protest music as part of a mediated commercial-cultural terrain and to elaborate on them as part of a digital space that allows people to participate in protest in different ways.

Online music videos can be sampled in various ways (cf. Way 2015). Our approach involved starting with a data set of 300,000 tweets generated by querying the Twitter API using the key word Gezi Parkı (as it would be written in Turkish) from 27 May to the end of June 2013. This was the time period during which Gezi Parkı was a regularly trending topic on Twitter and the protests were in full swing. As many as $20 \%$ of the tweets contained images and a smaller yet significant number of tweets contained links to content uploaded to YouTube (see Table 10.1). A random sample of 133 videos were harvested for qualitative thematic analysis.

Table 10.1. Data Set of Tweets and Content from the 'Aesthetics of Protest' Project

\begin{tabular}{lll}
\hline Type of tweets & Numbers & Percentages \\
\hline Total & 243,912 & $100 \%$ \\
Images & 51,781 & $21 \%$ \\
YouTube videos & 3,903 & $1.6 \%$ \\
\hline
\end{tabular}

Dissatisfied with the mainstream media coverage of the Gezi Park protests, protestors resorted to live-tweeting of protests as well as live-streaming and sharing YouTube videos. Thereafter, YouTube became a symbolic rallying point for the protestors. Of the 133 videos studied, the majority were pro-Gezi Park protests and anti-government policies and police violence. The YouTube videos shared via Twitter varied from documentaries, TV clips, collages and commentary all relating to the protest. As expected, documentary footage dominated and made up $29 \%$ of the sample whilst, somewhat surprisingly, the second largest category was music videos, which represented $25 \%$ of the sample. The latter stands out as a particularly interesting category and becomes the focus for this chapter. Our analysis of YouTube videos is based on the visual and textual content of videos circulated via Twitter as well as the descriptions and the titles that frame these videos. 
In addition to examining the protest message put across in the lyrics of the music videos, we also took into consideration the material qualities and aesthetic forms of each video. In our analysis, hence, we aimed to capture the multimodal aesthetical and formal characteristics of the music videos in order to elaborate on what makes them performative. When dealing with music videos published online, we came across several communicative elements coming in to play. These are namely the musical score, the lyrics, the visual style, the narrative arch, the tone and genre of the video itself. In addition, there is the context of conditions of production and distribution, and importantly for videos on social media, the social dimension. This comes to fore thanks to the audience's responses to the video within the comments field and, as in the case of the sample here, the remediation of the videos to appear in a new context, for example, embedded in a tweet. Our analytic strategies seek to respond to some of these multiple aspects and avoid treating protest music videos as static digital artefacts. ${ }^{3}$ In order to offer a more detailed analysis of the YouTube music video as protest communication, we have performed a close reading on three of the videos selected from our sample.

\section{Music as Protest}

Protest music in itself is a broad term and academically a wide field that expands far beyond the scope of this chapter, both historically and geographically. On the face of it, protest music is a relatively simple concept by which we mean music carrying a political message that is associated with a particular political protest or social movement. In other words, we are interested in deliberate political communication expressed through music. But actually, it is rarely this straightforward. Different cultures have different traditions and histories of protest music. Furthermore, part of the power of music, and the appeal of a particular song, is that it conveys sentiments and ideas through an aesthetics of protest that is layered, semantically unfixed, and playful rather than insistent.

The role of music in relation to social movements has mainly been explored from a musical point of view (Street 1986; Lynskey 2010; Way 2016) or through a political typology (cf. Mattern 1998). Both approaches have primarily focused on lyrics as the main conveyor of protest messages. However, Frith (1996) and Way (2016) investigated how musical sounds could 
also convey political meaning. Musical sound has 'a particularly powerful affective role in communication' because of its, 'very fluid affordances, which are highly adaptable in multimodal texts' (McKerrell and Way 2017: 15). In other words, it is important not to reduce protest music to the contents of a song's lyrics. It is important to approach music as multimodal to be able to appreciate its function and effectiveness when understood as part of a movement's communication. In this chapter, we seek to expand the focus on music (sound and lyrics) to also include the visual aspects of activist produced music videos.

\section{YouTube and Protest Communication}

YouTube plays a significant role as a platform for protest communication. In terms of grassroots campaigners' use of the platform, YouTube has mainly been discussed in terms of its potential for citizen journalism in relation to political conflict and activism (Poell and Borra 2012). Live-streaming has become an important tool enabling activists to 'evidence' the concerns they have (based on witnessing) and to report directly from rallies or protests as events are unfolding (Martini 2018). Yet, groups and individual activists also use YouTube to upload more technically and aesthetically proficient and crafted campaign videos, vlogs, and montages (see Thorson et al. 2010). Other researchers of YouTube activism have mainly focused on the comments field as a textual and discursive space (see Weij and Berkers 2017), noting that the platform 'extend $[\mathrm{s}]$ the discursive opportunities' of other activist spheres, importantly 'facilitating debate between otherwise disparate publics' (Uldam and Askanius 2013:1200). In their analysis of comments posted in relation to the politically explicit punk band Pussy Riots' music videos on YouTube, Weij and Berkers (2017:14) found that 'for YouTube audiences, political music is first and foremost a vehicle to discuss politics on levels beyond what is actually raised in the music'. Arguably, this tells us that the function of music, and the music video specifically, is broadening and evolving with new media.

Limited research is available on the use of music videos, the otherwise dominating popular culture format on YouTube, as part of protest communication. Railton and Watson (2011) highlight how music videos are complex media texts in their own right with carefully crafted images and dramatizations. They demonstrate how even a minute visual cue as the singer mouthing the lyrics signify meaning through visual codes that can be studied in terms of how these acts can lead to different political interpretations and readings. Railton and Watson's concern is purely the 
professionally produced music video, but today we also need to consider the music video as a media form open to digital remixing and amateur production - a tool online activists creatively put into productive use. Citizen or amateur creativity is widespread in fan communities. There are not necessarily any clearly delimiting lines between such playful fan praxis and more dedicated political applications. In both cases, Internet platforms such as YouTube are important for the mediation and remediation of both industry-produced music videos and user-generated productions.

Both Bianchi (2018) and Way (2016) note the importance of the Internet for the distribution of music during the Gezi Park protest. Turkish political music operates within a 'tightly controlled mediascape' dominated by the ruling AKP (Justice and Development Party) ideology (Way 2016: 426). Noriko Manabe (in Kutschke et al. 2017) argues that even internationally, the music industry is clearly discouraging protest songs. Therefore, the Internet and platforms such as YouTube become important for 'alternative musical voices' (Way 2016) and may be employed as 'a "subaltern tactic" (Certeau 1984) to reverse an asymmetry of power' (Mercea and Levy, this volume).

We should also note that uploading Gezi Park videos on YouTube was largely un-coordinated. Yet, the videos served to foster a sense of collective identity, solidarity and participation. For example, documentary footage from the protest features heavily, creating a link between the viewer and offline events and, as we will go on to discuss, the videos invite a viewer position of solidarity and identification with the çapulcu identity: a term that translates into 'marauder' and was first used by the government as a derogatory term to defame the protestors, but through its reappropriation by the movement the repressive meaning of the term was reversed and created a political community (McGarry et al. 2019). Some videos more directly encourage viewers to participate or connect by promoting the different Gezi Park protest hashtags such as \#occupyGezi etc. Such mobilization on social media as an alternative to collective action is what Bennett and Segerberg (2012) call 'connective action'. But what were people connecting to? In the case of music videos this question becomes quite complex. It may be that individuals' personal ideas connect with those of the protest movement (Lindgren 2017), but equally in the case of a pop song or hip-hop video, for example, the aesthetics of the video or the recognizable composition of the music may be what primarily resonates with an individual in the way a catchy pop tune may hold the listeners' attention. The algorithmic structure of YouTube adds another layer of complexity to this as users navigate content in ways that are determined by the platform's algorithm. If you have been watching Turkish rap videos, further rap videos relating to the Gezi Park 
protests may be recommended to you, based on a combination of data about the musical style and aggregated user choices (Airoldi et al. 2016).

\section{Music and Gezi Protest}

On the one hand, research on the relationship between popular music and the Gezi Park protest includes the work by Parkinson (2018) and Way (2016), both looking at Turkish indie rock as a politically oppositional voice in popular culture, coinciding with the Gezi Park movement by resisting rampant consumerism and value conservatism. Bianchi's (2018) research, on the other hand, explores the music performed at the location during the occupation of the park and how the image of making music also features in the visual representation of Gezi Park protest, such as the iconic image of the man with a guitar facing the riot police. The centrality of music making in the protest context is also exemplified by the music videos we have studied. Several videos visually represent people interacting around music, signalling its social dimension and function as collective action. Thus, as Bianchi states, 'music became political activism' (2018: 212). In the first month of protest, 'about 30 new songs were specifically composed' (2018: 213), but perhaps more importantly it is to a large extent through music that the protest energy has lived on beyond the couple of weeks of actual occupation through continuous subsequent engagement online and across other performance venues and cultural fora. In this way, the YouTube music videos discussed in this chapter are part of the protest continuum across the digital realm and the streets. Looking at our sample of music videos, we find typical features of online participatory popular culture, employed as activist efforts. These include different types of audio-visual remixes (often referred to as mash-ups) and digital bricolage combining moving image, text, graphics, music and sometimes spoken word. In the section that follows we seek to explore some of these aesthetics and practices that contribute to the efficiency of the music videos as protest communication and explore some of the defining features of the Gezi Park protest musical output online.

\section{Hybrid Sounds, Hybrid Forms: Unity in Diversity}

One of the main themes of Gezi Park protest was unity in diversity. A most unexpected alliance was formed for example between the rival fans of Beşiktaş, Fenerbahce, and Galatasaray - 'The Big Three' of the Turkish 
Football League. During the protests, fans got together and formed 'Istanbul United', symbolized by a new hybrid flag that combined the colours and the logos of all three teams. Such hybridity is also evident in the music videos we analysed. There were hybrid sounds borrowing from folk, rock, pop, rap and jazz. Lyrics of old songs were often adapted to speak to Gezi themes and videos created by combining multiple short video clips or still images from both broadcast media and citizen footage collected from social media. Footage of police violence, usage of water cannon and gas, people's involvement in the protests, and collective resistance was edited either to illustrate and dramatize a performed piece of music or was simply published with an added musical soundtrack. There is also linguistic hybridity: to appeal to international audiences, some songs are multilingual (English-Turkish) or have English subtitles and several have text superimposed on the images, for example, displaying lyrics or the \#direngeziparki hashtag onscreen. By combining sounds, forms, images and languages the protestors tried to present protest as something creative and artistic.

Visual mash-ups are one of the most commonly used creative strategy in the music videos. The most basic form of mash-up videos that we found are those that consist of a visually intact newscast package, reporting on the protest, with the original voiceover simply replaced with music. These videos still cast the documentary images in new light as the anchorage provided by the reporter is removed and images set to music are much more open to interpretation. Shared across different social networking sites and online platforms, they also provide cultural material for political commentary. The appropriation of mainstream (anti-Gezi) reporting performs a 'reading against the grain', suggesting that the same images can be interpreted differently. This is a significant strategy whereby activist use aesthetics to perform a critique of state ideology.

However, there are also some more sophisticated or skilful remixes, where an assortment of found footage (moving image) is carefully synced to the beat of the music. Typically, in these activist-produced videos the lyrics work to provide commentary to mainly documentary images. In one of the most viral videos from the protests, Everyday I'm Çapulling, a techno beat instrumental piece of music is used to convey the energy and atmosphere of the protests. By skilful editing of footage of protestors in the street, bodies are made to look like they move in sync with the music, conveying a gleeful portrayal of the protests as a dance party, or at least as something dynamic that you want to be part of. This video also, perhaps inadvertently, foregrounds the performativity of protest through the recasting of bodies in movement to music. The video is both playful and serious, and hence achieves a sense of legitimacy by adding authentic sound recordings of chants from the 
protests mixed with the techno music. In a way, this video is exemplary of the merging of popular culture and protest reporting that the Gezi Park protest music videos establish as a mode of online activism. It illustrates how the online DIY popular culture praxis of manipulating found footage in adept, often witty ways, to be eye-catching and fun to share, is used strategically in protest communication.

Several videos in the sample employ the strategy of 'recycling' a wellknown and already popular song adding newly written Gezi specific lyrics to it. An example of this is the video by the internationally known Bogaziçi Jazz Choir. During the protests, a choir member rewrote the lyrics of one of their most popular songs 'Entarisi ala benziyor' (Her dress is a beautiful red), ${ }^{4}$ otherwise a folk song popular across the Balkans, to convey a protest message and a call to mobilize:

Are you a çapulcu vay vay (well, well)

Are you an activist vay vay (well, well)

The gas mask like red

Pepper spray is like honey

My TOMA ${ }^{5}$ is spraying at me

There will be a solution - people have risen

They are on barricades on the way to Taksim

Gas masks come in many different styles

I'm marching for Taksim

Don't hang about,

Come for your rights

Gas masks come in many different styles

Gezi Park is as old as you

Come banging pans and pots ${ }^{6}$

With forks and spoons ${ }^{7}$

4 The choral arrangement is by Muammer Sun.

5 A TOMA (Toplumsal Olaylara Müdahale Aracı, or Intervention Vehicle against Social Incidents) is an armoured water cannon designed for riot control manufactured by a Turkish company.

6 Refers to the protest where people violently hit kitchenware with spoons in support of Gezi around 9 pm every evening.

7 'Çapulcu musun vay vay. Eylemci misin vay vay. Gaz maskesi ala benziyor. Biber gazı bala benziyor. Benim tomam bana sıkıyor. Bulunur bi çare halk ayaktadır. Taksimyolunda barikattadır. 
The video is shot by a member of the crowd that gathered around the choir members. It is lit up using mobile phones operating as torch lights as the choir were rehearsing the newly written lyrics, and posted on YouTube the next day. Despite being immersed in the political discourse and events of the protest, this video is clearly also about showcasing the group as musicians. It is a spontaneous street performance, channelling the 'Gezi spirit' symbolized by spontaneous collective singing. This instils some of the atmosphere from the protest on the ground into the online communication. The video is also an invitation to participate in protest (e.g. 'don't hang about come for your rights', 'come banging pans and pots') and protesting is depicted as social and fun (they can't help laughing at the new lyrics while singing) yet absurd (the TOMA spraying at its own people). A sense of hope dominates the video and it clearly seeks to unite around the Gezi activist identity of the çapulcu, which is a strongly emerging theme in the music videos. There are two main rhetorical mechanisms at play here: first the re-signification of the term 'çapulcu', giving it the new meaning of 'social activist' (as in the lyrics above where the two meanings are intertwined in the opening lines) and second a unifying of the movement around the çapulcu identification. The playful and rebellious remixes of songs, sounds, genres, as well as of clips and images hint at the characteristics of the çapulcu: all-embracing, witty and glocal. Extending the idea of the glocal, in the next section we will take a closer look at an example of çapulcu rap.

\section{Çapulcu Rap}

We were particularly drawn to the rap videos in our sample of music videos relating to the Gezi Park protest because of the way they exemplified an attempt to link the 'local' protest in Istanbul to wider international social justice movements. By using the genre of rap music, the activists not only stylistically link their music to socially conscious music that preceded them, but also take on the characteristics of the rebel performer telling it like it is, strongly associated with the genre. Taking a closer look at the example of the Ayakta Kal çArşı (Stand strong çArşı) video, posted by RAAD, ${ }^{8}$

Çapulcu musun vay vay. Eyleci misin vay vay. Gaz maskesi biçim biçim. Yürüyorum taksim için. Üşenme gel hakkın için. Bulunur bir çare halk ayaktadır. Taksim yolunda barikattadır. Çapulcu musun vay vay. Eylemci misin vay. Gaz maskesiçeşit çeşit. Gezi Parkı senle yaşıt. Vur tencere çatal kaşık. Bulunur bir çare halk ayaktadır. Taksim yolunda barikattadrı'

8 Also known as the Gezi Park March. 
we will discuss how the rap video calls out the injustices caused by the government's and media's treatment of the Gezi activists, how it aims to mobilize protestors and authenticate the çapulcu identity by linking it to the well-known Turkish football supporter group çArşı. ${ }^{9}$

Rap is broadly seen as giving voice to a disadvantaged, disenfranchised, and racialized group in American society - poor black urban youth - and thus has rebellion and resistance to oppression at its core. Despite the fact that many contemporary forms of hip-hop, both the commercial and sub-cultural scenes, are not primarily produced or consumed as radical expressions of politics or activism, the sounds, styles and composition of rap music have resonated with groups involved with political struggle around the world (Kahf 2012; Kellerer 2017; Tarifa 2012). Music journalist Andy Morgan (2011), who has written about the role of music in the Arab uprisings, portrays how rapper El Général helped spark the uprising in Tunisia by posting his videos challenging the regime on Facebook. As a commercially successful American popular culture export, rap culture has a global market and is accessible to huge audiences via online distribution. It is also highly adaptable to local tastes as illustrated by highly successful domestic artists rapping in their own language. Its bricolage or 'sampling' tradition means that it lends itself to playful remixes bringing in local and traditional music styles or borrowing highly recognizable cords and lines from a well-known song, which is essentially what the Everyday I'm Çapulling video does by channelling rapper Rick Ross's 2006 song 'Everyday I'm Hustlin".

The tradition of Turkish rap dates back to Germany and the Turkish minority, those so-called Turkish guest workers (Diessel 2001; Kaya 2002). Nonetheless, Turkish rappers are also active in other countries thanks to the Internet operating as an important tool for the Turkish-speaking hip-hop community (Solomon 2005). Solomon (2006) discusses insidious Turkish hiphop culture and presents the example of two rap groups - R.A.K. Sobataj and Tuzak, who explore and promote Islamic and conservative values. But Islam is not the only theme among rappers in Turkey. For instance, the group called Tahribad-ı İsyan, one of the groups that were active during the Gezi Park protests, uses rap to resist the restructuring of Istanbul neighbourhoods. ${ }^{10}$

9 An Istanbul-based football supporter group, founded in 1982 on leftist, anarchist, antiestablishment principles by small shop owners in the Beşiktaş's çArşı district.

10 Tahribad-1 İsyan's video is available on YouTube at https://www.youtube.com/ watch?v=FB253Dz4XGU, accessed 12.04.19. Further noteworthy examples of Turkish rap videos referencing the Gezi Park protest on YouTube include: Şanışer \& Alef High \#direngezi, https://www.youtube.com/watch?v=DOMAE-MTXBk, accessed 12.04.19; Fuat Ergin's Karar Bizim (in collaboration with Işıl Eğrikavuk and Jozef E. Amado), https://www.youtube.com/ 
The political merit of rap music in itself is not something we seek to settle in this chapter (see Baker 2011). However, what is clear is that the marketing strategy of rap to achieve 'authenticity' through a 'telling it like it is' rhetoric and image (Stapleton 1998) pairs with political communication. It produces, what Kane (2001, in Street 2012) calls, 'moral capital' as a form of emotional authenticity lending valuable rhetorical 'ethos' to the music as protest communication. In the case of the video posted by RAAD, performing the song Ayakta Kal çArşı (Stand strong çArşı), the 'moral capital' is compounded by the association with the football supporter group çArşı, one of the key actors during the protests (Övünç Ongur and Develi 2013) with an established public image of being the guardians of justice and a vocal voice against anything unfair. Their choice of the genre, therefore, also strikes a cord with çArşı's rebellious image. The group's logo contains the anarchist ' $A$ ', and their motto is 'çArşı is against everything'. With their creative and witty banners, they have announced being against many things including fascism, animal rights abuses, capitalism, nuclear plants, domestic violence, child pornography and climate change. The group was one of the first to join the Gezi Park protests (see figure 10.1) and the witty humour and antagonism its members brought to Gezi helped generate public support (Erhart 2014). The connection between the supporter group and the protest movement is manifested in the rap video when the performers speaking as çArşı members not only celebrate the çapulcu but fully take on the identity:

I'm just a 'ÇAPULCU'

I know who I am ${ }^{11}$

This video brings together amateur footage from the protests in the streets, interspersed with close ups of Bora Gramm performing his rap, energetically expressed to camera, with genre-characteristic body language. Bora Gramm is depicted in multifarious ways: recording in a studio setting, establishing him as a professional musician; street rapping whilst marching with the crowd; rapping outdoors in the night using a shaky handheld camera to give the impression of a spontaneous performer, and as such an integral part of the protest with his make-do approach to performance of protest. In this sense, the video also connects to a core characteristic of rap videos where artists often perform in an urban 'street' environment. The video makes

watch?time_continue $=19 \& \mathrm{v}=\mathrm{Mxcw} 4 \mathrm{gxNf} 2 \mathrm{U}$, and $O Z B \dot{I}-$ Asi (Gezi Park Şarkıs $\iota)$, https://www. youtube.com/watch? $\mathrm{v}=3 \mathrm{jFpsKhfdMQ}$, accessed 12.04.19.

11 'Ben sadece bir çapulcuyum. Ne olduğumu biliyorum'. 


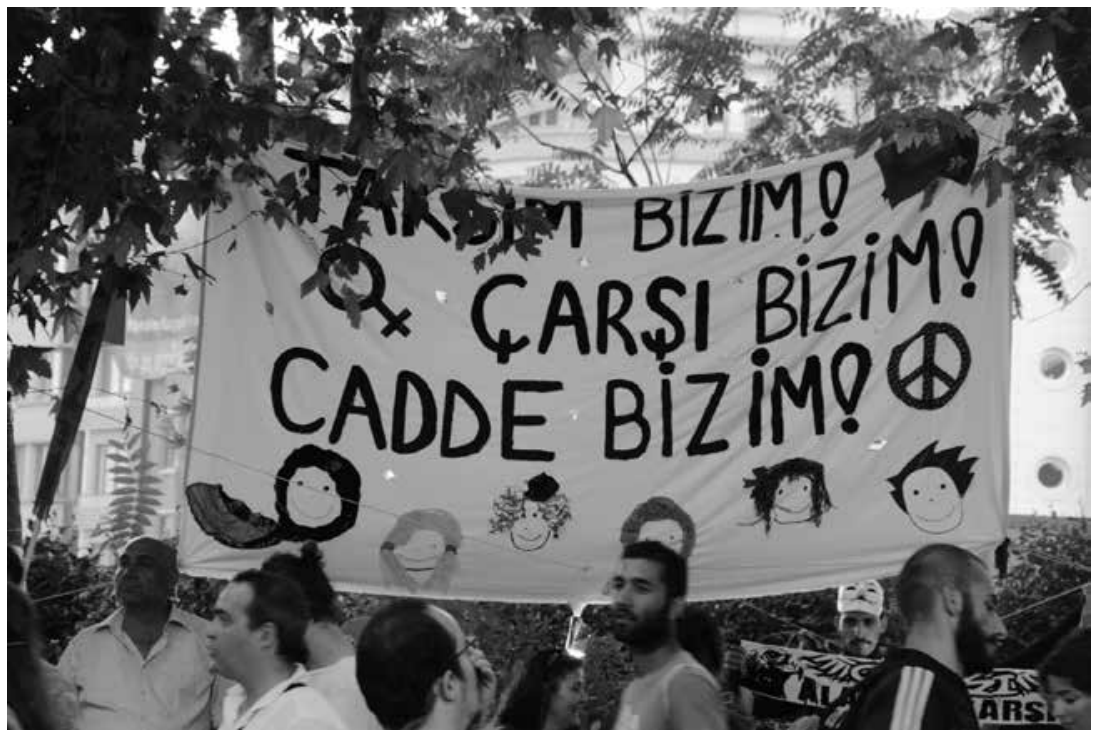

Figure 10.1. A çArşı supporters' banner in Gezi Park with the slogan 'Taksim is ours. çArşı is ours. The street is ours'. Licensed under the Creative Commons Attribution-Share Alike 2.0 Generic license.

a case for the right to protest and offers strong criticism of the media and the police. This relates to the point made by Özge Özdüzen (this volume) that within video activism, activists' bodies either depicted or indirectly represented through the movements of the handheld camera function as a source of protest narrative.

Images and text are juxtaposed to draw attention to the gap between what should be the case in terms of democratic justice and the freedom of expression, on the one hand, and the political reality of the situation in Turkey, on the other. The video starts with a quotation from the constitution of the Republic of Turkey noting Article 34, which says that 'everyone has the right to hold meetings, demonstrations without prior permission unarmed and peacefully'. Then follows a set of dictionary entries presented in a stylistically formal way, using typewriter lettering for key words such as direniş (resistance), dayanişma (solidarity), adalet (justice), polis (police) and medya (media). The media entry is accompanied the image of a penguin, one of the symbols of the protests that mocks the Turkish mainstream media's refusal to report on the events (CNN Türk broadcasted a documentary about penguins whilst protest events were unfolding in Istanbul and reported on by CNN International). The image of 'penguin media' draws heavily on irony as a rhetorical tool, and this 
indirect argumentative reasoning is used throughout the video: for instance, the police is seen destroying tents, removing banners and attacking the protestors which is juxtaposed with the dictionary entry for polis (police), which mentions the police force's duty to protect the citizens. The paradox of the 'universally' accepted dictionary definitions in contrast with what unfolds in the protest footage dramatizes the video. Similarly, the quote about the right to protest is set in contrast to images of protestors suffering violence and others helping those exposed to tear gas. For this strategy to be effective, we argue, the 'moral capital' of the sender, as discussed earlier, is imperative, and thus the 'rapper-protestor' position is what makes the ironic delivery ring true.

In the song rapper Bora Gramm addresses those who have been taken in custody during the protests urging them to 'stay strong'. It opens with a section sung in English:

You gotta stand on ya feet

If y'all need equality

Stand on ya feet

This is 'Anonymous'

'Red' and all these

Other colours around it

Hereby, the group is calling for citizens to mobilize, to stand up for what they believe in, and thereafter connects the Gezi Park struggle to the Internet-based activists of 'Anonymous' and places themselves at the heart of contemporary protest movements. Then the performer begins rapping in Turkish about the 'Istanbul United' spirit at Gezi, and how it has eradicated longstanding football fan antagonism declaring that the rivals Fenerbahçe and Galatasaray are no longer enemies with the following lines: 'See, we are not enemies anymore - Galatasaray Fenerbahçe and Beşiktaş are everywhere', and declaring that what unites them is their stance 'against this system' [the AKP government]. Later in the song the theme of standing united against a common opponent is further emphasized in the lines 'a day comes when there are jackals all around - merging is the only solution', and 'when it is time to defy, hold my arm - we are one although our colours are different'. The main chorus is sung in the style of a melodic chant:

Go on Gezi Park!

Resist Gezi Park!

Merge! 
Stay strong!

Go on Gezi Park!

Resist Gezi Park! ${ }^{12}$

The video shifts from Turkish to English and the narrative continues to talk about togetherness and brotherhood, drawing on the notion of a shared football fan identity, extending it to also apply to the protest movement. In some lines the political expression is more explicit: the performer advocates anti-consumption, anti-individualism - very much in the çArşı sprit he calls to 'say goodbye to buyin' anything you wanna have - Y'd betta share cuz we share this life'. He paints a picture of the Gezi protest as a leaderless movement that anyone can join: 'You should realize that a single hand can't make a noise - there are no commanders in us - this is a public resistance!' and describes çArşı as a group that is against all that is unfair, if need be, even against itself. ${ }^{13}$ However, the lyrics also narrate street bravado and toughness, typical of 'gansta rap': 'they all swore to die for their hood' and 'we are fair and tough in any hood', thus making it universally recognizable as a rap text, appealing to audiences that are into the music genre, as an expression of urban youth culture, but not necessarily attuned with Turkish politics. For example, utilizing the image of 'the hood', which is a hallmark trope of the genre, makes it familiar to listeners and widens its appeal. Social media is absolutely key to the global spread of a socially conscious hip-hop as an idiom of opposition that many different social movements have appropriated and engendered, but as we have demonstrated in this chapter, its aesthetics could equally be a resource for musical political communication.

\section{Concluding Remarks}

The Gezi protest yielded a wide range of musical expression across a diverse range of genres. The way it mediated and remediated recordings and remixes of music and visual content on YouTube served to amplify the protest voice, mobilized through energy and emotion, and both consolidate and make accessible to wider publics the çapulcu identity. Online platforms and

12 'Hadigezi parkı/Diren gezi parkı/Tekyürek ooo'.

13 Here, he is referring to an actual incident in 2008 when the spokesperson for the group announced that çArşı will put an end to all its actions. The unconfirmed reason was unrest within the group. A banner was also held by which the group members announced that çArşı was now against itself. 
social media are not only used to create audiences, but enable a wider participation. Digitally 'creative citizens' as well as activist performers contribute to movements and generate political commentary by producing music videos, ranging from visual collages of found footage set to music to recorded live performances and sharing these on social media. Thus, the proliferation of music online constitutes an additional dimension to how the 'local' protest in Istanbul has gained support around the world and resonated with wide ranging and diverse publics. The online output, we suggest, is a continuum of the protests that extends beyond the occupation of the Gezi Park area. Music videos, both original recordings and remixes, could be a vital part of a movement's larger ecology of communication, expressions and connections.

As demonstrated in this chapter, looking at the YouTube videos, music is often used to dramatize images, and to convey emotions. Editing practices are one tool through which vernacular voices express dissent, for example, by combining music, text and images in ways that reveal and challenge dominant framings of the protest movement, but also other strategies such as producing new lyrics to already popular songs were used. Furthermore, we found a particularly vital output in the rap videos. The remix ethos of rap music combined with its energy, and subaltern rebellious perspective, encapsulate the musical aesthetics of protest. Online music videos are a form of digital activism that sustains social and political consciousness affectively both during and beyond the protest event and as we have sought to demonstrate here are utilized to resist symbolic domination.

\section{References}

Airoldi, Massimo, Davide Beraldo, and Alessandro Gandini. 2016. 'Follow the Algorithm: An Exploratory Investigation of Music on YouTube', Poetics 57: 1-13. Arat, Yeşım. 2013. 'Violence, Resistance, and Gezi Park', International Journal of Middle East Studies 45(4): 807-809.

Askanius, Tina. 2013. 'Online Video Activism and Political Mash-up Genres', JOMEC Journalism, Media and Cultural Studies 4. http://portal.research.lu.se/ ws/files/419746o/4180639.pdf. Accessed 31.03.19.

Atak, Kıvanç. 2013. 'From Malls to Barricades: Reflections on the Social Origins of Gezi', paper presented at the symposium Rebellion and Protest from Maribor to Taksim Social Movements in the Balkans, Graz, Austria, 12-14 December.

Baker, Geoffrey. 2011. 'Preachers, Gangsters, Pranksters: MC Solaar and Hip-hop as Overt and Covert Revolt', Journal of Popular Culture 44(2): 233-255. 
Bennett, Lance, and Alexandra Segerberg. 2012. 'The Logic of Connective Action', Information, Communication \& Society 15(5): 739-768.

Bianchi, Raffaella. 2018. 'Istanbul Sounding Like Revolution: The Role of Music in the Gezi Park Occupy Movement', Popular Music 37(2): 212-236.

Certeau, Michel de. 1984. The Practice of Everyday Life. Berkeley: University of California Press.

Conti, Olivia. 2015. 'Political Remix Video as a Vernacular Discourse', in The Routledge Companion to Remix Studies, ed. Eduardo Navas, Owen Gallagher, and xtine burrough, 332-343. New York: Routledge.

Diessel, Caroline. 2001. 'Bridging East and West on the "Orient Express": Oriental Hip-hop in the Turkish Diaspora of Berlin', Journal of Popular Music Studies 13(2): 165-187.

Edwards, Bob, and John McCarthy. 2004. 'Resources and Social Movement Mobilization', in The Blackwell Companion to Social Movements, ed. D. Snow, S. Sarah, and H. Kriesi, 116-152. Oxford; Blackwell.

Erhart, Itir. 2014. 'United in Protest: From "Living and Dying with Our Colors" to "Let All the Colours of the World Unite", International Journal of the History of Sport 31(14): 1724-1738.

Frith, Simon. 1996. Performing Rites: On the Value of Popular Music. Cambridge, MA: Harvard University Press.

Kahf, Usama. 2012. 'Arabic Hip-hop: Claims of Authenticity and Identity of a New Genre'. In That's the Joint!: The Hip-hop Studies Reader, $2^{\text {nd }}$ ed., ed. M. Forman and M.A. Neal, 359-385. Abingdon: Routledge.

Kaya, Ayhan. 2002. 'Aesthetics of Diaspora: Contemporary Minstrels in Turkish Berlin', Journal of Ethnic and Migration Studies 28(1): 43-62.

Kellerer, Katja. 2017. “Mweya weToyitoyi - The Spirit of Protest”: Re-inventing Toyi-toyi in Zimbabwean Hip Hop', Social Dynamics 43(2): 199-214.

Kutschke, Beate, Noriko Manabe, and John Street. 2017. 'Responses to Peter Manuel's "World Music and Activism since the End of History [sic]", Music and Politics, 11(1). https://quod.lib.umich.edu/m/mp/9460447.0011.102/--responses-to-peter-manuelsworld-music-and-activism-since?rgn=main;view=fulltext. Accessed 31.03.19.

Lindgren, Simon. 2017. Digital Media \& Society. Los Angeles: SAGE.

Lynskey, Dorian. 2010. 33 Revolutions per Minute: A History of Protest Songs. London: Faber.

Manuel, Peter. 2017. 'World Music and Activism since the End of History [sic]', Music and Politics, 11(1). https://quod.lib.umich.edu/m/mp/9460447.0011.101/-world-music-and-activism-since-the-end-of-history-sic?rgn=main;view=fulltext. Accessed 31.03.19.

Martini, Michele. 2018. 'On the User's Side: YouTube and Distant Witnessing in the Age of Technology-Enhanced Mediability', Convergence 24(1): 33-49. 
Mattern, Mark. 1998. Acting in Concert: Music, Community, and Political Action. New Brunswick: Rutgers University Press.

McGarry, Aidan, Olu Jenzen, Hande Eslen-Ziya, Itir Erhart, and Umut Korkut. 2019. 'Beyond the Iconic Protest Images: The Performance of "Everyday Life" on Social Media During Gezi Park', Social Movement Studies 18(3): 184-204.

McKerrell, Simon, and Lyndon C.S. Way. 2017. 'Understanding Music as Multimodal Discourse', in Music as Multimodal Discourse: Semiotics, Power and Protest, ed. Lyndon C.S. Way and Simon McKerrell, 1-20. London: Bloomsbury Academic.

Mirzoeff, Nicholas. 2015. How to See the World. London: Pelican.

Morgan, Andy. 2011. 'The Soundtrack to the Arab Revolutions - From Fear to Fury'. https://www.andymorganwrites.com/soundtrack-to-the-arab-revolutions-fromfear-to-fury/ Accessed 31.03.19.

Övünç Ongur, Hakan, and Tevfik Orkun Develi. 2013. 'Bir Alt Kültür Olarak Türkiye'de Rock Müzik ve Toplumsal Muhalefet İlişkisi', VII. Uluslararası Sosyoloji Kongresi. 02-05 Ekim Muğla, 155-180.

Parkinson, Tom. 2018. "Indiestanbul”: Counter-hegemonic Music and Third Republicanism in Turkey', Popular Music 37(1): 40-62.

Poell, Thomas, and Erik Borra. 2012. 'Twitter, YouTube, and Flickr as Platforms of Alternative Journalism: The Social Media Account of the 2010 Toronto G2o Protests', Journalism 13(6): 695-713.

Railton, Diane, and Paul Watson. 2011. Music Video and the Politics of Representation. Edinburgh: Edinburgh University Press.

Solomon, Thomas. 2005. "Living Underground Is Tough": Authenticity and Locality in the Hip-hop Community in Istanbul, Turkey', Popular Music 24(1): 1-20.

Solomon, Thomas. 2006. 'Hardcore Muslims: Islamic Themes in Turkish Rap in Diaspora and in the Homeland', Yearbook for Traditional Music 38: 59-78.

Stapleton, Katina R. 1998. 'From the Margins to Mainstream: The Political Power of Hip-hop', Media, Culture \& Society 20(2): 219-234.

Street, John. 1986. Rebel Rock: The Politics of Popular Music. Oxford: Blackwell.

Street, John. 2012. Music and Politics. Cambridge: Polity.

Tarifa, Ariana. (2012). 'Hip Hop as Empowerment: Voices in El Alto, Bolivia', International Journal of Qualitative Studies in Education 25(4): 397-415.

Taylor, Verta, and Nella Van Dyke. 2004. “Get up, Stand up": Tactical Repertoires of Social Movements', in The Blackwell Companion to Social Movements, ed. David Snow, Sarah Soule, and Hanspeter Kriesi, 262-293. Oxford; Blackwell.

Thorson, Kjerstin, Brian Ekdale, Porismita Borah, and Kang Namkoong. 2010. 'YouTube and Proposition 8: A Case Study in Video Activism', Information, Communication \& Society 13(3): 325-349. 
Uldam, Julie, and Tina Askanius. 2013. 'Online Civic Cultures: Debating Climate Change Activism on YouTube', International Journal of Communication 7: 1185-1204.

Way, Lyndon. 2015. 'YouTube as a Site of Debate through Populist Politics: The Case of a Turkish Protest Pop Video',Journal of Multicultural Discourses 10(2): 180-196.

Way, Lyndon. 2016. 'Protest Music, Populism, Politics and Authenticity: The Limits and Potential of Popular Music's Articulation of Subversive Politics', Journal of Language and Politics 15(4): 422-445.

Weij, Frank, and Pauwke Berkers. 2017. 'The Politics of Musical Activism: Western YouTube Reception of Pussy Riot's Punk Performances', Convergence: The International Journal of Research into New Media Technologies. https://doi. org/10.1177/1354856517706493. Accessed 31.03.19.

\section{About the Authors}

Olu Jenzen is Principal Lecturer at the University of Brighton, UK, and the Director of the Research Centre for Transforming Sexuality and Gender. Her research ranges over different themes in Media Studies and Critical Theory, with a particular interest in the aesthetics of protest, social media and LGBTQ activism and popular culture.

Itır Erhart is an Associate Professor in the Department of Media and Communication Systems, Istanbul Bilgi University. She is the author of the book What Am I?' and several articles on gender, sports, human rights, social movements and media, including 'United in Protest: From "Living and Dying with Our Colors" to "Let All the Colors of the World Unite"' and 'Ladies of Besiktas: A Dismantling of Male Hegemony at Inönü Stadium'. She is also a social entrepreneur and an Ashoka fellow.

Hande Eslen-Ziya is an Associate Professor of Sociology at the University of Stavanger. She has a gender specialization from Central European University, in Budapest, Hungary. Her research has been published in Social Movement Studies, European Journal of Women's Studies, Culture, Health and Sexuality, Leadership, Men and Masculinities, and Social Politics. Eslen-Ziya has also authored a book that investigates how men construct their identities throughout their developmental trajectories: The Social Construction and Developmental Trajectories of Masculinities (Istanbul Bilgi Universitesi Yayınları, 2017). 


\section{Derya Güçdemir}

Umut Korkut is Professor in International Politics at Glasgow School for Business and Society at Glasgow Caledonian University. Prof. Korkut has expertise in how political discourse makes audiences and has recently studied visual imagery and audience making. Prof. Korkut is the Lead for the EU AMIF (Asylum and Migrant Integration Fund)-funded project 'VOLPOWER: Enhancing Community Building and Social Integration through Dialogue and Collaboration amongst Young Europeans and Third Country Nationals', which assesses youth volunteering in sports, arts, and culture in view of social integration. He is also the Primary Investigator for the Horizon 2020-funded RESPOND and DEMOS projects on migration governance and populism.

Aidan McGarry is a Reader in International Politics at the Institute for Diplomacy and International Governance at Loughborough University, London. His research focuses on social movements, protest, political voice, and marginalized communities (www.aidanmcgarry.com). He is the author of four books, including Who Speaks for Roma? (Continuum, 2010) and Romaphobia: The Last Acceptable Racism in Europe (Zed, 2017). He was Principal Investigator of an Arts and Humanities Research Council (AHRC)funded project 'Aesthetics of Protest: Visual Culture and Communication in Turkey' (www.aestheticsofprotest.com) from 2016 to 2018. In 2018-2019 he is a EURIAS/Marie Curie Fellow at the Netherlands Institute for Advanced Study in Amsterdam, where is writing a book on political voice. 



\title{
11 The Activist Chroniclers of Occupy Gezi: Counterposing Visibility to Injustice
}

\author{
Dan Mercea and Helton Levy
}

\begin{abstract}
With the benefit of hindsight, this chapter casts another glance at Occupy Gezi, a landmark protest in contemporary Turkey. We reflect on the pursuit of visibility by activists on Twitter as a means to garner the attention of the Turkish and the global public to the heavy-handed police crackdown of the popular mobilization. We interpret their quest for visibility as a 'subaltern tactic' employed to reverse an asymmetry of power through an aesthetics of indignation at the injustice perpetrated against peaceful demonstrators. In the longer run, however, such visibility poses an important dilemma when, as in the case of Turkey, it becomes the basis for reflexive state surveillance.
\end{abstract}

Keywords: Occupy Gezi, Twitter, visibility, injustice frame, recognition, participation

\section{Introduction}

In 2013, Occupy Gezi became a milestone in contemporary Turkish history and politics. The protest was an expression of participatory democracy understood as a desire for more immediate and efficacious collective input in democratic governance (Della Porta 2013a). At the same time, it was an outcry against the erosion of Turkish democracy. Its institutions, including the mainstream media (Karatas and Saka 2017) commanded decreasing levels of trust (KONDA 2014) while being increasingly hollowed out by a mix of neoliberal policies and the authoritarian tendencies of the Erdoğan government (Iğsız 2014).

McGarry, A., I. Erhart, H. Eslen-Ziya, O.Jenzen, U. Korkut (eds), The Aesthetics of Global Protest: Visual Culture and Communication. Amsterdam: Amsterdam University Press, 2020 DOI 10.5117/9789463724913_CH11 
The reflections that follow focus on the period between late May and late June 2013. In the final days of May, protestors embarked on a quest for visibility on Twitter to garner the attention of the Turkish and the global public to the heavy-handed police crackdown of peaceful demonstrations by environmental activists (Budak and Watts 2015). The protests followed a procedural court challenge to government plans to erect the 'Taksim Military Barracks', a building complex that included shopping and residential units alongside military facilities (Demirhan 2014). The plans would have seen the de facto privatization of Gezi (Iğsız 2014: 28), a metropolitan park that would sit at the heart of the redevelopment site. They evolved into a struggle for recognition and participation: a recognition of the stake that urban residents have in the democratic governance of the environment they inhabit, which they can seek to assert through the courts, within the bounds of the rule of law. Recognition was further sought for the democratic right to participate in a non-violent revolt against the expanding authoritarianism of the then Prime Minister Erdoğan's government, which was subjugating the country's judicial, political and media institutions (Iğsız 2014).

Over the course of two weeks of rolling protests, tweeting compensated for the anaemic coverage of the Gezi occupation by Turkish media. Twitter was used strategically to draw in the global media and help choreograph collective action (Mercea et al. 2018). The visibility thus attained publicized the pursuit of procedural, environmental and social justice (Schlosberg 2007) by the swelling number of politically, socio-economically and culturally diverse protestors (see Vatikiotis and Yörük 2016). The jarring aesthetics of police violence perpetrated against activists was channelled through an injustice frame so as to emphasize the democratic character, means and goals of the protests.

In what follows, we argue that this quest for visibility is an example of a 'subaltern tactic' (Certeau 1984) to reverse an asymmetry of power using an injustice frame. In the short run, this tactic can serve that very goal by subjecting governments to extraordinary levels of global, public scrutiny. In the longer run, however, it poses an important dilemma as it can become a basis for reflexive state surveillance. On the one hand, for the diverse assembly of protestors in Gezi Park, the official government response to the mobilization was portrayed as state repression by dint of a rallying injustice frame. Following the eviction of the encampment, Twitter was used to memorialize 'the Gezi spirit' so as to preserve and continue to make visible the democratic ethos and values of the movement and its legacy (Mercea et al. 2018). On the other hand, this act of resistance prompted a reflexive turn in state surveillance. In 2014, legislation was passed tightening the Turkish 
government's control of the Internet at the same time as rampant state monitoring of social media was aimed at silencing dissident voices (Karatas and Saka 2017:387). Despite rejoicing in a newly found solidarity during the occupation, participants that memorialized the protests by continuing to post about them on Twitter, struggled to preserve its legacy in the volatile political climate of the country since 2013 (Mercea et al. 2018). Below, we first discuss injustice frames and their use by activists around the world to raise the visibility of aggrieved groups.

\section{A Path to Visibility}

We derive the term 'injustice frame' from the tradition of frame analysis in social movements (for an overview, see Benford and Snow 2000). Snow et al. (1986: 466) built on Goffman's (1974: 21) notion of the frame, defined as 'schemata of interpretation' whereby one can make sense of the world around them to characterize an injustice frame as 'a mode of interpretation that defines the actions of an authority system as unjust and simultaneously legitimates noncompliance'. Thus, at a cognitive level, an injustice frame identifies both an issue as inherently egregious and its source as a known actor (Fisher 1997). Frames are thus a heuristic, distilled information, that are used by activists to expediently direct the actions of individuals or groups (Snow et al. 1986).

Young (in Schmitter 2011: 402-403) posited a set of ways in which activists shine a light on the shortcomings of 'real-existing' democracy (RED), its entrenched institutions, and the increasingly organized forms of (special) interest representation that crowd out the public domain of democratic politics. Activists have clamoured for a narrowing of the number of 'characters' involved in REDs (e.g. resource-rich lobby groups or vast transnational corporations that wield a disproportionate influence over elected representatives), that is, the 'exclusivity' of institutionalized deliberative procedures and the fundamental incompleteness of what one calls 'inclusion' in democracy. To them, activists counterpose visibility as a means to achieve recognition for minority or marginalized groups. In this view, visibility for activists is tantamount to securing a place in the public domain that can serve many purposes, from rallying supporters to subverting hegemonic discourses that suppress subaltern contestations of entrenched power relations (Doerr et al. 2013). Protests are a performative enactment of visibility that serves to contest power asymmetries through counterclaims on public space (see Hayward and Komarova, this volume) - both physical, of the street or the 
square and symbolic, as oppositional discourse expressed through placards, pamphlets, fliers or memes.

In past episodes of collective action, the aesthetics of openness, i.e. the way in which protests are performed as public events, has allowed for the bridging - not least through media coverage - of frames instigated by various aggrieved participant groups (Benford 1993). In 2011, the General Assembly at Occupy Wall Street was the embodiment of deliberations that thrashed out shared interpretations of movement grievances and aims, both of which stemmed from an evaluation of public spending cuts as socially unjust (Rehmann 2013). Injustice frames, notably, 'We are the 99\%', aided in the distillation of grievances into discursive tropes and an accessible numerical aesthetics of inequality. Such frames have further drawn on the aesthetics of indignation that was recognized and enacted through worldwide occupations of public space and was carried by the media into a broader public arena (Juris 2012). Aesthetics, in this interpretation, refers to the 'expression or performance of protest' (McGarry et al., this volume).

In the case of Occupy Gezi, an injustice frame emerged representing the coalescence of environmental, social and political grievances. They ranged 'from environmental destruction to the aggressive gentrification of urban spaces, from economic hardship to Turkey's aggressive involvement in the Syrian civil war, from the media and social media censorship to the blocked peace process with the Kurdish liberation movement' (Vatikiotis and Yörük 2016: 9). Everyday experiences shared among protestors can paint such grievances in familiar colours, turning them into appeals to social and political change (a process that Snow et al. [1986: 477] describe as 'frame resonance').

The violent police crackdown at the outset of the Gezi demonstrations on 31 May epitomized the injustice condoned or enforced by the institutions of the state. It acted as a touchpaper setting off large rallies and the occupation of Gezi Park. The aesthetics of police brutality captured with the iconic picture of the 'Woman in Red', a female protestor turned sideways while being pepper-sprayed by a male riot police officer, resonated with a subjective sense of indignation and urgency to respond to the violent hegemony of the state (Farro and Demirhisar 2014). Similarly, Black Lives Matter more recently seized on the conventional imagery of urban safety, the police car, to display the rebellion of those institutionally deemed as suspect, as depicted in a Kendrik Lamar video:

The cop car on stage was demolished as if bombed out, and he, powerfully and defiantly, stood on top of it performing the song that Black Lives 
Matter protestors would draw on weeks later, [...] a contemporary symbol of state oppression that had been re-appropriated as a sign of defiance and empowerment, first by a musician, then by grassroots organizers and protestors who refused to be intimidated. (Lebron 2017:36)

The distillation of daily experience and highly evocative symbols can engender the resonance that propels movements like Black Lives Matter into cultural phenomena that are afforded greater visibility. In its turn, Gezi Park moved from a local, urban planning issue to political resistance against the injustice of unwarranted police violence and a creep towards authoritarianism. This change of scale was overtly aesthetic. Occupy Gezi protestors used the Coca-Cola font to write anti-capitalist slogans (Emre et al. 2014), objecting to the neoliberal privatization of space; they exhibited a 'politics of the body' where 'any body who was discontented or outraged by police violence or felt choked by the authoritarian regime was out in the streets' (Gambetti 2014), and appealed to humour to attract attention to the demonstrations (Balaban 2015; Dagtas 2016).

On social media, the aesthetics of indignation served to reproduce the atmosphere of the occupation at Gezi, broadly framed as an 'injustice' perpetrated against peaceful demonstrators. On Twitter, the swell of information shared during Occupy Gezi made the movement visible both to its supporters, through the circulation of information pertaining to the movement's coordination or participant turnout, and to the media, through the accounting of police violence (Ogan and Varol 2017; Jost et al. 2018). In this chapter, we review Twitter user perceptions of Occupy Gezi and discuss attempts by Gezi protestors to achieve media visibility through this social network.

\section{Visibility Denied and Regained}

In our research, we used Twitter's streaming application programming interface to monitor four Occupy Gezi hashtags (\#direngeziparki, \#occupygezi, \#occupytaksim, \#occupyturkey, see Mercea et al. 2018). Following a close inspection of the tweets covering a period of a month at the height of the protests, in May-June 2013 (see figure 11.1), we contacted 100 users and successfully recruited 24 of them for in-depth interviews.

A small minority of less than 1 per cent of the users in our dataset had tweeted with the Gezi hashtags for at least ten days. The interviewees tweeted for at least 20 days during those two months in 2013 (fig. 11.1). This 


\section{Tweet Timeline}

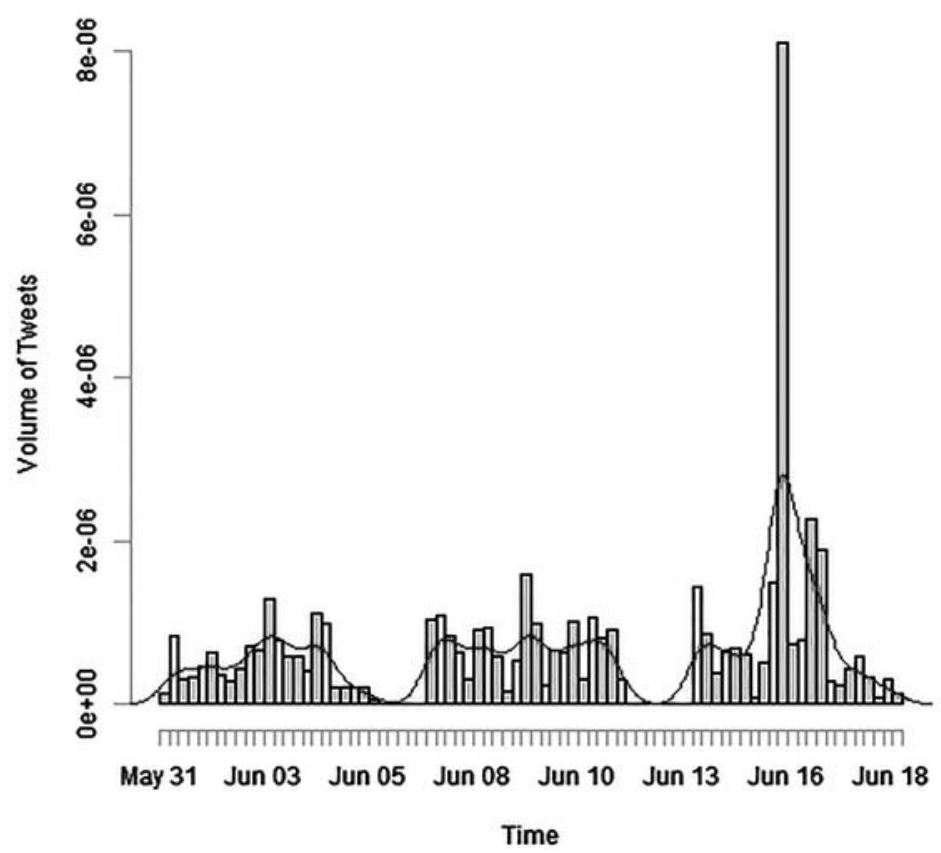

Figure 11.1. The time distribution of Occupy Gezi tweets for May-June 2013.

was a substantial investment of time into the protests whose implications we discussed, in the first instance, in light of the literature on activist persistence.

We showed that tweeting in the service of the Gezi Occupation was a moral act motivated by a desire to convey to a potentially global public the participatory, democratic values that the protests embodied, which were counterposed to the injustices perpetrated by the state (Mercea et al. 2018). This emphasis on values resonated over time. Its openness reminded us of the Global Justice Movement which, in its day, was depicted as 'a movement centred more around values than ideologies [articulated not] [...] through references to big theoretical constructions, but rather by recalling the founding values of justice and peace, dignity and democracy' (Della Porta 2013b: 141).

Occupy Gezi was an experiment in visibility. For our interviewees, all but three of whom were in Turkey and attended the protests, Occupy Gezi represented a temporary suspension of group differences that were recognized through inclusive, participatory decision-making within the governing forum of the occupation. The encampment thus personified a 
'sectional utopia' (Mannheim 1952), predicated on the ideals of the occupiers and the self-governing processes they instituted collectively. Rather than to negate a noted polarization among social groups (KONDA 2014), Occupy Gezi made visible efforts to crystallize and enact a political vision of participatory democracy. That vision was in part a response to the political and later physical violence of the government and state institutions under its control. Once organized, popular opposition to the attempt to force through the privatization of public space was physically repressed for being both an ideological threat and a material obstacle. ${ }^{1}$ As IP 5 (interview by author, 2015, in Mercea et al. 2018) explained,

[Occupy Gezi] was a struggle for justice. [We] were seeking our rights. [...] We emphasized the intervention by Ankara in [the planned redevelopment of] a park in Istanbul. We [had to] pull the government [back down] to the democratic ground again.

The stand-off with the authorities that unfolded over the course of the occupation conspicuously received scant attention from the national broadcasting media. Infamously, CNN Turk screened a penguin documentary as demonstrators clashed with the police on 31 May (Tufekci 2014). In the eyes of our interviewees, this was a glaring dereliction of duty for a pivotal democratic institution and a jarring realization that protestors and their supporters were able to tactically overcome by turning social media and particularly Twitter into an open and public channel for alternative coverage of the protests. In that way, the movement found itself in a position where it was able to generate and propagate its own frames. It thus escaped the definitional power of the media, which had for long decided a 'movement's fate' (Gitlin 2003: 3).

Twitter substituted the mass media but in turn imposed its own constraints on visibility accruing from its socio-technical affordances, its attention economy (Lovink 2011) and its regime of accelerated time (Kaun 2015). One interviewee evocatively described her experience with embracing Twitter to communicate about Gezi:

I have been using Twitter since 2009. I was already using it before Gezi, but I saw it as a platform like Facebook. After that, in 2011-2012, as Twitter use increased, the accounts I have been following turned [...] maybe

1 At least 26 Gezi protesters faced criminal charges, 8 people died and 8,ooo were injured (Letsch 2015). 
a little more political and activist. [...] [At] the beginning of Gezi, the people who got the news first were Twitter users mostly and it was on Facebook a day after. [...] I followed the Gezi process mostly on Twitter, I used Twitter. From the first night when the trees were cut down. [...] I spent the whole protest with an iPad on my lap. For us, the people on the streets, it was important to see what is happening and where because you couldn't reach anybody, anytime. So, we shared that we had many injured people and animals. I experienced this personally. Honestly, we went to some places to save the people who were stuck somewhere, or [...] like when we saw someone's tweet and we brought medicine for people who were having an asthma attack. (IP18, interview by author, 2015, quoted in Mercea et al. 2018)

It is important to understand that Twitter was a contested arena both during the protests and in their aftermath, especially as opponents of the protestors attempted to characterize the social media uprising as foreign interference. This and other conspiracy theories attempted to discredit them also by using flawed official statistics of event attendance (Özel 2014). An important reason why Twitter was and remained contested was because of the visibility within Turkish society that the protestors gained through it for their collective effort. The visibility pursued by the protestors was multipronged and served multiple purposes. On the one hand, interviewees recounted aiming to sensitize peers - family, friends, acquaintances - to the protests, their civic-ness and extraordinary nature as an enactment of participatory democracy. As one interviewee recalled:

I started to tweet as a reaction to the destruction of this green area. It was a social reaction. [...] It was a civic and social concern. [...] It was a desire and need to make things visible. It was a prompt response to share my concerns and worries. I wanted to share my worries and sensitivity. ( $\mathrm{IP}_{3}$, interview by author, 2015, in Mercea et al. 2018, emphasis added)

At the same time, visibility was a sought upshot of an already documented course of action (Olesen 2017:658) of chronicling the injustice of the asymmetrical symbolic violence perpetrated by the government and the media. They suppressed coverage so as to preserve the dominant discourse on the scope, significance and legitimacy of the protests (cf. Bourdieu 1999). Tweeting to attain visibility became a media practice whereby activists could wrest some control over the coverage of their outcry (Mattoni and Treré 2014), turning it into an eventful political protest with a potential 
to engender further social change (Della Porta 2008), by laying bare the physical aggression against them meted out by state institutions. Faced with the realization that '[the] authorit[ies] controlled the central media hubs', activists courted the attention of the international media, thereby loosening the grip of national institutions on the flow of information. IP9 argued that 'Twitter challenged the control of the media hubs' while IP4, $\mathrm{IP}_{5}$, and IP12 said:

The repression and dominance of the existing political organization over the public made people explode. And I exploded like [other] individuals in society. We used Twitter to get news and be aware of what is going on through the accounts that we know, and we trust. Twitter became an information tool for us, not a target. (IP4, interview by author, 2015, in Mercea et al. 2018)

The media [were reduced to a] Penguin [documentary]. We were all walking media. I tweeted in English, to the media in US, Russia, Italy. I tweeted directly mentioning the presidents, the prime ministers. I gained many followers Italian, German from different nations. (IP5, interview by author, 2015, in Mercea et al. 2018)

I tweeted about 27 May. [...] [C]elebrities retweeted and tweeted about [it]. [...] [B]ulldozers stopped and went away. Even though the media were there and recorded the events, there was no coverage of the event in the media. On 31 May [...] there were hundreds of thousands of people [in Taksim Square] and there was police violence on the streets. But there was nothing in the media. Then I prepared eight tweet templates on what was going on in Turkey and how the case developed and sent them to Twitter celebrities mentioning the international trustable news [outlets] like the New York Times, CNN, BBC, The Guardian, etc. [...] at the end of the tweets. It must have been 1 June. [The tweet to CNN alone got] more than 8,400 retweets. Then, later [that day] CNN International started to broadcast live from Taksim. (IP12, interview by author, 2015, in Mercea et al. 2018)

As IP12 clarifies, visibility allowed participants and potential participants to form a realistic impression of 'what is going on' onsite while providing remote media observers with stories ready for their news feeds and ticker tapes. The latter work was carried out strategically by protestors to ensure that international media are 'up to date' with events on the ground (Baruh and Watson 2015; Mercea et al. 2018). Importantly, also, Occupy Gezi received 
much support from the Turkish diaspora. The group tweeted extensively and helped the protest attain international visibility, albeit from the safety of their remote locations (Ogan et al. 2016).

This composite 'coverage' that surpasses the dichotomy between a hegemonic media narrative and an alternative activist one (see Levy 2018), ended up allowing the Gezi activists to narrate the events themselves with the best support they could get from within the movement. In the words of one activist:

Since the intervention was inhumane, I decided to use my talents and expertise which are on social media and organizational capabilities to support the protestors in the field. I helped the protestors through creating organizational opportunities, like mapping, providing coordination between people and monitoring CCTV. (IP13, interview by author, 2015, in Mercea et al. 2018)

\section{Conclusion}

In the short term, the Gezi activists were able to circumvent the obstacles to visibility for the Gezi movement. A scrambled protest event in a public square became an 'eventful' (Della Porta 2008) occupation that transformed a localized call for environmental justice into a wider appeal for recognition and participation. Its quest for visibility - made vivid through the images broadcasted via social media - was instrumental to this process. As Hayward and Komanova's (this volume) case study of the Orange parade in North Belfast cogently evinced, the visibility of a contentious event such as Occupy Gezi likewise opens up a space of solidarity, and resistance or challenge to authority. In turn, new political opportunities and threats (Tarrow 2011) can arise from the heightened visibility - in the form of new allies and adherents or, on the other hand, state repression and surveillance.

In the long term, the vivid aesthetics of the Gezi protest may survive attempts to efface it from public discourse. In 2018 Turkey, important sites for these events have seen abandonment and depredation when repurposed for showcasing the political right (Evered 2018; Zik 2018). While Twitter contributed to the attainment of visibility, a key outcome pursued by the protestors in Gezi Park and the nearby iconic Taksim Square, social media equally demonstrated their limitations. These were evident particularly in respect to access and continuity of service in the hands of activists (Tufekci 2017) rising in opposition to the erosion of democracy, freedom of assembly, 
freedom of speech and the rule of law, ongoing repression and surveillance. What is left in the wake of Gezi is the immaterial frame of a collective sense of 'injustice' whose erstwhile prominent place in public discourse has created a memory and political culture that, although fiercely tested following the 2016 attempted coup against president Erdoğan, endures.

\section{References}

Balaban, Utku. 2015. 'Vernacular Utopias: Mimetic Performances as Humour in Gezi Park and on Bayındır Street', in Creativity and Humour in Occupy Movements: Intellectual Disobedience in Turkey and Beyond, ed. A. Yalcintas, 48-74 Basingstoke: Palgrave.

Baruh, Lemi, and Hayley Watson. 2015. 'Social Media Use during Political Crises', in The Routledge Companion to Social Media and Politics, ed. Axel Bruns, Gunn Enli, Eli Skogerbø, Anders Olof Larsson, and Christian Christensen, 198-211. Abingdon: Routledge.

Benford, Robert D. 1993. "You Could Be the Hundredth Monkey": Collective Action Frames and Vocabularies of Motive within the Nuclear Disarmament Movement', Sociological Quarterly 34: 195-216.

Benford, Robert D., and David Snow. 2000. 'Framing Processes and Social Movements: An Overview and Assessment', Annual Review of Sociology 26: 611-639.

Bourdieu, Pierre. 1999. Language and Symbolic Power. Cambridge, MA: Harvard University Press.

Budak, Ceren, and Duncan J. Watts. 2015. 'Dissecting the Spirit of Gezi: Influence vs. Selection in the Occupy Gezi Movement', Sociological Science 2: 370-397.

Certeau, Michel de. 1984. The Practice of Everyday Life. Berkeley: University of California Press.

Dagtas, Mahiye Secil. 2016. 'Down With Some Things! The Politics of Humour and Humour as Politics in Turkey's Cezi Protests', Etnofoor 28(1): 11-34.

Della Porta, Donatella. 2008. 'Eventful Protests, Global Conflicts', Distinktion 17: 27-56.

Della Porta, Donatella. 2013a. Can Democracy Be Saved? Participation, Deliberation and Social Movements. Cambridge: Polity.

Della Porta, Donatella. 2013b. 'What We Can Do with Visual Analysis in Social Movement Studies: Some (Self) Reflections', in Advances in the Visual Analysis of Social Movements, ed. Nicole Doerr, Alice Mattoni, and Simon Teune 137-44 Bingley: Emerald Group.

Demirhan, Kamil. 2014. 'Social Media Effects on the Gezi Park Movement in Turkey: Politics under Hashtags', in Social Media in Politics: Case Studies on the Political Power of Social Media, ed. B. Pătruț and M. Pătruț 281-314 Cham:Springer International. 
Doerr, Nicole, Alice Mattoni, and Simon Teune. 2013. 'Towards a Visual Analysis of Social Movements, Conflict, and Political Mobilization', in Advances in the Visual Analysis of Social Movements, ed. Nicole Doerr, Alice Mattoni, and Simon Teune, xi-xxvi. Bingley: Emerald Group.

Emre, Ö. Perrin, Bariș Çoban, and Gülüm Şener. 2014. 'Humorous Form of Protest: Disproportionate Use of Intelligence in Gezi Park's Resistance', in New Opportunities and Impasses: Theorizing and Experiencing Politics: Materials of POLITSCI'13: Political science conference, comp. G.E. Zeynep, 430-447. Istanbul: DAKAM Publishing.

Evered, Kyle T. 2018. 'Erasing the Place of Dissent: Inscriptions and Eliminations of Gezi Park Graffiti', AREA: Royal Geographical Society 51(1): 1-11. https://doi. org/10.1111/area.12439.

Farro, Antimo L., and Deniz Günce Demirhisar. 2014. 'The Gezi Park Movement: A Turkish Experience of the Twenty-first-Century Collective Movements', International Review of Sociology 24: 176-189.

Fisher, Kimberly. 1997. 'Locating Frames in the Discursive Universe', Sociological Research Online 2(3): 1-24.

Gambetti, Zeynep. 2014. 'Occupy Gezi as Politics of the Body', in The Making of a Protest Movement in Turkey: \#occupygezi, ed. U. Özkırımlı, 89-102. London: Palgrave Pivot.

Gamson, William A., David Croteau, William Hoynes, and Theodore Sasson. 1992. 'Media Images and the Social Construction of Reality', Annual Review of Sociology 18(1): 373-393.

Gitlin, Todd. 2003. The Whole World Is Watching: Mass Media in the Making and Unmaking of the New Left. Berkeley: University of California Press.

Goffman, Erving. 1974. Frame Analysis: An Essay on the Organization of Experience. Cambridge, MA: Harvard University Press.

Iğsız, Aslı. 2014. 'Neoliberalism, Illegality and the State of Exception in Turkey', in The Making of a Protest Movement in Turkey: \#occupygezi, ed. U. Özkırımlı,121-131 London: Palgrave Pivot.

Jacobs, Jane M. 2002. Edge of Empire: Postcolonialism and the City. London: Routledge. Jost, John T., Pablo Barberá, Richard Bonneau, Melanie Langer, Megan Metzger, Jonathan Nagler, Johanna Sterling, and Joshua A. Tucker. 2018. 'How Social Media Facilitates Political Protest: Information, Motivation, and Social Networks', Political Psychology, 39(S1): 85-118.

Juris, Jeffrey. 2012. 'Reflections on \#Occupy Everywhere: Social Media, Public Space and Emerging Logics of Aggregation', American Ethnologist 39: 259-279.

Karatas, Duygu, and Erkan Saka. 2017. 'Online Political Trolling in the Context of Post-Gezi Social Media in Turkey', International Journal of Digital Television 8: $383-401$. 
Kaun, Anne. 2015. 'Regimes of Time: Media Practices of the Dispossessed', Time \& Society 24: 221-243.

KONDA. 2014. 'Gezi Report: Public Perception of the "Gezi Protests": Who Were the People at Gezi Park?', 5June.http://konda.com.tr/en/raporlar/KONDA_Gezi_Report.pdf. Accessed 31.03.19.

Lebron, Christopher J. 2017. The Making of Black Lives Matter: A Brief History of an Idea. New York: Oxford University Press.

Letsch, Constanze. 2015. 'Gezi Park Protest Trial: Turkish Court Acquits All 26 Defendants', The Guardian, 29 April.

Levy, Helton. 2018. 'Disrupting the Old Periphery: Alternative Media, Inequality and Counter-Mapping in Brazil', Westminster Papers in Communication and Culture 13: 61-76.

Lovink, Geert. 2011. Networks without a Cause: A Critique of Social Media. Cambridge: Polity Press.

Mannheim, Karl. 1952. Ideology and Utopia: An Introduction to the Sociology of Knowledge. London: Routledge and Kegan Paul.

Mattoni, Alice, and Emiliano Treré. 2014. 'Media Practices, Mediation Processes, and Mediatization in the Study of Social Movements', Communication Theory 24: 252-271.

Mercea, Dan, Duygu Karatas, and Marco T. Bastos. 2018. 'Persistent Activist Communication in Occupy Gezi', Sociology 52: 915-933.

Ogan, Christine, and Onur Varol. 2017. 'What Is Gained and What Is Left to Be Done When Content Analysis Is Added to Network Analysis in the Study of a Social Movement: Twitter Use during Gezi Park', Information, Communication \& Society 20(8): 1220-1238.

Ogan, Christine, Roya Imani Giglou, and Leen d'Haenens. 2016. 'The Relationship between Online and Offline Participation in a Social Movement', in Taking the Square: Mediated Dissent and Occupations of Public Space, ed. Maria Rovisco and Jonathan Corpus Ong, 117-138. London: Rowman \& Littlefield.

Olesen, Thomas. 2017. 'Memetic Protest and the Dramatic Diffusion of Alan Kurdi', Media, Culture \& Society 40: 656-672.

Özel, Soli. 2014. 'A Moment of Elation: The Gezi Protests/Resistance and the Fading of the AKP Project', in The Making of a Protest Movement in Turkey: \#occupygezi, 7-24. London: Palgrave Pivot.

Rehmann, Jan. 2013. 'Occupy Wall Street and the Question of Hegemony: A Gramscian Analysis', Socialism and Democracy 27: 1-18.

Schlosberg, David. 2007. Defining Environmental Justice: Theories, Movements, and Nature. Oxford: Oxford University Press.

Schmitter, Philippe. 2011. 'The Future of "Real-Existing” Democracy', Society and Economy 33: 399-428. 
Snow, David A., E. Burke Rochford, Jr, Steven K. Worden, and Robert D. Benford. 1986.

'Frame Alignment Processes, Micromobilization and Movement Participation', American Sociological Review 51: 464-481.

Tarrow, Sidney. 2011. Power in Movement. Cambridge: Cambridge University Press. Tufekci, Zeynep. 2014. 'Social Movements and Governments in the Digital Age: Evaluating a Complex Landscape', Journal of International Affairs 68: 1-18.

Tufekci, Zeynep. 2017. Twitter and Tear Gas: The Power and Fragility of Networked Protest. New Haven: Yale University Press.

Vatikiotis, Pantelis, and Zafer F. Yörük. 2016. 'Gezi Movement and the Networked Public Sphere: A Comparative Analysis in Global Context', Social Media + Society 2: 2056305116662184 .

Zik, M. Ragip. 2018. 'One Building, Several Facades: Political Showcasing in Contemporary Turkey, Open Democracy, 17 October. https://www.opendemocracy.net/ mrag-p-z-k/one-building-several-facades-political-showcasing-in-contemporaryturkey. Accessed 31.03.19.

\section{About the Authors}

Dan Mercea is Senior Lecturer in the Department of Sociology at City, University of London. He is the author of Civic Participation in Contentious Politics: The Digital Foreshadowing of Protest (Palgrave, 2016).

Helton Levy is a journalist, lecturer and Research Associate at University College London. He is author of The Internet, Politics, and Inequality in Contemporary Brazil: Peripheral Media (Rowman \& Littlefield, 2018). 


\title{
12 When Twitter Got \# woke: Black Lives Matter, DeRay McKesson, Twitter, and the Appropriation of the Aesthetics of Protest
}

\author{
Farida Vis, Simon Faulkner, Safiya Umoja Noble, and \\ Hannah Guy
}

\begin{abstract}
This chapter takes as its focal point a press photograph of the arrest of DeRay McKesson, a prominent black figure associated with the Black Lives Matter (BLM) movement in the United States. In the photograph, McKesson is shown wearing a T-shirt, produced by the social media company Twitter, that bears the hashtag \#StayWoke. This photographic image is examined by deploying an 'anatomy of an image' approach, defined by two qualitative modes of analysis. First, looking at the use of the photograph in the mainstream online press as well as selectively on Twitter; second, by treating the image and, in particular, the T-shirt McKesson wears as a starting point for a discussion of relationships between BLM, McKesson, and Twitter.
\end{abstract}

Keywords: Black Lives Matter, Twitter, DeRay McKesson, Images, aesthetics of protest

\section{Introduction}

Yes that is a@Twitter@blackbirds logo.Amazing to see tech as vehicle for social change. Respect. - Marc Benioff, CEO of Salesforce (quoted in Wong 2016)

That anyone could see a picture of a black man being arrested for protesting against the wrongful killing of another black man and respond, 'Hey look at the

McGarry, A., I. Erhart, H. Eslen-Ziya, O.Jenzen, U. Korkut (eds), The Aesthetics of Global Protest: Visual Culture and Communication. Amsterdam: Amsterdam University Press, 2020 DOI 10.5117/9789463724913_CH12 
Twitter logo', would be mind-boggling if it happened anywhere else. In the tech industry though, it's par for the course.

- Erica Joy Baker, senior engineer at Slack, founding member of Project Justice

(quoted in Wong 2016)

These two quotations refer to a highly publicized photograph of the arrest of the black American celebrity-activist DeRay McKesson, ${ }^{1}$ during a Black Lives Matter (BLM) ${ }^{2}$ demonstration in Baton Rouge, Louisiana, on the evening of 9 July 2016 (fig. 12.1). This arrest occurred during the second night of protests in the city in response to the police killings of Alton Sterling in Baton Rouge and Philando Castille in Minnesota, on 5 and 6 July, respectively. The photograph shows McKesson being held by two police officers, while kneeling on one knee with his hands cuffed behind his back. There are two other officers visible in the image, while behind them other demonstrators are documenting the arrest with smartphones. McKesson stares directly at the camera, giving him a powerful confrontational presence within the image. Also notable is the grey T-shirt McKesson is wearing, which was produced by the social media company Twitter and bears the hashtag \#StayWoke and a Twitter Blackbird logo. ${ }^{3}$ A cropped version of the photograph was used most often in mainstream media publications that reported this incident, as well as on social media, which further emphasized McKesson's central presence and position (figure 12.1 presents the full, un-cropped version).

1 We describe McKesson as a celebrity-activist, because his activism since late 2014 has been entwined with and dependent upon a process of him becoming a kind of celebrity, and also because he appears to have consciously sought celebrity status during this time. Deryn Springer and Zellic Imani (2018) also use this term to describe McKesson. The term is also used to define McKesson as someone who was recognized in the media as a 'leader' of BLM, but was not actually a leader of the movement in organizational terms. It is worth noting in this context that the three founders of the formal organization Black Lives Matter in 2013 were Alicia Garza, Patrisse Cullors, and Opal Tometi.

2 In their study of Twitter and the Black Lives Matter movement, Deen Freelon, Charlton McIlwain, and Meredith Clark distinguish between Black Lives Matter as an Internet hashtag (\#BlackLivesMatter), a formal organization, and a wider movement that includes formal and less formal elements as well as both online and offline practices. They use the full phrase 'Black Lives Matter' to describe the formal chapter-based organization with that name and the acronym 'BLM' to describe the wider movement (Freelon et al. 2016: 9). We use 'BLM' in line with their practice to define the larger movement that has developed in the United States, mostly since late 2014 .

3 This logo relates to the @Blackbirds account, launched in June 2014, according to Twitter, as a 'resource group' for black company employees. It was first used to promote the \#StayWoke T-shirt in April 2016, when the garment was available for purchase for a limited time. 


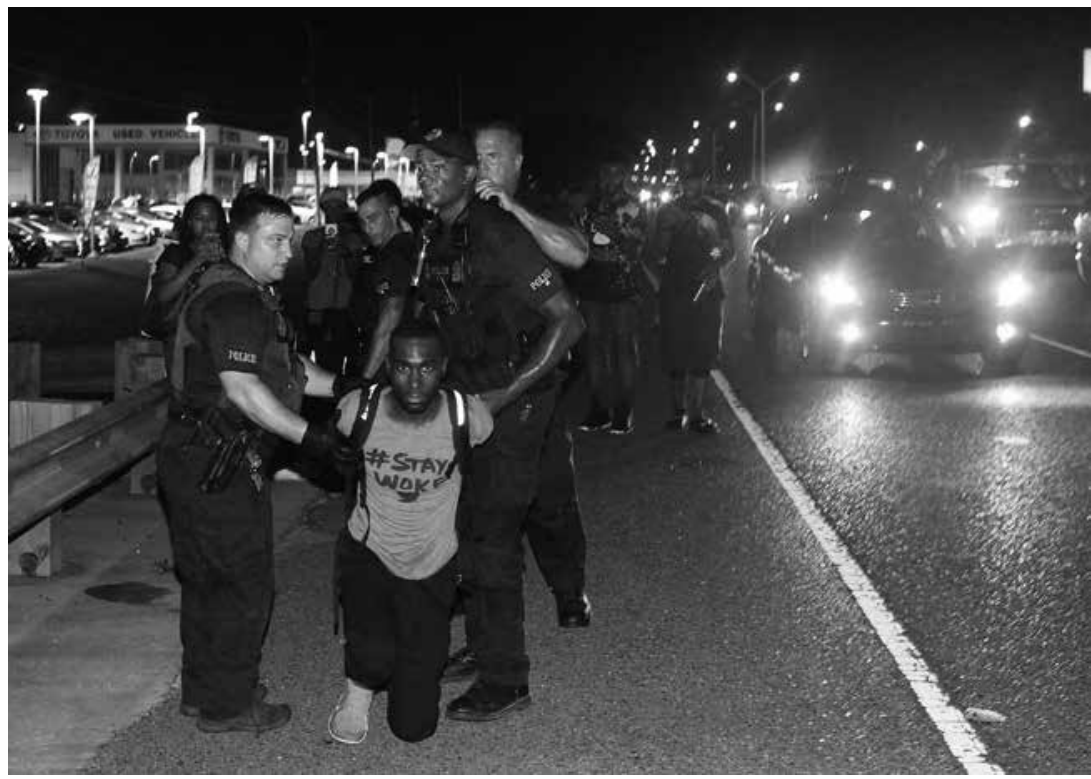

Figure 12.1. The arrest of the African-American celebrity-activist DeRay McKesson during a Black Lives Matter event. Source: AP Photo/Max Becherer.

The first quotation, a widely criticized tweet by Marc Benioff, the CEO of the software company Salesforce, that was later deleted, acknowledges that the image depicts a protest situation, but seems more concerned with the relationship between McKesson's T-shirt and the tech industry of which Benioff is part. The second quotation emphasizes the lack of political sensitivity apparent in Benioff's tweet and indicates a wider lack of awareness about racial injustice amongst people working in the tech industry. Read together they point to the complex relations that exist between contemporary black protest in the US and technology companies, like Twitter, that play an increasingly significant role in the information and news ecosystem. Approached from the perspective of Benioff's tweet, McKesson wearing a BLM themed T-shirt produced by Twitter does appear to endorse the idea that tech is helping a social movement to bring about progressive change. Yet when interpreted in relation to Baker's response, it can be understood as indicative of the superficiality of political relationships that appear to have developed between black protest and the tech industry, and also of the ways that Twitter in particular has benefitted from activists using its platform. Such readings of the photograph were also suggested by The Guardian newspaper among others at the time, when it defined McKesson's arrest as 'a branding opportunity' for elements of the tech industry (Wong 2016). 
In the discussion that follows, we take the photograph of McKesson's arrest as a focal point, approaching it in a number of different ways to explore its use and potential connotations. This analysis is undertaken within the conceptual frame of the aesthetics of protest, broadly defined in terms of an understanding that all political struggles are aesthetic to the extent that they are struggles over who can be seen and heard in political terms. The aesthetics of protest relates to the ways participants in social movements make their causes visible through acts of protest that are also efforts to gain forms of mediated visibility (Butler 2012: 129-131; Cottle 2006; McAdam 2000; Johnson 2007; Berger 2010). In line with this, we define the aesthetics of protest as something that is immediate to the physical space of protest - defined by what protestors do, or wear in the case of the \#StayWoke T-shirt - but also as something that is mediated through the creation and distribution of images. The photograph of McKesson's arrest in Baton Rouge is representative and illustrative of the latter aspect of the aesthetics of protest. The photograph was taken, as one in a series of images, by the photojournalist Max Becherer and distributed by Associated Press, meaning that it is a good example of the mainstream photojournalistic representation of BLM. But it also depicts activists using mobile media technologies to document the arrest, illustrating the intensity with which activists themselves documented BLM demonstrations. The woman shown in the background on the left is McKesson's friend Brittany Packnett, who is live-streaming his arrest with the Twitter-owned app Periscope using McKesson's phone (after McKesson was arrested and could no longer livestream the demonstration himself).

Also crucial for our analysis, from an aesthetic perspective, is an understanding that the aesthetics of protest does not define an entirely discrete field of practices and forms, but instead overlaps with other aspects of the social field and other kinds of aesthetics. This is key to understanding how in the era of social media, the mediation of dissent is inevitably mixed up with the corporate aesthetics of the platforms where much of the information about social movements and demonstrations now circulates. For many people being or becoming politically aware (or 'woke', to use parlance relevant to BLM) is now significantly dependent on social media communications. Yet, at the same time, this relationship between political awareness and social media also allows social media companies to link themselves to political dissent, enabling them to develop and benefit from an appearance of corporate progressiveness, that is particularly relevant to Twitter, given its association with democracy movements in places such as Iran in 2009 and Egypt in 2011. 
Existing academic research has emphasized the importance of Twitter for BLM, to the extent that some researchers have suggested that this research has resulted in the neglect of offline aspects of the movement (Mislan and Dache-Gerbino 2018). However, the existing literature on BLM makes it clear that the platform was of particular importance as 'the predominant hub for BLM online' (Freelon et al. 2016:14). Researchers thus need to take Twitter seriously as an online space for activism relating to contemporary struggles for racial justice in the US. A point underlined in the literature through discussions of 'black Twitter' in relation to the higher use of the platform amongst black Americans and of it enabling a space where issues particular to black experience can be discussed (Brock 2012; Bonilla and Rosa 2015: 5-8; Anderson et al. 2018: 4; Freelon et al. 2018:36-47). The need to develop research on black activism and Twitter can also be framed in terms of the relative absence of discussion of visual images in this context. There have been some exceptions to this, but even here images remain a relatively marginal concern (Bonilla and Rosa 2015; Jackson and Foucault Welles 2016). For example, Freelon, McIlwain, and Clark (2016: 30-32) emphasize the significance of images for the communication of BLM messages on Twitter, presenting a discussion of the top ten images circulated during their period of study, but this discussion is comparatively limited and could productively be subject to much further study. One study that pays close attention to an image arising from a BLM protest is Drainville's (2018) close examination of the arrest of Ieshia Evans in Baton Rouge, on the same day as McKesson's arrest, though here the focus is more on developing iconography as a method for interpreting social media images, rather than specifically engaging with the BLM literature, or protest movements more widely.

With the different considerations delineated so far in mind, the chapter will involve approaching the photograph of McKesson's arrest both as a compelling example of the photographic mediation of protest and as a means of exploring intersections between BLM and the tech industry. To engage in these different analyses, we introduce what we call an 'anatomy of an image' approach that involves the kind of close-reading of images common within visually oriented fields, such as art history (where focusing analysis on single artwork is an established practice), but that have generally not been deployed in relation to images circulated on social media (see Faulkner et al. 2017). This approach entails two general modes for analysing the McKesson arrest photograph. The first involving the treatment of the photograph as a visual artefact that was used and given meaning in specific ways in particular contexts. Thus our approach was to analyse the use of 
the photograph within mainstream news outlets to look at how different publications used the images Becherer produced of the arrest. This analysis then led us to also selectively look at the use of the dominant arrest image on Twitter, with a focus on responses that involved the uploading of the photograph in combination with iconic arrest images from the Civil Rights movement.

The second mode of analysis involved making connections between the photograph and subjects to which it is linked but does not literally depict. To think about these connections, it is useful to refer to historian Timothy Brook's idea that objects depicted in particular paintings by the Dutch artist Johannes Vermeer offer 'doors' that can be interpretatively opened to explore wider historical worlds (Brook 2008). In line with this, we approach the T-shirt that McKesson wears in the photograph of his arrest as an example of this very kind of door, that allows us to think more broadly about the significance of McKesson's celebrity-activist status and its function as a link between BLM and Twitter as a company that is brand aware and driven by profit motives. Indeed, the visibility of images, video, and memes of black people are directly tied to the galvanization of audiences that translate to increased ability for companies to sell advertising in online platforms (Noble 2018a, 2018b), and McKesson's influencer status on the platform is bolstered by his alignment with brand endorsements to the benefit of Twitter, too. This section will necessarily also involve a discussion of the concept of wokeness, given that the text on the T-shirt refers to this notion through the hashtag \#StayWoke. In contrast to our analysis of the publication of the photograph of McKesson's arrest in the mainstream press, this latter mode of analysis does not involve a formal method; rather, this approach involves treating it like a historical document to suggest connections between it and other contemporary social conditions and practices.

An overarching aim of the chapter is to introduce novel ways for the analysis of images circulated on social media and, crucially, to better understand intersections between the aesthetics of protest and corporate aesthetics that are made overtly visible through the photograph of McKesson's arrest. We feel our approach makes a valuable and timely contribution to the existing research on BLM and its relationship to Twitter, which has largely focused on the content of verbal communications (and networks) rather than dealing with either visual images, or the specific role played by Twitter as a corporation. Our anatomy of an image approach could open up productive new avenues for social media research as well as for research on relationships between political dissent and social media. 


\section{The Distribution and Use of the Image}

As already noted, the photojournalist Max Becherer took a series of photographs of McKesson's arrest in Baton Rouge on 9 July 2016. Besides the key image of McKesson on one knee, staring at the camera while being arrested, the news media also used other images from this series. Another widely used photograph shows McKesson being led away by the police, not looking directly at the camera. Becherer's photographs are the only professional images of McKesson's arrest in circulation, suggesting he was the only photojournalist present at the arrest. This is also affirmed by the Periscope footage of the event. The interaction between Becherer and McKesson at the moment of the arrest may have been fortuitous, though it is just as likely Becherer knew McKesson was a prominent and highly publicized figure associated with BLM and followed him in the hope of documenting his actions and possible arrest. This means that the photograph of McKesson's arrest was the product of a conventional relationship between a professional news photographer and a compelling newsworthy event. The photograph was also initially distributed in terms of the standard processes of the photojournalism industry in that Becherer will have sent his photographs to Associated Press, who sent these to the agency's subscribers, who will then have published selected images in their online publications and on social media.

Focusing on the distribution of the key photograph, a number of things become apparent. Out of the 45 online articles examined for this chapter, ${ }^{4}{ }_{3} 6$ $(80 \%)$ used one of Becherer's photographs as their main image. Of these 36 articles, 16 (44\%) used a version of the photograph of McKesson kneeling and staring at the camera, while 16 (44\%) used the arguably less visually striking image, showing McKesson being led away, while four (11\%) use another of Becherer's images as their main image. The other nine images $(20 \%)$ that were not Becherer's, were typically portrait-style images of McKesson making a black power salute, or showing him speaking at a technology conference. In all of these non-arrest images he is shown wearing his blue Patagonia vest, which he wore during the Ferguson protests in late 2014 and continued to wear as a recognizable item of clothing tied to his public persona as an activist. Returning to the arrest images, which are also notable for him not wearing his trademark vest, it is perhaps significant that the use of the photograph of McKesson being led away was predominantly used

4 To find these we used the search term 'DeRay arrest' on Google to identify articles that centrally discussed McKesson's arrest and examined the first fifteen pages of results, selecting 45 articles. For each article we closely examined the lead image. 
by traditional US news organizations (newspapers, television and radio broadcasting). The news websites that chose to use the more powerful and confrontational photograph of McKesson kneeling and staring at the camera while being arrested were generally either more recent, online and sometimes more partisan news sources, or sources from outside the US (mainly the UK).

What might be made of these differences between the use of photographs of McKesson's arrest in the US and elsewhere? One thing that can be done in response to this is to compare this differential use of Becherer's photographs to the differences in the use of photographs of the arrest of black activists in different sectors of the US press during the Civil Rights era. To do this it is useful to compare the photograph of McKesson kneeling and staring at the camera to Gene Herrick's iconic photograph of the fingerprinting of Rosa Parks on 22 February 1956 in Montgomery, Alabama, after she took part in a boycott of segregated public transport in that city. Martin A. Berger has commented on how this particular image of Parks was not used in the black press at the time in contrast to its use in newspapers with a primarily white readership. His explanation of this difference is that in the photograph, the white police officer fingerprinting Parks stands considerably taller than her diminutive figure, suggesting subordination rather than resistance. The black press used another of Herrick's photographs that showed the officer bending down towards the table on which he was taking Parks's prints, resulting in the apparent equalization of their stature (Berger 2015). Berger's research suggests that the photograph of Parks in which the white officer towers over her was less confrontational and to some degree reassuring for white newspaper readers. In relation to this, a similar point can be made in terms of the use of the two photographs of McKesson's arrest. The tendency in the US press to use the less confrontational image of McKesson in which he does not look directly at the camera is perhaps linked to the inevitably greater contentiousness of racial injustice in the US for North American audiences. Whereas the image in which McKesson looks at the camera, appearing to challenge the viewer with his stare, seems to have been more acceptable outside of the US, where audiences are distanced from the issues of US racial politics.

Thinking further about analogies between BLM and the Civil Rights movement, we also looked at selective responses to the circulation of the image of McKesson staring at the camera while being arrested on Twitter that involved users uploading the image in combination with images of activists being arrested during the Civil Rights era. ${ }^{5}$ For example, one montage image,

5 For the purposes of this chapter this was simply done through an manual search on Twitter itself using the \#FreeDeRay hashtag and identifying examples of this type of practice. 
tweeted by a number of different users, combined a cropped black-andwhite version of the photograph of McKesson with one of Charles Moore's photographs of Martin Luther King being arrested in Montgomery, Alabama, in September $195^{8}$ as well as with Herrick's most well-known photograph of Parks being fingerprinted and a less well-known photograph of the Civil Rights activist John Lewis being arrested in Nashville, Tennessee, in April 1964. Through this combination of images, users emphasized historical continuity between the Civil Rights period and BLM, and between King, Parks, Lewis, and McKesson as black political leaders and figures. This aligns with similar findings from Freelon, McIlwain, and Clark (2016) and Jackson and Foucault Welles (2016). Such historical connections made by users also indicate that the role of photography within the aesthetics of protest is more complex than its function as a documentary record circulated in the immediate aftermath of a protest event. Photographic images can continue to be reused within particular cultural and political contexts for decades after a movement has peaked, functioning as part of cultural memory and as aesthetic resources for subsequent protest movements. When it comes to the use of Civil Rights photographs in relation to BLM, a key aspect of the function of these photographs is to provide evidence of continuities in racist oppression and black resistance, affirming the understanding that little has changed between generations and encapsulating an understanding that struggle must continue. Although there are obviously differences between the Civil Rights movement and BLM in terms of context, goals, and tactics, the combination of images related to the two movements suggests that Twitter users recognized continuity more than difference between them. This also suggests that iconic Civil Rights photographs continue to have a civic role in line with Hariman and Lucaites's (2007) discussion of photojournalistic icons and in contrast to recent suggestions that photographic icons circulated on social media can lose their political and civic meaning through overuse and redundant adaptation (Boudana et al. 2017). The arrest photographs from the Civil Rights movement continue to carry symbolic significance in relation to past and present struggles against white supremacy, and by implication the image of McKesson's arrest also involves similar connotations.

\section{BLM, DeRay McKesson, Twitter, and Wokeness: How Twitter Got Woke?}

Having analysed the distribution and use of the key photograph of McKesson being arrested in Baton Rouge, we now turn to considering this image as 
the starting point for an exploration of the wider conditions within which McKesson gained his celebrity-activist status and in which he functioned as a point of connection between BLM and Twitter, the company. As discussed previously, this will be done by focusing on McKesson's T-shirt as an interpretive 'door' to the analysis of this broader context. Opening this 'door' will involve thinking further about McKesson's status within BLM and about his use of and relationship to Twitter as well as thinking about both McKesson and Twitter in relation to the concept of wokeness.

McKesson has been a key figure associated with BLM, especially in terms of the movement's use of Twitter. A number of existing studies on BLM and Twitter emphasize McKesson's prominence within their data. Freelon, Lopez, Clark, and Jackson report that McKesson's Twitter handle, @deray, was one of the top ten handles most referenced on the platform in relation to BLM between 2015 and 2016 (Freelon et al. 2018: 16-17). Freelon, McIlwain, and Clark also note that @deray is the 'most referenced participant in our dataset overall' (Freelon et al. 2016: 54; see also Freelon, Mcllwain, and Clark 2018: 999). It is also important that the year-long narrative of the online development of BLM that Freelon, McIlwain, and Clark (2016) construct in their study is to a significant extent a narrative of McKesson's rise to national prominence as a 'top leader' of the movement. As they observe, there is no obvious explanation of why McKesson gained this level of individual visibility, however they suggest that one answer is to be found in the consistency of his participation in BLM protests and that: 'This level of commitment likely established trust and respect between him and his audience' (Freelon et al. 2016: 54). We would not necessarily disagree with this assessment. However, we would also suggest that this explanation is not the whole story. There were other characteristics to McKesson's activism that also need to be considered, especially if we are to understand, not only his status within social media networks relating to BLM, but also his relationship to Twitter as a company. Key here is the way McKesson's activism was simultaneously a form of self-promotion. This is important for our discussion because the aesthetics of this self-promotional practice appear to constitute a crossover point between BLM and Twitter's corporate interests.

When McKesson travelled from Minnesota (where he then lived and worked) to Ferguson, Missouri, in August 2014 to join demonstrations against the police killing of Michael Brown, his response was to live-tweet these protests. This involved him publicizing these events at a national level. In the process, McKesson began to gain prominence as a national figure identified with BLM. However, he does not appear to have gotten involved 
with the grass-roots organization of the struggle in Ferguson. This meant that his involvement with the anti-police violence and anti-racist side of the protests was disconnected from the other anti-neoliberal and class-based concerns of Ferguson residents (Mislan and Dache-Gerbino 2018). As John Clegg has observed, 'the most visible activists in Black Lives Matter rarely adopt[ed] an anti-capitalist stance' (Clegg 2016). Instead, these activists focused on opposing racist police violence in ways that ended up being amenable to liberal political attitudes, rather than posing a radical challenge to social power structures in general. McKesson was no exception to this. His employment background in privatized education and his apparent affinity as an activist to corporate media (both social and mainstream) and to elements of establishment politics (for example, he met with President Obama on 13 July 2016), have made him, what one commentator described as the 'neoliberal "radical" par excellence' (AJB 2016). This suggests that, if McKesson was consistent in his commitment to the anti-racist issues at the heart of BLM, as Freelon, McIlwain, and Clark (2016) note, then this commitment was performed within particular critical limits, being informed as it was by a generally neoliberal outlook that largely accepted the dominant capitalist order in the United States.

There is also an important aspect to McKesson's rise as a celebrityactivist that meshes with the way 'everyday neoliberalism' involves the management of the social self as a kind of 'product to be sold' (Mirowski 2013: 108). McKesson developed his activist persona as a kind of brand image, a key element of which is the blue Patagonia vest he continued to wear almost exclusively in public after the Ferguson protests as a sign of his political credibility. He wore the vest over a tuxedo at the Oscars in 2018 and can be seen wearing it in his profile picture on Twitter. Having developed this image through his BLM-related social media activity, McKesson further promoted and enhanced his brand image through the mainstream media. His mainstream media break came in May 2015, through an article on him and his immediate activist associates in the New York Times Magazine (Kang 2015). This was followed, for example, by an interview in the New York Magazine in November 2015 (Browne 2015) and by an appearance on CBS's The Late Show in January 2016. On the back of this media coverage, McKesson attempted to mobilize his celebrity status as a 'leader' of BLM within mainstream politics, running as a mayoral candidate in Baltimore (where he grew up) between February and April 2016. Viewed from this perspective, McKesson's activism, which was to large extent based on the mediation of protest and himself through social media, generated a form of visibility that he attempted to use to 
his benefit in the other contexts. This did not involve the literal 'sale' of his celebrity-activist status for financial remuneration, but the use of this status to enable him to develop other projects that might themselves provide financial and social rewards, while at the same time to further building his profile as a public figure.

It is important to understand that protest can carry a powerful cultural cachet that can be attractive to parties who are not directly involved with social movements. In a general cultural sense, protest can signify progressiveness, justice, and freedom. For more conservative elements of society, activism and protest can be viewed as a disruptive challenge to the social order, while for more liberal elements, protest can be something attractive to associate with in superficial or symbolic ways, as long as this particular form of protest does not disturb the lives of those who desire to associate with it. Linked to this is a history of the commercial appropriation of protest images (Johnston and Taylor 2008) and their significant role in bolstering corporate-branded activism, which has been a subject of longstanding interest among media studies and advertising scholars concerned about the neoliberal co-optation of social movements (Crockett 2008; Gray 2013). A recent example, specifically related to BLM, is a 2017 Pepsi advert that featured the white supermodel Kendal Jenner attending an unidentified demonstration involving fashionably dressed multiethnic young people, where she hands a can of Pepsi to one of the officers in a line of police facing the demonstrators. The police in the advert adopt non-threatening poses, are apparently unarmed as well as being without body armour and mostly without helmets in contrast to the heavily armed and armoured officers, notably deployed in Ferguson in 2014. The atmosphere of this demonstration is also more in keeping with a carnival than an angry confrontation with the authorities. This avoidance of the often confrontational nature of protest, enabled the association of Pepsi with progressiveness, youth, and conflict resolution, while avoiding any sense that the young people in the demonstration actually wanted to change anything in political terms. The advert was, however, a widely derided failure, especially on Twitter, and was quickly pulled by Pepsi in response. Nevertheless, it is worth emphasizing here because it is comparable in certain ways to the celebrity-activist image presented by McKesson by 2016. McKesson's activism also carried positive (anti-racist and progressive) associations, without being too challenging to the overall social structure that enables the continuation of corporate capitalism. This made him an attractive figure to Twitter, a company that was itself seeking to have a progressive image in relation the BLM as part 
of its branding practices. ${ }^{6}$ As Scott Jay has pointed out, 'DeRay McKesson is not really a left-wing militant, but at times he sure looks like one' (Jay 2016). It is this appearance of progressiveness and radicalism that was most attractive and useful to the company Twitter.

To further understand the significance of the association between McKesson and Twitter, we now need to look in more detail at his relationship with Twitter as a company. McKesson used Twitter extensively in his BLM-related activism, which mainly involved locating himself at sites of protest, starting with Ferguson in 2014, and tweeting about what he experienced. McKesson has himself emphasized the centrality of Twitter to his understanding of BLM, claiming that Twitter is 'the revolution' (quoted in Kang 2015). But what we are interested in here is how this practice relates to his other, more direct, interactions with Twitter as a corporate commercial organization. McKesson appears to have first made contact with Jack Dorsey, Twitter's CEO, during the Ferguson protests. From there an acquaintance developed between the two men, that also involved McKesson establishing a relationship with the company. One key point in this relationship was when Twitter invited McKesson to the company's headquarters to take part in an event called \#AskDeRay in early November 2015, during which Dorsey interviewed McKesson on stage. This event occurred three days after the departure of Leslie Miley, a leading black engineer, who openly criticized the company for its lack of diversity. In this instance, McKesson appears to have functioned as a useful 'go to' black figure to limit the very public critique the company received for the departure of Miley and other black employees before him. This also suggests that McKesson was willing to lend his celebrity-activist status to Twitter's public relations efforts on diversity issues. This involved a form of mutual appropriation, through which Twitter used McKesson in an attempt to improve their image on the question of diversity and McKesson sought to use the corporate status of Twitter as a means of enhancing his own visibility. In June 2016, McKesson and Dorsey were also interviewed together on stage at the tech industry's Code Conference in California. In this interview McKesson remarked that he had been actively involved in product testing and development at Twitter, most notably for the live-streaming app Periscope (Recode staff 2016). Dorsey used this event as a branding opportunity for Twitter, not only presenting himself alongside McKesson

6 For example, the hashtags \#Ferguson and \#BlackLivesMatter were painted on a wall inside the Twitter headquarters in San Francisco in August and December 2014, respectively. The @Blackbirds Twitter account and the \#StayWoke T-shirt can also be seen as part of this self-branding. 
as a prominent figure of contemporary black activism, but also wearing a Twitter \#StayWoke T-shirt for the interview. In addition to this, all delegates at the conference were given their own \#StayWoke T-shirts. It is likely that McKesson acquired the T-shirt he wore in Baton Rouge at this event (Recode staff 2016). Overall, this discussion indicates that McKesson wearing of the T-shirt in Baton Rouge came after nearly two years of him actively using and promoting Twitter as a platform, and him meeting and collaborating with Jack Dorsey and Twitter as a company. The wearing of the T-shirt and the mediation of this act through Becherer's photograph provided a visual motif of this already existent relationship. It is this relationship between McKesson and Twitter, defined by the compatibility of the limitations of the former's activism with the latter's interest in being associated with progressive politics, that is encapsulated in this image. This is also why the image and the presence of Twitter's T-shirt within it, can function as a door to the analysis of this wider situation.

To end this section, it is necessary to consider the significance of the hashtag \#StayWoke on the T-shirt and the concept of wokeness it invokes. Although this concept can be traced back to the 196os and 1970s (Minamore 2017), it is in relation to BLM that it gained widespread use with reference to a state of awareness of structural racism within the US (Ashlee et al. 2017; Pulliam-Moore 2016). It is presumably this understanding of wokeness that informed McKesson's choice to wear the T-shirt in Baton Rouge. The question is, how did Twitter understand the imperative presented by the T-shirt to 'stay woke'? In answer to this question it is reasonable to suggest that they did not necessarily understand wokeness, or at least would not want to acknowledge its significance in quite the same way as McKesson did. When Dorsey was asked at the Code Conference in June 2016, about the meaning of being 'woke', he responded vaguely that it's about 'really being aware, and staying aware, and keep questioning' (Recode staff 2016). It is difficult to believe that this vagueness is a consequence of not being aware of the connection between wokeness and anti-racism. More likely is a disinclination to define wokeness as such, indicating that Twitter wanted to gain an association with the general idea of being politically aware and with the general idea of justice without connecting themselves explicitly and fully with the politics of BLM. This is something that Jia Tolentino criticized in Jezebel magazine, when she declared: 'You can't further degrade an already degraded social justice slogan for your corporation's T-shirt and also enjoy the kind of high-minded profiteering blandness that requires you to never call racism by its name' (Tolentino 2016). Understood like this, the production of the T-shirt can be linked to 
a popularization of the concept of wokeness in a relatively depoliticized form, especially amongst white Americans, that also involved its commercial appropriation (Iversen 2016). Again, what is important here is the meeting up of interests between McKesson and Twitter the company. The preceding discussion of wokeness suggests that the concerns of these two parties might not have been totally congruent when it came to the subject of racist police violence, however there was enough of a sharing of ideas and interests to create an informal alliance of convenience that served both their purposes and at the same time created a point of convergence between the aesthetics of protest and the aesthetics of corporate branding and public relations.

\section{Conclusion}

There has been a long history of using images of blackness and black racial or ethnic identity in the cultivation of audiences (Crockett 2008), but the technology sector, bolstered by its deep investments in colour-blind ideology (Daniels 2015) has been loath to identify with black people and causes. Thus, the photograph of the arrest of DeRay McKesson in Baton Rouge in July 2016 encapsulates and makes visible a number of these obvious tensions: the profit driven interests that underpin this sector resulting in a superficial, 'woke', and contradictory engagement with black political culture, while at the same time facing consistent criticisms of its racial practices. This rich example has provided us with the opportunity to emphasize the importance of analysing images as an aspect of the contemporary aesthetics of protest, both as a subject in themselves and as a means of thinking about the complex relations between social movements, mediation, social media companies, and the appropriation and commodification of images and meanings relating to protest. We have highlighted the circulation of the image of McKesson's arrest in the mainstream and online media as well as a limited number of examples of visually oriented responses on Twitter that showed it together with iconic arrest images from the Civil Rights era. This enabled us to think about how the visualization of connections between the Civil Rights movement and BLM can function as a means of affirming continuities in US racism and black resistance.

Reflecting on our overall approach we also recognize its limitations and seek to do further work on the wider responses it received on social media and elsewhere, adding important layers to our understanding of the circulation and reception of this image. For the purpose of this chapter, however, 
our methodology remains rooted in what piqued our interest in the first place: how the key arrest image circulated beyond Twitter and was written about in the mainstream media, in particular in terms of the problematic relationship between BLM and the technology industry. We introduced the 'anatomy of an image' approach, which involves different qualitative phases of analysis paying particular attention to so-called 'doors' within the image that can be opened to develop further contextual depth to the analysis. We demonstrated how this approach lends itself well to exploring a number of interconnected concerns in the case of our chosen image: the role of McKesson as a celebrity-activist, his connection to Twitter, as well as the mobilization of wokeness by both McKesson and Twitter. Our intention is not to disparage the sincerity of McKesson's commitment to BLM, but rather to define his position within the movement as a figure who gained prominence through social and mainstream media, rather than as a grass-roots organizer or leader. Hence our use of the term celebrity-activist. We have also sought to position McKesson's commitments to BLM alongside other interests that involved him capitalizing on his media visibility. McKesson's appearances in more recent events, such as the Salesforce 'Representation Matters' conference in November 2018 and his engagements with Twitter's CEO, Jack Dorsey, in \#StayWoke-branded activism, are important moments that illustrate the way racial neoliberalism needs to be engaged through the systematic study of the images of protest on commercial Internet platforms, particularly as the technology industry struggles to meaningfully employ and engage black people.

We highlight the need to engage in research that examines activism on social media from the perspective of the platform and the company, moving the current agenda beyond a core focus on activists and their use of technology. There is a need to critically examine how technology companies work with and benefit from the work of activists and how activists work with technology companies; and what important new questions such a research agenda could generate.

\section{References}

AJB. 2016. 'A Note on Deray McKesson', 22 June. https://ablackunbound. com/2016/06/22/a-note-on-deray-mckesson/. Accessed 31.03.19.

Anderson, Monica, Skye Toor, Lee Rainie, and Aaron Smith. 2018. 'Activism in the Social Media Age', Pew Research Center. https://www.pewinternet.org/2018/o7/11/ activism-in-the-social-media-age/. Accessed 31.03.19. 
Ashlee, Aeriel, Bianca Zamora, and Shamika N. Karikari. 2017. 'We Are Woke: A Collaborative Critical Autoethnography of Three "Womxn" of Color Graduate Students in Higher Education', International Journal of Multicultural Education 19 (1): 89-104.

Benibo, Saki. 2018. 'This Is (Black Neoliberal) America', Medium, 10 May. https:// medium.com/@mrbenibo/this-is-black-neoliberal-america-f2fdbe $5 f 6154$. Accessed 31.03.19.

Berger, Martin A. 2015. 'Rosa Parks Fingerprinted, Montgomery, Alabama, 1956', in Getting the Picture: The Visual Culture of the News, ed. Jason Hill and Vanessa R. Schwartz, 76-78. London: Bloomsbury.

Berger, Maurice. 2010. For All the World to See: Visual Culture and the Struggle for Civil Rights. New Haven: Yale University Press.

Bonilla, Yarimar, and Jonathan Rosa. 2015. '\#Ferguson: Digital Protest, Hashtag Ethnography, and the Racial Politics of Social Media in the United States', American Ethnologist 42(1): 4-17.

Boudana, Sandrine, Paul Frosh, and Akiba A. Cohen. 2017. 'Reviving Icons to Death: When Historic Photographs Become Digital Memes', Media, Culture, and Society 39(8): 1210-1230.

Brock, Andre. 2012. 'From the Blackhand Side: Twitter as a Cultural Conversation', Journal of Broadcasting \& Electronic Media 56(4): 529-549.

Brook, Timothy. 2008. Vermeer's Hat: The Seventeenth Century and the Dawn of the Global World. London: Profile Books.

Browne, Rembert. 2015. 'In Conversation: Deray McKesson', New York Magazine, 22 November. http://nymag.com/intelligencer/2015/11/conversation-with-deraymckesson.html?gtm=bottom. Accessed 31.03.19.

Butler, Judith. 2012. 'Bodies in Alliance and the Politics of the Street', in Sensible Politics: The Visual Culture of Nongovernmental Activism, ed. Meg McLagan and Yates McKee, 117-137. New York: Zone Books.

Clegg, John. 2016. 'Black Representation after Ferguson', The Brooklyn Rail: Critical Perspectives on Arts, Politics, and Culture, May 2016. https://brooklynrail. org/2016/05/field-notes/black-representation-after-ferguson. Accessed 31.03.19.

Cottle, Simon. 2006. Mediatized Conflict: Developments in Media and Conflict Studies. Maidenhead: Open University Press.

Crockett, David. 2008. 'Marketing Blackness: How Advertisers Use Race to Sell Products', Journal of Consumer Culture 8(2): 245-268.

Daniels, Jessie. 2015. “My Brain Database Doesn't See Skin Color”: Color-Blind Racism in the Technology Industry and in Theorizing the Web', American Behavioral Scientist 59(11): 1377-1393.

Drainville, Raymond. 2018. 'Iconography for the Age of Social Media', Humanities 7(1): 12. https://doi.org/10.339o/h7010012. 
Faulkner, Simon, Farida Vis, and Francesco D’Orazio. 2017. 'Analysing Social Media Images', in Sage Handbook of Social Media, ed. Alice Marwick, Jean Burgess, and Thomas Poell, 160-178. London: Sage.

Freelon, Deen, Charlton McIlwain, and Meredith D. Clark. 2016. Beyond the Hashtags: \#Ferguson, \#Blacklivesmatter, and the Online Struggle for Offline Justice. Washington, DC: Center for Media \& Social Impact. https://cmsimpact.org/resource/ beyond-hashtags-ferguson-blacklivesmatter-online-struggle-offline-justice/. Accessed 31.03.19.

Freelon, Deen, Lori Lopez, Meredith D. Clark, and Sarah J. Jackson. 2018. How Black Twitter and Other Social Media Communities Interact with Mainstream News. Miami: John S. and James L. Knight Foundation. https://doi.org/10.31235/osf. io/nhsd9. Accessed 31.03.19

Freelon, Deen, Charlton McIlwain, and Meredith Clark. 2016. "Quantifying the Power and Consequences of Social Media Protest." New Media \& Society: 1-22 Gray, Herman. 2013. 'Subject(ed) to Recognition', American Quarterly 65(4): 771-798. Hariman, Robert, and John Louis Lucaites. 2007. No Caption Needed: Iconic Photographs, Public Culture and Liberal Democracy. Chicago: University of Chicago Press. Iversen, Kristin. 2016. 'Please Let This Be the End of Performative Wokeness', Nylon, 16 November. https://nylon.com/articles/end-of-wokeness. Accessed 31.03.19.

Jackson, Sarah J., and Brooke Foucault Welles. 2016. '\#Ferguson Is Everywhere: Initiators in Emerging Counterpublic Networks', Information, Communication \& Society $19(3): 397-418$.

Jay, Scott. 2016. 'The Postmodern Left and the Success of Neoliberalism', Libcom, 5 January. https://libcom.org/library/postmodern-left-success-neoliberalism. Accessed 31.03.19.

Johnson, Davi. 2007. 'Martin Luther King Jr.'s 1963 Birmingham Campaign as Image Event', Rhetoric \& Public Affairs 10(1): 1-25.

Johnston, Josée, and Judith Taylor. 2008. 'Feminist Consumerism and Fat Activists: A Comparative Study of Grassroots Activism and the Dove Real Beauty Campaign', Signs 33(4): 941-966.

Kang, Jay Caspian. 2015. “Our Demand Is Simple: Stop Killing Us”: How a Group of Black Social Media Activists Built the Nation's First $21^{\text {st }}$-Century Civil Rights Movement', New York Times Magazine, 5 October.

McAdam, Doug. 200o. 'Movement Strategy and Dramaturgical Framing in Democratic States: The Case of the American Civil Rights Movement', in Deliberation, Democracy, and the Media, ed. Simone Chambers and Anne Costain, 117-133. New York: Rowman \& Littlefield.

Minamore, Bridget. 2017. 'Woke Has Been Added to the Dictionary, But What Does It Really Mean?', Grazia, 18 August. https://graziadaily.co.uk/life/real-life/ woke-added-dictionary-really-mean/. Accessed 31.03.19. 
Mirowski, Philip. 2013. Never Let a Serious Crisis Go to Waste: How Neoliberalism Survived the Financial Meltdown. London: Verso.

Mislan, Cristina, and Amalia Dache-Gerbino. 2018. 'Not a Twitter Revolution: Antineoliberal and Antiracist Resistance in the Ferguson Movement', International Journal of Communication 12: 2622-2640.

Noble, Umoja Safiya. 2018a. Algorithms of Oppression: How Search Engines Reinforce Racism. New York: NYU Press.

Noble, Umoja Safiya. 2018b. 'Critical Surveillance Literacy in Social Media: Interrogating Black Death and Dying Online', Black Camera: An International Journal 2:147-16o.

Pulliam-Moore, Charles. 2016. 'How "Woke" Went from Black Activist Watchword to Teen Internet Slang', Splinter, 8 January. https://splinternews.com/how-wokewent-from-black-activist-watchword-to-teen-int-1793853989. Accessed 31.03.19.

Recode staff. 2016. Twitter CEO Jack Dorsey and \#BlackLivesMatter Activist DeRay Mckesson at Code 2016 [video], ReCode, 8 June. https://www.recode. net/2016/6/8/11835638/jack-dorsey-deray-mckesson-twitter-blacklivesmatterfull-video-code. Accessed 31.03.19.

Springer, Devyn, and Zellie Imani. 2018. 'DeRay McKesson's Misguided Case for Hope', Truthout, 25 October. https://truthout.org/articles/deray-mckessonsmisguided-case-for-hope/. Accessed at 31.03.19.

Tolentino, Jia. 2016. 'Sweet Jesus, Twitter CEO Jack Dorsey's \#StayWoke Shirt Is Incredibly Embarrassing',Jezebel, 2 June. https://jezebel.com/sweet-jesus-twitterceo-jack-dorseys-staywoke-shirt-i-1780107535. Accessed 31.03.19.

Wong, Carrie Julia. 2016. 'How the Tech Industry Is Exploiting Black Lives Matter', The Guardian, 12 July.

$@$ Shaft. 2015. 'Thoughts on Diversity Part 2: Why Diversity Is Difficult', Medium, 3 November. https://medium.com/tech-diversity-files/thought-on-diversitypart-2-why-diversity-is-difficult-3dfd 552faif7. Accessed 31.03.19.

\section{About the Authors}

Farida Vis is Professor of Digital Media at the Manchester School of Art at Manchester Metropolitan University. She is the founding Director of the Visual Social Media Lab (VSML), which brings together researchers from academia and industry interested in better understanding the role of social media images. The VSML has been supported through funding from the Economic and Social Research Council (ESRC), Horizon 2020, and the Arts and Humanities Research Council (AHRC). Her high-profile work has included a co-edited volume (with O. Goriunova), The Iconic Image on Social 
Media: A Rapid Research Response the Death of Aylan Kurdi (VSML, 2015) as well as work on visual mis- and disinformation with First Draft, some of which is being developed into media literacy strategies. She is also leading (with Charlton McIlwain) a two-year research partnership with New York University on 'Critical AI and Online Visual Cultures'. She sits on the World Economic Forum's Global Future Council on Information and Entertainment.

Simon Faulkner is a Senior Lecturer in Art History and Visual Culture at Manchester School of Art, Manchester Metropolitan University. His recent individual research has focused on relationships between visual practices and the Israeli-Palestinian conflict. This research has addressed a range of artistic and photographic work, and has been particularly concerned with the ways that visual images are used for political purposes within the divided geography of Israel/Palestine. This work has resulted in a number of publications, including the book Between States (Black Dog Publishing, 2015), developed with the Israeli artist David Reeb. Since 2014, he has also been a member of the Visual Social Media Lab, the work of which focuses on researching social media images.

Safiya Umoja Noble, PhD, is an Associate Professor at the University of California, Los Angeles (UCLA) in the departments of Information Studies and African American Studies. She is the author of Algorithms of Oppression: How Search Engines Reinforce Racism (NYU Press, 2018), and is the co-editor of two volumes: The Intersectional Internet: Race, Sex, Culture and Class Online (Peter Lang, 2015) and Emotions, Technology \& Design (Elsevier/ Academic Press, 2016). She is a member of several academic journal and advisory boards, including the Journal of Critical Library and Information Studies, the Commentary \& Criticism section of the Journal of Feminist Media Studies, and Taboo: The Journal of Culture and Education.

Hannah Guy is a PhD student at Manchester Metropolitan University, supervised across the School of Childhood, Youth and Education Studies and the Department of Media. She is also a member of the Visual Social Media Lab. Prior to starting a PhD she undertook industry work in market research and completed MAs in Librarianship and Social Research at the University of Sheffield. Hannah's current project, which examines the role of images in the spread of disinformation on social media, is funded through an Economic and Social Research Council (ESRC) Collaborative Doctoral Award and is in partnership with First Draft. 


\section{Part III}

Conclusion 



\title{
13 Conclusion: Reflections on Protest and Political Transformation since $1789^{1}$
}

\author{
Jim Aulich
}

\begin{abstract}
This chapter contextualizes the nature of the aesthetics of contemporary political protest and public demonstration in their wider historical and theoretical contexts. It examines precedents in the French Revolution of 1789 , the Spring of Nations of 1848, the 'Turn' in the former Soviet bloc nations in 1989, and the 'colour revolutions' in former communist states in the first quarter of the twenty-first century. Theoretically, it attempts to extend Richard Grusin's concept of radical mediation, Jacque Rancière's politics of the sensible and Judith Butler's theory of performativity through a reading of Karen Barad's agential realism. The argument hypothesizes that not only the immediate aesthetics and performative actions of demonstrators, but the mechanisms and apparatuses of their mediation, carry the weight of ethical responsibility.
\end{abstract}

Keywords: performance, mediatization, communication, aesthetics, struggle, protest

\section{Defining Protest: Performativity, Embodiment, and Mediation}

According to the Oxford English Dictionary, 'protest' is constituted by a public, formal and solemn declaration of dissent. Historically, it usually concerned the non-payment of a bill or some other commercial contract where a breach of trust incurred a sense of injustice. A protest is a demonstration, an appearance

1 For reasons of space I have concentrated on political movements connected with regime change rather than single-issue protest movements such as CND, Stop the War, Occupy, Black Lives Matter, or the Me Too movement, neither have I discussed protest of people's under foreign occupation, such as the Palestinian Occupied Territories.

McGarry, A., I. Erhart, H. Eslen-Ziya, O.Jenzen, U. Korkut (eds), The Aesthetics of Global Protest: Visual Culture and Communication. Amsterdam: Amsterdam University Press, 2020 DOI 10.5117/9789463724913_CH13 
in a public space that has always carried with it an extrajudicial and performative imperative of putting things to right. Today, protest not only takes many forms and has multiple components, but clearly signals the breakdown of the social contract between the ruled and the rulers. As such, it is habitually met with government legislation, police control, and all too often state violence.

In many ways the aesthetics of protest in terms of its immediate visual, aural and formal characteristics have not changed a great deal since the socialist and artist Walter Crane made the following description of a demonstration in Trafalgar Square in London in 1887. He describes large numbers of people, replete with music bands and banners, being met by the 'enormous force' of an 'army' of police and how:

The next business of the police was to clear the sides of the square. [...] The state of things was not improved by the frequent charges of mounted police on the inoffensive crowd. I narrowly escaped myself in crossing over to Parliament Street. There were broken heads. I saw one unfortunate man led by, bleeding; but, worse than this, one man was knocked down by the mounted police and so injured he died in the hospital shortly afterwards. I never saw anything more like real warfare in my life - only the attack was all on one side. [...] After every charge [...] they returned again. So the Guards were called out, and I remember in the gloom of that November evening the glitter of their bayonets, and the red line in front of the National Gallery. (Crane 1907: 267)

The day has been known as 'Bloody Sunday' ever since. ${ }^{2}$

It sounds all too familiar and we might even go so far as to understand protest as something in which we, as academics and observers, necessarily belong as parts in a panopoly of components, which includes the location, protestors, organizational structures (in Crane's case the English socialists, trade unions and the Labour Party), police, print media, the historical record and its interpretation. Not to forget the smell, the taste, the noise, the spectacle, the sheer existential experience that once mediatized, is always just out of reach. The sensible and the aesthetic are something in excess of the merely political, social, or economic. ${ }^{3}$

2 The demonstration was designed to express solidarity with workers' leaders on death row in Chicago because of a bomb which killed a number of police at a strikers' meeting. Crane notes the presence of William Morris, Annie Besant, and H.M. Hyndman, among other prominent social radicals.

3 The analysis of protest in this chapter is founded on Karen Barad's "notion of "intra-action" [which] queers the familiar sense of causality (where one or more causal agents precede and 
For all the palpable emotions and physicality of protest and the important and impassioned contributions made to the debate by Judith Butler (2004, 2015 ) and Jacques Rancière $(2004,2010)$, for example, the writing of philosophers and academics can never quite connect or capture the collectivity of the crowd: the adrenalin, brutality, fear, bravery and solidarity (Hann 2013). We cannot reach the depth of feeling and the heritage of the cause at hand of whatever complexion. We wonder and make our studies, we unpick the mechanisms that underwrite appearance and configure the visual. We note its intersections and relations with other disciplines, aesthetic categories and each other. We pore over its archives and examine the routes by which its forms and iconographies have travelled in time, geography, and meaning. The new media scholar Richard Grusin has argued 'that although media and media technologies have operated and continue to operate epistemologically as modes of knowledge production, they also function technically, bodily, and materially to generate and modulate individual and collective affective moods or structures of feeling among assemblages of humans and nonhumans' (Grusin 2015: 124).

Understanding of the aesthetics of protest in terms of the sensible and the performative is extremely important in developing our knowledge of how we act in, and give shape to, the world. The look of things is more than mere appearance. In other words, the visual contributes to a cacophony that engages our interest, seduces our feelings, produces our reality and demands responsibility in action. Patrick Cockburn, the independent journalist and expert on the Middle East, described how Tahrir (Liberation) Square in Cairo, which concerns many of the essays in this collection, became emblematic for the events of 2011 in Egypt and more broadly for the Arab Spring. He relates how accounts are mediatized and embellished by inspirationally spectacular photographic and filmic evidence elaborated by interviews with English-speaking participants and nominal opposition leaders. To choose a word from Barad's vocabulary, Cockburn points out how part of what we

produce an effect), and more generally unsettles the metaphysics of individualism (the belief that there are individually constituted agents or entities, as well as times and places). [...] [I] ntra-action goes to the question of the making of differences, of "individuals," rather than assuming their independent or prior existence. "Individuals" do not not exist, but are not individually determinate. [...] [Likewise] "Phenomena," in an agential realist sense, are the entanglement - the ontological inseparability - of intra-acting agencies. [...] It is through specific agential intra-actions that the boundaries and properties of "individuals" within the phenomenon become determinate and particular material articulations of the world become meaningful. [...] The notion of intra-action marks an important shift in many foundational philosophical notions such as causality, agency, space, time, matter, meaning, knowing, being, responsibility, accountability, and justice' (Barad 2012: 79). 
might call the 'apparatus', that is, the mechanisms for the capture of events such as the official and unofficial reporting of the cyclical stand offs between protestors and security forces, create certain versions of events. Cockburn noted, 'none of this was necessarily phoney, but it was a highly sanitized version of developments' (2019: 22). For him, it presented a metropolitan version of reality where the freedom and democracy emblematic of the Arab Spring obscured sight of the geographical and political hinterland and the fact that the state and the military had never really lost control. Similarly, Meg McLagan and Yates McKee have argued that the subject's perception and cognition of the world are not naturally given or programmatically determined but are the product of an historical and 'shifting assemblage of technical and social forces' (2012: 12). Jacques Rancière framed the same phenomenon in terms of aesthetic practices and the distribution of the sensible which 'parcels out places and forms of participation in a common world by first establishing the modes of perception within which these are inscribed' (ibid.: 12, note 14).

As we can see from the example outlined by Cockburn above, the aesthetics of protest are Janus-faced. There is the aesthetic form of the protest in its present: the crowd, banners, posters, speeches, chants, songs, and actions of protestors and police. Then there are the aesthetics of the trace of the demonstrations in analogue and digital media, in the imagination and memory, and in their systems of distribution and wider cultural contexts. The 'phenomenon' and its 'image' are in an entangled relationship, each feeding the other to embody a collective act of protest. These can be difficult to prise apart, not least because the observer contribution to the reportage, archive, and historical record is in itself part of the phenomenon. The activist, interpretant, and participant share in the production of knowledge surrounding the protest, at the time and subsequently. In this way protest is dramatically enacted and embodied in the experience of certain kinds of reality embodied in action and mediation. Taking Barad's agential realism ${ }^{4}$ as a starting point, Grusin regards the medium supporting the representation as an object subject to processes of intra-action, where the boundaries between people, matter, materials, nature, and discourses emerge as phenomena in the world:

4 Agential realism offers a way of thinking about the politics, agencies and ethics of any act of observation and the nature of knowledge production. Barad proposes that everything is entangled with everything else. The observer is complicit and therefore ethically responsible in any apparatus of observation making impermanent 'cuts' between the included and the excluded to produce a particular phenomenon in the world. The familiar Cartesian subject object relationship is no more. See Barad (2007). 
I have meant to emphasize that all mediation entails an appropriation of prior acts, processes, or experiences of mediation and that mediation cannot be understood in a fixed, lifeless, static sense but can only be understood dynamically or relationally as it appropriates prior media formations and events. [...] Mediation becomes immediate and relations are all the more real in what they do or act rather than what they represent. (Grusin 2015: 142ff.)

Barad recognizes that the object of observation and the mechanism or apparatus by which it is measured, encapsulated, evaluated, and interpreted are not distinct but coexistent. Entities, agencies and events 'are only distinct in a relational, not an absolute sense, that is, agencies are only distinct in relation to their mutual entanglement; they don't exist as individual elements' (Barad 2010: 267 , note 1). The action of the protestor, the greater cause and its mediation are not separately determined. Their relations or intra-action determine their boundaries and properties, they are not there to be found as if they were pre-existent, the 'object' and the 'agency of observation' are inseparable: 'Concepts do not refer to the object of investigation. Rather, concepts in their material intra-activity enact the differentiated inseparability that is a phenomenon' (Barad 2010: 253). Leading to the observation that things and identities are not fixed or predetermined, rather they are performed differently under different circumstances.

Performativity, embodiment, and mediation finds early theoretical exegesis in classical rhetoric, which points to a significance for the visual and the generally sensible beyond appearance. Subjective bodily experience produces forms of knowledge and, in turn, physical familiarity with the world to mould our understandings and our relations to it. At the same time, in classical rhetoric expressive verbal and visual demonstrations were often understood to dissolve into what they describe. The distinction between the representation and what it seeks to represent is less than firm. According to the art historian Caroline van Eck, Aristotle and his followers took a psychological approach which stipulated 'that thought takes place in and through mental images, [...] which are stored in memory and can be reactivated'. As Grusin would have it: 'Mediation should be understood not as standing between preformed subjects, objects, actants, or entities but as the process, action, or event that generates or provides the conditions for the emergence of subjects and objects, for the individuation of entities within the world. Mediation is not opposed to immediacy but rather is itself immediate' (Grusin 2015: 129). As acts of imitation, mediations of protest recreate in the mind's eye the experiences of something no longer there (Van 
Eck 2015: 35-43), which, in turn, feed into action in both the present and the future present. Because protest is produced in the apparatuses through which it is encapsulated and interpreted those very same mechanisms are enormously significant. Drawing on Alfred Gell (1998), Van Eck argues how a representation is capable of acting on those who engage with it through the agency of the living beings it embodies through a 'network of intentionalities in which they are enmeshed' (2015: 49). This admission brings us to what the feminist theorist and philosopher of quantum physics, Karen Barad, has framed in terms of ethics and responsibility in relation to mediation and what James Elkins has defined as the wider 'dissonance[s] between moral and ethical imperatives and questions of injustice, sacrilege, piety and duty‘ (Eder and Klonk 2016: 224).

\section{Political Protest in Modern Times}

Protests in the name of democracy and freedom are not all generated from the emancipatory universal values associated with the Enlightenment and models of Western thought established in the French Revolution of 1789. Some issue from their archaic corollary, and some might say equally modern populist views, that spurn notions of universal equality in favour of chauvinistic versions of nation, ethnicity, religion and gender. Much contemporary dissent, for example, finds its sources of discontent in neoliberalism, monopoly capitalism, and the breakdown of social democracy and civil society as the result of the unequal distribution of opportunity and increased precarity. The point is that the apparatuses of opposition are not the exclusive preserve of socialists, liberal democrats, and the political 'left', and can equally belong to individualist neoliberals, religious fundamentalists or ethnic purists and the political 'right' (Butler 2015: 91). Protest and dissent originate with discontent arising from perceived exclusions and inclusions, injustices and inequalities in society with regard to, for example, employment, tax, civil rights, religious freedom and political representation. The Gilets Jaunes in France, the English Defence League in the UK, Fidesz with its origins in popular protest under communism in Hungary, and Pegida in Germany were all born of powerlessness, suppression, and a lack of voice and opportunity experienced by large sections of society. The under-reported protests of the Gilets Jaunes, for example, do not have an identifiable political agenda beyond an apparatus that deploys certain myths of patriotism and gender, a suspicion of foreigners, resistance to neoliberal austerity and what they see as the complacency of the political 
establishment to articulate certain ways of being in the world, where certain realities have authority over others. ${ }^{5}$ Their aims are not, except in the most limited sense, the pursuit of the universal Enlightenment and Republican ideals of liberté, égalité, fraternité and an inclusive citizenry regardless of social, ethnic or religious background and relationship to dominant elites.

It is useful to take a step back and to consider the appearance of civil protest in its historical context. The French Revolution of 1789 is a significant precedent for protest and civil disturbance as a political and potentially emancipatory phenomenon capable of contributing to the framing of alternative and ethically responsible realities. Often characterized as a 'media event' stimulated by the lifting of censorship, the popular journalism of daily newspapers, wall newspapers, pamphlets, broadsides, handbills, and print complemented and amplified by 'virtue of their characteristic emotionality, captivating melodies and visual presence, the political songs and graphic satires had a much stronger impact on the collective consciousness than texts and speeches' (Reichardt 2012: 6). Significantly, a lasting connection and structural element to protest was forged in 1789 between the free press, the 'mass' or 'public' where the body of Enlightenment thought and the Rights of Man transformed themselves into 'a new set of cultural practices based on the freest and most extensive possible public exchange of ideas' (Landes 1991: 97). ${ }^{6}$ Protests are generated in wider webs and structures from which social and political identities emerge; they are not strictly speaking spontaneous, although they may appear to be so. The public establishes its momentum through affiliations in physical and intellectual spaces defined by a variety of historically specific factors such as social class, ethnicity and occupation, for example. Historically, such identities were communicated and acted upon through print, theatre, song and other performative cultures and in networks of consumption in cafes, reading rooms, public meetings, and other social spaces amenable to conversation and debate, not least the demonstrations themselves. Trade associations, trade unions and organized religious, political and social affiliations were also important in carving out an arena for the display of solidarity and

5 See Ramdani (2019a, 2019b); O'Neill (2018); Mortimer (2019).

6 Alongside print media, 'Rolf Reichardt argues that illustrated broadsides, like other pictorial representations helped mobilize a broad social base that made the Revolution's political process, and its radicalization, possible in the first place. [...] Together with the nonwritten media of public speeches and songs, they approached the man and woman in the street in the terms of their own oral or semi-oral culture. They not only rendered the revolutionary message accessible but also drew ordinary people into the communication and opinion-making process of a widening public sphere, with its tendency toward democratization' (Landes 1991: 92). 
discontent. Since the mid-199os such affiliations have been in some cases augmented, and in others replaced by social media platforms supported by the physical materiality of the mobile phone. As an instrument the mobile or smartphone has prosthetic qualities, as an artificial device it does not so much replace something missing from the body, as augment its capabilities for communication, orientation and documentation. Held in the hand, it is an intimate extension of the body and its sensorium. Over time, protests as apparently spontaneous explosions of frustration have developed into sets of media tactics across different platforms 'weaving together the semiotic and the ethnographic, the political and the poetic, in a total campaign' (McLagan and McKee 2012:15).

Protests invariably involve the deployment of the power of the state against the 'people' to exert different degrees of control, violence and lethality such as we saw in the former communist regimes in Europe in 1989, for example, and at the time of writing, continue to see in Israel/Palestine, Sudan, Zimbabwe, Venezuela and France. ${ }^{7}$ As Judith Butler has pointed out, making the claim for 'we the people', is defined by appearance in public. In a protest the crowd is the materialization of a public coming together with a shared purpose. The mechanisms through which that is achieved are therefore paramount: 'If the people are constituted through a complex interplay of performance, image, acoustics, and all the various technologies engaged in those productions, then "media" is not just reporting who the people claim to be, but media has entered into the very definition of the people' (Butler 2015: 20). The media have to be understood as something more than mere reporting or the record of gestures of resistance found in the contemporaneous and historical record on the one hand, and the paraphernalia of handbills, banners or posters, on the other. Protest extends as a phenomenon into the many performative fields which constitute that vital appearance through speech, song, gesture, and the simple act of being present to bear witness and protest.

There is also the possibility that protest and the struggle for the demos and human rights can be institutionalized and to a certain extent naturalized. ${ }^{8}$

7 The three-sided engagements of the forces of the state with supporters of the right and left have characterized the historical antifascist movement. Such oppositions are nevertheless structural, whether they are democratic or not. Democracy simply eases the path for alternative views to be expressed through protest.

8 Contemporary organized protests are carefully choreographed. In British law, for example, routes are agreed and stewards required, and even as protestors develop different and more spontaneous tactics through the use of social media platforms and smartphones, the authorities develop countermeasures by surveillance of electronic traffic and physical measures such as 'kettling'. 
In some cases we can see how the 'apparatus' and the reality it produces shifts, making it more formulaic and safe within the terms of state sanctioned and economically viable versions of national heritage. ${ }^{9}$ In the light of the 2019 bicentenary of the Peterloo Massacre in Manchester, its prominence is rising in the public discourse. This highly disciplined and rehearsed peaceful demonstration in 1819 for the reform of parliamentary representation was undertaken in the name of cleanliness, sobriety, order and peace. The men and children wore their Sunday best, many women dressed in white. The protest was broken up by the authorities with armed force, resulting in the death of 18 and the injury of some 700 demonstrators in a crowd of some 6o,ooo. Jacqueline Riding's (2018) book-length account, and the Brechtian didacticism of Mike Leigh's feature film (2018) reclaim the important and half-forgotten Peterloo Massacre for history at a time when in the UK, the notion of the 'will of the people' is contested..$^{10}$ Contemporaneously, and in the very same city of Manchester, the National Museum of Labour History was renamed The People's History Museum in 2001 and rebranded in 2017 with the addition of the words: The National Museum of Democracy. The notion of a working-class or labour history has been subjected to a process of effacement. I do not denigrate these important interventions and institutions but it is important to note how the mediation of history carries dangers of appropriation. The Peterloo Massacre, for example, in reality, a murderous defeat for the cause of civil rights, is celebrated by various contemporary cultural institutions as a victory for democracy. Interestingly, Jeremy Deller, the artist commissioned in 2016 to design the projected Peterloo Memorial in Manchester, ${ }^{11}$ made the film The Battle of Orgreave (2001), ${ }^{12}$ a re-enactment of a notorious mounted police charge against pickets which took place during

9 'Gone are the days when people learned about history simply from reading books. People are increasingly looking for experiences that bring history to life in an engaging way and nothing beats standing on the spot where history happened. We offer a hands-on experience that will inspire and entertain people of all ages. Our work is informed by enduring values of authenticity, quality, imagination, responsibility and fun. Our vision is that people will experience the story of England where it really happened' (English Heritage 2019).

10 The so-called Brexit crisis where the ruling party claims the result of the Referendum of 2016 and the 'will of the people' as its own.

11 See http://peterloomassacre.org. The design was unveiled in November 2018. Instigated by the Peterloo Network, it 'grew out of a Manchester Histories Festival event five years ago and is led by Manchester Histories and People's History Museum and including Manchester City Council, Historic England, University of Manchester, Manchester Metropolitan University, various other cultural institutions, historians, campaigners and individuals'. See https://ilovemanchester. com/peterloo-massacre-memorial-artist-jeremy-deller-unveils-design/, accessed 15.01.19.

12 See https://www.artangel.org.uk/project/the-battle-of-orgreave/, accessed 15.01.19. 
the UK miners' strike (1984-1985), to make the precise point that state violence against protestors continues. Tamed by heritage and celebrated in terms of social change rather than political transformation, protests of certain kinds are becoming embedded in the national consciousness through institutions such as the National Trust and Arts Council England. A themed public arts programme titled Peoples' Landscapes led by the artist Jeremy Deller 'will involve artists engaging with sites where people assembled to stimulate significant social change. ${ }^{13}$ Some of our most interesting radical public intellectuals are engaged in a careful dance of words and practices that unsurprisingly obscures political significance in precarious times. ${ }^{14}$ Jacques Rancière warned of such processes in his notion of dissensus where once we recognize how notions of freedom and democracy function aesthetically, we can understand how these sensibilities begin to act in formulaic ways to undermine the chance of real political change (Jazeel and Mookherjee 2015: 354). Much as the dissidents in former communist Europe disrupted expectations and loyalties through refusal, it is possible to see how the disruptions to aesthetic expectations employed by the opposition organization Otpor in Serbia (see below), for example, and their use of social media in advance of the state deployment of technologies of surveillance were so effective, if only briefly.

Kurt Weyland (2014: 1) has made a useful genealogy of so-called democratic revolutions since 1848 , identifying social phenomena that challenge established orders 'in clusters that advance like waves' from a point of origin to other countries. In this context, and for the purposes of this short chapter, I'd like to briefly examine three people's democratic revolutions that in their own ways threatened the international political status quo: the 'Spring of Nations' of $1848^{15}$; the 'Turn' in the former Soviet bloc nations

13 Addley 2019. The sites include the Tolpuddle Martyr's Tree in Dorset; the mass trespass in 1932 at Kinder Scout in Derbyshire; also in Derbyshire the connections between Quarry Bank Mill and Dunham Massey stately home with the Peterloo Massacre; and the former mining community of Easington, Durham. Interestingly, the trust insists it is not making a political point but simply aims to tell stories of human suffering and joy in order to 'connect the local with the national' (Addley 2019:3).

14 People's Landscapes, https://www.nationaltrust.org.uk/features/how-we-are-challengingour-history, accessed 18.01.19. Unobtainable when re-visited on 09.02.19, as if to confirm the point, it is now called Landscapes: Explore the places that have shaped the nation: Unearthing stories of passion and protest. See https://www.nationaltrust.org.uk/features/ peoples-landscapes-explore-the-places-that-have-shaped-the-nation.

15 The revolutions of 1848 began in Sicily and spread to France and across Germany, Italy, the Austrian Empire and South America and eventually had a direct effect on some 50 countries, all of which ended in failure but succeeded in laying the deep foundations for modern democratic reform across Europe. 
in 1989 which saw the fall of communist regimes in the region ${ }^{16}$; and the role of Otpor in the Bulldozer Revolution of 2000 in Serbia, the first of the non-violent pro-democratic 'coloured revolutions' of the first decade of the twenty-first century. ${ }^{17}$ Comparing 1848 with the Arab Spring of 2010/2011, Weyland contends that protestors took inspiration from events in one country, not on rational decisions based on the available evidence, but as more or less spontaneous responses 'to particularly vivid, striking, easily accessible events, such as regime collapse across the border' (Weyland 2014: 7). Essentially, this led to an aesthetic of cognitive shortcuts in pictures, song and declarative slogans capable of encapsulating revolutionary events and it is easy to see how Twitter conformed to this pattern with its 140 characters and attached visual material and how important it was for the Arab Spring. Weyland does not address how in 1848 the news of revolution and protest travelled or what specific forms it took. Certainly, word of mouth, oratory, the handbill, pamphlet, almanacs, illustrated broadsides, the popular print and songsheets played their part, not least because of the relatively advanced modern communications industry in Paris, itself largely stimulated by the Revolution of 1789 (Landes 1991):

[W]ith the revolutionary forces gaining ground, revolutionary texts, images and hymns were exported on a large scale since the autumn of 1792, and even more so between 1796 and 1799, from the Austrian Netherlands and Brabant to Switzerland and the Italian 'sister republics'. (Reichardt 2012:12)

Importantly, the conviction was that the printed word, music, drama, festivals and the flood of images would help create the new people for the new society. ${ }^{18}$ It is easy to see how the blossoming of communications and a 'flood of images', identified with civic education and notions of individual liberty became a foundational myth for a free press and the fourth estate up until the first years of the twenty-first century. Although it has to be

16 Poland, East Germany, Czechoslovakia, Hungary and Romania.

17 Bulldozer Revolution, Serbia October 2000 - Otpor; Rose Revolution, Georgia November 2003 - Kmara; Orange Revolution, Ukraine November 2004 - PORA; Purple Revolution, Iraq, Jan 2005; Tulip Revolution, Kyrgyzstan, February 2005; Cedar Revolution, Lebanon, February 2005; Blue Revolution, Kuwait, March 2005, and many others were to follow (Finkel et al. 2013). 18 They believed that, combined with republican schooling, printed words in various formats, revolutionary music, didactic plays, civic festivals, and public monuments, the flood of images could contribute to an educational environment which would create a nouvel homme for the new society (James Leith, quoted in Landes 1991: 92). 
admitted that even in the eighteeth century many had warned of the dangers of what Jeremy D. Popkin called hidden subsidies and the fact that the print media, including pictorial and aural modes could be corrupted and used to undermine the development of democratic consciousness (Popkin 1990, 2002).

The 'turn' of 1989 in East-Central Europe, while only effecting five countries, forced governmental change and was the last wave of popular protests that spread like wildfire across national boundaries without the aid of social media. For that reason alone, it is worth some attention. Protestors demonstrating against repressive one-party states were given license by a signal from the then president of the USSR Mikhail Gorbachev that he would not interfere with the internal affairs of the countries of the Soviet bloc. Inspired by the lasting success of Solidarity in Poland since 1982 and the contemporaneous student protests in Tiananmen Square against the Chinese authorities, demands for free elections, a 'return to Europe', and freedom of expression and movement resulted in widespread mass civic unrest in urban centres such as Prague, Berlin, Leipzig, Budapest and Bucharest. Even without social media the communications landscape was complex and the political atmosphere of 1989 allowed the proliferation of open print media in all of its various forms and a corresponding growth in the number of political parties: 'One reporter noted in April 1990 that Polish writers were keeping practically every printing press, mimeograph machine and photocopier in Poland working round the clock' (Goldstein 1999). Printing presses and other means for the mass reproduction of material were controlled by the state, which also had a monopoly on news distribution in the mainstream press, radio and television. As a consequence, their offices were often the first target for the protestors. At the same time the BBC World Service and the American Radio Free Europe and Radio Liberty, and for those who could receive West German television broadcasts, provided Western accounts of the demonstrations to large swathes of the population which remained largely unreported or misreported by state-owned organs. Aware of their audience and in need of at least moral support from Western peoples and governments, many of the protestors' banners were written in English. Martin Arends, the East German writer, observed how '[i]n front of the humming cameras they hit upon grand gestures they had learned from television, because they were going to be on television too' (quoted in Aulich 1993: 27). Internationally, broadcast reports signalled tacit international support even if they fed into Western propaganda efforts to undermine the Soviet bloc during these late days of the Cold War. They were a vital component to the 'apparatus' of protest as a means of mutually reinforcing 
the 'will of the people' across national boundaries, just as it had been in 1968 for the anti-Vietnam War movement, Civil Rights, the student protests in Paris and the Prague Spring. 'News' carried with it the validation of the 'demos' and perspectives inherited from 1789 that had, by this time, been fully integrated into the notion of a free press capable of projecting the 'good' of a fully functioning liberal democracy.

Performativity and consistent physical presence over a period of time were essential. Xeroxed handbills and photocopied photographs of police brutality were widely circulated on the streets. In Czechoslovakia, for example, in emulation of the Bolshevik agit-prop trains, self-appointed cadres of students would go out to the countryside to distribute oppositional material and to bring news about the demonstrations. Civic and cultural centres such as theatres, universities and art galleries and other establishments relatively free from state interference such as trade union premises and churches, became places where the opposition could organize and produce posters, handbills and banners. In Prague, Civic Forum, formed in response to the state repression of student anti-government demonstrations, conducted their business from the Magic Lantern Theatre. In spite of the seriousness of the situation and the uncertainty surrounding what actions the local or state authorities or even the Soviets ultimately might take, there was often something carnivalesque about the demonstrations. Under communism, opposition had found expression in labour, cultural, artistic and religious circles in clandestine meetings, unofficial publications, performances and exhibitions to the extent that it created a relatively well-established counterpublic sphere which emphatically did not accept the wholesale adoption Western consumerist values any more than it did communism to provide a solid foundation for achieving political change (Kemp-Welch 2014). Posters expressing oppositional views flourished, often within and on the fringes of an official culture advertising theatre and film, and they soon developed into critical genre of its own: the 'Poster of Perestroika' (Sylvestrová and Bartelt 1992; Aulich and Sylvestrová 1999). Commonly, the symbolism of power was turned against itself and often engaged in elaborate processes of over-identification: in 1989 what Communist Party official could possibly deny the right of citizens to celebrate the bicentenary of the French Revolution?

Typically, mass demonstrations occupied important and large public spaces such as Wenceslas Square in Prague. As a location it was deeply symbolic for Czech national identity, it had been significant for the national movement during the nineteenth century and in 1918 it was the site of the declaration of national independence. Shop fronts and the equestrian statue 
of Charles II which teemed with protestors were decked, for example, with posters in which ' 68 became ' 89 in a numerological reference to the Prague Spring of 1968 and 'Socialism with a human face' (a short period of mass protest and political liberalization, crushed in the autumn of 1968 by the military invasion from the other Warsaw Pact countries). Throughout the region symbols of state power were subverted. Self-celebratory images of the crowd itself emblazoned the streets and civic buildings alongside romantic national and religious iconographies. Other imagery exposed the crimes of Stalin and hammers smashed sickles, while national flags with communist symbols torn from their fabric were paraded in public to be featured on television and depicted in the popular media of posters, postcards, cartoon and illustration, for example. The Berlin Wall was the symbolic divide between the East and the West, and it provides an illuminating focus. West German coverage of the initial demonstrations and the iconic 'Fall of the Wall' on 9 November 1989 as East Berliners flocked into West Berlin had a contagious effect on the protestors across the region and created a sense of euphoria. Graphic artists from both sides of the divide produced satirical postcards, posters and comic books many of which were for sale. These helped to create debate and, in true Habermasian fashion, contributed to the generation of a public sphere (Habermas 1989) close to that experienced in 1789 and 1848 to sustain the campaign for liberal democratic freedoms (Aulich and Sylvestrová 1999).

The public spectacle of resistance was underwritten by a culture of dissidence embedded in civic institutions, the cultural elite and the young. As a highly developed counterpublic sphere it provided the bedrock for these popular uprisings and made reinforced the strength and sustainability of the protests. Championed in the name of democracy in the West, in reality they represented a far more complex consciousness where active citizens avoided communist structures and made risky play with the rhetoric of the state, nation, church and liberal democracy. Beneath the claims for freedom, democracy and the all too brief calls for a 'third way' that might have preserved the best of communism and consumerism, lay an unbreakable connection with long suppressed grand and romantic narratives of national destiny and Christianity in its various forms. Solidarity in Poland and subsequently the protests in Leipzig in East Germany both had close connections with the church. Driven by a radical conservatism born of romantic individualism and independent nationalism, in the long term these protests represented a nostalgia for a past that never was and has found an afterlife in a reactionary reality that has captured the imaginations of peoples worldwide in the first quarter of the twenty-first century. 


\section{Protest and Neoliberalism}

Since the mid-199os new media played an increasingly important role in establishing global communities of interest, on the one hand, and the local organization of protest, on the other. In Serbia, Otpor (Resistance) supported, financed and trained by Western NGOs such as the International Republican Institute (York 2013) and Gene Sharp's Albert Einstein Institution was the core of the non-violent opposition movement that motivated the Bulldozer Revolution (1998-2000) to bring down the dictator Slobodan Milošević (Cohen 2000; Helvey 2004; Popovic and Miller 2015). ${ }^{19}$ Driven by an increasingly influential oppositional elite with technical knowhow and empathy with contemporary Western youth cultures, Otpor grew out of the universities, civic institutions, and a counterculture of music clubs, the radio station B92 and an alternative arts and media scene. Organizationally, fluid and flat without obvious figureheads it had a Hydra-like flexibility: once one centre of opposition was closed down it simply rose up again somewhere else. Under conditions of state propaganda and censorship of the mainstream media the opportunities provided by new media, even as they were in 1998, were ideal for such an organization. The regime had little interest in new media, at first believing computers were only for making calculations, and paradoxically their own censorship of the mainstream encouraged the protestors to take advantage of new media, although this was by no means without its problems with sporadic attempts by the authorities to close these outlets (Aulich 2011).

Otpor quickly established a sophisticated website and made good use of email and SMS mobile phones. The website listed future protests and documented past demonstrations and events with photographs and film. Many of these were agitprop events specifically designed for posting and communicating online. Significantly, picking up on the carnivalesque aspects of 1968 (in the West) and 1989 (in East-Central Europe) these actions often relied on over-identification with the symbols of power and Otpor's logo of a black clenched fist mimicked Milošević's red fist, for example. In this they were probably inspired by the actions of the Slovenian multimedia arts group Neue Slovensiche Kunst, which had been provoking the authorities with a subcultural strategy in Ljubljana since the 1980 os (Aulich 2011: 12ff.; Čolović 2002; Monroe 2005). Under these conditions, protest no

19 Cohen (2000) provides a partial and informative account of Otpor, its funding, training and hedonist youthful ideology: 'part political movement, part social club', it had 130 branches and 70,000 members. 


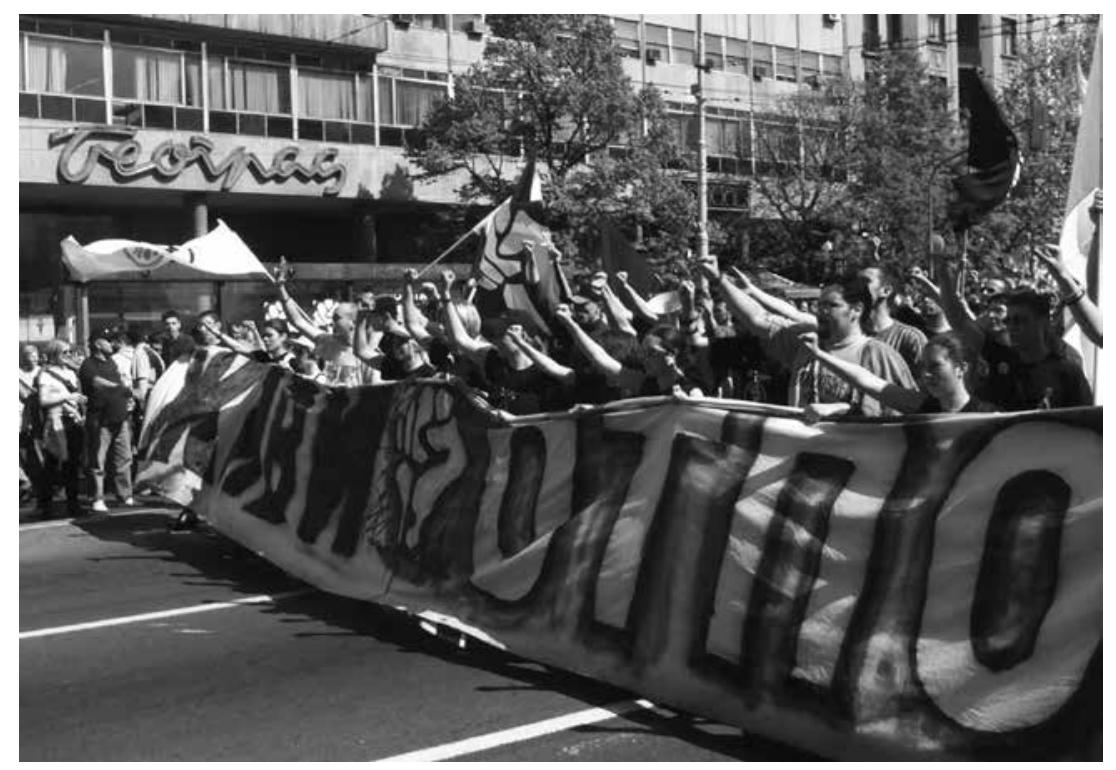

Figure 13.1. Darko Vojinovic, Opposition Rally, Belgrade Yugoslavia, 14 April 2000. Members of Otpor (Resistance), a student organization, arrive in central Belgrade's Republic Square during an antigovernment rally. In one of the biggest protests against the autocratic rule of Yugoslav President Slobodan Milosevic, over 100,000 opposition supporters streamed into central Belgrade to demand democratic elections and an end to state oppression. Source: Darko Vojinovic/AP/Shutterstock.

longer relied on exterior third-party intervention to create its mediated presence but generated its own. Significantly, this was executed within the aesthetic logic of the newly available digital technologies, which even at this embryonic stage had an individualized networked form suited to single issue politics and individual choice. In other words, it was very effective at telling the establishment what you do not want, but perhaps less effective at disseminating and introducing a consistent political programme. Since 1789 the print media had been closely associated with civil rights and the emancipation of the individual, but with the inception of new media, communications were now implicated in neoliberal ideologies and neo-conservative discourses of resistance and freedom, rather than genuine liberal democratic ideals of political liberty and social revolution associated with 1968 and the widespread unrest followed by political change in East-Central Europe in 1989. This ideological distinction and the nature of the apparatuses deployed to produce these various revolutionary realities is extremely important since under these circumstances it can be seen how the reality of genuinely felt revolutionary desires for freedom of movement 
and expression can easily be subverted by neoliberal and corporate interest. As I have pointed out elsewhere, contrary to claims by Gene Sharp (2005), Robert Helvey (2004) and others, this insight is particularly significant in the light of the failure of the opposition to Milošević to successfully transform mainstream politics in Serbia (Barnes 2018). The 'colour revolutions' in post-communist states and during the Arab Spring in the early twenty-first century saw new media play a much larger role and shared a similar fate (Beissinger 2007).

Flushed with success in 2003, Otpor transformed itself into The Centre for Applied Non-violent Action and Strategies (CANVAS ${ }^{20}$ to advise and train pro-democracy activists worldwide: versions of Optor's clenched fist logo appeared in Georgia in 2003, Russia in 2005, Venezuela in 2007, and Egypt in 2011 (Popovic and Miller 2015). ${ }^{21}$ CANVAS has faced criticism because of its close associations with US security agencies and the private intelligence firm Stratfor (Gibson and Horn 2013) which might suggest that in spite of its best intentions, CANVAS may well be regarded as an harbinger of what Sushana Zuboff (2019) has characterized as surveillance capitalism rather than social democracy.

\section{Conclusion}

The mobile phone and the smartphone have played a vital part in protest and, to a large extent new media platforms, have replaced print media. Apart from the mobile phone's communicative powers, it is capable of recording the user's immediate experience aurally and visually and provides instantaneous access to the Internet and potential worldwide audiences. It increases the potential presence of the protest exponentially. Among many other things, it can also identify where you are geographically and

20 'Headquartered in Belgrade, CANVAS is run by Slobodan Djinovic and Srdja Popovic. It operates a network of international trainers and consultants with experience of successful democratic movements. CANVAS is a non-profit institution which relies solely on private funding; there is no charge for workshops and revolutionary know-how can be downloaded for free on the Internet. CANVAS was founded in 2003 by Srdja Popovic and Slobodan Dinovic as an organization that advocates for the use of non-violent resistance to promote human rights and democracy. Since then, CANVAS has worked with pro-democracy activists from more than 50 countries, including Iran, Zimbabwe, Burma, Venezuela, Ukraine, Georgia, Palestine, Western Sahara, West Papua, Eritrea, Belarus, Azerbaijan, Tonga, Tunisia and Egypt. CANVAS works only in response to requests for assistance and offers free trainings to activists' (CANVAS 2019).

21 They claim to have worked in more than 50 countries (Henley 2015). 
how to proceed to a rallying point, for example. From an organizational point of view these were extremely effective assets for protest on a local level, however, once state security services had acquired effective electronic monitoring skills and equipment, mobile and smartphones had to be used in less direct ways. Protestors kept their phones turned off to avoid surveillance and to prevent arrest and effective mobilization by the police and state security agencies. Alex Comninos in his report 'Twitter Revolutions and Cyber Crackdowns' (2011) and Evgeny Morozov in his book The Net Delusion (2011) claimed that social media and the Internet are as much the 'tools of oppressors' as the 'tools of liberators' because the authorities can use new media for spying, propaganda, and censorship (Morozov 2011: 311). Content generated on social media platforms is certainly a powerful aid to protest, although some research indicates its influence is not as pervasive as I might be suggesting (Theocharis et al. 2013). Nevertheless, the landscape is treacherous and the state can use new media to spread fear, disinformation and fake news.

Opposition movements, since the beginning of the twenty-first century, for all the richness of their cultural manifestations, their satirical overidentifications with dominant ideologies, their creativity, instantaneity, performativity and youthfulness in large part facilitated through these same new media platforms, essentially lacked a thorough programme of political emancipation in the traditional modernist sense. New media are short and fast in their generation and reception: operating in real time, speed is of their essence. Potentially global in reach, everything is just a click away and one might argue that new media fails to provide the opportunity for reflection and in-depth debate. Print media more often requires commitment, physical presence and conscious acts to purchase and read the pamphlet, look at the poster on the wall, to take the handbill, to experience the speeches and the violence, potential or otherwise. In the shift from print, new media have contributed to the apparatus of protest to signal a different political environment, where technological advance has generated an ideological change that undermines the authentic desire to guarantee political emancipation. The form of the mass protest as a performative choreography has remained largely the same but circumscribed within the 'cuts' of inclusion and exclusion, there has been something of a transformation in the apparatuses of protest, their mediation and their ethics of responsibility. The analogy of the apparatus is drawn from Karen Barad's philosophy of quantum physics. In physics the apparatus is consciously designed and the 'cuts' can be repeated and the results tested. If we regard protest as a phenomenon generated by an apparatus 
which includes its media technologies and the corporate ambitions of their owners alongside the overall mediation in imagination and appearance, then things are altogether less controllable and open to influences and objectives unknown to the protestors. The global capitalist imperatives of Twitter, Facebook and Instagram, for example, for all of their benefits, have arguably subverted the demos and laid the ground for surveillance capitalism, partly defined as: 'A new economic order that claims human experience as free raw material for hidden commercial practices of extraction, prediction and sales', and 'An expropriation of critical human rights that is best understood as a coup from above: an overthrow of the people's sovereignty' (Zuboff 2019, The Definition).

There is a kind of aching romanticism to the profoundly ethical philosophical thinking of Barad, Butler and Rancière, with which I strongly identify, even though it could be said that their speculations on the demos, the will of the people, responsibility and ethics lays a screen of theoretical distraction that elides over the fact that arrests are made, skulls are cracked, bones are broken, tear gas is inhaled, and protestors, even unarmed ones, do get shot. People suffer traumatic physical and psychological injury, some die in the cause of democratic freedoms. While non-violent protest can be extremely effective in expressing discontent and in creating new realities and new futures in the world, since the turn of the century protest has unconsciously been subverted by the support received from neoliberal organizations which would wish to promote their own interests above those of the protestors. A state of affairs now made infinitely more complex through the well-documented uses and abuses of social media. Protests are born of a sense of injustice and are filled with hopes for democratic freedoms and equality in an unstable environment which opens the gates for the forces of reaction, such as nationalism and forms of meaning easily exploited by imperatives which lie beyond the demos. The vital and political question is where do the boundaries fall, what does the particular apparatus include or exclude and why? The apparatus and the realities it creates consist of people and things, picture and image, subject and object, discourse and material, culture and nature: they are all radically interdependent and co-constitute phenomena in ways that are contested in the profoundest of ways. Unpredictable and overdetermined, protest is ultimately unknowable, yet it remains deeply implicated in what we do and how we perceive ourselves in the world. 


\section{References}

Addley, Esther. 2019. 'Less of the Cream Tea: National Trust to Focus Its Year on Protest, Marches and Social Change', The Guardian, 18 January.

Aulich, James. 1993. 'Through the Looking Glass. Visual Expression in Central Europe 1989-93', in Europe without Walls: Art, Posters and Revolution, eds. James Aulich and Timothy Wilcox, 9-71. Manchester Art Galleries.

Aulich, James. 2011. 'The Democratic Delusion: New Media, Resistance and Revolution in Serbia 1995-200o', Digital Icons: Studies in Russian, Eurasian and Central European New Media 5: 1-21.

Aulich, James, and Marta Sylvestrová. 1999. Political Posters in Central and Eastern Europe, 1945-1995: Signs of the Times, Manchester: Manchester University Press. Barad, Karen. 2007. Meeting the Universe Halfway: Quantum Physics and the Entanglement of Matter and Meaning. Durham, NC: Duke University Press.

Barad, Karen. 2010. 'Quantum Entanglements and Hauntological Relations of Inheritance: Dis/continuities, SpaceTime Enfoldings, and Justice-to-Come', Derrida Today 3(2): 240-268.

Barnes, T. 2018. 'Serbia Protests: Demonstrations in Belgrade over Alleged Government Corruption Enter Fourth Week'. The Independent, 30 December.

Beissinger, Mark R. 2007. 'Structure and Example in Modular Political Phenomena: The Diffusion of Bulldozer/Rose/Orange/Tulip Revolutions', Perspectives on Politics 5(2): 259-276.

Butler, Judith. 2004. Precarious Life: The Powers of Mourning and Violence. London: Verso.

Butler, Judith. 2015. Notes toward a Performative Theory of Assembly. Cambridge, MA: Harvard University Press.

CANVAS. 2019. 'About Us: Who We Are'. Canvasopedia. http://canvasopedia.org/ about-us/. Accessed 31.03.19.

Cockburn, Patrick. 2019. 'College Green Has Become the Tahrir Square of Brexit', The I Paper, 19 January, p. 22.

Cohen, Roger. 2000. 'Who Really Brought Down Milosevic?', New York Times, 26 November.

Čolović, Ivan. 2002. The Politics of Symbol in Serbia: Essays in Political Anthropology, trans. Celia Hawkesworth. London: Hurst \& Company.

Comninos, Alex. 2011. 'Twitter Revolutions and Cyber Crackdowns: User-Generated Content and Social Networking in the Arab Spring and Beyond', Association for Progressive Communications, June. https://www.apc.org/sites/default/files/ AlexComninos_MobileInternet.pdf. Accessed 31.03.19.

Crane, Walter. 1907. An Artist's Reminiscences. New York: The Macmillan Company. 
Deller, Jeremy. 2001. The Battle of Orgreave, Artangel. https://www.artangel.org. $\mathrm{uk} /$ project/the-battle-of-orgreave/. Accessed 31.03.19.

Deller, Jeremy. 2018. The Memorial for the Victims of the Peterloo Massacre. http:// peterloomassacre.org. Accessed 31.03.19.

Eder, Jens, and Charlotte Klonk. 2016. Image Operations: Visual Media and Political Conflict. Manchester: Manchester University Press.

English Heritage. 2019. 'Vision and Values', English Heritage website. https://www. english-heritage.org.uk/about-us/our-values/. Accessed 31.03.19.

Finkel, Evgeny, and Yitzhak M. Brundy. 2013. 'No More Colour! Authoritarian Regimes and Colour Revolutions in Eurasia', Perspectives on Politics 11(3): 734-752.

Gell, Alfred. 1998. Art and Agency: An Anthropological Theory. Oxford: Clarendon Press.

Gibson, Carl, and Steve Horn. 2013. 'Exposed: Globally Renowned Activist Collaborated with Intelligence Firm Stratfor', Occupy.com, 2 December. https:// www.occupy.com/article/exposed-globally-renowned-activist-collaboratedintelligence-firm-stratfor\#sthash.Bx4oY8wI.dpbs. Accessed 31.03.19.

Goldstein, Justin Robert. 1999. 'The European Revolutions of 1848 and 1989: A Comparative Analysis', in Encyclopedia of 1848 Revolutions, ed.James Chastain. .https://www.ohio.edu/chastain/dh/eurorev.htm. Accessed 31.03.19.

Grusin, Richard. 2015. 'Radical Mediation', Critical Inquiry 42 (1): 124-148.

Habermas, Jürgen. 1989. The Structural Transformation of the Public Sphere: An Inquiry into a Category of Bourgeois Society. Cambridge: Polity.

Hann, Dave. 2013. Physical Resistance: A Hundred Years of Anti-Fascism. Winchester: Zero Books.

Helvey, Robert L. 2004. On Strategic Nonviolent Conflict: Thinking about the Fundamentals. Boston: The Albert Einstein Institution. https://www.aeinstein.org/ wp-content/uploads/2013/og/OSNC.pdf. Accessed 31.03.19.

Henley, Jon. 2015. 'Meet Srdja Popovic, the Secret Architect of Global Revolution', The Guardian, 8 March.

Jazeel, Tariq, and Nayanika Mookherjee. 2015. 'Aesthetics, Politics, Conflict', Journal of Material Culture 20(4): 353-359.

Kemp-Welch, Klara. 2014. Antipolitics in Central European Art: Reticence as Dissidence under Post-totalitairan Rule, 1965-1989. London: I.B. Tauris.

Kleinmann, Adam. 2012. 'Intra-actions' [Interview with Karen Barad], Mousse 34(13): 76-81. https://www.academia.edu/1857617/_Intra_actions_Interview_of_Karen_Barad_by_Adam_Kleinmann. Accessed 31.03.19.

Landes, Joan B. 1991. 'More Than Words: The Printing Press and the French Revolution', Eighteenth-Century Studies 25(1): 85-98.

Leigh, Mike, dir. 2018. Peterloo [film], Thin Man Films, Film 4, BFI Film Fund. 
McLagan, Meg, and Yates McKee, eds. 2012. Sensible Politics: The Visual Culture of Nongovernmental Activism. New York: Zone Books.

Monroe, Alexei. 2005. Interrogation Machine:Laibach and the NSK State. Cambridge, MA: MIT Press.

Morozov, Evgeny. 2011. The Net Delusion. London: Penguin.

Mortimer, Gavin. 2019. 'The Yellow Vests Are at the Vanguard of a Politically Incorrect Uprising', The Spectator, 14 January.

O’Neill, Brendan. 2018. 'In Praise of the Gilets Jaunes', The Spectator, 3 December. https://blogs.spectator.co.uk/2018/12/in-praise-of-the-gilets-jaunes. Accessed 31.03.19.

Popkin, Jeremy D. 1990. Revolutionary News: The Press in France, 1789-1799. Durham, NC: Duke University Press.

Popkin, Jeremy D. 2002. Press, Revolution, and Social Identities in France, 1830-1835. University Park: Pennsylvania State University Press.

Popovic, Srdja, and Matthew Miller. 2015. Blueprint for Revolution: How to Use Rice Pudding, Lego Men, and Other Non-violent Techniques to Galvanize Communities, Overthrow Dictators, or Simply Change the World. Brunswick: Scribe Publications.

Ramdani, Nabila. 2019a. 'The Success of Yellow Vest Protestors in France Hinges on Their Whiteness - and This Is Why', The Independent, 20 January.

Ramdani, Nabila. 2019b. 'The UK Yellow Vests Have Nothing to Do with Their French Counterparts - but They Could Be Just as Influential', The Independent, 10 January.

Rancière, Jacques. 2004. The Politics of Aesthetics: The Distribution of the Sensible. London: Continuum.

Rancière, Jacques. 2010. Dissensus: On Politics and Aesthetics, ed. and trans. Steven Corcoran. London: Continuum.

Reichardt, Rolf. 2012. 'The French Revolution as a European Media Event', European History Online (EGO), Leibniz Institute of European History (IEG), Mainz. http:// ieg-ego.eu/en/threads/european-media/european-media-events/rolf-reichardtthe-french-revolution-as-a-european-media-event. Accessed 31.03.19.

Riding, Jacqueline. 2018. Peterloo: The Story of the Manchester Massacre. N.p.: Head of Zeus.

Sharp, Gene. 2005. Waging Nonviolent Struggle: $20^{\text {th }}$ Century Practice and $2{ }^{\text {st }}$ Century Potential. Boston: Extending Horizons Books.

Sylvestrová, Marta, and Dana Bartelt. 1992. Art as Activist: Revolutionary Posters from Central and Eastern Europe. London: Thames \& Hudson with the Smithsonian Institution.

Theocharis, Yannis, Will Lowe, Jan W. van Deth, and Gema M. García Albacete. 2013. 'Using Twitter to Mobilise Protest Action: Transnational Online Mobilisation Patterns and Action Repertoires in the Occupy Wall Street, Indignados and 
Aganaktismenoi Movements', paper presented at the $41^{\text {st }}$ ECPR Joint Sessions of Workshops, Johannes Gutenberg Universität, Mainz, 11-16 March. http:// dl.conjugateprior.org/preprints/ecprjs-theocharis-et-al.pdf. Accessed 31.03.19. Van Eck, Caroline. 2015. Art, Agency and Living Presence: From the Animated Image to the Excessive Object. Berlin: De Gruyter/Leiden: Leiden University Press.

Weyland, Kurt. 2014. Making Waves: Democratic Contention in Europe and Latin America since the Revolutions of 1848 . Cambridge: Cambridge University Press. York, Steve. 2013. 'Robert Helvey on Strategic Nonviolence'. Popular Resistance. org, 3 August. https://popularresistance.org/col-robert-helvey-on-strategicnonviolence/. Accessed 31.03.19.

Zuboff, Shoshana. 2019. The Age of Surveillance Capitalism: The Fight for the Future at the New Frontier of Power. London: Profile Books.

\section{About the Author}

Jim Aulich is Professor of Visual Culture in the Department of Art at Manchester Metropolitan University. Since 1985 his research has engaged with how conflicts are pictured and meanings are produced in propaganda, publicity, advertising, and reportage in the graphic arts. The research has involved partnerships with galleries and museums in this country and internationally, such as the Imperial War Museums (IWM), in London; the Moravian Gallery in Brno, in the Czech Republic; and Manchester art galleries. He is editing a special issue on the theme 'Pictures and Conflicts since 1945 ' for the open-access online journal Humanities. 



\section{Index}

\#StayWoke $87,247-248,250,252,259-260$, 262,265

Abbasağa Park 205-206

Academics for Peace 200

Activestills $\quad 6-7,30,151-15^{2}, 154-162,164-169$

Activist groups 41

Aesthetics

Aesthetic philosophers 105

Aesthetic Sensibility 105, 107

Aesthetics and World Politics 106, 119

Africa $5,20,28-29,39-44,47,49-51,53-58,168$ African 8, 29, 39-44, 51-52, 56-58, 152, 208, 249,266

Agency 18, 23, 26-27, 31-32, 34, 59, 77, 103-104, $154,210,271,273-274,289,291$

AIDS $41-43,51,57-58,186$

AKP 82, 84, 86, 191-192, 194, 196, 199, 205, 211, 218, 226, 245

Al Arakib $\quad 157-158$

Alevi 16, 194, 203

Sterling, Alton $\quad 248$

Ambiguity 29, 106-107, 116, 118

Amsterdam 9-11, 14-15, 32, 34, 39, 59, 78, 81, 87, 99, 121, 137, 141-142, 144, 147, 151, 171, 191, 211, 231, 233, 247, 269

Anatolia 81, 131

Anonymous $20,83,128,132,225$

Anonymous protests 20

Anti-apartheid 43

Anti-capitalist Islamists $\quad 16$

Anti-capitalist Muslim group 84

Anti-coal movement 201

Anti-consumerist messages $\quad 115$

Apartment Project 87

Arab Spring $16,21,25,33-34,41,186,207,209$, $271,272,279,285,288$

Architecture 24, 64, 78, 122

Ardoyne 7,59-61, 66-71, 73, 77

Arendt, Hannah 12, 14

Argentina $5,20,28,33,99-101,107,113-120$, 133,156

Art

Art exhibition 81

Art historian $88-89,106,128,273$

Art photographer $29,39,45$

Artistic

Artistic media 27

Artistic practice $55,81,84,95$

Artistic research process 81

Artık Işler 93

Artvin 87

Atatürk, Mustafa Kemal 83,156
Atelier of Revolutionary Posters 130, 136

Athens $5,7,17,29,33,55,121-123,125-127$, 131-139

Attire 69

Auschwitz 108

Authoritarianism $\quad 6,12,82,85-86,97,191-192$, 194, 196, 199, 202, 206-208, 234, 237

Barad, Karen ～269-274, 286-289

Bakur 193, 196, 204-205

Bangkok 24, 30, 34, 171, 173-174, 176, 178, 180-181, 183, 187

Bantu Education Act of $1953 \quad 43$

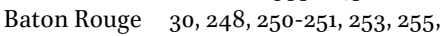
260-261

Becherer, Max $8,249-250,25^{2-254}, 260$

Belfast 29, 59-6o, 75, 77-79, 242

Belonging 84, 125, 132, 138, 209

Berlin 33, 87, 98, 137, 139, 228, 280, 282, 291

Berlin Wall, The $\quad 282$

Beyoglu 196, 198

Birbuçuk 94

Birds in the Mire 133

Black feminists 40

Black Lives Matter $6,8,30,236-237,245$, 247-249, 257, 265, 269

Black power 101, 253

Black Sea 86-87, 209

Bleiker, Roland $\quad 106,118$

Blood 24, 114

Bloody Sunday $\quad 156,168,270$

Bodies $18-19,28,47-48,51,53,64,92,100,104$, 107-108, 110-113, 133, 152, 167, 172, 177-178, 180$181,192,195,198,201,207,219,224,263,274$

Bogaziçi Jazz Choir 220

Bongela $53-54,56$

Bourriaud, Nicholas 88,96

Breaking their fast 84

Bremen 87, 97

Butler, Judith $13,14,16,18-19,24,31,122$, 133-134, 136-137, 159, 167, 192, 208, 250, 263, $269,271,274,276,287-288$

Cairo 17, 25, 41, 271

Cameras $65,67,75-76,159-160,163,172-174$, $179,184,195,202,207,280$

Cape Town $43-45,56,58$

Çapulcu 83, 129, 195, 212, 217, 220-223, 226

çArşı 8, 221-224, 227

Censored films 29-30, 193-194, 197, 202, 204-206

Centre for Applied Non-violent Action and Strategies, The $\quad 285$ 
Cihangir 86

Çılgın Projeler (Crazy projects) 86

Civil Rights Movement $\quad 23,33,120,152$, $167-168,252,254-255,261,264$

clicktivism 22

clothes $18,47,198$

CNN Turk 129, 239

Cockburn, Patrick $\quad$ 271-272, 288

Cold War 280

Collective memory $\quad 61-62,103,111,133-135$

Collectivity $16,81,88-91,95,98,104,108,128$, $171,180,271$

Commemoration 61-62

Communication $15,17,19-24,26-27,30,63,67$, 70, 72, 124, 159, 211-213, 215-216, 218, 220-221, $223,226-227,250-252,263,276,279-280,284$

Community

Community art practices $\quad 81,88-89$

Community gardens 86

Conflict $\quad 59-61,63-64,67,72,75,77,156,172$, $175,213,216,258,266$

Consolidation 30

Cooking 81, 83-84, 95, 195

Coup d'état 171,183

Crane, Walter 270

Crazy Projects (Çılgın Projeler) 86

Critical utopia $\quad 5^{1}$

Cruising Utopia 54

Crumlin Ardoyne Residents Association, CARA $\quad 73-74$

Crumlin Road $59-60,67,69,73$

Dadans 91, 93

Deller, Jeremy $\quad 277^{-278}$

Democratic expression $\quad 26,30$

Demonstration $102,125^{-12} 6,151-166,176,224$, 234, 236

De Oro, Margareta 109

Dialogical aesthetics $\quad 85,88-90,92$

Digital

Digital culture $3^{0}$

Digital technologies $\quad 15,18-23,25,159,180$, 211-212, 284

Dink, Hrant 197

Dirty War 100, 112-114, 133

Disney War 116

DIY workshops 93

Documentaphobia 191

Documentary activism 191, 194

Dorsey, Jack 259-26o, 262

Drone cameras $\quad 172-173$

Drone theory 171

Duma, Buyani $\quad 40,49,51-53$

East Asia 11

Easter rising 61

Ecological activists 86

Economic and Social Research Council

(ESRC) 60
El argentinazo $\quad 99,113-114,117$

El siluetazo $\quad 7,99,107,110-112,117,119-120$

Elvan, Berkin $\quad 123,125-127$

Enlightenment $\quad 274-275$

Epistemological history $\quad 29,39$

Espace conçu 123

Espace perçu 123

Espace vecu 123

Euromaidan protests 174

Exarcheia $125-127,132$

Facebook 19, 25, 87, 142, 173, 196, 222, 239, 240,287

Fanon, Frantz $\quad 11,13$

Fascism 83, 213, 223

Fatih 86

Ferrari, Leon 112

Fidesz 274

Fierce Pussy 41

French Revolution 269, 274-275, 281

Fuera Congreso (Out, Congress) 114

Fuera politicos (Out, politicians) 114

GARC $\quad 73-74$

Gas mask 18, 132, 220

Gender DynamiX 45

Gezi Park 9, 16-17, 28-30, 81-83, 85-88, 122, 126-127, 129, 134-135, 191-193, 196, 200-201, $203,205,211-214,217-218,220-227,234$, $236-237,242$

Gezi spirit $16,85-86,128,221,234$

Gilets Jaunes 274, 290

Global Justice Movement $\quad 238$

Goodwin, Jeff 103,105

Gorbachev, Mikhail 280

Goliath 116

Graffiti $18-19,27-29,41,100,114,121,128,130$, $132,134,177$

Grigoropoulos, Alexandros $\quad 123,125-127$

Guy Fawkes 20

Gündüz, Erdem 83

HAH $91-93$

Halka Art Project 94

Hamblin, Robert $\quad 29,39-40,43-49,54-55$

Hank, Johnston 105

Hashtag 29, 146, 217, 219, 237, 247-248, 252, 260

Hardt, Michael 11

HIV/AIDS activist work 42

Hoca, Nasreddin 131

Hong Kong 19-20, 83, 142

Humour 18, 25, 28, 48, 129-131, 223, 237

Hybrid Spaces of Resistance 134

Indignados 24-25

Instagram $\quad 25,135,287$

InterseXion $\quad 40,44-46,48-49$ 
Introvert's Protest 141-142

Israel $28,30,142,151,154,156-157,160-166,276$ Istanbul Permaculture Collective 93

Istanbul United $\quad 219,225$

Iziko National Gallery in Cape Town

Jasper, James 105

Justice and Development Party $\quad 82,191,217$

\section{KABA HAT 84}

Kemalists $16,203,213$

King, Martin Luther $\quad$ 168, 255, 264

Klandermans, Bert $\quad 105$

Ku Klux Klan 155

Kurds 16, 206, 213

Kuzguncuk Garden 86

Labeija, Pepper $\quad 5^{1}$

LABOFII (Laboratory of Insurrectionary Imagination) 44

Labour Party 270

Lamar, Kendrik $\quad 236$

Languages 11, 219

Latour, Bruno 13

Leigh, Mike $\quad 48-49,277,289$

LGBTIQ 16

Live-stream $\quad 25,214,216,250,259$

Lived experience $\quad 27$

Love 13, 193, 195-196, 202, 204, 277

Magic Lantern Theatre $\quad 281$

Mail and Guardian 53

Mainstream media $\quad 22,25,132,194,197,205$, 211-212, 214, 224, 233, 243, 257, 262, 283

Malvinas/Falklands War 107, 109

Marching bands 68

Marea, Desire $\quad 40,49,51$

Marx 11, 102

Mask 18, 20, 32, 132, 162, 220-221

Maybe, We Will Benefit from Our Neighbour's Good Fortune $\quad$ 5, 29, 81, 88, 90, 95, 98

McKesson, DeRay $\quad 6,8,30,247-249,255,259$, 261-263, 265

Mediation $13,21-23,28,30,60,115,152,159$, $215,217,245,250-251,257,260-261,269$, 272-274, 277, 286-287, 289

Manchester $\quad$ 168-169, 265-266, 277, 288-291

Mediterranean 121-122

Members of the Legislative Assembly (MLAs) 71

Mhlongo, Somizi $5^{2}$

Mickey Mouse 116

Middle East $\quad 20,57,130,138,208-210,227,271$

Middle East Technical University 131

Military $7,71,99-100,107,109,113,119,130,135$, $161,164,171-172,175-177,179-181,183^{-186}, 234$, 272,282

Milošević, Slobodan $\quad 283-285$

Mimetic 106, 134, 243
Mimic the past $87,193,283$

Mobilize $15-17,40,100,104,132,154,156,167$, $176,194,200,213,220,222,225^{-22} 6,257,275$

Monitoring $25,78,235,242,282$

Mosque 95, 199

Mother Earth meals 84

Mothers 49, 82, 100, 107-110, 119

Mothers of the Plaza de Mayo movement 107109,156

Movies 25, 163

Muholi, Zanele $\quad 39,42-43,50$

Neighbourhood $81-83,85,88,90-91,94,114$, $183,199,122$

Neighbourliness $81,85,88,90-91,94$

Neo-authoritarianism 82

Neoliberalism 11-12, 31, 41, 82, 86, 97, 210, 244, $257,262,264-265,274,283$

Networked 13, 26, 43, 135, 139, 246, 284

New social movements 15,120

New York 12, 14, 29, 32, 41, 49, 51, 56-57, 83, $118,120,136,138,141-142,146,161,167-168$, 186-188, 206, 208-209, 228, 241, 245, 257, 263-266, 288, 290

New York Public Library 141

NGO 44-45, 56, 212, 283

No 1 Likes Us We Don't Care 69

Non-gated condominium 81

Non-violent action $\quad 83,285$

North Belfast 59

Northern Ireland $5,28-29,59-63,65,67,69$, $71,73,76-79,156$

Occupy Wall Street $12,187,236,245,290$

Orange Tent (Turuncu Çadır) $\quad 87$

Orangeman parade $\quad 29$

Ottoman 86

Palestine $6,11,28,30,151,153,155,157,159,161$, $165,167-169,266,276,285$

Pallywood 163,169

Parades Commission $59-60,66,68-70,72-73$, 79

Paris Spring 101

Parliamentary democracy 94

Peterloo Massacre $\quad$ 277-278, 289-290

Patriarchy $11,45,5^{1}$

Pegida 274

Pelesiyer 91

Penguins 127, 129, 224

People's Democratic Reform Committee 173

Performance art $27,56,84,98$

Performances $\quad 24-25,28-29,47,63,83,89$, $120-121,123,135,138,152,213-214,227,230$, 243,281

Performative $\quad 15-16,18-21,28,31,40-41,47-48$, $63,76,84,107,112,115,117,121,124,134-136$, $139,141-143,155^{-156,208,215}, 235,264$, 269-271, 275-276, 286, 288 
Performative protests 41

Periscope 250, 253, 259

Photography $4,6-7,27,30,39-41,43,45,56$, $106,126,151-157,159,161,163,165-169,188$, 213,255

Photoshop 45

Plaça de Catalunya 26

Playing House 7,93

Plaza de Mayo $100,107-109,111,156$

Polarization $30,86,143,210,239$

Police Service of Northern Ireland (PSNI) 60

Polis 129, 173-174, 178, 224-225

Political identities $59,115,275$

Positions $\quad 48,63,67,72,75,177,179,186$

Post-apartheid $40-41,44,54,56-5^{8}$

President Obama 257

Protest communication 6

Protest repertoires 139

Protestant 28, 59, 61, 69, 72, 75

Protestant Orange Order parade 59

Public space $12,15,17,19,21,24-25,29,42,79$, $82,84,86,96,111,113,116-117,121,123-124$, $127-128,130,132-134,136,138,141,157,192$, 195-196, 198, 207, 235-236, 239, 244-245, 270, 281

Public square $25,65,242$

Quality 17, 20, 40, 91, 142, 143, 277

Que se vayan todos $100,114,116$

Queer 5, 16, 19, 29, 39-45, 47, 49-58, 270

Queer Visual Activism $\quad 5,39,41,43-45,47,49$, $5^{1-53}, 55,57^{-5} 8$

Rainbow stairs 83

Ramadan 84

Rap 217, 219, 221-223, 225-227

Re-claiming city 123

Red shirt protests $\quad 24,172-174,177-178$

Regimes of visibility $\quad 64-65$

Relational aesthetics $\quad 88,96$

Remembering 87, 91, 96

Representational space (espace vecu) 123

Representations of space (espace conçu) $\quad 123$

Republicanism $=$ Cultural Apartheid $7^{0}$

Resource mobilization (RM) framework 102103, 119

Roma Garden 86

Russia $19,145,241,285$

Se cayó el sistema 115

Security guards 81

Self-styling 54

Silenced 196-197, 235

Silhouettes 93

Sistaaz Hood, The $\quad 7,40,44-49$

Slactivism 22

Slang 28

Slogans $18,28-29,83,115,121-122,125^{-130}$, 132-133, 142, 204, 237
Social change $\quad 17,19-21,31,103,241,247,278$, 288

Social media $\quad 18-22,24-26,31-32,35,74,122$, 134, 139, 154-155, 16o, 162, 169, 177, 180, 211212, 215, 217, 219, 226-227, 229-230, 235-237, 239-240, 242-248, 250-253, 255-257, 261-266, $276,278,280,286-287$

social microcosm 83

social mobilization $\quad 5,99,101,103,105,107,109$, 111, 113, 115, 117-119, 195

social movement theory (SMT) 101

Social relationship $11,24,59$

Society $11-13,21,23,25,30-32,35,48,51-53,62$, $78,88,101,103,107-108,120,123,128-129,137$, 139, 167-168, 194-195, 208, 210, 222, 228-229, 231, 240-241, 244-246, 258, 263-264, 274, 279, 289

Socio-political $15,25,40,76,106,131$

Sociocultural $15,17,23,25,40,124$

Sociologist $17,79,131$

Solidarity $13,16-19,22-26,30,48-49,54-55$, 61-62, 67, 76, 81, 83-87, 89, 95-96, 127-128, 132-134, 161, 173, 196, 200, 204-205, 209, 211, $213,217,224,235,242,270-271,275,280,282$

South Africa $\quad 5,11-12,20,28-29,39-45,47$, $49-5^{8}, 15^{2}, 168$

South America $\quad 19,278$

Spain 9, 24-25, 31

Spatial Politics 28, 123

Spatial practice (espace perçu) 123

Spring of Nations $\quad 269,278$

Standing Man 83,97

State authorities $\quad 25,281$

Stay with Me 87

Stencil 100-101, 107, 109, 114-121, 127, 129-130, 132,138

Stigma $\quad 5^{1}$

Street art $5,17,27-29,33,55,99-101,103,105$, $107,109,111,113,115-117,119-124,126-128$, 130-139

Structuralist/Rationalist Bias 101

Sudan 276

Sur 199

Surveillance $25,65-66,75,78,173,195,206$, $233^{-234}, 242-243,265,276,278,285^{-287}, 291$

Tahrir Square $\quad 17,25,27,138,271,288$

Taksim Square $7,18,83,127-128,134,174,201$, 241-242

Tamimi, Mohammad $\quad$ 161-164

Tamini, Mustafa $\quad 156$

Tear Gas $\quad$ 19, 26, 125, 127-130, 175-177, 225, 246, 287

Thailand $\quad 6,20,171-175,177-179,181,183,185-189$

Thaksin regime $173,176-177,188$

Theatre $25,65,83,206,209,275,281$

Tiananmen Square $\quad 280$

TOMA 220-221

Trade associations $\quad 275$ 
Trade unions $\quad 270,275$

Transgender $40,45,270$

Trump, Donald 241

Tumblr 25

Turkish politics $30,88,207,226$

Turuncu Çadır (Orange Tent) $\quad 87$

Twitter 6, 22, 25-26, 30, 65-66, 163, 173, 176, 210-214, 229, 233-235, 237, 239-242, 245-265, 279, 286-288, 290

UN Declaration of Human Rights 143

Union Jack 71

UK miners' strike $\quad 278$

Urban $7,11,13,17,24-25,29,34,78-79,82$, 86-87, 96, 101, 110-111, 114, 117, 121-125, 127, 131-132, 135-139, 172-173, 177, 183, 187, 191-192, $196-198,208,210,213,222-223,226,234$, $236-237,275,280$

landscape $\quad 29,114,117,122,135$

protest 25

space $11,13,17,78-79,121,123-124,131,187$

US Constitution $\quad 28,141,143$

US President George W. Bush 116

USA $9,20,30,145$

Uyang'Khumbula 40,54

Venezuela $\quad 276,285$

Vfor Vendetta 20, 32

Vegan activists $\quad 213$

Vegetable Gardens 86

Video $6-7,13,27,30,45-46,48,60,93,161$, $164,169,176,180,186-187,191-202,207-213$, 215-217, 219-230, 236, 252, 265

Video activism $\quad 6,191-192,195-197,202,210-212$, $224,227,229$

Video collective 93

Videoccupy $193,195,197,200-201$

Videophobia 191

Vietnam War $155^{-156,281}$
Vignette 99,107

Violence $\quad 25,30,40,51,57-58,60,62,66,75,77$, 79, 100, 108, 117, 153, 155-156, 174, 179-180, 183, 193, 195, 197, 199-201, 204, 207, 214, 219, 223, 225, 227, 234, 237, 239-241, 257, 261, 270, 276, $278,286,288$

Visibility as 'recognition' 65

Visibility as social 'control' 65

Visual Culture $\quad 3,5,9,11,14-15,19-25,27,29$, $33-34,39,41,56-57,59,65,70,78,81,85,99$, 121, 141, 147, 151, 167-169, 171, 178-179, 191, 211, 231, 233, 247, 263, 266, 269, 290-291

Visual images $\quad 22,24-25,169,25^{1-252,266}$

Visual materialization 112

Voice $15-21,23-24,26,28,31,34,63,108,112$, $136,141,147,154,156,182-183,185-186$, 191-192, 197, 199, 207, 209, 213, 218, 222-223, 226, 231, 274

Vomito Attack 114-115

Wait Lorraine $\quad 5^{1}$

Walls 81, 91, 100, 109, 112, 114-115, 122, 125-131, 133-138, 288

Waste of Istanbul, The 94

Wenceslas Square $\quad 181$

Western feminism 40

Whirling Dervish $\quad 7,18$

White supremacy $11-12,18,255$

Women for Peace Initiative 193, 200

Yedikule 86, 96

Yellow paper umbrellas $\quad 19$

Yirca 201

YouTube $\quad 6,12,25,30,51,169,186,196-197$, 199-201, 210-219, 221-223, 225-231

Zimbabwe $\quad 276,285$

Zuccotti Park 12 

Protestors across the world use aesthetics in order to communicate their ideas and ensure their voices are heard. This book looks at protest aesthetics, which we consider to be the visual and performative elements of protest, such as images, symbols, graffiti, art, as well as the choreography of protest actions in public spaces. Through the use of social media, protestors have been able to create an alternative space for people to engage with politics that is more inclusive and participatory than traditional politics. This volume focuses on the role of visual culture in a highly mediated environment and draws on case studies from Europe, Thailand, South Africa, USA, Argentina, and the Middle East in order to demonstrate how protestors use aesthetics to communicate their demands and ideas. It examines how digital media is harnessed by protestors and argues that all protest aesthetics are performative and communicative.

Aidan McGarry is a Reader in International Politics at the Institute for Diplomacy and International Governance at Loughborough University, London.

Itir Erhart is an Associate Professor at Istanbul Bilgi University, Department of Media and Communication Systems.

Hande Eslen-Ziya is an Associate Professor of Sociology at the University of Stavanger.

Olu Jenzen is Principal Lecturer at the University of Brighton, UK and the Director of the Research Centre for Transforming Sexuality and Gender.

Umut Korkut is Professor in International Politics at Glasgow School for Business and Society at Glasgow Caledonian University. 